\title{
Molekularbiologische Charakterisierung und vergleichende Genomik von ausgewählten Vertretern mariner Roseobacter-Stämme
}

\author{
Dissertation \\ zur Erlangung des mathematisch-naturwissenschaftlichen Doktorgrades \\ "Doctor rerum naturalium" \\ der Georg-August-Universität Göttingen \\ im Promotionsgrundprogramm Biologie \\ der Georg-August University School of Science (GAUSS) \\ vorgelegt von \\ John Felix Vollmers \\ aus Bad Soden
}

Göttingen 2013 
$\underline{\text { Betreuungsausschuss }}$

Prof. Dr. Rolf Daniel, Abteilung für Genomische und Angewandte Mikrobiologie und Laboratorium für Genomanalyse, Institut für Mikrobiologie und Genetik

Prof. em. Dr. Gerhard Gottschalk, Abteilung für Genomische und Angewandte Mikrobiologie und Laboratorium für Genomanalyse, Institut für Mikrobiologie und Genetik

\section{Mitglieder der Prüfungskommission}

Referent:

Prof. Dr. Rolf Daniel, Abteilung für Genomische und Angewandte Mikrobiologie und Laboratorium für Genomanalyse, Institut für Mikrobiologie und Genetik

Korreferent:

Prof. em. Dr. Gerhard Gottschalk, Abteilung für Genomische und Angewandte Mikrobiologie und Laboratorium für Genomanalyse, Institut für Mikrobiologie und Genetik

Weitere Mitglieder der Prüfungskommission:

Jun.-Prof. Dr. Kai Heimel, Abteilung für Mikrobielle Zellbiologie, Institut für Mikrobiologie und Genetik

PD Dr. Michael Hoppert, Abteilung für Allgemeine Mikrobiologie, Institut für Mikrobiologie und Genetik

PD Dr. Wilfried Kramer, Abteilung für Molekulare Genetik, Institut für Mikrobiologie und Genetik

Prof. Dr. Stephanie Pöggeler, Abteilung für Genetik Eukaryotischer Mikroorganismen, Institut für Mikrobiologie und Genetik

Tag der mündlichen Prüfung: 18.07 .2013 


\section{Inhaltsverzeichnis}

Abbkürzungsverzeichnis V

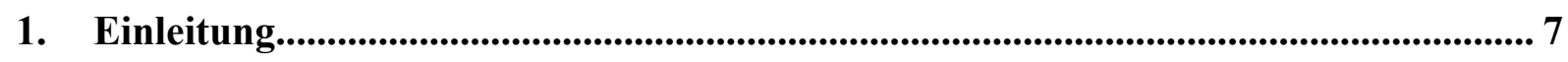

1.1 Die Vielfalt mariner mikrobieller Habitate ....................................................... 7

1.2 Besonderheiten der Polarregionen ............................................................... 9

1.3 Ökologische und wissenschaftliche Bedeutung der Roseobacter-Gruppe.............. 12

1.4 Physiologische Diversität und Adaptivität der Roseobacter-Gruppe ..................... 14

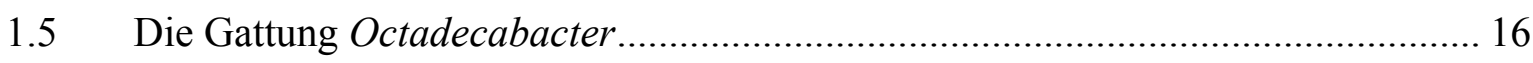

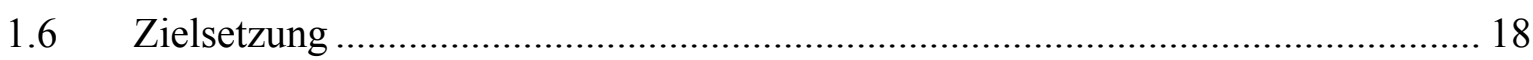

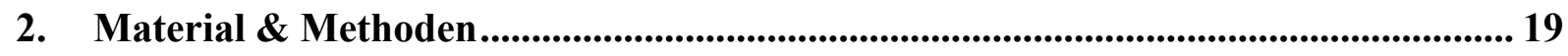

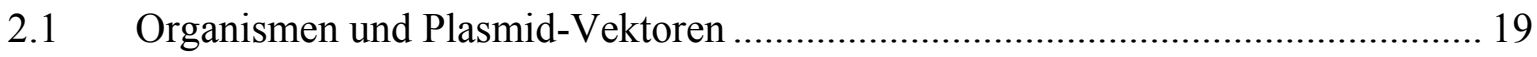

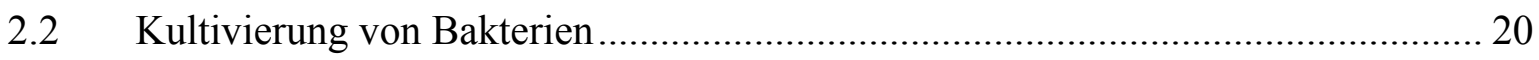

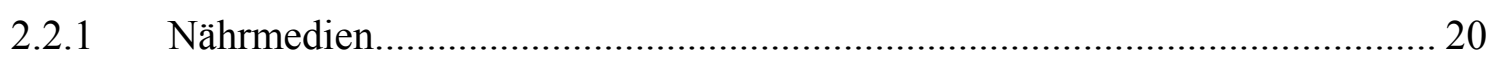

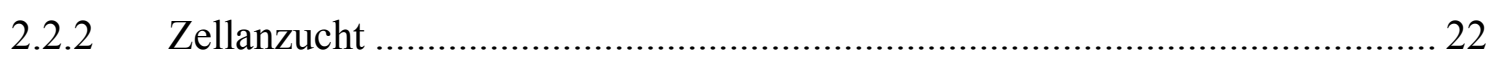

2.2.3 Verfolgung des Bakterienwachstums durch photometrische Messungen ....... 23

2.2.4 Untersuchungen zu Schwermetall-Resistenzen ......................................... 23

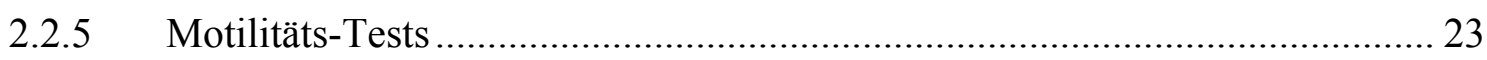

2.2.6 Lagerung von Bakterienkulturen ........................................................... 24

2.3 Allgemeine Techniken für die Arbeit mit Nukleinsäuren..................................... 25

2.3.1 Native Agarose-Gelektrophorese zur analytischen Auftrennung von linearen

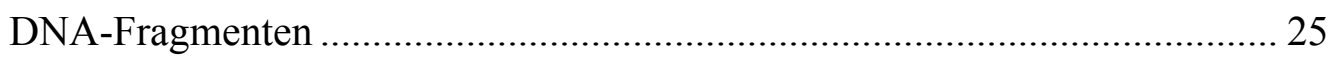

2.3.2 Extraktion und Aufreinigung von Nukleinsäuren...................................... 26

2.3.2.1 Extraktion von DNA aus Bakterien .................................................... 26

2.3.2.2 Extraktion von RNA aus Octadecabacter-Kulturen ................................ 26

2.3.2.3 Direkte Aufreinigung von DNA-Fragmenten ....................................... 27

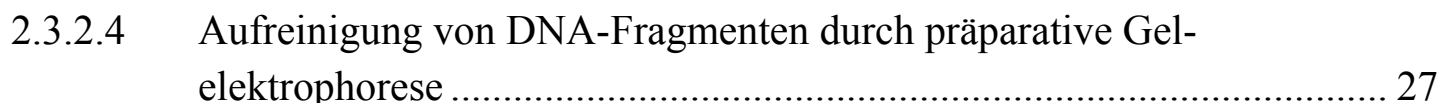

2.3.3 Konzentrationsbestimmung von Nukleinsäuren......................................... 27

2.3.4 Fällung und Aufkonzentrierung von Nukleinsäuren .................................... 28

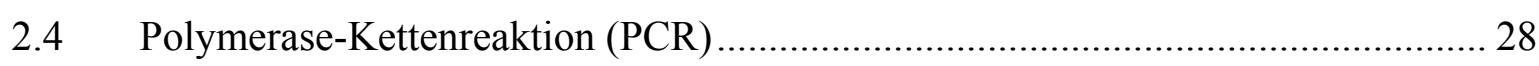

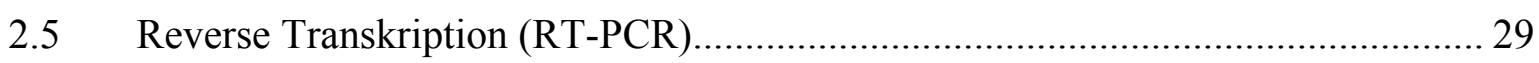

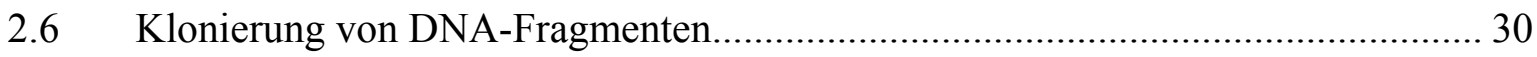

2.6.1 Mechanische Fragmentierung von DNA für Subklonierungen aus Fosmiden 30

2.6.2 Erzeugung von glatten Enden (end repair) ..................................................... 30

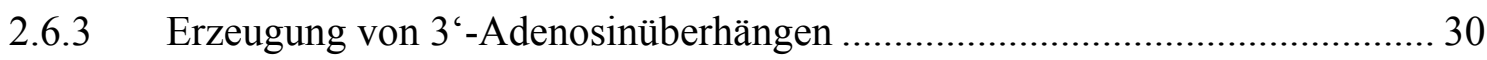


2.6.4 Dephosphororylierung von linearen Vektoren und Phosphorylierung von

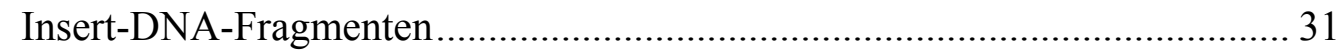

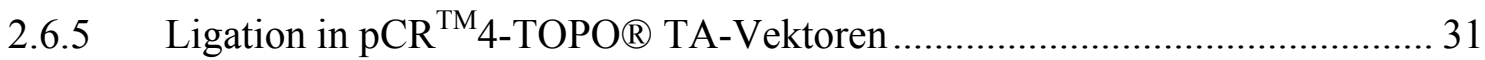

2.6.6 Ligationen in pET24d- und pBAD/Myc-His A-Vektoren ............................... 31

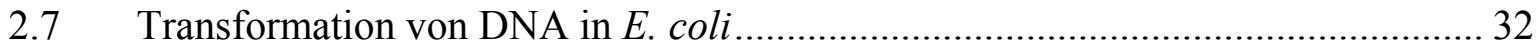

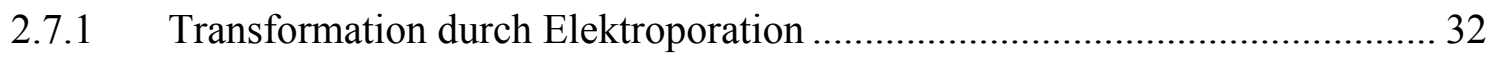

2.7.2 Transformation durch Hitzeschock-Behandlung .......................................... 32

2.7.3 Regeneration von rekombinanten Zellen nach der Transformation ................ 32

2.8 Sequenzierung von PCR-Produkten und rekombinanten Plasmiden ....................... 33

2.9 Sequenzierung und Annotation der Octadecabacter-Genome................................. 34

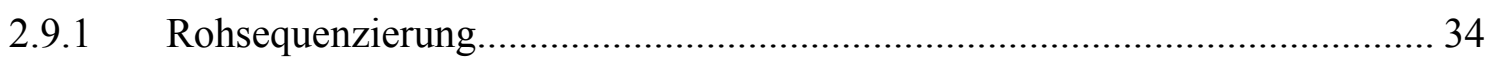

2.9.2 Assemblierung, Lückenschluss und Verbesserung der Sequenzqualität......... 34

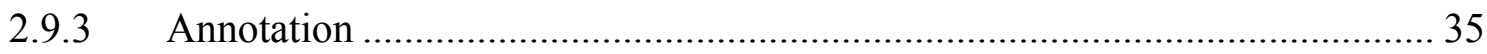

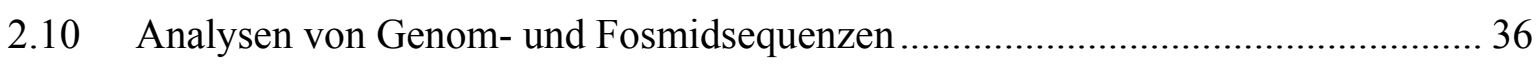

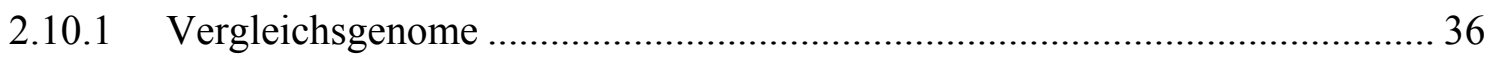

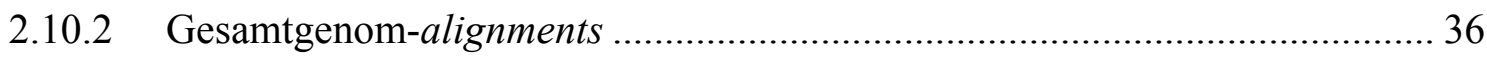

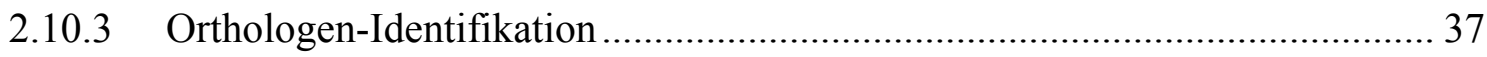

2.10.4 Identifikation von potentiellen genomischen Inseln................................... 38

2.10.5 Vergleiche der Genausstattung (Gene content-Analysen).............................. 38

2.10.6 Vergleichende Analysen der Nukleotid-Zusammensetzung ............................ 39

2.10.7 Phylogenetische Analysen basierend auf Gen- und Proteinsequenzen ........... 39

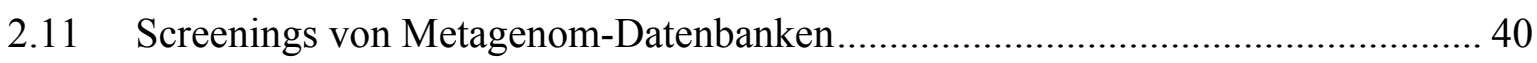

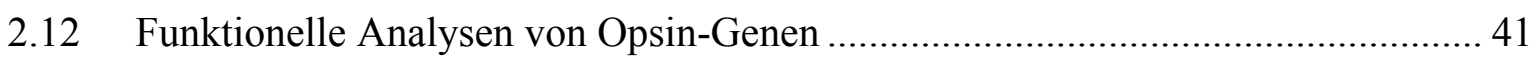

2.12.1 Erzeugung von Expressionsstämmen ........................................................ 41

2.12.2 Heterologe Expression von Opsingenen................................................... 43

2.12.3 Erzeugung und Gewinnung von Membranfragmenten................................... 43

2.12.4 Nachweis von Opsinen in Membranfragmenten .......................................... 43

2.12.4.1 SDS-Polyacrylamid-Gelelektrophorese (SDS-PAGE) ........................... 43

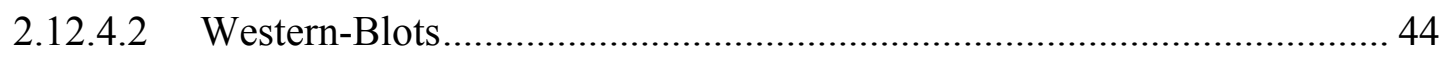

2.12.5 Extraktion von Salinixanthin aus Salinibacter ruber ..................................... 45

2.12.6 Spektralanalysen von Rhodopsingenprodukten.......................................... 45

2.12.7 Bestimmung der Protonenpumpen-Aktivität von Rhodopsinen..................... 46

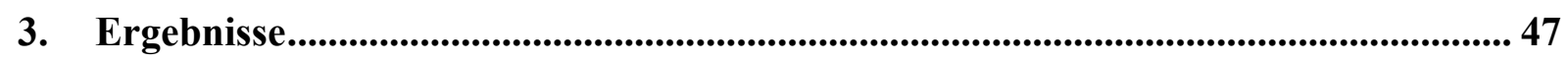

3.1 Allgemeine Vergleiche der bislang sequenzierten Roseobacter-Vertreter ............ 47

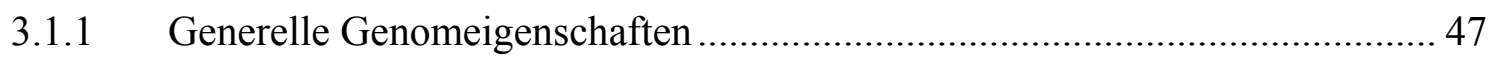

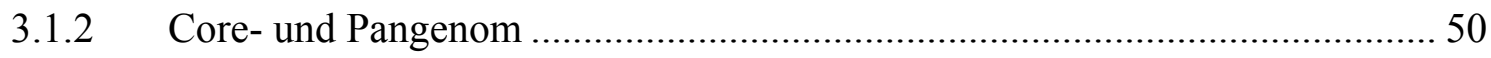

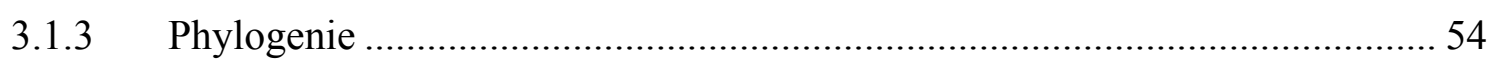

3.1.3.1 Multilokus Sequenzanalysen (MLSA) .............................................. 54 
3.1.3.2 16S + 23S rRNA-Gensequenzvergleiche......................................... 56

3.1.3.3 Vergleiche auf Basis der Gesamtgenomsequenzen................................ 58

3.2 Spezielle Betrachtung des Genus Octadecabacter ................................................ 60

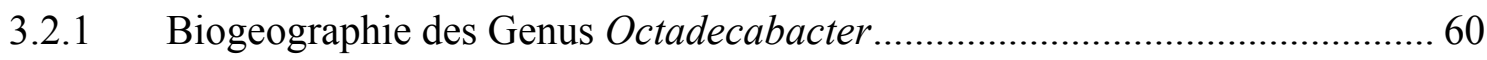

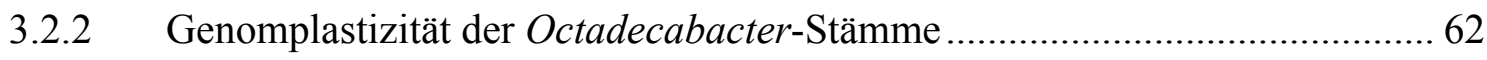

3.2.2.1 Genomische Inseln und Regionen erhöhter Genomplasitizität................ 62

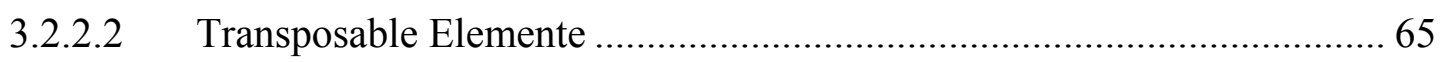

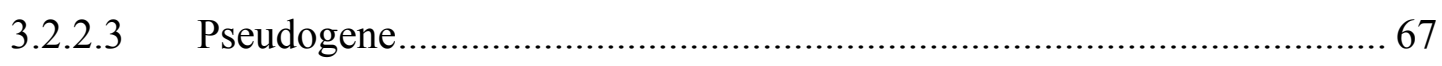

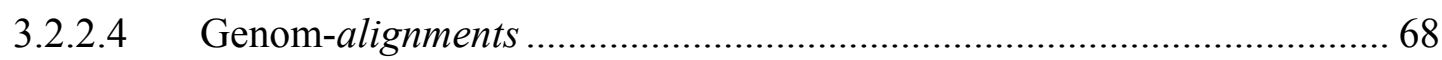

3.2.3 Unterschiede zwischen $O$. arcticus und $O$. antarcticus............................... 70

3.2.3.1 Cyanophycin-Gencluster in O. arcticus ............................................. 70

3.2.3.2 Assimilatorische Nitrat-Reduktion in O. antarcticus............................. 75

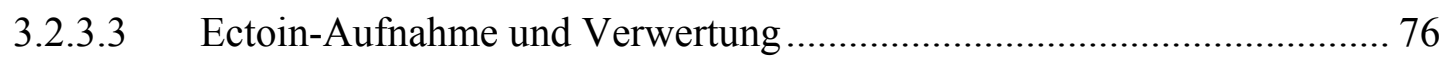

3.2.3.4 Ribulose-1,5-Bisphosphat-Carboxylase/Oxygenase(RuBisCO)-ähnliches

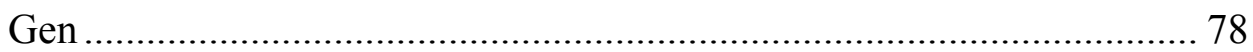

3.2.3.5 Typ IV-Sekretionssystem in $O$. arcticus .............................................. 79

3.2.4 Charakteristische Gemeinsamkeiten zwischen $O$. arcticus und $O$. antarcticus 81

3.2.4.1 Gene Transfer Agents (GTAs) .......................................................... 81

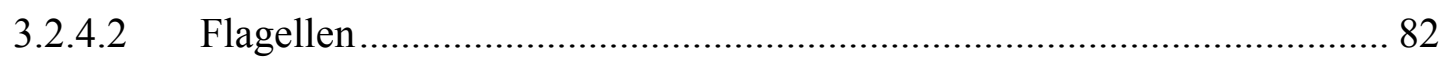

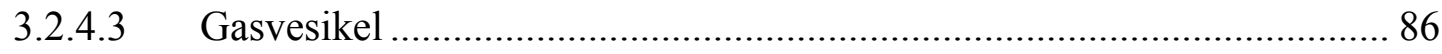

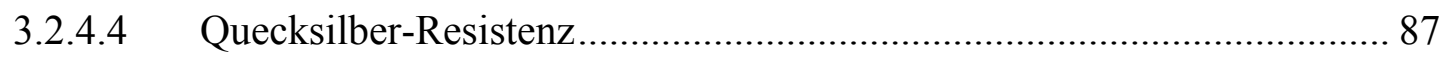

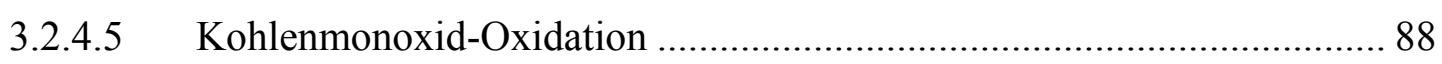

3.2.4.6 Rhamnose Aufnahme- und Verwertungssystem.................................. 88

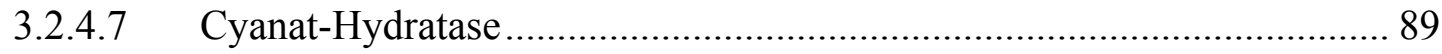

3.2.4.8 Weitere Gemeinsamkeiten .............................................................. 90

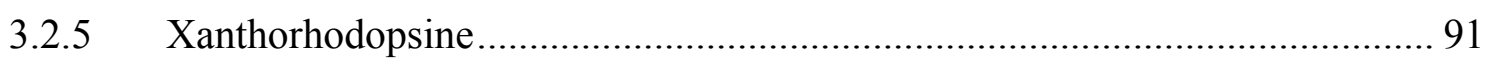

3.2.5.1 Phylogenie der Xanthorhodopsine ........................................................ 91

3.2.5.2 Biogeographie der Xanthorhodopsine.................................................. 93

3.2.5.3 Funktionelle Analysen der Xanthorhodopsine...................................... 96

$\begin{array}{lll}\text { 3.2.5.3.1 Sequenzbasierte Analysen } & 96\end{array}$

3.2.5.3.2 Experimentelle Analysen 99

3.3 Zusatzergebnis: Erste Betrachtung des marinen Myxobakterienclusters (MMC) durch Sequenzanalysen von Fosmid-Klonen ............................................... 102

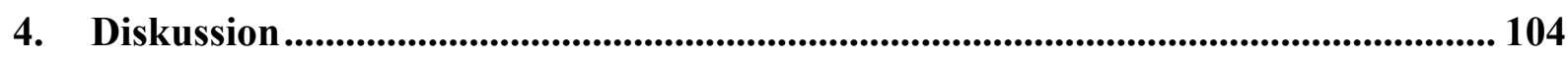

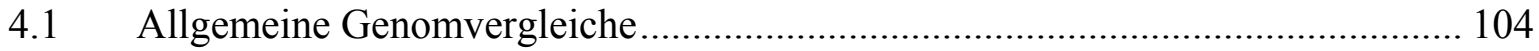

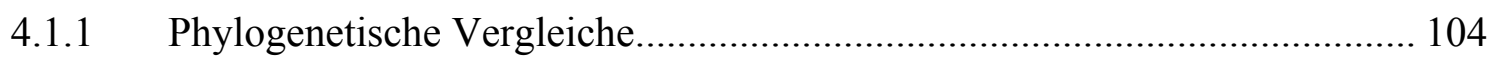

4.1.2 Zusammenhänge zwischen Genomeigenschaften und Habitat bzw.

Lebensweise 108 
4.1.3 Genomische Flexibilität der Roseobacter-Gruppe ..................................... 111

4.1.4 Methodische Aspekte der Roseobacter Genomvergleiche ............................ 116

4.2 Spezifische Betrachtung der Octadecabacter-Stämme....................................... 118

4.2.1 Erhöhte Genomplastizität der Octadecabacter Stämme............................... 118

4.2.2 Rückschlüsse auf die Biogeographie bipolar verbreiteter Organismen......... 122

4.2.3 Generelle Adaptionen an Polargebiete bzw. Meereishabitate ........................ 124

4.2.4 Xanthorhodopsine: Ökologie und Funktion ............................................... 126

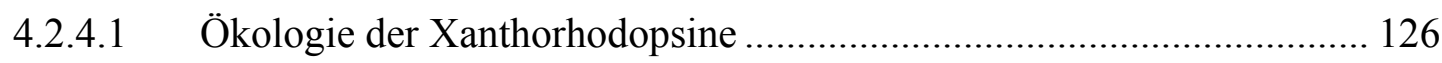

4.2.4.2 Funktion der Xanthorhodopsine......................................................... 131

4.3 Diskussion der Zusatzergebnisse: Erste Einblicke in die Genomausstattung von Vertretern des marinen Myxobakterienclusters (MMC)..................................... 133

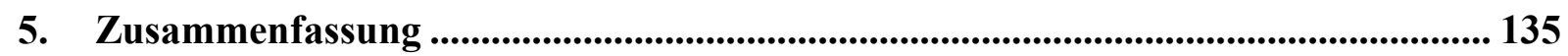

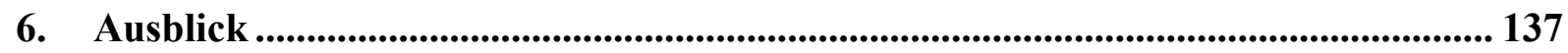

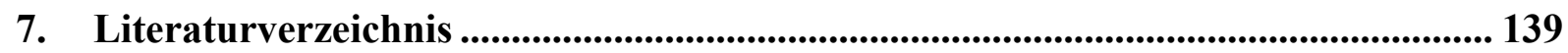

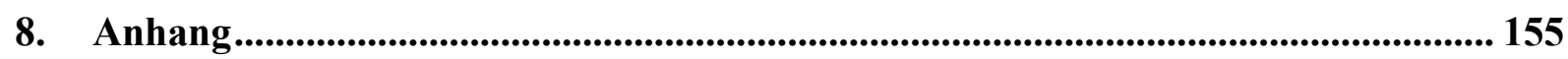

Abbildungsverzeichnis ........................................................................................................... VII

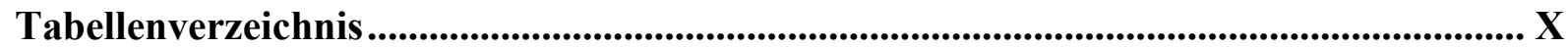




\section{Abbkürzungsverzeichnis}

\begin{tabular}{|c|c|}
\hline$\mu 1$ & Mikroliter \\
\hline$\mu \mathrm{m}$ & Mikrometer \\
\hline$\mu \mathrm{M}$ & Mikromolar \\
\hline A & Ampere \\
\hline Acc & $\begin{array}{l}\text { Accession-Nummer (Kürzel unter dem Sequenz- und Metainformationen in } \\
\text { öffentlichen Datenbanken hinterlegt sind) }\end{array}$ \\
\hline AS & Aminosäure \\
\hline $\mathrm{BBH}$ & Bidirektionaler bester hit. Methode der Orthologen-Identifikation \\
\hline BLAST & Basic Local Alignment Search Tool (Programm für Sequenzsuche) \\
\hline bp & Basenpaar \\
\hline bzw. & Beziehungsweise \\
\hline $\mathrm{cm}$ & Zentimeter \\
\hline $\mathrm{COG}$ & Cluster of Orthologeous Groups (Protein-Klassifikations Datenbank) \\
\hline DNA & Desoxyribonukleinsäure \\
\hline DSMZ & Deutsche Sammlung von Mikroorganismen und Zellkulturen \\
\hline EDTA & Ethylendiamintetraessigsäure \\
\hline e-value & $\begin{array}{l}\text { Expect value. Parameter zur Bestimmung der statistischen Signifikanz eines } \\
\text { BLAST-Treffers }\end{array}$ \\
\hline GOLD & Genomes Online Database (Datenbank für Genomprojekte) \\
\hline GTA & $\begin{array}{l}\text { Gene Transfer Agent } \\
\text { (Virenartige Partikel welche dem horizontalen Gentransfer dienen) }\end{array}$ \\
\hline $\mathrm{h}$ & Stunde \\
\hline $\mathrm{H}_{2} \mathrm{O}_{\text {bidest }}$ & Zweifach destilliertes Wasser (Millipore, Billerica, USA) \\
\hline HGT & Horizontaler Gentransfer \\
\hline His-Tag & Polyhistidinschwanz \\
\hline ICBM & Institut für die Chemie und Biologie der Meere \\
\hline IPTG & Isopropyl-ß-D-thiogalactopyranosid \\
\hline IS-Element & Insertionssequenz-Element \\
\hline $\mathrm{kb}$ & Kilobasenpaar(e) \\
\hline 1 & Liter \\
\hline M & Molar \\
\hline $\mathrm{m}$ & Meter \\
\hline $\mathrm{mA}$ & Milliampere \\
\hline $\mathrm{MB}$ & Marine Broth (Mikrobielles Nährmedium) \\
\hline $\mathrm{Mb}$ & Megabasenpaar(e) \\
\hline $\min$ & Minute \\
\hline $\mathrm{ml}$ & Milliliter \\
\hline $\mathrm{mm}$ & Millimeter \\
\hline
\end{tabular}




$\begin{array}{ll}\text { mM } & \text { Millimolar } \\ \text { n.b. } & \text { Nicht bestimmt } \\ \text { NCBI } & \text { National Center for Biotechnology Information, Bethesda, MD, USA } \\ \text { NCBI-nr } & \text { Nicht-redundante Sequenzdatenbank des National Center for Biotechnology } \\ & \text { Information, Bethesda, MD, USA } \\ \mathrm{nm} & \text { Nanometer } \\ \mathrm{Nr} . & \text { Nummer } \\ \mathrm{OD}_{600 \mathrm{~nm}} & \text { Optische Dichte bei einer Wellenlänge von } 600 \mathrm{~nm} \\ \mathrm{PCR} & \text { Polymerase-Kettenreaktion } \\ \mathrm{pH} & \text { pondus Hydrogenii } \\ \mathrm{RBH} & \text { Reziproker bester hit. Methode der Orthologen-Identifikation. Synonym zu } \\ & \text { BBH. } \\ \text { RefSeq } & \text { NCBI Reference Sequence Database. Kurierte Sequenzdatenbank von NCBI. } \\ \mathrm{RNA} & \text { Ribonukleinsäure } \\ \text { rpm } & \text { Revolutions per minute. Umdrehungen pro Minute } \\ \text { rRNA } & \text { Ribosomale RNA } \\ \mathrm{s} & \text { Sekunde } \\ \text { TE } & \text { Transposables Element (transposons und IS-Elemente) } \\ \mathrm{UV} & \text { Ultraviolett } \\ \text { V } & \text { Volt } \\ \text { z. B. } & \text { Zum Beispiel } \\ \Omega & \text { Ohm (Einheit des elektrischen Widerstands) } \\ & \end{array}$




\section{1. $\quad$ Einleitung}

Die Roseobacter-Gruppe, welche im Mittelpunkt der hier vorliegenden Arbeit steht, repräsentiert einen hohen Anteil der Bakteriengemeinschaften weltweiter mariner Habitate. Diese monophyletische Gruppe der Alphaproteobacteria ist phylogenetisch kohärent, aber physiologisch sehr divers (Buchan, Gonzalez \& Moran 2005). Dies lässt darauf schließen, dass die Vertreter dieser Gruppe vielfältige ökologische Nischen besetzen. Aufgrund der hohen Diversität und starken Verbreitung der Roseobacter-Gruppe in verschiedenen Meeresgebieten ist $\mathrm{zu}$ erwarten, dass vergleichende Analysen entsprechender Vertreter entscheidend dazu beitragen können, unser Wissen über biologische Zusammenhänge und Dynamiken in marinen Lebensräumen zu vertiefen. Um ein besseres Verständnis über die Bedeutsamkeit und Komplexität dieses Themas vermitteln zu können, folgt nun zunächst in den Abschnitten 1.1 \& 1.2 eine zusammenfassende Darstellung der Vielfalt mariner Habitate. Eine Einführung in die Biologie und Bedeutung der Roseobacter-Gruppe wird in den anschließenden Abschnitten 1.3-1.5 gegeben.

\subsection{Die Vielfalt mariner mikrobieller Habitate}

Meere bedecken ca. 71\% der Oberfläche und enthalten mehr als 95\% des Wassers unseres Planeten (Kirchman 2008). Mehr als die Hälfte der globalen Primärproduktion wird durch Mikroorganismen in marinen Habitaten geleistet, somit liegt es auf der Hand, dass Meere eine hohe Bedeutung für das Weltklima und unsere Biosphäre haben. Obwohl phototrophe Mikroorganismen wie Cyanobakterien für den Großteil der Primärproduktion in diesen Habitaten verantwortlich sind (im offenen Ozean bis zu 90\%), ist der weitaus größere Anteil der marinen Bakterien heterotroph (Kirchman 2008). Diese Organismen sind maßgeblich an der Remineralisierung von Nährstoffen aus organischen Material beteiligt und prägen somit die Stoffkreisläufe in den Ozeanen.

Meere sind im allgemeinen gekennzeichnet durch hohe Salinitäten (durchschnittlich ca. $35 \mathrm{psu}$ ) und niedrige Nährstoffkonzentrationen (Giovannoni \& Stingl 2005). Darüber hinaus lassen sich im Meer zahlreiche verschiedene Lebensräume unterscheiden. So differenziert man prinzipiell zwischen Benthal (Meeresboden und Sedimente) und Pelagial (Wassersäule). Im Pelagial unterscheidet man wiederum zwischen freilebenden, aggregatgebundenen und wirtsassoziierten Bakteriengemeinschaften. Die Eindringtiefe des Sonnenlichts in die Wasser- 
säule ist begrenzt, weshalb sich im oberflächennahen Bereich eine photische Zone, das Epipelagial, von bis zu 200 m Tiefe abgrenzen lässt. Innerhalb dieser Zone ist Photosynthese möglich, allerdings nehmen Lichtintensität und -spektrum in ihrem Tiefenverlauf ab. Der Großteil der Primärproduktion findet in dieser oberflächennahen Schicht statt und wird auch hier wieder in Mineralstoffe umgesetzt. Demgegenüber ist die Tiefsee geprägt durch die Abwesenheit von Licht, vergleichsweise niedrige Zelldichten, hohen Druck und größtenteils niedrige Temperaturen (Horikoshi \& Tsujii 1999). Einige Organismen sind spezifisch an diese Bedingungen angepasst und benötigen beispielsweise einen hohen Wasserdruck für optimales Wachstum (Lauro \& Bartlett 2008; Fang, Zhang \& Bazylinski 2010). Die genannten Umweltfaktoren ändern sich graduell mit zunehmender Tiefe, jedoch sind die genauen Abgrenzungen zwischen den einzelnen Tiefseezonen (Meso-, Bathy-, Abysso- und Hadopelagial) biologisch nicht von Bedeutung. Trotz des Mangels an Licht gibt es auch auf dem Grund der Tiefsee produktive Gemeinschaften in Form von chemoautotrophen Organismen, beispielsweise am Rande von Hydrothermalquellen. Dennoch erfolgt der Eintrag organischer Nährstoffe in die Tiefsee zum überwiegenden Teil durch den Import von „gelöstem“ organischem Material (dissolved organic matter, DOM) oder durch Sedimentation von Aggregaten ,partikulären“ organischen Materials (POM), auch Marine Snow genannt, aus dem Epipelagial (Jiao et al. 2010). Marine Snow-Aggregate stellen, je nach Herkunft und Beschaffenheit, wiederum eigene sehr dynamische mikrobielle Habitate dar (Alldredge \& Silver 1988).

Auch geographisch gibt es Unterschiede zwischen marinen Lebensräumen. In Küstengebieten führen Auftrieb von Tiefenwasser sowie Einträge aus Flüssen zu anderen Nährstoffverhältnissen als im offenen Ozean. Ferner gibt es, vor allem entlang der Längengrade, starke Gefälle der Oberflächentemperatur (Abb. 1A) sowie der saisonalen Ausprägung von TagNacht-Zyklen. Einerseits werden hierdurch die jeweiligen Bakteriengemeinschaften direkt beeinflusst, indem sich verschiedene Temperaturoptima und Ernährungsstrategien durchsetzen. Andererseits wird, vor allem in flachen küstennahen Schelfmeeren, die Transpirationsrate und somit die Salinität in den entsprechenden oberflächennahen Wasserschichten beeinflusst. In den Polarmeeren führen dagegen die Bildung und das Abschmelzen von Meereis zu Veränderungen der Salinität. Aus diesen Prozessen resultieren starke regionale Unterschiede in Temperatur, Salinität und Dichte, die das Aufsteigen bzw. Absinken von Wassermassen bedingen. Dieser Prozess treibt globale Meeresströmungen an und bewirkt, dass sich unterschiedliche Wassermassen übereinander schieben. Hierdurch ergeben sich regional verschiedene Schichtungen welche auch biologisch von Bedeutung sein können (Abb. 1B). 

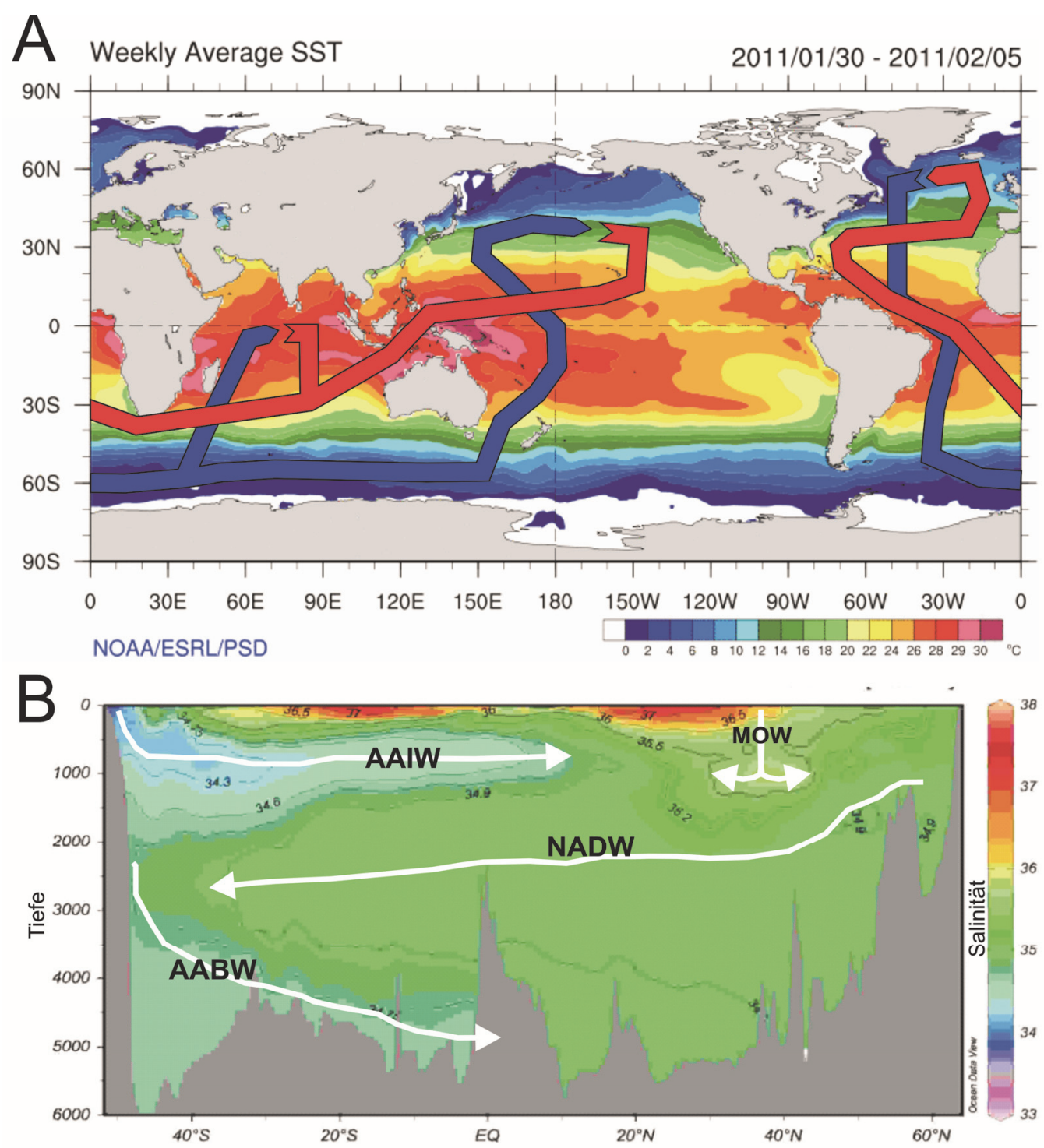

Abb. 1 Beispiele mariner Wassermassen und Meereströmungen

A) Die kartographische Darstellung der marinen Oberflächentemperaturen wurde aus Wikimedia Commons (http://commons.wikimedia.org/wiki/File:Weeklysst.gif) entnommen und bearbeitet. Die marinen Oberflächentemperaturen sind durch eine Farbskala dargestellt. Weiße Flächen stellen Meeresgebiete mit Eisbedeckung dar. Auf diese Karte wurde der grobe Verlauf wichtiger Meeresströmungen projiziert. Blaue Pfeile stellen Tiefenströmungen, rote Oberflächenströmungen dar. B) Salinitätsprofil der CTD-Stationen der Polarstern-Expedition ANTXXVII-5 (Erstellt von Florian Remke, ICBM, Oldenburg). Salinitäten sind durch eine Farbskala dargestellt. Verschiedene Wassermassen lassen sich durch distinkte Übergänge des Salzgehaltes unterscheiden. $\mathrm{Zu}$ erkennen sind die Wassermassen Antarctic Intermediate Water (AAIW), Antarctic Bottom Water (AABW), North Atlantic Deep Water (NADW) und Mediterranean Outflow Water (MOW). Die jeweilige Strömungsrichtung ist durch Pfeile angezeigt.

\subsection{Besonderheiten der Polarregionen}

Unter den weltweiten Meeresgebieten nehmen das Südpolarmeer und das Nordpolarmeer eine Sonderstellung ein. Diese Meere sind durch physische Barrieren von den übrigen Ozeanen abgetrennt: das Nordpolarmeer durch umgebende Landmassen und das Südpolarmeer durch eine starke Oberflächenströmung, dem sogenannten Zirkumpolarstrom (Antarctic 
Circumpolar Current, ACC). Absinkendes salzreiches und kaltes Wasser aus diesen Regionen bildet Ausgangspunkte für wichtige Tiefenströmungen wie das North Atlantic Deep Water (NADW) und das Antarctic Bottom Water (AABW) (Morozov et al. 2010). Diese Tiefenströmungen sind treibende Kräfte des ,globalen Förderbandes“, welches das Weltklima maßgeblich beeinflussen (Broecker 1991). Die Umweltbedingungen in diesen Gebieten weisen extreme saisonale Schwankungen auf, vor allem in Bezug auf Temperatur und Lichtintensität. Die durchschnittlichen Wassertemperaturen sind allgemein deutlich niedriger als in allen anderen marinen Habitaten. Entsprechend sind in diesen Regionen spezialisierte, überwiegend psychrotolerante und psychrophile Organismen vorzufinden (Staley \& Gosink 1999).

Sowohl das Nord- als auch das Südpolarmeer weisen eine großflächige, saisonal schwankende Eisbedeckung auf. Dieses Meereis stellt einen eigenen, extremen und einzigartigen Lebensraum dar. Meereis ist gekennzeichnet von niedrigen NährstoffDiffusionsraten und starken räumlichen sowie zeitlichen Gradienten in Temperatur, Salinität und Lichteinfall. Man unterscheidet zwischen einjährigem Meereis, welches im Verlauf des nächsten Sommers wieder vollständig schmilzt, und mehrjährigem Meereis, welches aufgrund seiner Dicke mindestens eine Sommerperiode übersteht. Meereis entsteht aus gefrierendem Meerwasser und ist somit deutlich von Schelfeis und Eisbergen abzugrenzen, welche glazialen Ursprungs sind. Die Bildung von Meereis beginnt wenn die Wassertemperatur auf ca. $-1,9{ }^{\circ} \mathrm{C}$ abgesunken ist. Das im Meerwasser enthaltene Salz wird im Laufe des Gefrierprozesses ausgeschieden und sammelt sich teilweise als konzentrierte Salzlake in kleinen Kanälen innerhalb des Eises an. Dadurch variieren die Salinitäten innerhalb des Meereises extrem. Zwischen den Eiskristallen herrschen nahezu Süßwasserbedingungen, während die Salzlake-Kanäle mehr als dreifach höhere Salinitäten als Meerwasser aufweisen können. Je höher die Eisschicht wächst, desto stärker bilden sich vertikale Temperaturgradienten zwischen der oberen Grenzschicht zur Luft und der unteren Grenzschicht zum Meerwasser aus. Während der untere Bereich des Meereises nahezu konstante Temperaturen nahe am Gefrierpunkt des Meerwassers $\left(-1,9^{\circ} \mathrm{C}\right)$ aufweist, schwankt die Temperatur im oberen Bereich mit den polaren Lufttemperaturen, welche $-50{ }^{\circ} \mathrm{C}$ unterschreiten können (Thomas \& Dieckmann 2002).

Während des Eisbildungsprozesses werden auch Organismen des Meerwassers in der wachsenden Eismatrix eingeschlossen. Einige dieser Organismen sind speziell an diesen extremen Lebensraum angepasst und können dort gedeihen, während andere nur überdauern oder absterben. Folglich unterscheiden sich die Bakteriengemeinschaften des Meereises 
signifikant von denen des darunterliegenden Meerwassers (Bowman et al. 2012). Im Gegensatz zu polaren Meerwasserbakterien, welche größtenteils psychrotolerant zu sein scheinen (Delille 1992; Pesciaroli et al. 2012), sind Meereisbakterien zum überwiegenden Teil psychrophil (Bowman et al. 1997; Junge, Christner \& Staley 2011). Sowohl im Meereis als auch im Meerwasser werden mikrobielle Gemeinschaften der Polargebiete häufig dominiert von Gammaproteobacteria, Alphaproteobacteria und Vertretern der CytophagaFlavobacterium-Bacteriodetes (CFB)-Gruppe (Brinkmeyer et al. 2003; Bowman et al. 2012), wobei die genauen Verhältnisse allerdings starken saisonalen Schwankungen unterliegen (Collins, Rocap \& Deming 2010; Ghiglione \& Murray 2012). Archaeen hingegen, welche üblicherweise mit extremen Standorten assoziiert werden, sind zwar in polarem Meerwasser stark vertreten, aber in Meereis überraschenderweise nur in relativ geringer Zahl nachzuweisen (Collins, Rocap \& Deming 2010).

Die stabilsten Lebensbedingungen sind im unteren Bereich des Meereises zu finden. Aufgrund des nahen Kontaktes mit dem darunterliegenden Meerwasser findet hier noch am ehesten eine Diffusion von Nährstoffen aus der Wassersäule statt, und auch Schwankungen der Salinitäten und Temperaturen sind weniger stark ausgeprägt als in höheren Bereichen. Bei geringer oder fehlender Schneedecke sind hier zudem auch die Lichtintensitäten selbst bei bis zu zwei Meter dicken Eisschichten noch ausreichend für photoautotrophe Ernährung. Aus diesen Gründen bildet sich vorwiegend in den unteren 10-20 cm des Meereises häufig eine überaus dichte und hochproduktive mikrobielle Gemeinschaft aus: die sogenannte Sea Ice Microbial Community (SIMCO) (Hollibaugh, Lovejoy \& Murray 2007). Die primären Produzenten der SIMCO sind Diatomeen. Diese bewirken durch ihre charakteristische Färbung, dass die SIMCO in Querschnitten von Meereis als deutlich erkennbare bräunliche Bande hervortritt (Staley \& Gosink 1999).

Trotz vieler Gemeinsamkeiten, unterscheiden sich Nord- und Südpolarregionen in einigen Punkten deutlich voneinander. Das Nordpolarmeer (Arktis) ist eng von den nördlichen Grenzen der Landmassen Nordamerikas, Asiens und Europas umschlossen und somit starken terrestrischen und anthropogenen Einflüssen ausgesetzt. Eine eigene Landmasse ist jedoch nicht vorhanden, vielmehr handelt es sich um ein reines Meeresgebiet. Die Antarktis dagegen ist ein eigenständiger, zu großen Teilen mit Eis bedeckter, Kontinent umschlossen vom weitläufigen Südpolarmeer. Das Ausmaß terrestrischer Einflüsse, beispielsweise durch den Eintrag von Flüssen, ist im Südpolarmeer vergleichsweise gering. Inwiefern sich diese Unterschiede auf die mikrobiellen Gemeinschaften dieser Habitate auswirken, ist bislang noch nicht ausreichend verstanden. Ebenso wenig ist bekannt, inwiefern sich diese 
geographisch getrennten Gemeinschaften gegenseitig beeinflussen, denn auf rRNA Gensequenzebene existieren zum Teil bemerkenswerte Parallelen (Staley \& Gosink 1999). So weisen einige Taxa eine bipolare Verteilung (Anwesenheit nah verwandter Vertreter in beiden Polarregionen, aber Abwesenheit in temperaten und tropischen Regionen) auf (z. B. Montresor et al. 2003; Bano et al. 2004; Pearce et al. 2007; Zeng et al. 2010). Eine solche Verteilung wurde auch bei eindeutig psychrophilen Organismen beobachtet, welche einen Transport über warme Äquatorregionen, beispielsweise über Oberflächenströmungen oder mittels Verschleppung durch Zugvögel, nicht überleben würden (z. B. Gosink, Herwig \& Staley 1997; Comte et al. 2007). Detaillierte Genomanalysen, wie die hier vorliegende Arbeit, tragen dazu bei, die genauen Verwandtschaftsbeziehungen sowie potentielle Unterschiede zwischen solchen bipolar verbreiteten Organismen zu beleuchten.

\section{3 Ökologische und wissenschaftliche Bedeutung der Roseobacter-Gruppe}

Die Roseobacter-Gruppe ist eine monophyletische Gruppe innerhalb der Familie Rhodobacteraceae, welche wiederum der Klasse Alphaproteobacteria angehört (Buchan, Gonzalez \& Moran 2005). Ihr Name ist von den ersten charakterisierten Isolaten dieser ursprünglich nur in 16S rRNA Genbanken nachgewiesenen Gruppe abgeleitet: Roseobacter litoralis und Roseobacter denitrificans (Shiba 1991). Diese beiden Arten repräsentieren jedoch nur einen der mittlerweile fast 40 beschriebenen Genera dieser Gruppe (Brinkhoff, Giebel \& Simon 2008). Die bislang bekannten Mitglieder der Roseobacter-Gruppe sind fast ausschließlich marine oder zumindest halotolerante, aquatische Organismen. Eine Ausnahme stellt die Gattung Ketogulonicigenium dar, deren Vertreter aus Bodenproben stammen (Urbance et al. 2001). Vertreter der Roseobacter-Gruppe stellen in küstennahen Oberflächenschichten bis zu 25\% der marinen Bakterienpopulation (Buchan, Gonzalez \& Moran 2005). Sie sind in allen geographischen Breiten (siehe Tab. DA01, digitaler Anhang) und in einer Vielzahl unterschiedlicher ökologischer Nischen (Abb. 2) zu finden. Viele Vertreter scheinen in ihrer Verbreitung auf bestimmte Klimazonen beschränkt zu sein, doch einige sind nahezu ubiquitär (Brinkhoff, Giebel \& Simon 2008).

Obwohl die Roseobacter-Gruppe eine hohe ökologische Bedeutung besitzt, stellt sie nicht die am stärksten vertretene bakterielle Gruppe in marinen Habitaten dar. Der Großteil der Bakteriengemeinschaften in marinen Habitaten wird durch weniger als 20 phylogenetische Gruppen aus 11 bakteriellen Phyla ausgemacht (Giovannoni \& Stingl 2005; Kirchman 2008). 


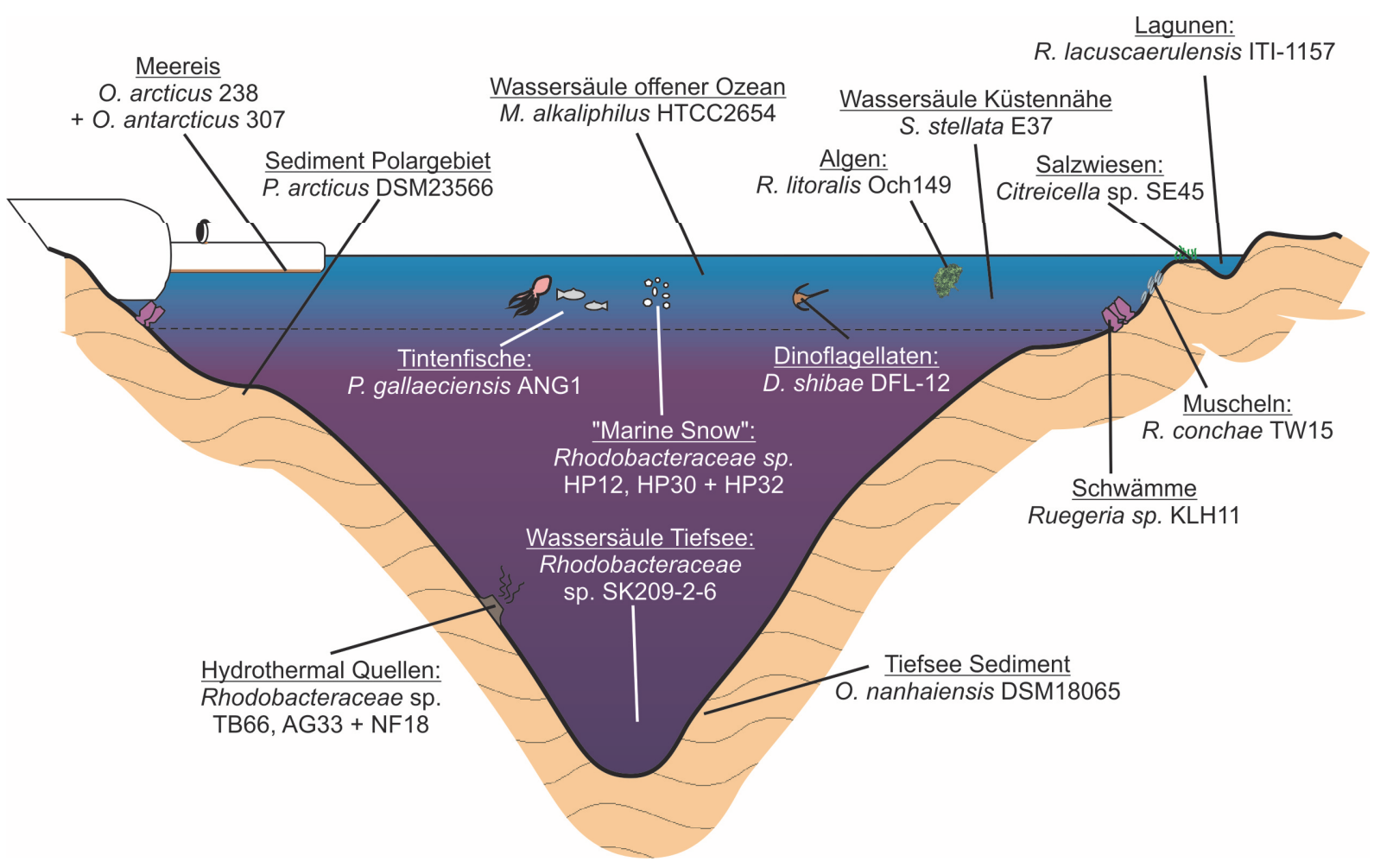

\section{Abb. 2 Herkunft exemplarischer Vertreter der Roseobacter-Gruppe}

Dargestellt sind Bezeichnung sowie Herkunft verschiedener mariner Roseobacter-Vertreter zur Verdeutlichung der hohen ökologischen Vielfalt der Roseobacter-Gruppe.

Die meisten dieser Gruppen sind dem Phylum Bacteriodetes, und den Klassen Gammaproteobacteria und Alphaproteobacteria des Phylums Proteobacteria zugehörig. Vor allem in oberflächennahen Wasserschichten werden Alphaproteobacteria hauptsächlich durch den SAR11-Cluster und die Roseobacter-Gruppe repräsentiert. Der SAR11-Cluster ist mit einem Anteil von 33\% an der Bakteriengemeinschaft in der photischen Zone und von 25\% der Gemeinschaft im Mesopelagial meist abundanter als die Roseobacter-Gruppe und damit die weltweit in marinen Habitaten am stärksten vertretene Bakteriengruppe (Morris et al. 2002). Da sich Vertreter dieses Clusters jedoch nur mit speziellen Kultivierungsmethoden isolieren und anziehen lassen (Rappé et al. 2002), sind sie als Modellorganismen wenig geeignet. Anders stellt es sich für die Roseobacter-Gruppe dar: Vertreter dieser Gruppe sind durch kultivierungsunabhängige Untersuchungen in hoher Zahl nachweisbar (González \& Moran 1997), aber auch häufig und aus diversen marinen Habitaten isoliert worden (Abb. 2) und somit leicht unter Laborbedingungen anzuziehen. Dies eröffnet die Möglichkeit intensiver physiologischer Laborversuche, wodurch Roseobacter-Vertretern eine enorme wissenschaftliche Bedeutung als repräsentative Modellorganismen mariner Habitate zukommt (Nichols 2007). 


\subsection{Physiologische Diversität und Adaptivität der Roseobacter-Gruppe}

Entsprechend ihrer oben beschriebenen ökologischen Vielfalt (Abb. 2), weist die Roseobacter-Gruppe eine enorme physiologische Diversität auf (Wagner-Döbler \& Biebl 2006). Die Verteilung prägnanter Merkmale auf die verschiedenen Vertreter dieser Gruppe scheint jedoch zu großen Teilen unabhängig von phylogenetischen Verwandtschaftsverhältnissen $\mathrm{zu}$ sein. So werden diverse Eigenschaften von phylogenetisch entfernten Vertretern geteilt, während sie in den jeweils nächstverwandten Organismen nicht vorhanden sind (Moran et al. 2007). Dies deutet auf einen ausgedehnten horizontalen Gentransfer (HGT) zwischen Roseobacter-Vertretern hin, eine Annahme die durch die hohe Verbreitung von Gene transfer agents (GTAs) innerhalb dieser Organismengruppe unterstützt wird (Newton et al. 2010). Bei GTAs handelt es sich um Phagen-ähnliche Partikel, welche zufällige Fragmente des Wirtsgenoms verpacken und auf nah verwandte Organismen übertragen können (Biers et al. 2008). Wie ausgeprägt HGT innerhalb der Roseobacter-Gruppe stattfindet und in welchem Ausmaß Gentransfers durch GTAs vermittelt werden, ist jedoch bislang nicht vollständig bekannt.

$\mathrm{Zu}$ den in verschiedenen Vertretern beschriebenen Merkmalen gehören unter anderem die Befähigung zur Kohlenmonoxid-Oxidation (Moran et al. 2004), fakultativ anaerobes Wachstum (Swingley et al. 2007), assimilatorische und dissimilatorische Nitratreduktion (Shiba 1991) und die Fixierung von Kohlenstoffdioxid (Newton et al. 2010). Wirtschaftliche Bedeutung könnten einige Roseobacter-Isolate durch ihren antagonistischen Effekt auf das Wachstum von Meeresalgen und andere durch die Produktion von antibiotisch wirksamen Substanzen erlangen (Wagner-Döbler \& Biebl 2006). Einige Vertreter, wie beispielsweise Roseobacter litoralis und Roseobacter denitrificans, sind in der Lage, sogenannte anaerobe anoxygene Photosynthese (AAnP) zu betreiben. Der Begriff „Photosynthese“ ist in diesem Zusammenhang jedoch irreführend, da dieser Prozess nicht zur Fixierung von Kohlenstoff führt und somit keine Photosynthese im klassischen Sinne darstellt. Vielmehr handelt es sich um einen Mechanismus der photoheterotrophen Ernährung. Vor wenigen Jahren wurde in den Genomsequenzen der drei Roseobacter-Vertreter Octadecabacter arcticus 238, Octadecabacter antarcticus 307 und Rhodobacteraceae sp. HTCC2255 ein weiteres Merkmal identifiziert, welches mit photoheterotropher Energiegewinnung in Zusammenhang steht: mikrobielles Rhodopsin. Aufgrund der hohen Bedeutung die den Rhodopsinen in dieser Doktorarbeit zugeordnet wird, werden bekannte Eigenschaften solcher Proteine im Folgenden detailliert beschrieben. 


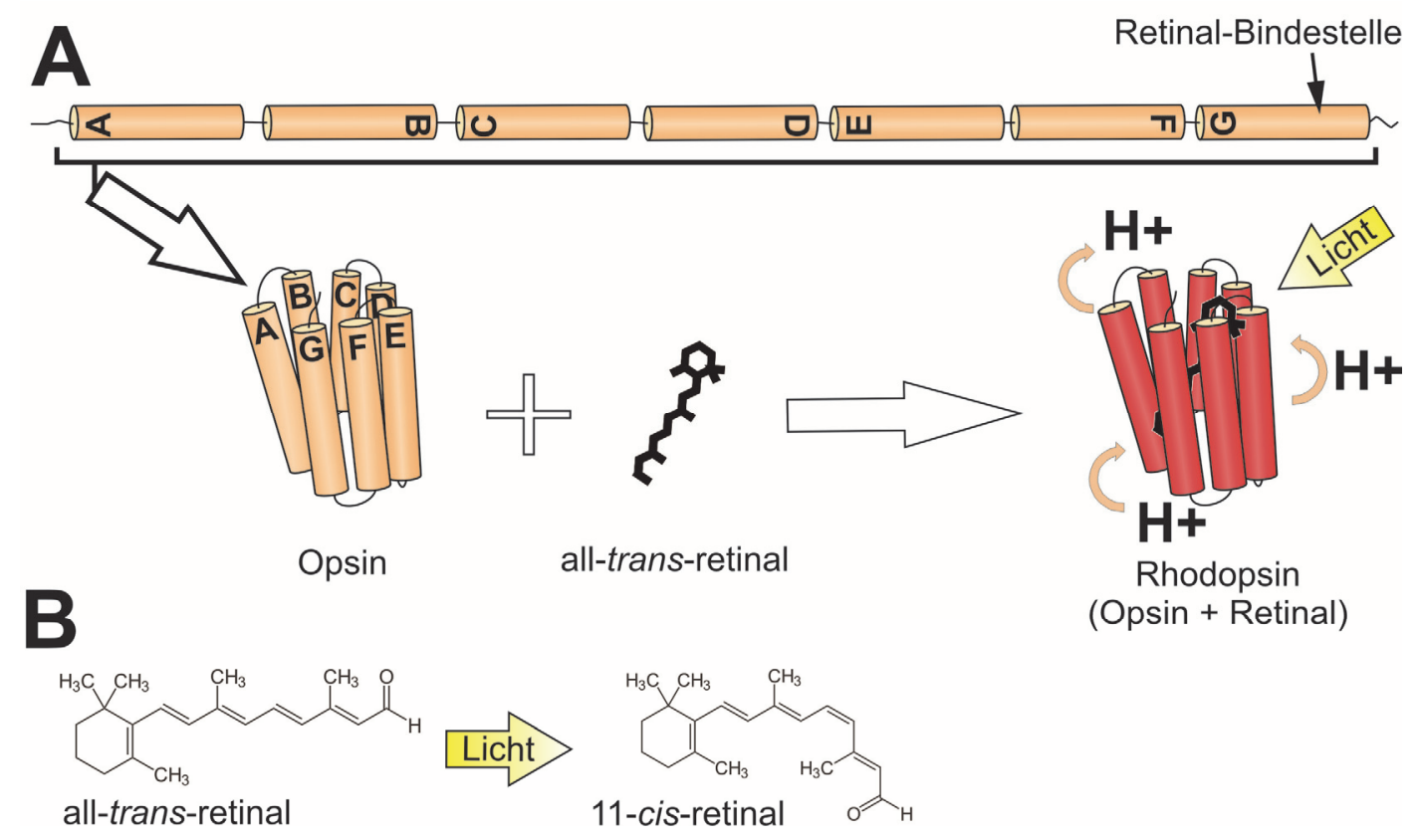

\begin{abstract}
Abb. 3 Mikrobielle Rhodopsine. Schematischer Aufbau
A) Aufbau eines Rhodopsins. Oben: lineare Darstellung des Opsin-Apoproteins, bestehend aus sieben Transmembranhelices (Helices A-G). Unten: Opsine bilden Taschen innerhalb der Zellmembran. Erst durch die Bindung eines Retinalmoleküls an Helix G im Inneren dieser Tasche entsteht ein funktionales Rhodopsin mit der charakteristischen rötlichen Färbung. Lichtinduzierte Konformitätsveränderungen des Rhodopsins bewirken eine Translokation von Protonen oder Kationen. B) Lichtabhängige Strukturänderung von All-trans-Retinal zu 11-cis-Retinal.
\end{abstract}

Rhodopsine, auch als Retilyden-Proteine bezeichnet, sind photoaktive Membranproteine (Spudich et al. 2000). Der Apoenzym-Teil des Rhodopsins wird als Opsin bezeichnet, dieser bindet das Vitamin A-Aldehyd Retinal als prosthetische Gruppe und Chromophor. Man unterscheidet Typ II Rhodopsine, welche als Sehpigmente in der Netzhaut von höheren Tieren vorkommen, und Typ I Rhodopsine (auch mikrobielle Rhodopsine genannt), welche in den Membranen von Mikroorganismen wie Archaeen, Bakterien und Pilzen vorkommen (Spudich et al. 2000; Spudich \& Jung 2005). Typ I Rhodopsine sind phylogenetisch und funktional sehr divers (McCarren \& DeLong 2007). Sie teilen jedoch eine hochkonservierte Tertiärstruktur aus sieben Transmembran-Helices, welche eine Tasche innerhalb der Zellmembran bilden (Abb. 3A). Der Chromophor wird in Form von all-trans-Retinal kovalent über eine protonierte Schiffsche Base $\left(-\mathrm{NH}^{+}=\right)$an eine konservierte Lysin-Seitengruppe im Inneren dieser Tasche gebunden.

Wird das Retinal durch Licht angeregt, ändert sich seine isomere Form zu 11-cis-Retinal (Abb. 3B). Dies führt zu einer Reihe von Konformationsänderungen des Rhodopsins (Haupts, Tittor \& Oesterhelt 1999), welche je nach phylogenetischer Zugehörigkeit für unterschiedliche Prozesse genutzt werden können (McCarren \& DeLong 2007): 
Energiegewinnung durch Protonentranslokation, Aufrechterhaltung von Salinitätsgradienten durch Ionentranslokation oder Anpassung an veränderte Lichtverhältnisse durch Signaltransduktion. Im Folgenden werden die verschiedenen bekannten Rhodopsingruppen und ihre jeweiligen Eigenschaften vorgestellt.

Bacterio-, Halo- und sensorische Rhodopsine fungieren jeweils als Protonenpumpen, Ionenpumpen oder Signaltransduktoren. Sie sind größtenteils archaeellen Ursprungs, jedoch gibt es auch zahlreiche bakterielle Vertreter. Eng verwandt mit diesen Gruppen sind die fungalen Rhodopsine, deren genaue Funktion jedoch noch nicht geklärt ist (Brown 2004). Die große Gruppe der Proteorhodopsine dagegen ist hauptsächlich bakteriellen Ursprungs und es wird angenommen, dass es sich bei diesen Rhodopsinen größtenteils um Protonenpumpen handelt (Fuhrman, Schwalbach \& Stingl 2008). Diese Gruppe ist vor allem unter marinen Bakterien weit verbreitet (de la Torre et al. 2003; McCarren \& DeLong 2007). Balashov et al. beschrieben schließlich 2005 mit den Xanthorhodopsinen eine weitere Gruppe von Rhodopsinen (Balashov et al. 2005; Imasheva et al. 2009), welche phylogenetisch zwischen den größtenteils archaeellen Bacteriorhodopsinen und den Proteorhodopsinen liegt. Diese neue Gruppe weist die unter mikrobiellen Rhodopsinen einzigartige Eigenschaft auf 4-ketoCarotenoide als Antennenpigmente zu binden.

\subsection{Die Gattung Octadecabacter}

In polaren marinen Habitaten wird die Roseobacter-Gruppe hauptsächlich durch den Genus Octadecabacter repräsentiert. Die Typstämme der zwei beschriebenen Arten dieses Genus, Octadecabacter arcticus 238 und Octadecabacter antarcticus 307, wurden aus den unteren $20 \mathrm{~cm}$ von Eiskernen arktischen bzw. antarktischen Packeises isoliert (Gosink, Herwig \& Staley 1997). Sie waren Teil einer großen Gruppe von phylogenetisch sehr diversen heterotrophen Bakterien, welche in den Jahren 1989 bis 1993 von Gosink und Staley aus arktischem und antarktischem Meerwasser und -eis isoliert wurden und durch das Vorhandensein von Gasvesikeln auffielen (Gosink \& Staley 1995). Dabei handelt es sich um intrazelluläre, gasgefüllte Proteinstrukturen welche der vertikalen Positionierung innerhalb der Wassersäule dienen (Walsby 1994; Pfeifer 2012) und für heterotrophe Bakterien mariner Habitate eher ungewöhnlich sind (Staley \& Gosink 1999). Der Name Octadecabacter begründet sich durch den erhöhten Anteil einfach ungesättigter Octadecansäure in den Membranen dieser Isolate, durch den sich die Vertreter dieses Genus von den übrigen 
heterotrophen Gasvesikel-bildenden Bakterien der Polargebiete abgrenzten (Gosink, Herwig \& Staley 1997). Für Vertreter des Roseobacter-Clusters ist ein solch hoher Anteil an Octadecansäure jedoch nicht ungewöhnlich.

Die beschriebenen Vertreter der beiden Arten weisen keine Pigmentierung auf und gelten als unbeweglich. Sie sind psychrophil und somit endemisch in den jeweiligen Polarregionen, da die zumeist wärmeren Oberflächentemperaturen anderer Gewässer für sie lebensfeindlich wären. Bakterien dieser Gattung werden in polarem Meerwasser und Meereis häufig nachgewiesen (Brinkmeyer et al. 2003; Bowman et al. 2012; Grzymski et al. 2012). Es handelt sich somit um autochthone Vertreter dieser Habitate.

Stämme der beiden Octadecabacter-Arten stimmen in über 99\% ihrer 16S rRNA Gensequenz überein. Dies ist in Anbetracht ihres jeweiligen endemischen Vorkommens, das scheinbar keine direkte räumliche Verbindung aufweist, bemerkenswert. Die Ähnlichkeiten auf 16S rRNA Sequenzebene sind so gravierend, dass es nicht möglich ist, die genaue Artzugehörigkeit nur anhand dieses Markers zu bestimmen. Dass trotzdem zwei verschiedene Arten deklariert wurden, liegt an den niedrigen DNA/DNA-Hybridisierungswerten der jeweiligen Typstämme O. arcticus 238 und O. antarcticus 307. Diese weisen demnach auf Gesamtgenom-Ebene nur eine Übereinstimmung von 42\%, weit unterhalb des Grenzwertes für identische Spezies, auf (Wayne et al. 1987). Diese Diskrepanz zwischen den Sequenzidentitäten auf Ebene der 16S rRNA und des Gesamtgenoms, verbunden mit der speziellen Biogeographie und dem extremen Habitats der Octadecabacter-Arten, macht diese Vertreter besonders interessant für vergleichende Genomanalysen. 


\subsection{Zielsetzung}

Auch in Zeiten intensiver Metagenom- und Metatranskriptom-Sequenzierungen („metaomics“) bleiben Genomanalysen einzelner Isolate essentiell. Die teilweise sehr hohe Sequenzvariabilität innerhalb von Populationen sowie potentieller horizontaler Gentransfer zwischen den Spezies erschweren die Assemblierung von meta-omics-Daten zu einem schlüssigen Gesamtbild. Vollständige Genomsequenzen sind hierbei hilfreich, da sie als Referenzen für die Assemblierung von Metagenomdaten dienen können. Zudem erlauben sie die Betrachtung genetischer Informationen in Bezug auf die jeweiligen Organismen und deren spezifischer Gesamtausstattung, was bei Metagenomen nur sehr begrenzt möglich ist. Aus diesen Gründen befasst sich die vorliegende Arbeit mit vergleichenden Genomanalysen repräsentativer Bakterienstämme der Roseobacter-Gruppe. Es sollen Gemeinsamkeiten und Unterschiede in der genetischen Ausstattung verschiedener Roseobacter-Vertreter identifiziert und mit Habitateigenschaften bzw. individueller Lebensweise der Vergleichsorganismen in Zusammenhang gebracht werden. Die Ergebnisse sollen dazu beitragen globale Dynamiken zwischen marinen Bakterienpopulationen sowie spezifische genetische Anpassungen an unterschiedliche marine Lebensräume aufzuzeigen und $\mathrm{zu}$ verstehen. Ein besonderer Schwerpunkt soll auf die Genomanalyse von Octadecabacter arcticus 238 und Octadecabacter antarcticus 307, den Typstämmen der beiden Arten des Genus Octadecabacter, gelegt werden. Hierfür sollen die bislang nur als Rohsequenzen verfügbaren Genomsequenzen dieser Organismen vollständig geschlossen, auf Sequenzungenauigkeiten hin überprüft und anschließend intensiv Untersucht werden.

Die Octadecabacter-Typstämme nehmen aufgrund ihres besonderen Meereishabitats sowie ihrer bipolaren geographischen Verteilung innerhalb der Roseobacter-Gruppe eine Sonderstellung ein. Daher sollen die Genomdaten genutzt werden um die Verwandtschaftsbeziehungen zwischen arktischen und antarktischen Octadecabacter-Populationen zu beleuchten und potentielle Habitat-spezifische Anpassungen $\mathrm{zu}$ identifizieren. Diese Ergebnisse sollen das Verständnis der Biogeographie, Genomdynamik und Anpassungsfähigkeit mariner Roseobacter-Vertreter weiter vertiefen.

In diesem Zusammenhang soll auch die Bedeutung und Funktion der innerhalb der Roseobacter-Gruppe einzigartigen Xanthorhodopsine in den Octadecabacter-Stämmen genauer untersucht werden. 


\section{Material \& Methoden}

\subsection{Organismen und Plasmid-Vektoren}

Bakterienstämme und Vektoren, welche im Rahmen dieser Arbeit verwendet wurden, sind in Tab. 1 und Tab. 2 aufgelistet.

Tab. 1 Verwendete Bakterienstämme

\begin{tabular}{|c|c|c|}
\hline Organismus & Funktion/Beschreibung/Referenz & Herkunft \\
\hline Octadecabacter arcticus 238 & $\begin{array}{c}\text { Typstamm } \\
\text { (Gosink, Herwig \& Staley 1997) }\end{array}$ & $\begin{array}{l}\text { CRBIP, Paris, } \\
\text { Frankreich }\end{array}$ \\
\hline Octadecabacter antarcticus 307 & $\begin{array}{c}\text { Typstamm } \\
\text { (Gosink, Herwig \& Staley 1997) }\end{array}$ & $\begin{array}{l}\text { CRBIP, Paris, } \\
\text { Frankreich }\end{array}$ \\
\hline Gloeobacter violaceus PCC7421 & $\begin{array}{c}\text { Typstamm (Rippka, Waterbury \& } \\
\text { Cohen-Bazire 1974) }\end{array}$ & $\begin{array}{l}\text { CRBIP, Paris, } \\
\text { Frankreich }\end{array}$ \\
\hline Salinibacter ruber & Typstamm (Anton et al. 2002) & DSMZ, Braunschweig \\
\hline $\begin{array}{l}\text { Escherichia coli C43(DE3) } \\
\text { (Chemisch kompetent) }\end{array}$ & $\begin{array}{l}\text { Expressionsstamm. Angepasst für } \\
\text { Überexpression von Membranproteinen } \\
\text { (Miroux \& Walker 1996) }\end{array}$ & $\begin{array}{l}\text { Lucigen, Middleton, } \\
\text { WI, USA }\end{array}$ \\
\hline $\begin{array}{l}\text { Escherichia coli UT5600 } \\
\text { (Chemisch kompetent) }\end{array}$ & $\begin{array}{l}\text { Expressionsstamm. Wurde bereits für } \\
\text { heterologe Expression von Rhodopsinen } \\
\text { verwendet (Beja et al. 2000) }\end{array}$ & $\begin{array}{l}\text { NEB, Ipswich, MA, } \\
\text { USA }\end{array}$ \\
\hline $\begin{array}{l}\text { Escherichia coli } \mathrm{DH} 10 \mathrm{~B}^{\mathrm{TM}} \\
\text { (Elektrokompetent) }\end{array}$ & Transformationsstamm & Invitrogen, Darmstadt \\
\hline $\begin{array}{l}\text { Escherichia coli } \mathrm{DH} 5 \alpha \\
\text { (Elektrokompetent) }\end{array}$ & Transformationsstamm & Invitrogen, Darmstadt \\
\hline $\begin{array}{l}\text { Escherichia coli } \mathrm{pBAD}_{-} \\
\text {EBAC } 31 \mathrm{~A} 08\end{array}$ & $\begin{array}{l}\text { Subklon des Proteorhodopsingens von } \\
\text { EBAC31A08 (Beja et al. 2000) }\end{array}$ & $\begin{array}{l}\text { DeLong, E.F., MIT, } \\
\text { Cambridge, MA, USA }\end{array}$ \\
\hline
\end{tabular}

Tab. 2 Verwendete Plasmid-Vektoren

\begin{tabular}{|c|c|c|}
\hline Vektor & Beschreibung & Herkunft \\
\hline $\mathrm{pBAD} / M y c$-His $\mathrm{A}$ & $\mathrm{Amp}^{\mathrm{r}}, \operatorname{ara} C, m y c, 6 \mathrm{xHis}$ & $\begin{array}{l}\text { Invitrogen }{ }^{\mathrm{TM}} \text { (Fa. Life } \\
\text { Technologies, Darmstadt) }\end{array}$ \\
\hline pET24d & $\mathrm{Kan}^{\mathrm{r}}$, lacI, 6xHis & Novagen ${ }^{\circledR}$ (Fa. Merck, Darmstadt) \\
\hline $\mathrm{pCR}^{\mathrm{TM}} 4-\mathrm{TOPO}^{\circledR} \mathrm{TA}$ & $A m p^{\mathrm{r}}, \mathrm{Kan}^{\mathrm{r}}, l a c Z \alpha$ & $\begin{array}{c}\text { Invitrogen }^{\mathrm{TM}} \text { (Fa. Life } \\
\text { Technologies, Darmstadt) }\end{array}$ \\
\hline
\end{tabular}




\subsection{Kultivierung von Bakterien}

\subsubsection{Nährmedien}

E. coli-Kulturen wurden standardmäßig in Luria-Bertani-(LB)-Medium angezogen $(1 \%$ [w/v] Trypton, $0,5 \%$ [w/v] Hefeextrakt, $1 \%$ [w/v] NaCl). Nach Transformationen (siehe 2.7) wurde SOC-Medium (2\% [w/v] Trypton, 0,5\% [w/v] Hefeextrakt, $1 \%$ [w/v] NaCl, 1,5 mM KCl, $10 \mathrm{mM} \mathrm{MgCl}_{2}, 10 \mathrm{mM} \mathrm{MgSO}_{4}$ ) zur Zellregeneration verwendet.

Salinibacter ruber-Kulturen wurden in einem hypersalinen Medium nach Anton et al. (Medium B; 2002) angezogen, während für Gloeobacter violaceus-Kulturen das Medium BG-11 verwendet wurde. Marine Roseobacter Vertreter, wie die Octadecabacter-Stämme, wurden in modifiziertem Marine Broth (MB) 2216-Medium oder in modifiziertem Sea Water Complete (SWC)-Medium angezogen. Da diese Medien weniger geläufig und zum Teil komplexer sind als die Standard-Medien der E. coli-Anzucht, ist die jeweilige Zusammensetzung in den untenstehenden Tabellen gesondert aufgeführt.

\begin{tabular}{lr} 
S. ruber Medium B & \\
\hline $\mathrm{NaCl}$ & $195 \mathrm{~g}$ \\
$\mathrm{MgCl}_{2} \times 6 \mathrm{H}_{2} \mathrm{O}$ & $34,6 \mathrm{~g}$ \\
$\mathrm{MgSO}_{4} \times 7 \mathrm{H}_{2} \mathrm{O}$ & $49,5 \mathrm{~g}$ \\
$\mathrm{CaCl}_{2} \times 2 \mathrm{H}_{2} \mathrm{O}$ & $1,25 \mathrm{~g}$ \\
$\mathrm{KCl}$ & $5 \mathrm{~g}$ \\
$\mathrm{NaHCO}_{3}$ & $0,25 \mathrm{~g}$ \\
$\mathrm{NaBr}$ & $0,625 \mathrm{~g}$ \\
$\mathrm{Hefe}-$ Extrakt & $1 \mathrm{~g}$ \\
$\mathrm{H}_{2} \mathrm{O}_{\text {bidest }}$ & ad $1000 \mathrm{ml}$ \\
\hline \multicolumn{2}{l}{ pH-Wert auf 7.2 eingestellt }
\end{tabular}

\section{BG-11-Medium}

\begin{tabular}{lr}
\hline $\mathrm{NaNO}_{3}$ & $1,5 \mathrm{~g}$ \\
$\mathrm{~K}_{2} \mathrm{HPO}_{4} \times 3 \mathrm{H}_{2} \mathrm{O}$ & $4 \mathrm{mg}$ \\
$\mathrm{MgSO}_{4} \times 7 \mathrm{H}_{2} \mathrm{O}$ & $75 \mathrm{mg}$ \\
$\mathrm{CaCl}_{2} \times 2 \mathrm{H}_{2} \mathrm{O}$ & $36 \mathrm{mg}$ \\
$\mathrm{Citronensäure}_{\text {Ammoniumeisen(III)-citrat }}$ & $6 \mathrm{mg}$ \\
EDTA (Dinatriumsalz) & $1 \mathrm{mg}$ \\
$\mathrm{NaCO}_{3}$ & $20 \mathrm{mg}$ \\
Spurenelement-Lsg. A5 $_{\mathrm{H}_{2} \mathrm{O}_{\text {bidest }}}$ & $1 \mathrm{ml}$ \\
\hline
\end{tabular}

pH lag nach dem Autoklavieren bei 7,1

\section{Spurenelement-Lsg. A5}

\begin{tabular}{lrl}
\hline $\mathrm{H}_{3} \mathrm{BO}_{3}$ & $2,86 \mathrm{~g}$ \\
$\mathrm{MnCl}_{2} \times 4 \mathrm{H}_{2} \mathrm{O}$ & $1,81 \mathrm{~g}$ \\
$\mathrm{ZnSO}_{4} \times 7 \mathrm{H}_{2} \mathrm{O}$ & $0,222 \mathrm{~g}$ \\
$\mathrm{NaMoO}_{4} \times 2 \mathrm{H}_{2} \mathrm{O}$ & $0,39 \mathrm{~g}$ \\
$\mathrm{CuSO}_{4} \times 5 \mathrm{H}_{2} \mathrm{O}$ & $79 \mathrm{mg}$ \\
$\mathrm{Co}\left(\mathrm{NO}_{3}\right) 2 \times 6 \mathrm{H}_{2} \mathrm{O}$ & $49,4 \mathrm{mg}$ \\
$\mathrm{H}_{2} \mathrm{O}_{\text {bidest }}$ & ad $1000 \mathrm{ml}$ \\
\hline
\end{tabular}




\section{MB-Medium (modifiziert)}

MB-Komponente A $\quad 500 \mathrm{ml}$

MB-Komponente B $\quad 500 \mathrm{ml}$

Beide Komponenten wurden getrennt angesetzt und nach dem Autoklavieren vereint

MB-Komponente A (modifiziert)

\begin{tabular}{lrl}
\hline Pepton & 10 & $\mathrm{~g}$ \\
Hefeextrakt & 2 & $\mathrm{~g}$ \\
Eisen(III)citrat & 0,2 & $\mathrm{~g}$ \\
$\mathrm{Na}_{2} \mathrm{SO}_{4}$ & 6,48 & $\mathrm{~g}$ \\
$\mathrm{NaCl}$ & 38,9 & $\mathrm{~g}$ \\
$\mathrm{KCl}$ & 1,1 & $\mathrm{~g}$ \\
$\mathrm{NaHCO}$ & \\
Tris & 0,32 & $\mathrm{~g}$ \\
$\mathrm{MB}_{3}$ Spurenelementlsg. & 2.4 & $\mathrm{~g}$ \\
$\mathrm{H}_{2} \mathrm{O}_{\text {bidest }}$ & 10 & $\mathrm{ml}$ \\
\hline pH-Wert wurde auf 7,5 eingestellt & ad 1 & 1 \\
\hline
\end{tabular}

\section{SWC-Medium}

\begin{tabular}{lrl}
\hline $\mathrm{NaCl}$ & 24 & $\mathrm{~g}$ \\
$\mathrm{MgSO}_{4} \times 7 \mathrm{H}_{2} \mathrm{O}$ & 7 & $\mathrm{~g}$ \\
$\mathrm{MgCl} \times 6 \mathrm{H}_{2} \mathrm{O}$ & 5,2 & $\mathrm{~g}$ \\
$\mathrm{CaCl}_{2} \times 2 \mathrm{H}_{2} \mathrm{O}$ & 1,2 & $\mathrm{~g}$ \\
$\mathrm{KCl}$ & 0,7 & $\mathrm{~g}$ \\
$\mathrm{KH}_{2} \mathrm{PO}_{4}$ & 10 & $\mathrm{mg}$ \\
Eisen-Citrat & 1 & $\mathrm{mg}$ \\
$\mathrm{NH}_{4} \mathrm{Cl}$ & 0,4 & $\mathrm{~g}$ \\
$\mathrm{Hefeextrakt}$ & 0,4 & $\mathrm{~g}$ \\
Rindfleischextrakt & 0,4 & $\mathrm{~g}$ \\
Trypton & 0,4 & $\mathrm{~g}$ \\
Tris & 2,4 & $\mathrm{~g}$ \\
SWC-Vitamin-Lsg. (1000x) & $1 \mathrm{ml}$ \\
Spurenelement-Lsg. TES & $2 \mathrm{ml}$ \\
$\mathrm{H}_{2} \mathrm{O}_{\text {bidest }}$ & ad 1 & 1 \\
\hline
\end{tabular}

\begin{tabular}{|c|c|}
\hline \multicolumn{2}{|c|}{$\begin{array}{l}\text { MB-Medium Komponente B } \\
\text { (modifiziert) }\end{array}$} \\
\hline $\mathrm{MgCl}_{2} \times 6 \mathrm{H}_{2} \mathrm{O}$ & $25,2 \mathrm{~g}$ \\
\hline $\mathrm{CaCl}_{2} \times 2 \mathrm{H}_{2} \mathrm{O}$ & $4,76 \mathrm{~g}$ \\
\hline $\mathrm{Na}_{2} \mathrm{HPO}_{4} \times 2 \mathrm{H}_{2} \mathrm{O}$ & $0,02 \mathrm{~g}$ \\
\hline Tris & $2,4 \mathrm{~g}$ \\
\hline $\mathrm{H}_{2} \mathrm{O}_{\text {bidest }}$ & ad 11 \\
\hline
\end{tabular}

\begin{tabular}{lrl} 
MB-Spurenelementlsg. & & \\
\hline $\mathrm{KBr}$ & 8 & $\mathrm{~g}$ \\
$\mathrm{SrCl}_{2} \times 6 \mathrm{H}_{2} \mathrm{O}$ & 5,7 & $\mathrm{~g}$ \\
$\mathrm{H}_{3} \mathrm{BO}_{3}$ & 2,2 & $\mathrm{~g}$ \\
$\mathrm{NaF}$ & 0,24 & $\mathrm{~g}$ \\
$\mathrm{H}_{4} \mathrm{~N}_{2} \mathrm{O}_{3}$ & 0,16 & $\mathrm{~g}$ \\
$\mathrm{Na}_{2} \mathrm{O}_{7} \mathrm{Si}_{3}$ & 0,5 & $\mathrm{~g}$ \\
$\mathrm{H}_{2} \mathrm{O}_{\text {bidest }}$ & $\mathrm{ad} 1$ & 1 \\
\hline
\end{tabular}

SWC-Vitamin-Lsg. (1000x)

\begin{tabular}{lrl}
\hline Biotin & $20 \mathrm{mg}$ \\
Folsäure & $20 \mathrm{mg}$ \\
Pyridoxin-HCL & $100 \mathrm{mg}$ \\
Riboflavin & $50 \mathrm{mg}$ \\
Thiamin-HCL & $50 \mathrm{mg}$ \\
Nicotinamid & $50 \mathrm{mg}$ \\
D-Panthothensäure, & & \\
Calciumsalz & $50 \mathrm{mg}$ \\
Vitamin B12 & $1 \mathrm{mg}$ \\
4-Aminobenzoesäure & $50 \mathrm{mg}$ \\
Ethanol (50\%) & $\mathrm{ad} 1 \mathrm{l}$ \\
\hline
\end{tabular}

Spurenelement-Lsg. TES

\begin{tabular}{lrl}
\hline $\mathrm{ZnSO}_{4} \times 7 \mathrm{H}_{2} \mathrm{O}$ & $100 \mathrm{mg}$ \\
$\mathrm{MnCl}_{2} \times 4 \mathrm{H}_{2} \mathrm{O}$ & $30 \mathrm{mg}$ \\
$\mathrm{H}_{3} \mathrm{Bo} 3$ & $300 \mathrm{mg}$ \\
$\mathrm{CoCl}_{2} \times 6 \mathrm{H}_{2} \mathrm{O}$ & $200 \mathrm{mg}$ \\
$\mathrm{CuCl}_{2} \times 2 \mathrm{H}_{2} \mathrm{O}$ & $10 \mathrm{mg}$ \\
$\mathrm{NiCl}_{2} \times 6 \mathrm{H}_{2} \mathrm{O}$ & $20 \mathrm{mg}$ \\
$\mathrm{NaMoO}_{4} \times 2 \mathrm{H}_{2} \mathrm{O}$ & $30 \mathrm{mg}$ \\
$\mathrm{H}_{2} \mathrm{O}_{\text {bidest }}$ & $\mathrm{ad} 1 \mathrm{l}$ \\
\hline
\end{tabular}


Bei Wachstumsversuchen mit verschiedenen Nährstoffkonzentrationen wurde das MBMedium zusätzlich modifiziert. Die Menge an zugegebenen Pepton und Hefeextrakt wurde in diesen Fällen auf $10 \%, 1 \%$ oder $0,1 \%$ der oben angegebenen Mengen reduziert. Für Wachstumsversuche mit verschiedenen Kohlenstoff- bzw. Stickstoffquellen wurde das SWCMedium modifiziert. In diesen Fällen wurde die Menge an Hefeextrakt auf 0,05 g/L herabgesenkt. Auf Pepton wurde vollständig verzichtet, und stattdessen eine der folgenden Kohlenstoffquellen in Endkonzentrationen von 33,3 mM zugegeben: Ectoin, Hydroxyectoin, Glucose oder Rhamnose. Als Negativkontrolle dienten Medien ohne Zugabe einer Kohlenstoffquelle. Bei Wachstumsversuchen mit verschiedenen Stickstoffquellen wurde darüber hinaus Ammoniumchlorid durch $8 \mathrm{mM}$ Natriumnitrat ersetzt. Als Negativkontrollen dienten Medien, welche weder Ammoniumchlorid noch Natriumnitrat enthielten.

\subsubsection{Zellanzucht}

Flüssigkulturen wurden größtenteils in Schikanekolben angezogen. Für Wachstumsversuche mittels eines Klett-Summerson-Photometers (siehe 2.2.3) wurden Flüssigkulturen in Reagenzgläsern angezogen. Angeimpft wurde entweder mit einer Einzelkolonie von einer Agarplatte, oder mit $1 \mu 1$ einer Glycerol-Stammkultur. Die Inkubation von Flüssigkulturen erfolgte auf einem Rundschüttler bei $225 \mathrm{rpm}$. Kulturen von E. coli und $S$. ruber wurden bei $37^{\circ} \mathrm{C}$ angezogen, Octadecabacter-Kulturen dagegen bei $4-8^{\circ} \mathrm{C}$. Für Wachstumsversuche von Octadecabacter-Kulturen bei verschiedenen Lichteinflüssen wurde eine selbstgefertigte Lichtbank (Patrick Regin, Institut für Mikrobiologie und Genetik, Göttingen), bestehend aus zwei $18 \mathrm{~W}$ Vollspektrum-Leuchtstoffröhren des Typs „Solar Natur 9000K“ (Fa. JBL, Neuhofen) in einem Abstand von $30 \mathrm{~cm}$ über den Kulturgefäßen angebracht. Kulturen von G. violaceus PCC 7421 wurden bei $22{ }^{\circ} \mathrm{C}$ in einem Innova 4230 Inkubator (Fa. Eppendorf, Hamburg) bei Beleuchtung durch eine gerätinterne Wachstumslampe angezogen.

Aufgrund der niedrigen Wachstumsraten von O. arcticus und O. antarcticus (Gosink, Herwig \& Staley 1997) dauerte die Anzucht von Octadecabacter-Kulturen mehrere Wochen. Sichtbares Wachstum trat bei solchen Kulturen meist erst nach zwei bis drei Wochen auf. 


\subsubsection{Verfolgung des Bakterienwachstums durch photometrische Messungen}

Die optische Dichte von Bakterienkulturen wurde als Absorptionswert bei einer Wellenlänge von $600 \mathrm{~nm}\left(\mathrm{OD}_{600 \mathrm{~nm}}\right)$ durch photometrische Messung in einem Lambda25 UV/vis Spectrometer (Fa. Perkin Elmer, Rodgau) bestimmt. Als Blindprobe diente unbeimpftes Medium.

Alternativ wurde die zunehmende Trübung von Bakterienkulturen in Klett-Einheiten mittels eines Klett-Summerson-Colorimeters des Modells 900-3 (Klett, New York, USA). bestimmt. Dieses Colorimeter erlaubte die direkte und daher zeitsparende Trübungsmessung von Kulturen in Reagenzgläsern. Diese Methode wurde bei der Verfolgung des Wachstums von Octadecabacter-Kulturen bevorzugt verwendet, da durch die Zeitersparnis die Erwärmung der Bakterienkulturen während den Messungen minimiert wurde.

\subsubsection{Untersuchungen zu Schwermetall-Resistenzen}

Es wurden Agarplatten mit MB-Medium (siehe 2.2.1) und verschiedenen Konzentrationen unterschiedlicher Schwermetalle angesetzt (siehe unten). Die eingesetzten SchwermetallKonzentrationen orientierten sich an den Ergebnissen von Nies (1999), welcher minimal inhibitory concentrations (MICs) verschiedener Schwermetalle für E. coli bestimmte. Octadecabacter-Kulturen wurden mit einer Impföse als Verdünnungsausstrich nach dem 13Strich-Verfahren aufgetragen. Anschließend wurde das Wachstum der OctadecabacterKulturen auf den einzelnen Verdünnungsstrichen bei verschiedenen Schwermetallkonzentrationen dokumentiert.

Liste der getesteten Schwermetalle und der jeweils eingesetzten Konzentrationen

\begin{tabular}{cccc}
\hline Schwermetall & \multicolumn{1}{c}{ Konzentrationen } & Schwermetall & Konzentrationen \\
\hline $\mathrm{HgCl}_{2}$ & $1 \mu \mathrm{M} ; 5 \mu \mathrm{M} ; 10 \mu \mathrm{M} ; 50 \mu \mathrm{M}$ & $\mathrm{CoCl}_{2}$ & $10 \mu \mathrm{M} ; 0,1 \mathrm{mM} ; 1 \mathrm{mM} ; 2 \mathrm{mM}$ \\
$\mathrm{CdCl}_{2}$ & $10 \mu \mathrm{M} ; 50 \mu \mathrm{M} ; 0,5 \mathrm{mM}, 1 \mathrm{mM}$ & $\mathrm{NiCl}_{2}$ & $10 \mu \mathrm{M} ; 0,1 \mathrm{mM} ; 1 \mathrm{mM} ; 2 \mathrm{mM}$ \\
$\mathrm{CuCl}_{2}$ & $10 \mu \mathrm{M} ; 0,1 \mathrm{mM} ; 1 \mathrm{mM}, 2 \mathrm{mM}$ & $\mathrm{SnCl}_{2}$ & $10 \mu \mathrm{M} ; 0,1 \mathrm{mM} ; 1 \mathrm{mM} ; 2 \mathrm{mM}$ \\
$\mathrm{PbCl}_{2}$ & $50 \mu \mathrm{M} ; 0,5 \mathrm{mM} ; 1 \mathrm{mM}, 2 \mathrm{mM}$ & $\mathrm{AgNO}_{3}$ & $1 \mu \mathrm{M} ; 10 \mu \mathrm{M} ; 20 \mu \mathrm{M} ; 0,1 \mathrm{mM}$ \\
\hline
\end{tabular}

\subsubsection{Motilitäts-Tests}

Zur Überprüfung der Beweglichkeit von Octadecabacter-Zellen wurden Weichagarmedien hergestellt. Hierzu wurden MB- und SWC-Medien (siehe 2.2.1) mit 0,3-0,5\% (w/v) Agar versetzt, und in sterile Reagenzgefäße gegossen. Alternativ wurden mit diesen Lösungen Weichagarplatten in Petrischalen angesetzt. Die Inokulation von Weichagarmedien in 
Reagenzgefäßen erfolgte mit Impfnadeln, wobei tief in den Agar in der Mitte des Gefäßes gestochen wurde (Stichkulturen). Bei diesen Kulturen wurde darauf geachtet, ob Wachstum nur entlang des Einstiches erfolgt (Hinweis auf fehlende Motilität), oder ob Zellen in das Innere des Agars eindringen (Hinweis auf Motilität). Die Inokulation von Weichagarplatten erfolgte durch das Überimpfen von Einzelkolonien mittels einer Impföse. Hier wurde auf schwarmförmige Ausbreitung der Kolonien, bzw. Eindringen in die Agarschicht (Hinweise auf Motilität) geachtet. Ergänzt wurden diese Versuche durch mikroskopische Betrachtung von Proben aus Flüssigkulturen mittels eines BX41 Phasenkontrastmikroskops (Fa. Olympus, Hamburg), wobei auf gerichtete Fortbewegung der Zellen geachtet wurde.

Zudem wurde versucht, potentielle Flagellen der Octadecabacter-Vertreter durch Flagellenfärbung (Clark 1976) sichtbar zu machen. Da diese Methode sehr anfällig für hohe Salzkonzentrationen ist, mussten die Kulturen zunächst in mehreren Schritten entsalzt werden. Zunächst wurden $100 \mu \mathrm{l}$ Bakterienkultur abzentrifugiert $\left(5 \mathrm{~min}, 8.000 \mathrm{x} g, 4{ }^{\circ} \mathrm{C}\right)$, in $1,6 \%$ $\mathrm{NaCl}$ aufgenommen, erneut zentrifugiert ( 5 min, 8.000x g, $4{ }^{\circ} \mathrm{C}$ ) und schließlich in $\mathrm{H}_{2} \mathrm{O}_{\text {bidest }}$ aufgenommen. Auf Objektträger, welche mit einer Reinigungslösung (3\% $\mathrm{HCl}$ in 95\% Ethanol[reinst]) entfettet und über einer Bunsenbrennerflamme getrocknet wurden, wurde mit Wachs eine rechteckige Begrenzung aufgetragen. Die Bakteriensuspension wurde in diese Begrenzung aufgetragen, luftgetrocknet und mit Färbelösung (0,4\% Fuchsin, 0,5\% NaCl, 1\% Tannin, 32\% Ethanol[reinst], pH 5,3; Leifson 1951) überschichtet. Nach Inkubationszeiten von 2-10 min wurde die Färbelösung mit $\mathrm{H}_{2} \mathrm{O}_{\text {bidest }}$ abgespült, und die gefärbten Zellen wurden unter dem Phasenkontrastmikroskop betrachtet.

\subsubsection{Lagerung von Bakterienkulturen}

Zur langfristigen Lagerung von Bakterienkulturen wurden jeweils $800 \mu$ l Flüssigkultur mit $200 \mu 1$ Glycerol (87\%) versetzt und bei $-80{ }^{\circ} \mathrm{C}$ eingefroren. Diese Ansätze dienten als Stammkulturen für das Animpfen neuer Wachstumskulturen. Bei Verwendung wurden diese Stammkulturen langsam auf Eis aufgetaut und nach Gebrauch so schnell wie möglich wieder eingefroren. 


\subsection{Allgemeine Techniken für die Arbeit mit Nukleinsäuren}

\subsubsection{Native Agarose-Gelektrophorese zur analytischen Auftrennung von linearen DNA-Fragmenten}

Es wurden stets Elektrophoresekammern der Fa. G\&P Kunststofftechnik (Kassel) verwendet. Als Laufpuffer diente 1xTAE-Puffer (40 mM Tris, $20 \mathrm{mM}$ Acetat, 1mM EDTA, pH 8,5; Sambrook, Fritsch \& Maniatis 1989). Als Trennmittel wurde ein Gel bestehend aus 0,8\% Agarose gelöst in 1xTAE-Puffer eingesetzt. DNA-Proben wurden mit 0,4 Vol. Ladepuffer versetzt und in Vertiefungen (Geltaschen) des Agarosegels aufgetragen. $2 \mu 1$ des „GeneRuler ${ }^{\mathrm{TM}}$ DNA Ladder Mix“ (Fa. Thermo Scientific, Schwerte) wurden als Größenstandard in jeweils eigene Geltaschen aufgetragen. Die Auftrennung der DNAFragmente erfolgte bei einer konstanten Spannung von 80-110 V und einer Stromstärke von $400 \mathrm{~mA}$ für $45 \mathrm{~min}$ bis $2 \mathrm{~h}$. Anschließend wurde das Gel für 10-20 min in einer wässrigen Ethidiumbromid-Lösung (1 $\mu \mathrm{g} / \mathrm{ml})$ gefärbt, 5-10 min in $\mathrm{H}_{2} \mathrm{O}_{\text {bidest }}$ entfärbt und mittels eines AlphaImager ${ }^{\circledR}$ HP UV-Transilluminators (Fa. Innotech, Kasendorf) unter UV-Beleuchtung $(\lambda=302 \mathrm{~nm})$ betrachtet und dokumentiert.

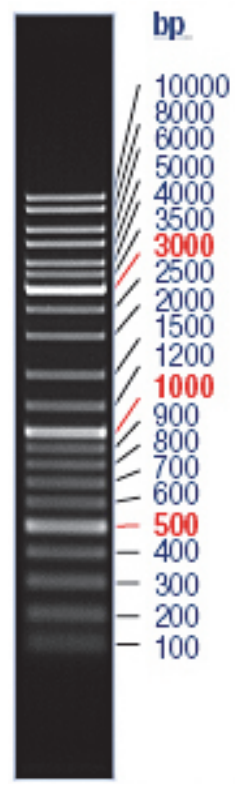

\begin{tabular}{lr} 
DNA-Ladepuffer & \\
\hline Bromphenolblau & $0,125 \mathrm{~g}$ \\
Xylencyanol & $0,125 \mathrm{~g}$ \\
Ficoll 400 & $7,5 \mathrm{ml}$ \\
$\mathrm{H}_{2} \mathrm{O}_{\text {bidest }}$ & ad $50 \mathrm{ml}$ \\
\hline
\end{tabular}

GeneRuler $^{\mathrm{TM}}$ DNA Ladder Mix 


\subsubsection{Extraktion und Aufreinigung von Nukleinsäuren}

\subsubsection{Extraktion von DNA aus Bakterien}

Bakterielle Gesamt-DNA wurde mit dem MasterPure ${ }^{\mathrm{TM}}$ DNA Purification Kit (Fa. Epicentre, Madison, USA) extrahiert. Dieses Kit beruht auf einer Zellyse durch eine Kombination aus Detergenz-, Proteinase K- und Hitzebehandlung, gefolgt von einer Protein- und einer Nukleinsäurefällung. Es wurde nach Anleitung des Herstellers vorgegangen, mit Ausnahme des letzten Schritts: der Aufnahme der aufgereinigten Nukleinsäuren in einer Pufferlösung. Hierfür wurde Tris-Puffer anstelle des in der Anleitung angegebenen Tris-EDTA-Puffers verwendet.

Plasmid-DNA wurde unter Verwendung des QIAprep ${ }^{\circledR}$ Spin Miniprep Kit (Fa. Qiagen, Hilden) Säulenbasiert aufgereinigt. Hierbei wurde nach den Angaben des Herstellers vorgegangen.

\subsubsection{Extraktion von RNA aus Octadecabacter-Kulturen}

Octadecabacter-Kulturen wurden bis zu einer $\mathrm{OD}_{600 \mathrm{~nm}}$ von 1,6 angezogen, mit 1 Vol. einer auf $-80{ }^{\circ} \mathrm{C}$ gekühlten Abstopplösung (1\% [v/v] ß-Mercaptoethanol in Methanol) versetzt und anschließend sofort abzentrifugiert (10 min, 4000x $\left.g,-10^{\circ} \mathrm{C}\right)$. RNA-Extraktion aus dem Zellpellet erfolgte mittels des RNeasy ${ }^{\circledR}$ Mini Kit (Qiagen, Hilden). Zunächst wurden die Zellen in $700 \mu \mathrm{l} \quad$ RLT-Puffer und $7 \mu \mathrm{l} \quad$ B-Mercaptoethanol resuspendiert und durch Ultraschallbehandlung mittels eines Sonifier ${ }^{\circledR} 250$ Ultraschallgeräts (Fa. Branson Ultrasonics, Danbury, USA) aufgeschlossen (Stufe 5, 50\% Leistung, 100 Zyklen). Im weiteren Verlauf der Extraktion wurde nach dem Handbuch des RNeasy ${ }^{\circledR}$ Mini Kits vorgegangen. Anschließend erfolgte ein DNAse Verdau mittels der Ambion ${ }^{\circledR}$ TURBO ${ }^{\mathrm{TM}}$ DNase (Fa. Life Technologies, Carlsbad, USA) nach Angaben des Herstellers. Für Arbeiten mit aufgereinigter RNA wurden ausschließlich zweifach autoklavierte Labormaterialien und Ambion ${ }^{\circledR}$ Nuklease-freies Wasser (Fa. Life Technologies, Carlsbad, USA) verwendet. RNA-Lösungen wurden bei $-80{ }^{\circ} \mathrm{C}$ gelagert. 


\subsubsection{Direkte Aufreinigung von DNA-Fragmenten}

War eine Differenzierung zwischen verschiedenen DNA-Fragmenten nicht nötig (z.B. bei spezifischen PCR-Produkten), erfolgte die Aufreinigung säulenbasiert mittels des „QIAquick ${ }^{\circledR}$ PCR Purification Kit“" (Fa. Qiagen, Hilden) nach Angaben des Herstellers. Die Eluation von DNA aus den Aufreinigungs-Säulen des Kits erfolgte mit sterilem $\mathrm{H}_{2} \mathrm{O}_{\text {bidest. }}$.

\subsubsection{Aufreinigung von DNA-Fragmenten durch präparative Gelelektrophorese}

Präperative Gelelektrophoresen fanden Anwendung, wenn eine PCR-Reaktion mehr als ein eindeutiges Produkt hervorrief oder ein spezifisches Fragment eines Restriktionsverdaus benötigt wurde. Hierbei wurde prinzipiell so vorgegangen wie bei analytischen Gelelektrophoresen (siehe 2.3.1). Allerdings wurde ein zusätzliches kleines Aliquot jeder Probe auf einen getrennten Abschnitt des Gels aufgetragen. Nur dieser gesonderte Gelabschnitt, welcher auch den Größenstandard enthielt, wurde gefärbt und unter UV-Licht betrachtet (siehe 2.3.1). Hierdurch sollte verhindert werden, dass mutagene Einflüsse (Ethidiumbromid und UV-Licht) die zu extrahierende DNA beeinflussen. Gelbereiche, welche Banden von interressanten DNA-Fragmenten aufwiesen, wurden mit dem Skapell markiert. Die entsprechenden Bereiche wurden anschließend aus dem ungefärbten Gelabschnitt ausgeschnitten und in sterile Reaktionsgefäße gegeben. Die Extraktion von DNA aus diesen Stücken erfolgte durch eine säulenbasierte Aufreinigung mittels des QIAquick ${ }^{\circledR}$ Gel Extraction Kit (Fa. Qiagen, Hilden) nach Angaben des Herstellers. Die Eluation von DNA aus den Aufreinigungs-Säulen des Kits erfolgte mit sterilem $\mathrm{H}_{2} \mathrm{O}_{\text {bidest }}$.

\subsubsection{Konzentrationsbestimmung von Nukleinsäuren}

Konzentrationsbestimmung von Nukleinsäuren erfolgten mit Hilfe eines NanoDrop ${ }^{\circledR} 1000$ Spektrophotometers (Fa. Peqlab Biotechnologie, Erlangen) anhand der Absorption von Nukleinsäuren bei einer Wellenlänge von 260nm. Der Nullabgleich des Gerätes erfolgte mit $\mathrm{H}_{2} \mathrm{O}_{\text {bidest }}$ oder Tris-Pufferlösung, abhängig davon, in welcher dieser Substanzen die DNA gelöst war. Für DNA-Messungen wurde die Einstellung „DNA-50“, für RNA-Messungen die Einstellung „RNA-40“ verwendet. Diese Einstellungen unterscheiden sich im Wert des Extinktionskoeffizienten, welcher bei der Berechnung der Nukleinsäure-Konzentraion mittels des Lambert-Beerschen Gesetzes eingesetzt wird. Bei DNA-Quantifizierungen beträgt dieser 
Wert $50 \mathrm{ng}-\mathrm{cm} / \mu 1$, bei RNA-Quantifizierungen 40 ng-cm/ $\mu$ l (NanoDrop 1000 Spectrometer V3.7 User's Manual). Mittels der Quotienten der Absorptionswerte bei Wellenlängen von 230, 260 und $280 \mathrm{~nm}$ konnte zudem die Reinheit der Nukleinsäurelösung abgeschätzt werden (Sambrook \& Russel 2001).

\subsubsection{Fällung und Aufkonzentrierung von Nukleinsäuren}

DNA-Fragmente, welche in $\mathrm{H}_{2} \mathrm{O}_{\text {bidest }}$ gelöst waren, konnten mithilfe einer Concentrator 5301 Vakuumzentrifuge aufkonzentriert werden. Hierfür wurden die entsprechenden Reaktionsgefäße offen in das Gerät gestellt und 5-20 min bei 30-60 ${ }^{\circ} \mathrm{C}$ unter Vakuum zentrifugiert.

DNA-Lösungen in Tris-Puffer oder empfindliche RNA-Lösungen wurden durch Ethanolfällung aufkonzentriert. Hierfür wurden die Nukleinsäure-Lösungen mit 0,1 Vol. $3 \mathrm{M}$ Natriumacetat ( $\mathrm{pH} 5,2)$ und 2,5 Vol. Ethanol (reinst) versetzt und durch Schütteln gemischt. Die Proben wurden bei $-20{ }^{\circ} \mathrm{C}$ über Nacht oder bei $-80{ }^{\circ} \mathrm{C}$ für mindestens 30 min inkubiert, und anschließend zentrifugiert (13.000 rpm, $4{ }^{\circ} \mathrm{C}, 30 \mathrm{~min}$ ). Der Überstand wurde verworfen und das nukleinsäurehaltige Pellet wurde zweimal mit 70\%igem Ethanol (v/v) gewaschen. Anschließend wurde das Pellet für mindestens 10 min unter der Sterilbank luftgetrocknet und dann im gewünschten Volumen $\mathrm{H}_{2} \mathrm{O}_{\text {bidest }}$ oder Tris-Puffer aufgenommen.

\subsection{Polymerase-Kettenreaktion (PCR)}

Für in vitro-Amplifikation von DNA-Fragmenten durch Polymerase-Kettenreaktion (PCR) wurde standardmäßig die BIO-X-ACT ${ }^{\mathrm{TM}}$ Short DNA-Polymerase (Fa. Bioline, Luckenwalde) verwendet. Bei problematischer Matrizen-DNA (template) oder langen Produkten wurde zum Teil auf das PCR-Extender-System (Fa. 5 Prime, Hamburg) ausgewichen. Die AnlagerungsTemperatur (Annealing-Temperatur) wurde stets wenige (1-4) Grad Celsius unterhalb des Schmelzpunktes der verwendeten Oligonukleotid-Primer gewählt, welcher durch den Hersteller (Fa. Thermo Scientific, Schwerte) jeweils experimentell bestimmt wurde. Die Zusammensetzung typischer PCR-Ansätze sowie der Ablauf typischer PCR-Programme sind im Folgenden aufgelistet. Wies die Matrizen-DNA stabile Sekundärstrukturen auf, welche die Amplifikation behinderten, so wurde Betain oder DMSO (Jensen, Fukushima \& Davis 2010) hinzugegeben. 
Zusammensetzung eines Standard-PCR-Ansatzes

\begin{tabular}{|c|c|c|}
\hline $\begin{array}{c}\text { BIO-X-ACT }^{\mathrm{TM}} \text { Short } \\
\text { DNA-Polymerase }\end{array}$ & $\begin{array}{l}\text { PCR-Extender- } \\
\text { System }\end{array}$ & Komponente \\
\hline $1 \mu 1$ & $1 \mu 1$ & Matrizen-DNA $(10-100 \mathrm{ng} / \mu \mathrm{l})$ \\
\hline $4 \mu 1$ & $4 \mu 1$ & Oligonukleotid-Primer $1(5 \mathrm{pmol} / \mu \mathrm{l})$ \\
\hline $4 \mu \mathrm{l}$ & $4 \mu \mathrm{l}$ & Oligonukleotid-Primer $2(5 \mathrm{pmol} / \mu \mathrm{l})$ \\
\hline $5 \mu l$ & $5 \mu \mathrm{l}$ & Polymerase-Puffer (10x) \\
\hline $5 \mu 1$ & $2,5 \mu 1$ & dNTP's (10 mM) \\
\hline $3 \mu \mathrm{l}$ & & $\mathrm{MgCl}_{2}(50 \mathrm{mM})$ \\
\hline $0,5 \mu 1$ & $0,5 \mu 1$ & Polymerase $(4 \mathrm{U} / \mu \mathrm{l})$ \\
\hline$(2,5 \mu l)$ & $(2,5 \mu \mathrm{l})$ & (Betain $(5 \mathrm{M})$ oder DMSO $(99,9 \%)$ ) \\
\hline ad $50 \mu 1$ & ad $50 \mu 1$ & $\mathrm{H}_{2} \mathrm{O}_{\text {bidest }}$ \\
\hline
\end{tabular}

\begin{tabular}{|c|c|c|c|}
\hline \multicolumn{4}{|c|}{ PCR-Programm für BIO-X-ACT ${ }^{\mathrm{TM}}$-Ansätze } \\
\hline Reaktionsschritt & Temperatur & Dauer & Zyklen \\
\hline Denaturierung & $98^{\circ} \mathrm{C}$ & $2 \min$ & 1 \\
\hline Denaturierung & $96^{\circ} \mathrm{C}$ & $20 \mathrm{~s}$ & \\
\hline Annealing & $\left(50-68^{\circ} \mathrm{C}\right)^{\mathrm{a}}$ & $20 \mathrm{~s}$ & 30 \\
\hline Elongation & $68^{\circ} \mathrm{C}$ & $(1-12 \mathrm{~min})^{\mathrm{b}}$ & \\
\hline Restelongation & $72{ }^{\circ} \mathrm{C}$ & $10 \mathrm{~min}$ & 1 \\
\hline \multicolumn{4}{|c|}{ a Abhängig von verwendetem Primer; ${ }^{b} 1$ min pro 1 kb Produktlänge } \\
\hline \multicolumn{4}{|c|}{ PCR-Programm für PCR-Extender-Ansätze } \\
\hline Reaktionsschritt & Temperatur & Dauer & Zyklen \\
\hline Denaturierung & $96^{\circ} \mathrm{C}$ & $2 \mathrm{~min}$ & 1 \\
\hline Denaturierung & $96^{\circ} \mathrm{C}$ & $15 \mathrm{~s}$ & \\
\hline Annealing & $\left(50-68^{\circ} \mathrm{C}\right)^{\mathrm{a}}$ & $30 \mathrm{~s}$ & 20 \\
\hline Elongation & $68^{\circ} \mathrm{C}$ & $(1-12 \min )^{b}$ & \\
\hline Denaturierung & $96^{\circ} \mathrm{C}$ & $15 \mathrm{~s}$ & \\
\hline Annealing & $\left(50-68^{\circ} \mathrm{C}\right)^{\mathrm{a}}$ & $30 \mathrm{~s}$ & 10 \\
\hline Elongation & $68^{\circ} \mathrm{C}$ & $\begin{array}{c}(1-12 \text { min })^{\mathrm{b}}+20 \mathrm{~s} \\
\text { /Zyklus }^{\mathrm{c}}\end{array}$ & 10 \\
\hline
\end{tabular}

\subsection{Reverse Transkription (RT-PCR)}

Zum spezifischen Nachweis von Transkripten wurde bakterielle Gesamt-RNA (siehe 2.3.2.2) zunächst mittels einer reversen Transkriptase und zufälligen Hexamer-Primern in cDNA umgeschrieben. Hierfür wurde das QuantiTect ${ }^{\circledR}$ Reverse Transcription Kit (Qiagen, Hilden) nach Anleitung des Herstellers verwendet. Anschließend wurden einzelne Transkripte durch PCR (siehe 2.4) mit genspezifischen Primern nachgewiesen. 


\subsection{Klonierung von DNA-Fragmenten}

\subsubsection{Mechanische Fragmentierung von DNA für Subklonierungen aus Fosmiden}

Für die Erstellung von Plasmid-Genbanken durch Subklonierung aus Fosmiden, musste die Fosmid-DNA zunächst in gleichmässige Fragmente geschert werden. Dies erfolgte auf mechanische Weise unter Anwendung des Hydroshear-Systems (Fa. Genemachines, San Carlos, USA) bei 25 Zyklen und einer Geschwindigkeitseinstellung von 17. Anschließend wurden Fragmente im Größenbereich von 3-5 kb durch präparative Gelelektrophorese (siehe 2.3.2.4) aufgereinigt.

\subsubsection{Erzeugung von glatten Enden (end repair)}

Vor allem nach mechanischer Scherung können DNA-Fragmente ungleichmäßige Strangüberhänge aufweisen. Um diese Überhänge zu glätten, wurden Fragmente, welche für die Ligation in $\mathrm{pCR}^{\mathrm{TM}} 4-\mathrm{TOPO}{ }^{\circledR} \mathrm{TA}-$ Vektoren vorgesehen waren, mit einer T4-DNA-Polymerase (fa. Fermentas, St. Leon Rot) behandelt (end repair). Die end repair-Ansätze (siehe unten) wurden für 30 min bei $37^{\circ} \mathrm{C}$ inkubiert und anschließend direkt aufgereinigt (siehe 2.3.2.2).

\begin{tabular}{|c|c|}
\hline nd repair-Ansatz & \\
\hline DNA-Fragmente & $\mathrm{x} \mu 1$ \\
\hline T4 DNA Polymerase Puffer (5x) & $10 \mu 1$ \\
\hline dNTPs (10 mM) & 5 \\
\hline T4-DNA-Polymerase (5 U/ $\mu 1)$ & $2 \mu 1$ \\
\hline $\mathrm{H}_{2} \mathrm{O}_{\text {bidest }}$ & ad $50 \mu 1$ \\
\hline
\end{tabular}

\subsubsection{Erzeugung von 36-Adenosinüberhängen}

Für Klonierungen mittels des $\mathrm{pCR}^{\mathrm{TM}} 4-\mathrm{TOPO}{ }^{\circledR} \mathrm{TA}-$ Vektorsystems mussten 3 '-Adenosinüberhänge der Fragmente erzeugt werden. Dies erfolgte mittels einer Taq-DNA-Polymerase (Fa. Fermentas, St. Leon Rot). Die Reaktionsansätze (siehe unten) wurden 25 min bei $72{ }^{\circ} \mathrm{C}$ inkubiert und anschließend direkt aufgereinigt (siehe 2.3.2.2).

\begin{tabular}{ll} 
Ansatz zur Erzeugung von 3'-Adenosinüberhängen \\
\hline DNA Fragmente mit glatten Enden & $\mathrm{x} \mu \mathrm{l}$ \\
$\mathrm{Taq}-\left(\mathrm{NH}_{4}\right) \mathrm{SO}_{4}$-Puffer ohne $\mathrm{MgCl}_{2}(10 \mathrm{x})$ & $7 \mu \mathrm{l}$ \\
$\mathrm{MgCl}_{2}(25 \mathrm{mM})$ & $6 \mu \mathrm{l}$ \\
$\mathrm{dATP}(2 \mathrm{mM})$ & $6 \mu \mathrm{l}$ \\
Taq DNA Polymerase $(5 \mathrm{U} / \mu \mathrm{l})$ & $1 \mu \mathrm{l}$ \\
$\mathrm{H}_{2} \mathrm{O}_{\text {bidest }}$ & $\mathrm{ad} 70 \mu \mathrm{l}$ \\
\hline
\end{tabular}




\subsubsection{Dephosphororylierung von linearen Vektoren und Phosphorylierung von Insert-DNA-Fragmenten}

Linearisierte Vektoren wurden mit der alkalinen Phosphatase FastAP ${ }^{\mathrm{TM}}$ (Fa. Fermentas, St. Leon-Rot) dephosphoryliert, um Vektor-Rezirkularisierungen auszuschließen. Hierfür wurden die Dephosphorylierungsansätze (siehe unten) 10 min bei $37^{\circ} \mathrm{C}$ inkubiert und anschließend durch eine Hitzebehandlung für 5 min bei $75^{\circ} \mathrm{C}$ inaktiviert.

Die Insert-DNA-Fragmente wurden hingegen mittels einer T4 Polynukleotid Kinase (Fermentas, St. Leon-Rot) phosphoryliert. Die Phosporylierungsansätze wurden 20 min bei $37^{\circ} \mathrm{C}$ inkubiert und 10 min bei $75^{\circ} \mathrm{C}$ hitzeinaktiviert.

\begin{tabular}{lr} 
Dephosphorylierungsansatz & \\
\hline Linearisierter Vektor & $17 \mu \mathrm{l}$ \\
FastAP ${ }^{\mathrm{TM}}$-Puffer $(10 \mathrm{x})$ & $2 \mu \mathrm{l}$ \\
FastAP $^{\mathrm{TM}}$ Phosphatase $(1 \mathrm{U} / \mu \mathrm{l})$ & $1 \mu \mathrm{l}$ \\
$\mathrm{H}_{2} \mathrm{O}_{\text {bidest }}$ & ad $20 \mu \mathrm{l}$ \\
\hline
\end{tabular}

\begin{tabular}{lr} 
Phosphorylierungsansatz & \\
\hline Insert-DNA & 1 pmol \\
T4 PNK -Puffer A (10x) & $2 \mu 1$ \\
T4 Polynukleotid-Kinase (10 U/ $\mu \mathrm{l})$ & $1 \mu \mathrm{l}$ \\
$\mathrm{H}_{2} \mathrm{O}_{\text {bidest }}$ & ad $20 \mu \mathrm{l}$ \\
\hline
\end{tabular}

\subsubsection{Ligation in $\mathrm{pCR}^{\mathrm{TM}} 4-\mathrm{TOPO}{ }^{\circledR} \mathrm{TA}-$ Vektoren}

Das Vektorsystem $\mathrm{pCR}^{\mathrm{TM}} 4$-TOPO ${ }^{\circledR} \mathrm{TA}$ wurde für die Klonierung von DNA-Fragmenten zur Erstellung von Plasmid-Genbanken verwendet. Dieser Vektor besitzt 3'-Thyminüberhänge an welche sich 3'-Adenosinüberhänge entsprechender Fragmente (siehe 2.6.3) anlagern können. TOPO ${ }^{\circledR}$ TA-Ligationsansätze wurden $1 \mathrm{~h}$ bei Raumtemperatur inkubiert. Anschließend wurde direkt mit den Transformationsprotokollen (siehe 2.7) fortgefahren.

\begin{tabular}{ll} 
TOPO ${ }^{\circledR}$ TA-Ligationsansatz & \\
\hline DNA-Fragmente & $4 \mu 1$ \\
1:4 verdünnte „Salt Solution“ & $1 \mu 1$ \\
Vektor & $1 \mu 1$ \\
\hline
\end{tabular}

\subsubsection{Ligationen in pET24d- und pBAD/Myc-His A-Vektoren}

Die Vektorsysteme pET24d und pBAD/Myc-His A wurden für die heterologe Expression von Rhodopsingenen verwendet. Sowohl die Vektoren als auch die Insert-DNA-Fragmente besaßen aufgrund eines zweifachen Restriktionsverdaus mit den Enzymen NcoI und XhoI (siehe 2.12.1) jeweils zwei verschiedene, nicht-komplementäre Strangüberhänge. Hierdurch konnte die Orientierung des Inserts während der Ligation festgelegt werden. Die Ligation erfolgte mittels einer T4-DNA-Ligase (Fa. Fermentas, St. Leon Rot) bei einem molaren 
Vektor-Insert-Verhältnis von $1 \mathrm{zu}$ 5. Ligationsansätze wurden $1 \mathrm{~h}$ bei Raumtemperatur inkubiert. Anschließend wurde direkt mit den Transformationsprotokollen (siehe 2.7) fortgefahren.

\begin{tabular}{lr} 
Ligationsansatz & \\
\hline Insert-DNA-Fragmente & $0,1 \mathrm{pmol}$ \\
Linearer Vektor & $0,02 \mathrm{pmol}$ \\
Ligase-Puffer $(10 \mathrm{x})$ & $2 \mu \mathrm{l}$ \\
T4-DNA-Ligase $(1 \mathrm{U} / \mu \mathrm{l})$ & $1 \mu \mathrm{l}$ \\
$\mathrm{H}_{2} \mathrm{O}_{\text {bidest }}$ & ad $20 \mu \mathrm{l}$ \\
\hline
\end{tabular}

\subsection{Transformation von DNA in $E$. coli}

\subsubsection{Transformation durch Elektroporation}

Ligationsansätze mussten vor der Elektroporation durch Dialyse mittels einer Nitrocellulosemembran (Fa. Millipore, Billerica, USA) auf $\mathrm{H}_{2} \mathrm{O}_{\text {bidest }}$ für mind. 20 min entsalzt werden. Für die Elektroporation wurden ein GenePulser II Elektroporationsgerät (Fa. Bio-Rad, München) und elektrokompetente E. coli Top10- und DH10B-Zellen (Fa. Invitrogen, Karlsruhe) verwendet. $20 \mu 1$ Zellsuspension wurden mit maximal $2 \mu 1$ entsalzter DNA-Lösung versetzt und für 4-5 ms einer Spannung von $2 \mathrm{kV}$ bei einem Widerstand von $200 \Omega$ und einer Kapazität von $25 \mu \mathrm{F}$ ausgesetzt. Anschließend wurden die Ansätze sofort auf Eis gestellt und es wurde mit dem Protokoll der Zellregeneration fortgefahren (siehe 2.7.3).

\subsubsection{Transformation durch Hitzeschock-Behandlung}

Für Transformationen durch Hitzeschock-Behandlung wurden $5 \mu$ l Ligationsansatz zu $100 \mu 1$ chemisch kompetenten E. coli C43(DE3)-Zellen gegeben. Der Transformationsansatz wurde zunächst 30 min auf Eis inkubiert, dann $90 \mathrm{~s}$ bei $43{ }^{\circ} \mathrm{C}$ inkubiert und sofort auf Eis gestellt. Anschließend wurde mit dem Protokoll der Zellregeneration fortgefahren (siehe 2.7.3).

\subsubsection{Regeneration von rekombinanten Zellen nach der Transformation}

Die Transformationsansätze wurden mit $1 \mathrm{ml} \mathrm{SOC-Medium} \mathrm{(siehe} \mathrm{2.2.1)} \mathrm{versetzt} \mathrm{und} 45 \mathrm{~min}$ bei $37^{\circ} \mathrm{C}$ unter Schütteln (225 rpm) inkubiert. Anschließend wurden die Zellen auf selektiven LB-Agarplatten ausplattiert und über Nacht bei $37^{\circ} \mathrm{C}$ inkubiert. Die Agarplatten enthielten je 
nach verwendetem Vektorsystem (Tab. 2) entweder $100 \mu \mathrm{g} / \mathrm{ml}$ Ampicillin oder $50 \mu \mathrm{g} / \mathrm{ml}$ Kanamycin.

\subsection{Sequenzierung von PCR-Produkten und rekombinanten Plasmiden}

Die Sequenzierung von PCR-Produkten und Plasmiden erfolgte nach der Sanger-Methode (Sanger, Nicklen \& Coulson 1977) mittels eines 3730XL DNA AnalyzerKapillarsequenzierers und des BigDye ${ }^{\circledR}$ Terminator v1.1 Cycle Sequencing Kits (Fa. ABI Applied Biosystems, Foster City, USA) mit fluoreszenzmarkierten Didesoxynukleotiden (ddNTPs). Die Menge an zugegebener Matrizen-DNA richtete sich nach der Größe des zu sequenzierenden Matrizen-DNA-Moleküls. Bei DNA-Fragmenten bis $3 \mathrm{~kb}$ wurden pro 100 bp Länge 10 ng Template-DNA in den Sequenzieransatz zugegeben. Bei Matrizen-DNAMolekülen $>3 \mathrm{~kb}$ (z.B. Fosmide) wurden 300 ng DNA pro Reaktion eingesetzt. Wies die Matrizen-DNA stabile Sekundärstrukturen auf, welche zu Sequenzabbrüchen führen könnten, wurden Additive (Betain bzw. DMSO; Jensen, Fukushima \& Davis 2010) hinzugegeben.

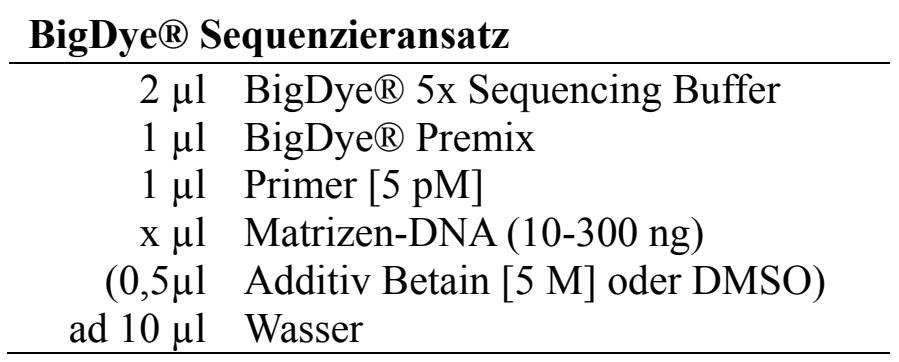

Bei hartnäckigen Sekundärstrukturen wurde das Illustra TempliPhi Sequence Resolver Kit (GE Healthcare, Buckinghamshire, UK) eingesetzt. Durch TempliPhi-vermittelte DNAAmplifikation mit zufälligen Hexamer-Primern entstehen aus einer Matrizen-DNA ungleichmäßige und stark verzweigte Amplifikations-Produkte, welche ein stark vermindertes Potential zur Ausbildung von Sekundärstrukturen aufweisen. Da dieses Kit für zirkuläre Matrizen-DNA ausgelegt ist, mussten lineare DNA-Fragmente zunächst mittels Klonierung in einen zirkulären Vektor integriert werden (siehe 2.6). Anschließend wurde nach Angaben des Herstellers vorgegangen. 


\subsection{Sequenzierung und Annotation der Octadecabacter-Genome}

\subsubsection{Rohsequenzierung}

Die Rohsequenzierung der Genome von O. arcticus 238 und $O$. antarcticus 307 erfolgte im Rahmen des Gordon and Betty Moore Foundation Marine Genome Sequencing Project (https://moore.jcvi.org/moore/) durch das J. Craig Venter Institut (JCVI, Rockville, MD, USA) und wurde durch das Niedersächsische VW_Vorab Projekt finanziert. Es wurde nach der Sanger-Methode (Sanger, Nicklen \& Coulson 1977) unter Verwendung von sowohl Plasmid- als auch Fosmid-Shotgun-Klonbanken vorgegangen. Sowohl Plasmide als auch Fosmide wurden mit Vektor-spezifischen Primern von beiden Seiten her ansequenziert (paired-end Ansatz). Durch diesen Ansatz können pro Shotgun-Klon jeweils zwei Sequenzen (reads) einander zugeordnet werden, wobei der Abstand zwischen diesen Sequenzen durch die Art des Vektors definiert ist: 2-3 kb bei Plasmiden und 40-50 kb bei Fosmiden. Rohsequenzen und Klonbanken wurden anschließend durch das JCVI an das Göttinger Genomlabor übergeben.

\subsubsection{Assemblierung, Lückenschluss und Verbesserung der Sequenzqualität}

Die Assemblierung der Sequenzdaten erfolgte mithilfe des Staden-Packages (Staden 1996), wobei die paired end-Informationen der Shotgun-Sequenzierung (siehe 2.9.1) bei der Zusammensetzung und Anordnung der contigs (Gruppierungen überlappender Sequenzen) berücksichtigt wurden. Lückenschluss (finishing) und Verbesserung der Sequenzqualität (polishing) wurden mittels PCR-basierter Techniken auf Fosmiden der Shotgun-Klonbanken und auf genomischer DNA durchgeführt. Hierfür wurden an den contig-Enden bzw. an den flankierenden Bereichen der fraglichen Genomabschnitte spezifische Primer abgeleitet. Die Spezifität der Primer wurde durch BLAST-Vergleiche mit dem teilassemblierten Genom überprüft, wobei vor allem Wert auf hohe Spezifität des $3^{6}$-Endes gelegt wurde. Potentielle Primerpaare, deren Sequenzen sich mehr als einem Genomabschnitt zuordnen ließen, wurden abgelehnt. Um möglichst hohe Annealing-Temperaturen zu ermöglichen, was die Ausprägung von Sekundärstrukturen deutlich verminderte, wurden Primersequenzen so gewählt, dass ihre Schmelzpunkte möglichst bei $>60^{\circ} \mathrm{C}$ lagen. PCRs wurden wie in 2.4 beschrieben durchgeführt. Ergab sich ein eindeutiges PCR-Produkt, wurde dieses direkt aufgereinigt (siehe 2.3.2.2), ansonsten wurden die PCR-Produkte durch Agarose-Gelelektrophorese 
aufgetrennt und aus dem Gel extrahiert (siehe 2.3.2.4). Die aufgereinigten PCR-Produkte wurden anschließend sequenziert (siehe 2.8). Aufgrund der hohen Anzahl an repetitiven genetischen Elementen in den Octadecabacter-Genomen, mussten zahlreiche PCRs mit insgesamt über 1.000 Primern durchgeführt werden um die korrekte Assemblierung des Genoms zu gewährleisten. Aus diesem Grund wird hier auf eine Auflistung der einzelnen finishing- und polishing-Primer verzichtet.

\subsubsection{Annotation}

Offene Leseraster (open reading frames, ORFs) wurden mithilfe der Programme YACOP (Tech \& Merkl 2003) und Glimmer (Delcher et al. 2007) vorhergesagt. Die resultierenden ORFs wurden mittels Artemis v.11 (Rutherford et al. 2000) basierend auf GC frame plotAnalysen, der Anwesenheit von Ribosomen-Bindestellen sowie Vergleichen zu bekannten Protein-kodierenden Sequenzen manuell korrigiert.

Funktionelle Annotationen der korrigierten ORFs wurden zunächst mithilfe des ERGO software package (Overbeek et al. 2003) automatisiert erstellt und anschließend anhand von BLAST-Vergleichen zu den Swiss-Prot- und Trembl-Datenbanken (http://kr.expasy.org/) und anhand von Domänenanalysen mittels des Programms Interpro-Scan (http://www.ebi.ac.uk/Tools/pfa/iprscan; Zdobnov \& Apweiler 2001) manuell korrigiert.

Annotationen von BLAST-Treffern wurden nur dann übernommen wenn wichtige sämtliche, für die entsprechende Funktion essentielle, Proteindomänen identifiziert werden konnten, und der Treffer einen e-value (Expect value; Parameter zur Bestimmung der statistischen Signifikanz eines BLAST-Treffers) von weniger als 1e-10 aufwies. BLAST-Treffer zu Einträgen der manuell kurierten Swiss-Prot-Datenbank wurden stärker gewichtet als Treffer zu größtenteils auf automatische Annotationen beruhenden Einträgen der Trembl-Datenbank. Ebenso wurden Annotationen von Datenbank-Einträgen welche durch Untersuchungen auf Proteinebene bestätigt wurden, gegenüber rein Sequenzhomologie-basierten Annotationen bevorzugt.

Anschließend wurden die Genprodukte der annotierten ORFs sämtlicher RoseobacterVertreter mithilfe des IMG/ER (Integrated Microbial Genomes/Expert Review) Systems (http://img.jgi.doe.gov/; Markowitz et al. 2012) in funktionelle Kategorien der COG (Cluster of Orthologous Groups)-Datenbank (Tatusov et al. 2003) eingeordnet. Die COG-Datenbank fasst Proteine verschiedener Organismen anhand von Sequenzähnlichkeiten zu orthologen 
Gruppen zusammen, welche wiederum in 24 funktionelle Kategorien eingeteilt werden (Tab. 3), und erleichtert dadurch den Vergleich funktioneller Charakteristika von Organismen und Organismengemeinschaften.

Tab. 3 COG-Kategorien

\begin{tabular}{lllll}
\hline A & RNA Prozessierung & I Lipidmetabolismus & Q & Sekundärmetabolismus \\
B & Chromatin-Struktur & J Translation & T & Signaltransduktion \\
C & Energiestoffwechsel & K Transkription & R & Funktion unsicher \\
D & Zellzyklus & L Replikation + Rekomb. & S & Funktion unbekannt \\
E & Aminosäuremetabolismus & M Zellwandsynthese & U Sekretion \\
F & Nukleotidmetabolismus & N Motilität & V Abwehrmechanismen \\
G & Kohlenhydratmetabolismus & O Posttransl. Modifikation & W Extrazelluläre Strukturen \\
H Coenzymmetabolismus & P Transp. inorg. Ionen & Z Cytoskelett \\
\hline
\end{tabular}

\subsection{Analysen von Genom- und Fosmidsequenzen}

\subsubsection{Vergleichsgenome}

Zum Zeitpunkt an dem diese Arbeit verfasst wurde, standen von den 69 in der GOLDDatenbank (Genomes Online Database, http:/www.genomesonline.org) angemeldeten Genomprojekten verschiedener Vertreter der Roseobacter-Gruppe, 49 Genomsequenzen für vergleichende Analysen zur Verfügung (Tab. DA01, digitaler Anhang). Öffentlich verfügbare Referenz-Genomsequenzen (siehe 2.10.1) wurden von der NCBI GenBank Sequenzdatenbank (http::/www.ncbi.nlm.nih.gov) oder vom J. Craig Venter Institut (http://www.jcvi.org) heruntergeladen. Für bidirektionale BLAST-Analysen (siehe 2.10.3) von Sequenzen rekombinanter Fosmide, welche inserts myxobakteriellen Ursprungs trugen, wurden Genomsequenzen folgener Myxobakterien herangezogen: Anaeromyxobacter dehalogenans 2CP-C, Anaeromyxobacter dehalogenans 2CP-1, Anaeromyxobacter sp. K, Anaeromyxobacter sp. Fw109-5, Myxococcus xantus DK1622, Sorangium cellulosum So ce 56 und Haliangium ochraceum DSM14365.

\subsubsection{Gesamtgenom-alignments}

Für Genom-alignments wurde das Programm Mauve (Darling et al. 2004) mit dem ProgressiveMauve-Algorithmus (Darling, Mau \& Perna 2010) verwendet. Dieses Programm erkennt konservierte Bereiche zwischen Vergleichsgenomen und stellt diese als lokale kollineare Blöcke (local collinear blocks, LCBs) dar. Verschiedene LCBs werden verschiedenfarbig dargestellt, wobei farbige Balkendiagramme den Grad der 
Sequenzübereinstimmung anzeigen. Hierdurch lassen sich intragenomische Rekombinationsvorgänge sichtbar machen.

Alternativ wurde das im IMG/ER (Integrated Microbial Genomes/Expert Review) System (http://img.jgi.doe.gov/; Markowitz et al. 2012) integrierte Programm DotPlot genutzt, welches auf dem NUCmer-Tool der MUMmer suite basiert (Kurtz et al. 2004). Dieses Programm stellt Sequenzalignments zwischen zwei Genomen in Form von Dotplots dar, wobei parallele übereinstimmende Bereiche in Blau und antiparallele übereinstimmende Bereiche in Rot angezeigt werden.

\subsubsection{Orthologen-Identifikation}

Der Begriff Homologe bezeichnet zwei (oder mehr) Gene, welche von einem gemeinsamen Vorläufer abstammen. Homologe werden grundsätzlich unterschieden in Paraloge, Xenologe und Orthologe. Paraloge entstehen durch Genduplikation innerhalb eines Genoms. Als Xenologe werden verwandte Gene bezeichnet, welche durch horizontalen Gentransfer auf verschiedene Organismen übertragen wurden. Demgegenüber stehen Orthologe für verwandte Gene verschiedener Organismen, welche durch vertikalen Gentransfer übertragen wurden. Häufig wird davon ausgegangen, dass Orthologe bzw. Xenologe in den jeweiligen Vergleichsorganismen ähnliche oder äquivalente Funktionen erfüllen (insbesondere wenn eine hohe Übereinstimmung der Proteinsequenzen vorliegt). Die genaue Unterscheidung zwischen Orthologen und Xenologen ist jedoch problematisch und kann durch keine gängige bioinformatische Methode der Orthologen-Identifikation gewährleistet werden (Kuzniar et al. 2008). Da diese Differenzierung zudem für funktionelle vergleichende Analysen nicht von Belang ist, wird bei vergleichenden Analysen verwandter Gene phylogenetisch diverser Organismen meist zunächst von Orthologen ausgegangen (Newton et al. 2010; z.B. Kalhöfer et al. 2011). Auch in der hier vorliegenden Doktorarbeit wurde dies im Folgenden so gehandhabt.

Potentielle Orthologe wurden mithilfe des laborinternen software tools BiBag (Wollherr 2010) auf Basis von Proteinsequenzen ermittelt. Dieses Programm verbindet BLAST-Analysen (http://www.ncbi.nlm.nih.gov/) zur Bestimmung bidirektionaler bester hits (BBH; häufig auch bezeichnet als reziproke beste hits, RBH) (Hulsen et al. 2006; Altenhoff \& Dessimoz 2009) mit globalen alignments, basierend auf dem Needleman-Wunsch Algorithmus (Needleman \& Wunsch 1970). Nur BBHs welche e-values unterhalb von 1e-10 aufwiesen, wurden berück- 
sichtigt. Um falsche, auf kurzen lokalen alignments konservierter Proteindomänen basierende Treffer auszuschließen, wurden die Ergebnisse anhand der entsprechenden Sequenzidentitäten auf globaler alignment-Ebene gefiltert. Wie bereits in früheren vergleichbaren Studien (Newton et al. 2010; Kalhöfer et al. 2011; Thole et al. 2012), wurde ein unterer Grenzwert von $30 \%$ Sequenzidentität festgelegt, um potentielle Orthologe zu definieren. Außerdem wurde, anhand eines Grenzwertes von mindestens 60\% Sequenzidentität, der Anteil hochkonservierter Orthologe bestimmt, da bei Proteinen mit Sequenzidentitäten von $>50 \%$ die Wahrscheinlichkeit für äquivalente Funktion deutlich erhöht ist (Sangar et al. 2007). Auf diese Weise kann jedem Gen eines Referenzorganismus maximal ein Ortholog pro Vergleichsorganismus zugeordnet werden. Paraloge werden durch diese Methode nicht berücksichtigt.

\subsubsection{Identifikation von potentiellen genomischen Inseln}

Für die Identifizierung von potentiellen genomischen Inseln wurde das WEB-basierte Programm IslandViewer eingesetzt (http://www.pathogenomics.sfu.ca/islandviewer) (Langille \& Brinkman 2009). Dieses Programm kombiniert drei verschiedene Ansätze der Fremdgenbestimmung, darunter SIGI-HMM (Waack et al. 2006) und IslandPath-DIMOB (Hsiao et al. 2003). Diese beiden Methoden, welche auf die Roseobacter-Genome angewandt wurden, basieren hauptsächlich auf Veränderungen der Nucleotidzusammensetzung und codon-usage innerhalb eines Genoms. Demgegenüber verwendet die dritte Methode des IslandViewerProgramms, IslandPick (Langille, Hsiao \& Brinkman 2008), direkte Genomvergleiche zwischen nah verwandten Organismen zur Vorhersage von genomischen Inseln. Da sie jedoch auf einer festen Datenbank mit nur sehr wenigen Roseobacter-Genomen beruht, konnte diese dritte Methode nicht auf Roseobacter-Vertreter angewandt werden.

\subsubsection{Vergleiche der Genausstattung (Gene content-Analysen)}

Gene content-Analysen wurden nach dem Vorbild von Newton et al. (2010) durchgeführt. Anhand der Ergebnisse der Orthologen-Identifikation (siehe 2.10.3) wurden, mit Ausnahme von singletons (einzigartigen Genen), sämtliche in Roseobacter-Vertretern vorhandenen Gene aufgelistet. Indem diese Genliste einer Namensliste der Vergleichsorganismen gegenübergestellt wurde, konnte eine Matrix erstellt werden, in der die Anwesenheit bzw. 
Abwesenheit von Orthologen eines Gens in den verschiedenen Vergleichsorganismen in binärer Schreibweise angegeben ist (Tab. DA02, digitaler Anhang). Diese binäre Matrix wurde unter Verwendung des Programms Clustering Calculator (http://www2.biology.ualberta.ca/jbrzusto/ cluster.php) (Czechowska et al. 2013) in eine Distanzmatrix umgewandelt und Clusteranalysen mittels des Neighbor-Joining Algorithmus unterzogen.

\subsubsection{Vergleichende Analysen der Nukleotid-Zusammensetzung}

Die Verfügbarkeit von vollständigen Genomsequenzen ermöglicht eine in silico Bestimmung der genetischen Übereinstimmung zwischen Vergleichsorganismen, analog zu den früher üblichen und experimentell aufwendigen DNA-DNA Hybridisierungstechniken (RossellóMora \& Amann 2000; Goris et al. 2007). Als Messgrößen werden beispielsweise durchschnittliche Nukleotid-Übereinstimmungen (average nucleotide identities, ANI) oder Ähnlichkeiten in den Oligonukleotidsignaturen herangezogen (Richter \& Rosselló-Móra 2009). Das Programm JSpecies (http://www.imadea.uib.es/jspecies/) wurde verwendet, um BLAST-basierte ANI-Werte (ANIb) sowie Korrelationskoeffizienten der Tetranukleotidsignaturen durch direkte Vergleiche zwischen den verfügbaren Roseobacter-Genomen zu bestimmen. Die Ergebnisse wurden verwendet, um Distanzmatrizen zu erstellen, welche wie in 2.10.5 beschrieben, für Neighbor-Joining Analysen mittels des Programms Clustering Calculator herangezogen wurden.

\subsubsection{Phylogenetische Analysen basierend auf Gen- und Proteinsequenzen}

Protein- und Gensequenzen wurden von der NCBI-nr Datenbank heruntergeladen oder den Referenzgenomen (siehe 2.10.1) entnommen. Für Proteinalignments wurde das Programm ClustalW (Larkin et al. 2007), und für 16S rRNA Gensequenzalignments das Programm SINA (Pruesse, Peplies \& Glöckner 2012) verwendet. Für Multilokus-Sequenzanalysen (MLSA) wurden alignments von Proteinsequenzen, welche in sämtlichen Vergleichsgenomen ein Ortholog aufwiesen, innerhalb dieser Genome aber einzigartig waren (also keine Paraloge aufwiesen), konkateniert. Um hierbei Paraloge auszuschließen, wurden sämtliche Treffer der Orthologensuche einem anschließenden BLAST-Vergleich gegen die Referenzgenome unterzogen. Gene, welche mehr als einen Treffer bei einem e-value Grenzwert von 1e-20 
aufwiesen, wurden bei MLSA nicht berücksichtigt. Neighbor-Joining und MaximumLikelihood Stammbäume wurden mit der Softwareumgebung ARB v5.1 (Ludwig et al. 2004) erstellt. Bei MLSA wurde die ARB-interne Filterfunktion angewandt, um lückenhafte alignment-Positionen von der Stammbaumberechnung auszuschließen. Um ein möglichst zuverlässiges Grundgerüst der phylogenetischen Stammbäume zu erhalten, wurden für Neighbor-Joining und Maximum-Likelihood Berechnungen ausschließlich 16S Sequenzen mit einer Länge von $>1200$ bp bzw. vollständige Proteinsequenzen verwendet. Kurze unvollständige Sequenzen wurden nachträglich per Parsimony-Funktion den Grundgerüsten hinzugefügt.

\subsection{Screenings von Metagenom-Datenbanken}

Verschiedene, öffentlich verfügbare, Metagenom-Datensätze aus Süßwasser, marinen, hypersalinen, termophilen sowie Eis-assoziierten Habitaten wurden von den CAMERA (http:// camera.calit2.net/) und MG-RAST (http://metagenomics.anl.gov/) Datenbanken heruntergeladen (Tab.4), und mittels BLAST-Analysen nach Octadecabacter 16S rRNA Gensequenzen sowie Rhodopsinen und Cyanophycin-Ligasen durchsucht (gescreent). Bei der Suche nach Rhodopsinen wurden nur Proben aus Oberflächenbereichen bis zu einer Tiefe von $30 \mathrm{~m}$ berücksichtigt. Allgemein wurden nur Datensätze mit mehr als 100.000 Sequenzen analysiert. Um eine hohe Sensitivität zu gewährleisten, wurden mindestens zwei Vertreter jeder Gruppe der entsprechenden phylogenetischen Rhodopsin- und CyanophycinProteindatensätze (siehe 2.10.7) ausgewählt und als query-Sequenz für primäre tBLASTnAnalysen mit einem unstringenten $e$-value Grenzwert von 1 eingesetzt. Die resultierenden Treffer wurden durch sekundäre BLASTx-Vergleiche mit der NCBI-RefSeq-Datenbank sowie selbst erstellen phylogenetischen Datenbanken (siehe 2.10.7) unter Verwendung stringenter $e$ value und alignment-Grenzwerte validiert. Bei Analysen von Metagenomen mit einer durchschnittlichen Sequenzlänge von $>150$ bp wurde ein e-value Grenzwert von 1e-20 festgelegt und bei Datensätzen mit Sequenzlängen von $<150$ bp ein e-value Grenzwert von 1e-10. Die entsprechenden alignments mussten mind. 60\% der Referenz-Sequenz oder $80 \%$ der query-Sequenz abdecken. Validierung und Klassifizierung der Ergebnisse erfolgte durch Abgleich mit der NCBI RefSeq-Datenbank und selbst erstellten phylogenetischen Datensätzen (siehe 2.10.7). 
Tab. 4 Liste der nach spezifischen Genen durchsuchten Metagenom-Projekte

\begin{tabular}{|c|c|c|c|c|}
\hline ame/Beschreibung & Quelle & $\begin{array}{c}\text { MG-RAST/CAMERA } \\
\text { accession-Nr. }\end{array}$ & $\begin{array}{l}\text { Sequenzier- } \\
\text { methode }\end{array}$ & Referenz \\
\hline $\begin{array}{l}\text { Antarctica aquatic microbial } \\
\text { metagenome }\end{array}$ & RA & $\begin{array}{c}\text { CAM_PROJ_Antarctica } \\
\text { Aquatic }\end{array}$ & $\begin{array}{c}454 / \\
\text { Sanger }\end{array}$ & 2011) \\
\hline $\begin{array}{l}\text { Ward Hunt Ice Shelf melt pool } \\
\text { metagenome }\end{array}$ & $\mathrm{T}$ & WHI & 454 & (Varin et al. \\
\hline $\begin{array}{l}\text { Markham Ice Shelf melt pool } \\
\text { metagenome }\end{array}$ & MG & MIS & 454 & (Vari \\
\hline Botany Bay metagenome & $\mathrm{CA}$ & CAM_PROJ_Bot & $\begin{array}{c}454 / \\
\text { Sanger }\end{array}$ & \\
\hline $\begin{array}{l}\text { Global Ocean } \\
\text { Expedition }\end{array}$ & CAMERA & CAM_PROJ_GOS & $\begin{array}{l}454 / \\
\text { Sanger }\end{array}$ & (Rus \\
\hline $\begin{array}{l}\text { Ice metagenome of the northern } \\
\text { Schneeferner }\end{array}$ & ERA & $\begin{array}{l}\text { CAM_PROJ_IceMeta- } \\
\text { genome }\end{array}$ & 454 & \\
\hline $\begin{array}{l}\text { Marine bacterioplankton meta- } \\
\text { genomes }\end{array}$ & $\mathrm{CA}$ & CAM_PROJ_Bacterio- & 454 & \\
\hline $\begin{array}{l}\text { Marine metagenome from coastal } \\
\text { waters project at Plymouth Marine } \\
\text { Laboratory }\end{array}$ & $\mathrm{CA}$ & CAM_PROJ_PML & 454 & et \\
\hline $\begin{array}{l}\text { enome from Yellowstone } \\
\text { Hot Spring }\end{array}$ & $\mathrm{CA}$ & CAM_PROJ_Bison & 454 & (Hav \\
\hline $\begin{array}{l}\text { ic analysis of the } \\
\text { tic spring bloom }\end{array}$ & $\mathrm{CAl}$ & CAM_PROJ_BATS & 454 & - \\
\hline $\begin{array}{l}\text { mmunity genomics at } \\
\text { OHA station }\end{array}$ & CAMERA & CAM_PROJ_HOT & Sanger & $\begin{array}{r}\text { Ma } \\
\text { Tys } \\
\text { De } \\
20\end{array}$ \\
\hline udy & $\mathrm{CAI}$ & $\begin{array}{c}\text { CAM_PROJ_Monterey- } \\
\text { Bay }\end{array}$ & 454 & (Ricl \\
\hline $\begin{array}{l}\text { enomes } \\
\text { alinities }\end{array}$ & $\mathrm{CAl}$ & $\begin{array}{l}\text { CAM_PROJ_Saltern- } \\
\text { Metagenome }\end{array}$ & 454 & (Din \\
\hline $\begin{array}{l}\text { Yellowstone Lake: Genetic and } \\
\text { gene diversity in a freshwater lake }\end{array}$ & AIVIEK & $\mathrm{AKE}$ & Sanger & $\begin{array}{c}\text { Kan et al. } \\
2011)\end{array}$ \\
\hline
\end{tabular}

\subsection{Funktionelle Analysen von Opsin-Genen}

\subsubsection{Erzeugung von Expressionsstämmen}

Opsingene verschiedener Donor-Organismen wurden mittels spezifischer Primer amplifiziert, welche an ihren 5'-Enden Anhänge mit Erkennungssequenzen der Restriktionsenzyme XhoI bzw. NcoI trugen (Tab. 5). Bei Primerpaaren mit dem Kürzel „rho2“ enthielt der Reverseprimer ein Stopcodon, welcher das Anhängen von Polyhistidinschwänzen (His-Tags) in pET24d-und pBAD/Myc His A-Expressionsvektoren verhinderte. Diese Primerpaare waren für Klonierungen zum Zwecke funktioneller Analysen vorgesehen. Primerpaare mit dem Kürzel „rho1“ enthielten dagegen kein solches Stopcodon und waren für den Nachweis von heterolog exprimierten Opsingenprodukten durch Westernblots vorgesehen (siehe 2.12.4). Die entsprechenden PCR-Amplifikationen fanden stets bei einer Annealing-Temp. von $60{ }^{\circ} \mathrm{C}$ statt. 
Tab. 5 Primer zur Amplifikation von Opsingenen

\begin{tabular}{|c|c|c|}
\hline Primer & Primersequenz & $\begin{array}{c}\text { Matrizen- } \\
\text { DNA }\end{array}$ \\
\hline \multicolumn{3}{|c|}{ oarrho1_f GGGGCCATGGAAACATTATCATTGGGTCAATATG } \\
\hline oarrho1_r & GGGGGCTCGAGTTCAGCAGGGACTGCTGTCTTTATGGAATCGTTG & O. arcticus \\
\hline oarrho2_f & GGGGCCATGGAAACATTATCATTGGGTCAATATG & 238 \\
\hline \multicolumn{3}{|c|}{ oarrho2 $\mathrm{r}$ GGGGGCTCGAGTTATTCAGCAGGGACTGCTGTCTTTATGGAATCGTTG } \\
\hline \multicolumn{3}{|c|}{ oanrho1_f GGGGCCATGGAAACTTTATCACTGGGTCAGTATG } \\
\hline oanrhol_r & 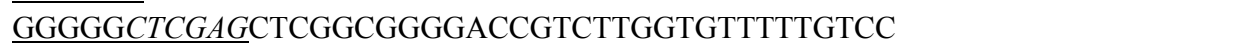 & \\
\hline oanrho2_f & 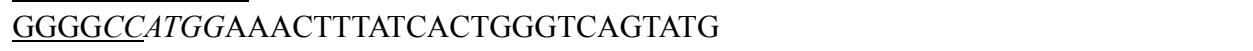 & \\
\hline oanrho2 $\mathrm{r}$ & GGGGGCTCGAGTTACTCGGCGGGGACCGTCTTGGTGTTTTTGTCC & 307 \\
\hline \multicolumn{3}{|c|}{ gviolrhol_f GGGGCCATGGGGATGTTGATGACCGTATTTTCTTCTGC } \\
\hline \multicolumn{3}{|c|}{ gviolrhol_r GGGGGCTCGAGGGAGATAAGACTGCCTCCCGATTTATTTGC } \\
\hline \multicolumn{3}{|c|}{ gviolrho2_f GGGGCCATGGGGATGTTGATGACCGTATTTTCTTCTGC } \\
\hline \multicolumn{3}{|c|}{ gviolrho2 $\mathrm{r}$ GGGGGCTCGAGCTAGGAGATAAGACTGCCTCCCGATTTATTTGC } \\
\hline \multicolumn{3}{|c|}{ protrho1_f GGGGCCATGGAAATGAAATTATTACTGATATTAGGTAGTGTTATTGCACTTCCTACATTTG } \\
\hline protrhol_r & 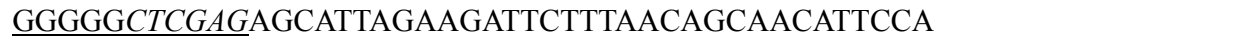 & \\
\hline protrho2_f & GGGGCCATGGAAATGAAATTATTACTGATATTAGGTAGTGTTATTGCACTTCCTACATTTG & \\
\hline protrho $2 \mathrm{r}$ & GGGGGCTCGAGCTAAGCATTAGAAGATTCTTTAACAGCAACATTCCA & \\
\hline
\end{tabular}

Sowohl Insert als auch Vektor wurden durch Verdau mittels der Restriktionsenzyme XhoI und NcoI zweifach geschnitten und besaßen dadurch nicht-komplementäre Strangüberhänge. Hierdurch war die Wahrscheinlichkeit für eine Rezirkularisierung des Vektors stark eingeschränkt, während gleichzeitig die korrekte Orientierung des Inserts während der Ligation (siehe 0) gewährleistet wurde. Transformation in E. coli erfolgte durch Hitzeschock (siehe 2.7.2). Der Vektor pET24d wurde in Verbindung mit dem Expressionsstamm E. coli C43(DE3) verwendet, um eine mögliche Toxizität durch Überexpression von Opsinen vorzubeugen (Wagner et al. 2008). Um höhere Expressionsraten zu erzielen, wurde alternativ der Vektor pBAD/Myc His A in Verbindung mit dem Expressionsstamm E. coli UT5600 verwendet (Tab. 6).

Tab. 6 In dieser Arbeit erzeugte rekombinante $E$. coli-Stämme zur heterologen Expression von Opsingenen

\begin{tabular}{|c|c|c|c|c|c|c|c|c|c|}
\hline $\begin{array}{c}\text { Klon- } \\
\text { Kürzel }\end{array}$ & $\begin{array}{c}\text { Donor- } \\
\text { Organismus/ } \\
\text { Vektor } \\
\end{array}$ & $\begin{array}{c}\text { Expres- } \\
\text { sions- } \\
\text { Stamm } \\
\end{array}$ & $\begin{array}{c}\text { Expres- } \\
\text { sions- } \\
\text { Vektor } \\
\end{array}$ & $\begin{array}{l}\text { His- } \\
\text { Tag } \\
\end{array}$ & $\begin{array}{c}\text { Klon- } \\
\text { Kürzel }\end{array}$ & $\begin{array}{c}\text { Donor- } \\
\text { Organismus/ } \\
\text { Vektor } \\
\end{array}$ & $\begin{array}{c}\text { Expres- } \\
\text { sions- } \\
\text { Stamm } \\
\end{array}$ & $\begin{array}{c}\text { Expres- } \\
\text { sions- } \\
\text { Vektor } \\
\end{array}$ & $\begin{array}{l}\text { His- } \\
\text { Tag }\end{array}$ \\
\hline $\begin{array}{l}\text { OAN- } \\
\text { Rho1 }\end{array}$ & O. antarcticus & $\begin{array}{c}\mathrm{C} 34 \\
\text { (DE3) }\end{array}$ & pET24d & + & $\begin{array}{l}\text { Prot- } \\
\text { Rho1 }\end{array}$ & $\begin{array}{c}\text { pBAD } \\
\text { EBAC31A08 }\end{array}$ & $\begin{array}{c}\mathrm{C} 34 \\
\text { (DE3) }\end{array}$ & pET24d & + \\
\hline $\begin{array}{l}\text { OAN- } \\
\text { Rho2 }\end{array}$ & O. antarcticus & $\begin{array}{c}\text { C34 } \\
\text { (DE3) }\end{array}$ & pET24d & - & $\begin{array}{l}\text { Prot- } \\
\text { Rho2 }\end{array}$ & $\begin{array}{c}\text { pBAD } \\
\text { EBAC31A } 08\end{array}$ & $\begin{array}{c}\mathrm{C} 34 \\
(\mathrm{DE} 3)\end{array}$ & pET24d & - \\
\hline $\begin{array}{l}\text { OAN- } \\
\text { Rho3 }\end{array}$ & O. antarcticus & UT5600 & $\begin{array}{c}\mathrm{pBAD} / \\
M y c \text { His A }\end{array}$ & - & $\begin{array}{l}\text { Gviol- } \\
\text { Rhol }\end{array}$ & G. violaceus & $\begin{array}{l}\mathrm{C} 34 \\
\text { (DE3) }\end{array}$ & pET24d & + \\
\hline $\begin{array}{l}\text { OAR- } \\
\text { Rhol }\end{array}$ & O. arcticus & $\begin{array}{c}\mathrm{C} 34 \\
\text { (DE3) }\end{array}$ & pET24d & + & $\begin{array}{l}\text { Gviol- } \\
\text { Rho2 }\end{array}$ & G. violaceus & $\begin{array}{c}\mathrm{C} 34 \\
\text { (DE3) }\end{array}$ & pET24d & - \\
\hline $\begin{array}{l}\text { OAR- } \\
\text { Rho2 }\end{array}$ & O. arcticus & $\begin{array}{l}\mathrm{C} 34 \\
\text { (DE3) }\end{array}$ & pET24d & - & $\begin{array}{l}\text { Gviol- } \\
\text { Rho3 }\end{array}$ & G. violaceus & UT5600 & $\begin{array}{c}\text { pBAD/ } \\
M y c \text { His A }\end{array}$ & - \\
\hline $\begin{array}{l}\text { OAR- } \\
\text { Rho3 }\end{array}$ & O. arcticus & UT5600 & $\begin{array}{c}\text { pBAD/ } \\
M y c \text { His A }\end{array}$ & - & & & & & \\
\hline
\end{tabular}

+ His-Tag vorhanden; - Kein His-Tag vorhanden 


\subsubsection{Heterologe Expression von Opsingenen}

Rekombinante E. coli-Stämme (Tab. 6) wurden in LB-Medium mit $100 \mu \mathrm{g} / \mathrm{ml}$ Ampicillin (UT5600) bzw. $50 \mu \mathrm{g} / \mathrm{ml}$ Kanamycin (C34[DE3]) bis zu einer $\mathrm{OD}_{600 \mathrm{~nm}}$ von ca. 0,5 angezogen. Anschließend erfolgte eine Induktion der Opsin-Produktion mittels 0,2\% (w/v) Arabinose (UT5600) bzw. $100 \mu \mathrm{M}$ IPTG (C34[DE3]) und eine weitere Inkubation für 3-6 h. Waren die Kulturen für Protonenpumpen-Versuche (siehe 2.12.7) vorgesehen, erfolgte an dieser Stelle eine Zugabe von $100 \mu$ l Retinal $(10 \mathrm{mM})$.

\subsubsection{Erzeugung und Gewinnung von Membranfragmenten}

Expressionskulturen wurden abzentrifugiert $\left(10 \mathrm{~min}, \quad 4.000 \mathrm{x} g, \quad 4{ }^{\circ} \mathrm{C}\right)$, in $1-10 \mathrm{ml}$ Membranpuffer (50 mM Tris, $5 \mathrm{mM} \mathrm{MgCl}_{2}, \mathrm{pH}$ 8) aufgenommen und durch Ultraschallbehandlung mittels eines Sonifier ${ }^{\circledR} 250$ Ultraschallgeräts (Fa. Branson Ultrasonics, Danbury, USA) aufgeschlossen (Stufe 5, 50\% Leistung, 300 Zyklen). Grobe Zelltrümmer wurden duch Zentrifugation bei $10.000 \mathrm{x} g\left(5 \mathrm{~min}, 4{ }^{\circ} \mathrm{C}\right)$ entfernt. Der Überstand wurde anschließend einer Ultrazentrifugation (1-2 h, 160.000x $\left.g, \quad 4{ }^{\circ} \mathrm{C}\right)$ ausgesetzt, um Membranfragmente zu pelletieren. Die Pellets wurden in Membranpuffer resuspendiert.

\subsubsection{Nachweis von Opsinen in Membranfragmenten}

Um heterolog exprimierte Opsine in den Membranfraktionen rekombinater Zellen nachzuweisen, wurde eine SDS-PAGE, gefolgt von einem Western-Blot, durchgeführt. Hierfür wurden Klone verwendet, deren Opsin-Inserts einen His-Tag aufwiesen („Rho1“-Klone, Tab. 6).

\subsubsection{SDS-Polyacrylamid-Gelelektrophorese (SDS-PAGE)}

Für die SDS-PAGE wurde eine Mini-PROTEAN 2-D Elektrophoresekammer (Fa. BioRad, München) verwendet. Hierbei wurde das Standardprotokoll nach Laemmli (1970) modifiziert, indem ein veränderter Ladepuffer mit erhöhter SDS-Konzentration und Zugabe von Urea verwendet wurde. Mit Ladepuffer versetzte Membranfragment-Suspensionen wurden 15 min bei $65{ }^{\circ} \mathrm{C}$ denaturiert, um die bei Membranproteinen häufig auftretende Aggregatbildung zu 
verhindern (Hennessey \& Scarborough 1989). Die Zusammensetzung der Sammel- und Trenngele sowie des Ladepuffers sind unten angegeben. Der Laufpuffer wurde als 10x Stammlösung (125 mM Tris, $959 \mathrm{mM}$ Glycin, 35,7 mM SDS, pH 8,4) angesetzt und vor Gebrauch 1:10 verdünnt. Als Größenstandard wurde der Prestained Molecular Weight Marker (Fa. Fermentas, St. Leon Rot) aufgetragen. Die Elektophorese wurde $45 \mathrm{~min}$ bei einer Stromstärke von $20 \mathrm{~mA}$ durchgeführt.

\begin{tabular}{lr} 
Sammelgel & \\
\hline Acrylamid (30\%) & $400 \mu 1$ \\
0,5 M Tris, pH 6,8 & $250 \mu 1$ \\
SDS (10\%) & $25 \mu 1$ \\
TEMED & $3 \mu 1$ \\
APS (10\%) & $10 \mu 1$ \\
$\mathrm{H}_{2} \mathrm{O}_{\text {bidest }}$ & $1,8 \mathrm{ml}$ \\
\hline
\end{tabular}

\begin{tabular}{lr} 
Trenngel & \\
\hline Acrylamid (30\%) & $2 \mathrm{ml}$ \\
$1,5 \mathrm{M}$ Tris, pH 8,8 & $1 \mathrm{ml}$ \\
SDS $(10 \%)$ & $50 \mu l$ \\
TEMED & $4 \mu 1$ \\
APS $(10 \%)$ & $30 \mu 1$ \\
$\mathrm{H}_{2} \mathrm{O}_{\text {bidest }}$ & $1,94 \mathrm{ml}$ \\
\hline
\end{tabular}

\subsubsection{Western-Blots}

SDS-PAGE Gele wurden mit jeweils einer Lage Hybond ECL Nitrocellulosemembran (Fa. Amersham Biosciences, Freiburg) und sechs Lagen Whatman 3 MM Filterpapier (Fa. Schleicher und Schuell, Dassel) in Transferpuffer (25 mM Tris, $192 \mathrm{mM}$ Glycin, 20\% [v/v] Methanol, pH8,1) getränkt. Drei Lagen des Filterpapiers, gefolgt von der Nitrocellulosemembran, dem SDS-Gel und weiteren drei Lagen des Filterpapiers wurden luftblasenfrei auf der Anodenseite einer Perfect Blue ${ }^{\mathrm{TM}}$ Mini-Blot-Apperatur (Fa. Peqlab, Erlangen) gestapelt. Anschließend erfolgte für 60 min eine Elektrophorese bei $300 \mathrm{~mA}$ und $10 \mathrm{~V}$. Die nun proteinhaltige Nitrocellulosemembran wurde über Nacht bei $5^{\circ} \mathrm{C}$ in Blocklösung $(5 \%$ Magermilchpulver [w/v] in TBS-T-Puffer) inkubiert. Nach drei Waschschritten in TBS-TPuffer wurde die Membran $2 \mathrm{~h}$ in einer His-Tag spezifischen Antikörperlösung inkubiert und anschließend wieder 3x in TBS-T-Puffer gewaschen. Die Detektion spezifisch gebundener Anti-His-Tag Antikörper erfolgte mittels des BCIP/NBT Color Development Substrats (Fa. Promega, Mannheim) nach Angaben des Herstellers.

\begin{tabular}{c} 
TBS-T-Puffer \\
\hline $10 \mathrm{mM}$ Tris-HCl \\
$140 \mathrm{mM} \mathrm{NaCl}$ \\
$0,01 \%(\mathrm{w} / \mathrm{v})$ Tween 20 \\
\hline
\end{tabular}

\begin{tabular}{l} 
Antikörperlösung \\
\hline 14 ml TBS-T-Puffer \\
$7 \mu 1$ Anti-His-Tag Antikörper \\
$200 \mu 1$ Blocklösung \\
\hline
\end{tabular}




\subsubsection{Extraktion von Salinixanthin aus Salinibacter ruber}

Aus S. ruber Kulturen wurde Salinixanthin nach den Methoden von Imasheva et al. (2009) und Lutnaes et al. (2002) extrahiert. Es wurden 2-3 Liter Kulturen von S. ruber angezogen. Die Zellen wurden abzentrifugiert $\left(15 \mathrm{~min}, 10.000 \mathrm{xg}, 4{ }^{\circ} \mathrm{C}\right)$, in $20 \mathrm{~mL} \mathrm{H}_{2} \mathrm{O}_{\text {bidest }}$ aufgenommen und durch Ultraschallbehandlung aufgeschlossen (Sonifier ${ }^{\circledR}$ 250, Fa. Branson Ultrasonics, Danbury, USA). Zur Extraktion von Carotenoiden wurde das Lysat mit mindestens $200 \mathrm{ml}$ einer Aceton/Methanol (7:3)-Lösung versetzt und zentrifugiert (10 min, $4.000 \mathrm{x} g, 4{ }^{\circ} \mathrm{C}$ ), woraufhin der Überstand abgenommen und lichtgeschützt aufbewahrt wurde. Der Extraktionsschritt wurde mit dem Pellet mehrfach wiederholt, bis keine rötliche Färbung des Pellets mehr zu erkennen war. Die Überstände wurden jeweils vereint und durch lichtgeschützte Inkubation unter einem Laborabzug bei Raumtemperatur fast vollständig eingetrocknet. Der resultierende Feststoff wurde mit eiskaltem Aceton $\left(-20{ }^{\circ} \mathrm{C}\right)$ versetzt und über Nacht bei $-20^{\circ} \mathrm{C}$ inkubiert um Proteine auszufällen. Nach einer weiteren Zentrifugation (20 min, 4.000x $g, 4{ }^{\circ} \mathrm{C}$ ) wurde der Salinixanthin-haltige Überstand abgenommen und lichtgeschützt unter einem Laborabzug eingetrocknet. Das eingetrocknete Salinixanthin wurde anschließend in Ethanol (reinst) aufgenommen.

Die Salinixanthin-Konzentration wurde nach Imasheva et al. (2009) anhand der auf dem

Lambert-Beerschen Gesetz beruhenden Formel $c=\frac{A}{\varepsilon} d$ berechnet. $c$ entspricht in dieser Formel der Salinixanthin-Konzentration, $A$ enspricht der Absorption der Lösung bei einer Wellenlänge von $480 \mathrm{~nm}, d$ ist die Schichtdicke und $\varepsilon$ ist der Extinktionskoeffizient, welcher von Imasheva et al. für Salinixanthin auf $140.000 \mathrm{M}^{-1} \mathrm{~cm}^{-1}$ geschätzt wurde.

\subsubsection{Spektralanalysen von Rhodopsingenprodukten}

Die Absorbtionsspektren verschiedener Membranfragment-Suspensionen (siehe 2.12.3) wurden mittels eines Lambda25 UV/vis Spektrophotometers (Fa. Perkin Elmer, Rodgau) im Wellenlängenbereich von 300-800 nm bestimmt. Die Messungen erfolgten bei Raumtemperatur und zu verschiedenen Zeitpunkten vor und nach Zugabe der Chromophore Retinal (Fa. Sigma-Aldrich, Steinheim) bzw. Salinixanthin (siehe 2.12.5). Retinal wurde in einer Endkonzentration von $10 \mu \mathrm{M}$ und Salinixanthin in einer Endkonzentration von $1 \mu \mathrm{M}$ zugegeben. Als Blindwert diente jeweils Membranpuffer mit bzw. ohne Zugabe von Retinal oder Salinixanthin. Durch Abzug der Messwerte vor Zugabe von Chromophoren von den 
entsprechenden Messwerten nach Zugabe von Chromophoren wurden Differenzspektren gebildet.

\subsubsection{Bestimmung der Protonenpumpen-Aktivität von Rhodopsinen}

Die Protonenpumpen-Funktion von heterolog exprimierten Rhodopsinen wurde nach Vorbild von Beja et al. (2000) direkt in Suspensionen rekombinanter E. coli-Zellen gemessen. Die Zellen wurden mind. $2 \mathrm{x}$ durch Zentrifugation $\left(10 \mathrm{~min}, 5.000 \mathrm{x} g, 8^{\circ} \mathrm{C}\right)$ und anschließende Resuspension in ungepufferter Protonenpumpenlösung $(10 \mathrm{mM} \mathrm{NaCl}, 10 \mathrm{mM} \mathrm{MgSO}$, $100 \mu \mathrm{M} \mathrm{CaCl}_{2}$ ) gewaschen, um Nährstoffe des Wachstumsmediums zu entfernen. Die nährstoffreien Zellsuspensionen wurden vor den Messungen mind. $15 \mathrm{~min}$ bei Raumtemperatur inkubiert. Der Nachweis lichtabhängiger Protonentranslokation (Protonenpumpenaktivität) erfolgte durch Messung vorübergehender Veränderungen der Ansäuerungsrate der Zellsuspensionen unter Verwendung eines WTW pH33i pH-meters und einer Sentix81 pH-Elektrode (WTW, Weilheim). Eine $500 \mathrm{~W}$ Tungsten Halogen-Lampe (Fa. Osram, Augsburg) diente als Lichtquelle. Die Messungen fanden bei Raumtemperatur statt. Um den Einfluss der Wärmestrahlung der Lampe zu minimieren, wurde das Licht durch eine $15 \mathrm{~cm}$ Schicht eiskalten Wassers gefiltert. Die Temperatur der Zellsuspensionen wurde mittels eines in der pH-Elektrode integrierten Temperatursensors während des gesamten Experiments beobachtet. Bei Bedarf wurden die Zellsuspensionen mit Hilfe eines flachen Wasserbads gekühlt. 


\section{Ergebnisse}

3.1 Allgemeine Vergleiche der bislang sequenzierten Roseobacter-Vertreter

\subsubsection{Generelle Genomeigenschaften}

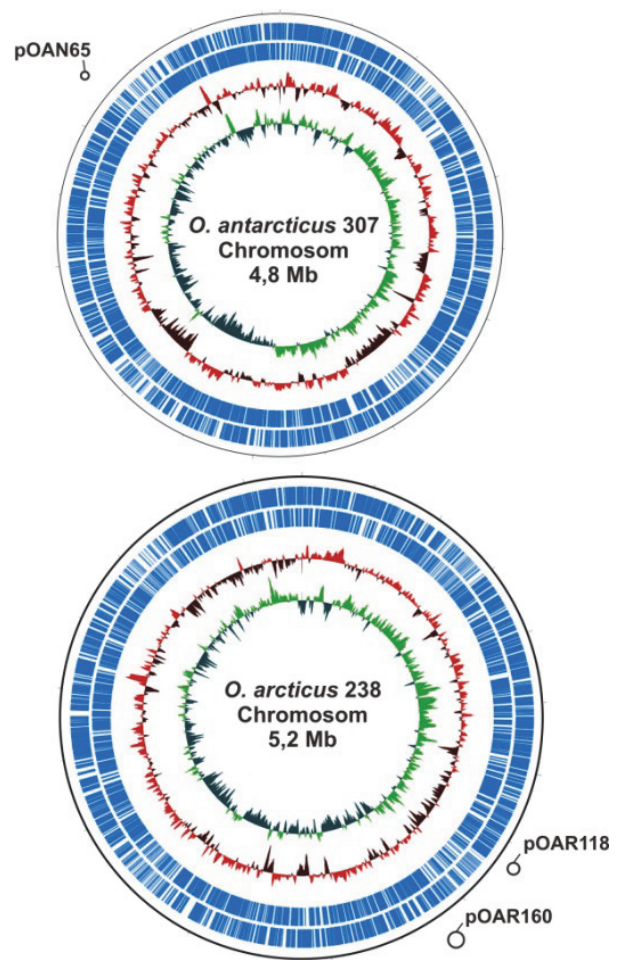

Abb. 4 Graphische Übersicht der Octadecabacter Genome.

Die Größenverhältnisse sind maßstabsgetreu dargestellt. Blaue Striche zeigen Protein-kodierende Gene auf den Chromosomen an. Rote Graphen zeigen Schwankungen des GC-Gehalts an. Grüne Graphen stellen den jeweiligen GC-skew dar.
Die Genome von Octadecabacter arcticus 238 und Octadecabacter antarcticus 307 wurden vollständig sequenziert, assembliert und auf Sequenzierfehler hin überprüft (siehe 2.9). Das Genom von O. arcticus 238 besteht aus einem 5,2 Megabasen $(\mathrm{Mb})$ großen Chromosom und zwei Plasmiden mit jeweils Größen von $118 \mathrm{~kb}$ und $160 \mathrm{~kb}$ (Abb. 4). Im Vergleich dazu ist das Genom von O. antarcticus 307, bestehend aus einem 4,8 Mb Chromosom und einem $65 \mathrm{~kb}$ Plasmid etwas kleiner. Beide Genomgrößen liegen im Vergleich zu den übrigen Vertretern der RoseobacterGruppe (durchschnittlich ca. 4,29 Mb) im oberen Bereich (Tab. 7).

Entsprechend ist auch die Zahl der in den Genomen von $O$. arcticus und $O$. antarcticus enthaltenen Gene überdurchschnittlich hoch. Jedoch liegt die Zahl der t-RNA- und rRNA-Gene in beiden Stämmen (49 und 48) deutlich unter dem Durchschnitt der Roseobacter-Gruppe (ca. 60). Auch der GC-Gehalt der Octadecabacter-Genome (55\%) liegt im Vergleich zu den Genomen anderer RoseobacterVertreter im unteren Bereich (Durchschnitt 60\%).

Besonders auffällig ist hingegen die hohe Zahl an Pseudogenen in den OctadecabacterGenomen, welche 322 in O. antarcticus und 406 in O. arcticus beträgt. Diese Werte sind nicht nur einzigartig innerhalb der Roseobacter-Gruppe sondern auch allgemein ungewöhnlich für bakterielle Genome. Auf diese Pseudogene und ihre möglichen Ursachen wird im Abschnitt 3.2.2.2 gesondert eingegangen. 
Tab. 7 Genomeigenschaften der Untersuchten Roseobacter-Vertreter

\begin{tabular}{|c|c|c|c|c|c|c|c|c|}
\hline \multirow[b]{2}{*}{ Organismus } & \multirow[b]{2}{*}{$\begin{array}{l}\text { Lebens- } \\
\text { weise }\end{array}$} & \multirow[b]{2}{*}{$\begin{array}{l}\text { Habitat/ } \\
\text { Wirt }\end{array}$} & \multirow[b]{2}{*}{$\begin{array}{l}\text { GC - } \\
\text { Gehalt }\end{array}$} & \multirow[b]{2}{*}{$\begin{array}{c}\text { Genom } \\
\text { grösse } \\
{[\mathrm{Mb}]}\end{array}$} & \multicolumn{3}{|c|}{ Anzahl Gene } & \multirow[b]{2}{*}{$\mathrm{TEs} / \mathrm{Mb}$} \\
\hline & & & & & $\begin{array}{l}\text { Protein- } \\
\text { kodierend }\end{array}$ & $\begin{array}{l}\text { Pseudo- } \\
\text { gene }\end{array}$ & $\begin{array}{l}\text { RNA- } \\
\text { Gene }^{a}\end{array}$ & \\
\hline Citreicella aestuarii 357 & mar./ass. & Sediment & $64 \%$ & 4,60 & 4528 & 0 & 45 & 31 \\
\hline Citreicella sp. SE45 & mar./ass. & Schlickgras & $67 \%$ & 5,52 & 5425 & 2 & 72 & 18 \\
\hline Dinoroseobacter shibae DFL-12* & mar./ass. & Dinoflagellat & $66 \%$ & 4,42 & 4186 & 33 & 52 & 22 \\
\hline Jannaschia sp. CCS1* & mar./pel. & Freiwasser & $62 \%$ & 4,40 & 4283 & 0 & 56 & 6 \\
\hline Ketogulonicigenium vulgare Y25* & terr. & Boden & $62 \%$ & 3,29 & 3213 & 0 & 74 & 5 \\
\hline Ketogulonicigenium vulgare WSH-001 & terr. & Boden & $62 \%$ & 3,28 & 3054 & 0 & 71 & 6 \\
\hline Loktanella sp. CCS2 & mar./pel. & Freiwasser & $55 \%$ & 3,50 & 3660 & 0 & 43 & 3 \\
\hline Loktanella sp. SE62 & mar./ass. & Schlickgras & $62 \%$ & 4,58 & 4596 & 0 & 43 & 8 \\
\hline Loktanella vestfoldensis SKA53 & mar./pel. & Freiwasser & $60 \%$ & 3,06 & 3068 & 0 & 49 & 9 \\
\hline Maritimibacter alkaliphilus HTCC2654 & mar./pel. & Freiwasser & $64 \%$ & 4,53 & 4712 & 0 & 48 & 9 \\
\hline Nautella italica R11 & mar./ass. & Algen & $60 \%$ & 3,82 & 3655 & 1 & 69 & 3 \\
\hline Oceanibulbus indolifex HEL-45 & mar./pel. & Freiwasser & $60 \%$ & 4,11 & 4153 & 0 & 55 & 16 \\
\hline Oceanicola batsensis HTCC 2597 & mar./pel. & Tiefsee & $66 \%$ & 4,44 & 4212 & 0 & 49 & 12 \\
\hline Oceanicola granulosus HTCC2516 & mar./pel. & Freiwasser & $70 \%$ & 4,04 & 3792 & 0 & 63 & 6 \\
\hline Octadecabacter antarcticus $307^{*}$ & mar./ass. & Meereis & $55 \%$ & 4,88 & 4492 & 361 & 48 & 74 \\
\hline Octadecabacter arcticus $238^{*}$ & mar./ass. & Meereis & $55 \%$ & 5,20 & 4683 & 413 & 49 & 175 \\
\hline Pelagibaca bermudensis HTCC2601 & mar./pel. & Freiwasser & $66 \%$ & 5,43 & 5452 & 0 & 62 & 23 \\
\hline Phaeobacter arcticus DSM 23566 & mar./ass. & Sediment & $59 \%$ & 5,05 & 4726 & 102 & 81 & 10 \\
\hline Phaeobacter caeruleus 13 & mar./ass. & Biofilm & $63 \%$ & 5,35 & 5146 & 81 & 108 & 13 \\
\hline Phaeobacter daeponensis DSM 23529 & mar./ass. & Sediment & $64 \%$ & 4,64 & 4284 & 69 & 78 & 9 \\
\hline Phaeobacter gallaeciensis $2.10^{*}$ & mar./ass. & Algen & $60 \%$ & 4,16 & 3875 & 16 & 69 & 4 \\
\hline Phaeobacter gallaeciensis DSM17395* & mar./pel. & Fischkultur & $60 \%$ & 4,23 & 3875 & 16 & 69 & 10 \\
\hline Phaeobacter inhibens T5 & mar./pel. & Freiwasser & $60 \%$ & 4,13 & 3884 & 39 & 63 & 7 \\
\hline Phaeobacter sp. Y4I & mar./pel. & Freiwasser & $64 \%$ & 4,34 & 4132 & 1 & 69 & 13 \\
\hline ,Ca. Planktomarina temperata' RCA23* & mar./pel. & Freiwasser & $54 \%$ & 3,29 & 3053 & 1 & 47 & 20 \\
\hline Rhodobacteraceae sp. AzwK-3b & mar./pel. & Freiwasser & $62 \%$ & 4,18 & 4145 & 0 & 52 & 37 \\
\hline Rhodobacteraceae sp. HTCC2083 & mar./pel. & Freiwasser & $53 \%$ & 4,02 & 4177 & 2 & 47 & 32 \\
\hline Rhodobacteraceae sp. HTCC 2150 & mar./pel. & Freiwasser & $49 \%$ & 3,58 & 3667 & 0 & 46 & 4 \\
\hline Rhodobacteraceae sp. HTCC2255 & mar./pel. & Freiwasser & $39 \%^{\mathrm{b}}$ & $4,81^{b}$ & $4507^{b}$ & 0 & $86^{b}$ & 18 \\
\hline Rhodobacteraceae sp. MED193 & mar./pel. & Freiwasser & $57 \%$ & 4,65 & 4535 & 0 & 70 & 15 \\
\hline Rhodobacteraceae sp. R2A57 & mar./pel. & Freiwasser & $51 \%$ & 4,14 & 4386 & 0 & 43 & 16 \\
\hline Rhodobacteraceae sp. SK209-2-6 & mar./pel. & Freiwasser & $57 \%$ & 4,56 & 4537 & 0 & 73 & 20 \\
\hline Roseobacter denitrificans OCh $114^{*}$ & mar./ass. & Algen & $59 \%$ & 4,33 & 4129 & 17 & 55 & 8 \\
\hline Roseobacter litoralis Och $149^{*}$ & mar./ass. & Algen & $57 \%$ & 4,75 & 4537 & 0 & 40 & 14 \\
\hline Roseovarius nubinhibens ISM & mar./pel. & Freiwasser & $64 \%$ & 3,67 & 3547 & 0 & 58 & 2 \\
\hline Roseovarius sp. 217 & mar./pel. & Freiwasser & $61 \%$ & 4,76 & 4772 & 0 & 51 & 23 \\
\hline Roseovarius sp. TM1035 & mar./ass. & Dinoflagellat & $61 \%$ & 4,21 & 4102 & 0 & 56 & 9 \\
\hline Ruegeria lacuscaerulensis ITI-1157 & mar./pel. & Freiwasser & $63 \%$ & 3,52 & 3608 & 3 & 63 & 14 \\
\hline Ruegeria pomeroyi DSS-3* & mar./pel. & Freiwasser & $64 \%$ & 4,60 & 4252 & 31 & 72 & 5 \\
\hline Ruegeria sp. KLH11 & mar./ass. & Schwamm & $58 \%$ & 4,49 & 4269 & 5 & 64 & 24 \\
\hline Ruegeria sp. TM1040 & mar./pel. & Freiwasser & $60 \%$ & 4,15 & 3864 & 6 & 94 & 7 \\
\hline Ruegeria sp. TrichCH4B & mar./pel. & Freiwasser & $59 \%$ & 4,69 & 4734 & 1 & 79 & 20 \\
\hline Ruegeria conchae TW15 & mar./ass. & Muscheln & $56 \%$ & 4,49 & 4380 & 0 & 45 & 8 \\
\hline Sagittula stellata E-37 & mar./pel. & Freiwasser & $65 \%$ & 5,26 & 5067 & 0 & 54 & 17 \\
\hline Sulfitobacter sp. EE-36 & mar./pel. & Freiwasser & $60 \%$ & 3,55 & 3474 & 0 & 68 & 11 \\
\hline Sulfitobacter sp. GAI101 & mar./pel. & Freiwasser & $59 \%$ & 4,53 & 4202 & 1 & 55 & 15 \\
\hline Sulfitobacter sp. NAS-14.1 & mar./pel. & Freiwasser & $60 \%$ & 4,00 & 3962 & 0 & 64 & 23 \\
\hline Thalassiobium sp. R2A62 & mar./pel. & Freiwasser & $55 \%$ & 3,49 & 3696 & 0 & 48 & 34 \\
\hline Wenxinia marina DSM 24838 & mar./ass. & Sediment & $71 \%$ & 4,18 & 4045 & 0 & 59 & 10 \\
\hline
\end{tabular}

$\mathrm{Mb}=$ Megabase; TEs = transposable Elemente; mar. = marin; terr. = terrestrisch; pel. = pelagisch; ass. $=$ assoziiert mit Partikeln/Eukaryoten

a tRNA- und rRNA-Gene; $\quad{ }^{\mathrm{b}}$ Genomsequenz weist Kontaminationen durch E.coli auf; $\quad$ * Genomsequenz vollständig geschlossen und überprüft (finished + polished) 
Um mögliche Zusammenhänge zwischen Genomeigenschaften und Habitat aufzuzeigen, wurden die Genome anhand der prinzipiellen Lebensweise der entsprechenden Organismen gruppiert und verglichen (Abb. 5). Hierbei wurde unterschieden zwischen marinen Organismen welche mit Partikeln bzw. Eukaryoten assoziiert sind, marinen Organismen mit pelagischer Lebensweise (Organismen des Freiwassers) und terrestrischen Organismen.
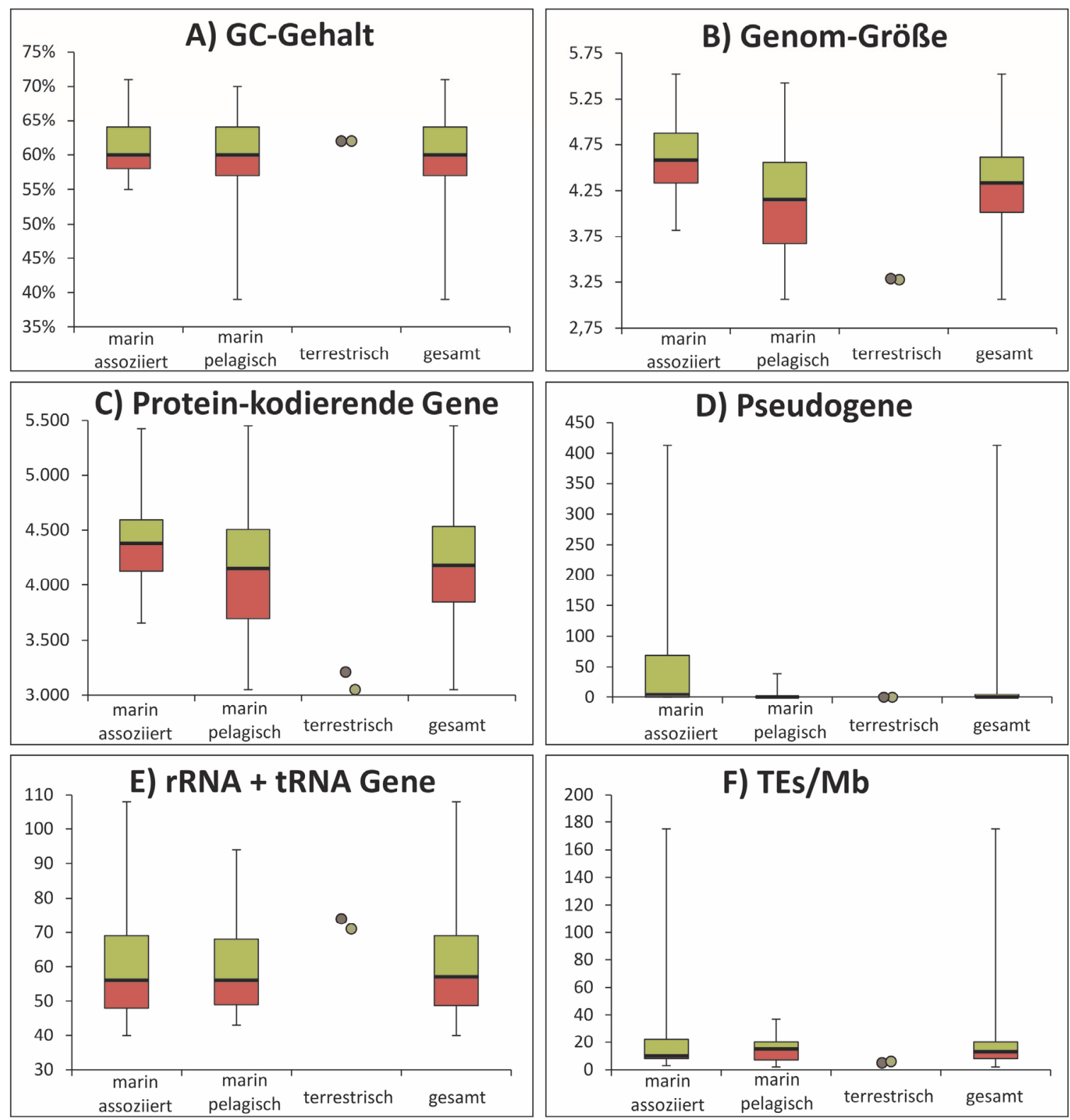

Oberes Quartil

Unteres Quartil

\section{Median I Minimal-/Maximalwerte}

Abb. 5 Genomeigenschaften von Roseobacter-Vertretern mit unterschiedlicher Lebensweise

Die Verteilung der Werte für GC-Gehalt (A), Genomgröße (B), Anzahl kodierender Gene (C), Anzahl Pseudogene (D), Anzahl an RNA Genen (E) und Dichte an TEs (F) innerhalb der Roseobacter-Gruppe ist jeweils als Boxplot dargestellt. Die Vergleichsorganismen wurden gruppiert nach prinzipieller Lebensweise (marin assoziiert, marin pelagisch und terrestrisch). Zusätzlich ist für jeden Vergleichswert eine Übersicht der gesamten Roseobacter-Gruppe angegeben. Abgesehen von den terrestrischen Vertretern sind die Verteilungen der Vergleichswerte als Boxplots dargestellt. Da nur zwei terrestrische Vertreter zur Verfügung standen, sind die entsprechenden Werte durch Punkte dargestellt. Dunkle Punkte repräsentieren K. vulgare Y25, helle Punkte $K$. vulgare WSH-100. 
Tendentiell scheinen marine Roseobacter-Vertreter mit eukaryoten- bzw. partikelassoziierter Lebensweise im Vergleich zu pelagischen Vertretern einen etwas erhöhten Anteil an Pseudogenen zu besitzen. (Abb. 5D). Deutlichere Unterschiede treten jedoch in Bezug auf Genomgröße und Gen-Gehalt auf (Abb. 5B+C). Diese Werte liegen bei marinen RoseobacterVertretern mit assoziierter Lebensweise im Durchschnitt höher als bei pelagischen Vertretern.

\subsubsection{Core- und Pangenom}

Die Gesamtheit aller Gene aller Mitglieder einer Organismen-Gruppe wird als das Pangenom dieser Gruppe bezeichnet (Tettelin et al. 2008). Das Pangenom lässt sich wiederum differenzieren in das Core-Genom, welches aus Genen besteht, die ausnahmslos in allen Vertretern der Gruppe zu finden sind, und in das flexible Genom (auch als „entbehrliches“ Genom bezeichnet; Medini et al. 2005), welches alle übrigen Merkmale beinhaltet (Hacker \& Carniel 2001). Das Octadecabacter-Pangenom, bestehend aus der Summe aller Gene der beiden sequenzierten Octadecabacter-Stämme (siehe 2.9) umfasst 9175 Proteinkodierende Gene. Für ungefähr 76\% dieser Gene konnten durch reziproke BLAST-Analysen (siehe 2.10.3) Orthologe in mindestens einem Roseobacter-Vertreter außerhalb des Genus Octadecabacter nachgewiesen werden. In der überwiegenden Zahl (85\%) dieser Fälle besaßen die Orthologe zudem hohe Sequenzidentitäten von über $60 \%$, was auf nahe Verwandtschaft und erhöhte Wahrscheinlichkeiten für identische Funktion schließen lässt. In den übrigen Fällen könnten orthologe Genprodukte in den Vergleichsstämmen durch Mutation und genetische Drift abweichende Funktionen erlangt haben. Zusammensetzung und Anzahl der entsprechenden Orthologe variierten sehr stark zwischen den verschiedenen Roseobacter-Vertretern. In direkten Vergleichen teilen die einzelnen Vergleichsstämme nur 32-50\% des OctadecabacterPangenoms. Die geringste Zahl an Orthologen wiesen die Vertreter der terrestrischen Art Ketogulonicigenium vulgare auf, während die höchste im Genom von Roseobacter litoralis zu finden war.

Das Roseobacter-Core-Genom, nimmt nur einen kleinen Teil (ca. 16\%) des OctadecabacterPangenoms ein. Im Gegensatz dazu macht das Octadecabacter Core-Genom ungefähr 59\% der proteinkodierenden Gene beider Stämme aus. Jedoch ist nur ein Bruchteil (ca. 2\%) dieser Gene ausschließlich spezifisch für den Genus Octadecabacter.

Für 1091 proteinkodierende Gene in O. arcticus und 892 in O. antarcticus konnten keine reziproken besten Blasthits ermittelt werden. Solche vermeintlich einzigartigen Gene werden 
als singletons bezeichnet. Diese beinhalten jedoch auch viele Paraloge von TE-assoziierten Genen, denen zwar keine bidirektionalen besten Treffer zugeordnet werden konnten, welche aber dennoch prinzipiell auch in anderen Roseobacter-Stämmen nah verwandte Homologe aufweisen (siehe 3.2.2.2). Zieht man TE-assoziierte Gene von den durch reziproke BLASTAnalysen ermittelten singletons ab, so bleiben nur noch 83 dieser Gene in O. arcticus und 689

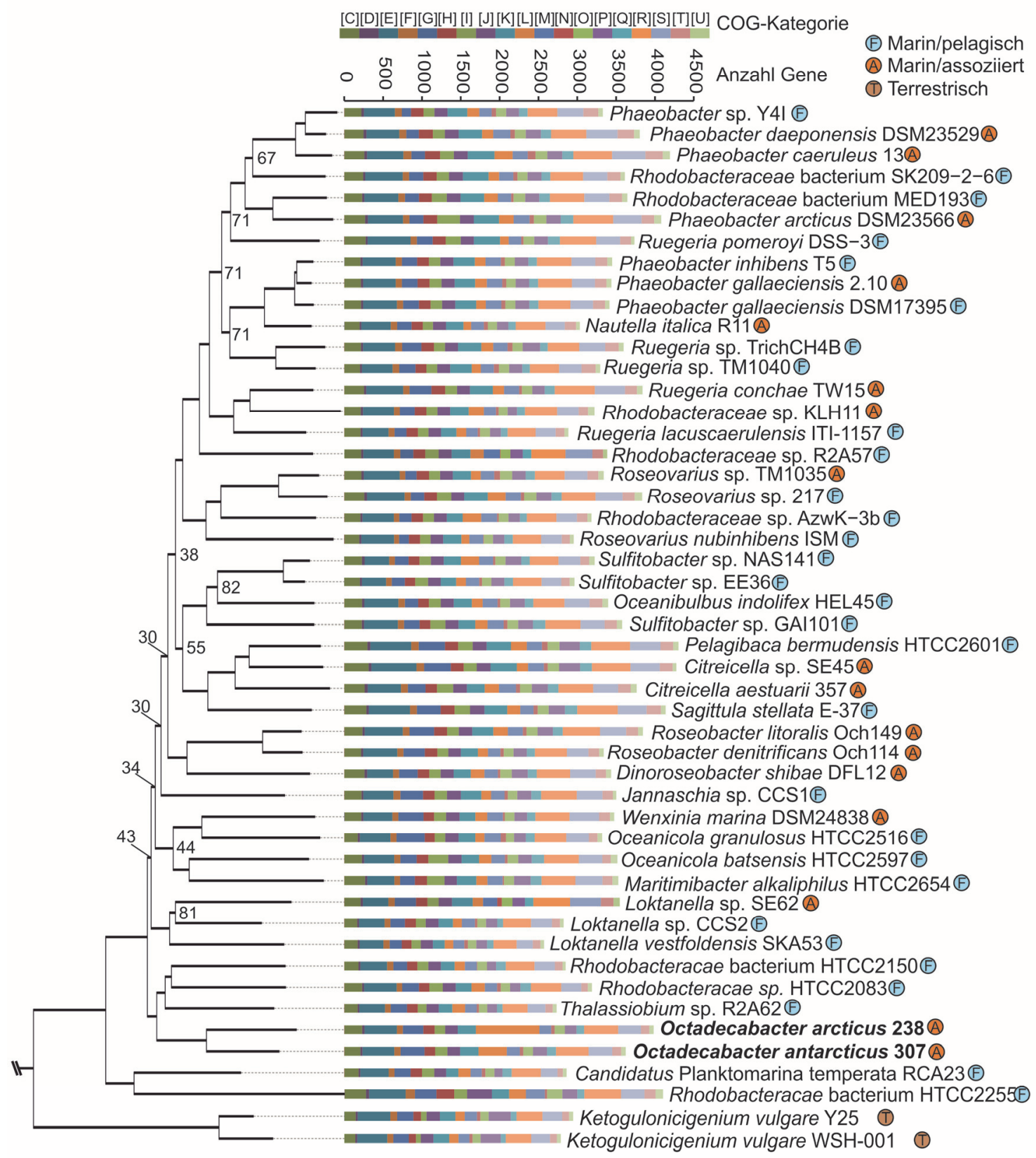

Abb. 6 Neighbor-Joining Baum basierend auf der Gen-Ausstattung (gene content) von RoseobacterVertretern mit Darstellung der entsprechenden COG-Kategorien

Dargestellt ist ein Neighbor-Joining-Baum basierend auf unterschiedlicher Orthologenzusammensetzung (siehe 2.10.5). Nur Bootstrap-Werte unter 90\% sind angegeben. Für jeden Vergleichsorganismus sind die absoluten Anteile an Genen verschiedener COG-Kategorien (siehe Tab. 3, 2.9.3) als Balkendiagramm angegeben. die entsprechenden COG-Kategorien sind der Farblegende in der Abbildung zu entnehmen. Zusätzlich ist die grundsätzliche Lebensweise (marin/pelagisch, marin/assoziiert, terrestrisch) für jeden Organismus angegeben. 
in O. antarcticus übrig. Das entspricht jeweils einem Anteil von 8\% des Genoms von O. arcticus und $15 \%$ von O. antarcticus. Hierbei handelt es sich größtenteils um hypothetische Gene unbekannter Funktion. Sämtliche der oben genannten Werte beziehen sich auf reziproke BLAST Analysen die von den Octadecabacter-Genomen als Referenzen ausgingen. Entsprechende Analysen wurden zusätzlich von jedem Vergleichsorganismus ausgehend wiederholt (Tab. DA03-DA53, digitaler Anhang). Anhand dieser Ergebnisse wurde eine Distanzmatrix der Vergleichsorganismen erstellt (siehe 2.10.5), um Clusteranalysen bezüglich der jeweiligen genomischen Ausstattung durchführen zu können (Abb. 6).Vergleiche der Zusammensetzung an Genen unterschiedlicher Cluster of Orthologeous Groups (COG)-Kategorien sind ebenfalls in Abb. 6 dargestellt.

Gene content Analysen erlauben einen über phylogenetischen Beziehungen hinausgehenden Rückschluss auf ähnliche oder unterschiedliche Lebensweisen von Vergleichsorganismen (Newton et al. 2010). Demnach weisen die beiden Meereis-Organismen O. arcticus 238 und O. antarcticus 307 untereinander eine höhere Übereinstimmung in ihrer genomischen Ausstattung auf, als zu anderen Roseobacter-Vertretern. Darüber hinaus bilden die Octadecabacter-Vertreter in Bezug auf ihre Genausstattung eine zusammenhängende Gruppe mit den Organismen Thalassiobium sp. R2A62, Rhodobacteraceae sp. HTCC283 und Rhodobacteraceae sp. HTCC2150. Beide Octadecabacter-Vertreter weisen einen überdurchschnittlich hohen Anteil an Genen der COG-Kategorie L (Replikation, Rekombination und Reparatur) auf. Dies liegt vor allem an der hohen Zahl an transposablen Elementen in diesen Organismen. Allerdings sind auch zahlreiche Gene UV-induzierter DNA-Reperaturmechanismen vorhanden, welche ebenfalls in diese Kategorie fallen. Da Gene der COGKategorie L vor allem im Genom von $O$. arcticus überrepräsentiert sind, scheinen die prozentualen Anteile der meisten anderen COG-Kategorien in diesem Organismus im Vergleich zu O. antarcticus deutlich erniedrigt zu sein (Abb. 7). Die absoluten Anteile der meisten COGKategorien sind jedoch in beiden Octadecabacter-Vertretern sehr ähnlich (Abb. 6).

Der Anteil an Genen der COG-Kategorie G (Kohlenhydrat-Stoffwechsel) ist in beiden Octadecabacter-Stämmen im Vergleich zu den meisten anderen Roseobacter-Vertretern etwas erhöht. Die prozentualen Anteile an Genen der COG-Kategorien C (Energiestoffwechsel), H (Coenzym-Stoffwechsel), M (Zellwandsynthese) und T (Signaltransduktion) liegen dagegen in beiden Octadecabacter-Vertretern unterhalb des Roseobacter-Durchschnitts. Innerhalb der marinen Roseobacter-Vertreter zweigen „Ca. planktomarina temperata“ RCA23 und Rhodobacteraceae sp. HTCC2255 am weitesten ab. Wie zu erwarten, zweigen die beiden terrestrischen Roseobacter-Vertreter K. vulgare Y25 und K. vulgare WSH-001 in Bezug auf 
ihre Genomausstattung tief von den übrigen (marinen) Vertretern ab (Abb. 6). Beispiele für diese Unterschiede sind geringere prozentuale Anteile an Genen der COG-Kategorien Energie-, Coenzym- und Lipidstoffwechsel sowie erhöhte Anteile an Genen der Kategorien Ionentransport sowie Aminosäure- und Nukleotidstoffwechsel (Abb. 7).

Deutliche Unterschiede zwischen pelagischen und partikel- bzw. wirtsgebundenen (assoziierten) Vertretern ergaben sich vor allem in Bezug auf die COG-Kategorien G und T, welche in pelagischen Roseobacter-Vertretern weniger stark repräsentiert sind als in assoziierten, und in Bezug auf die Kategorien I und $\mathrm{J}$, welche in assoziiert lebenden Roseobacter-Vertretern weniger stark repräsentiert sind als in pelagischen.

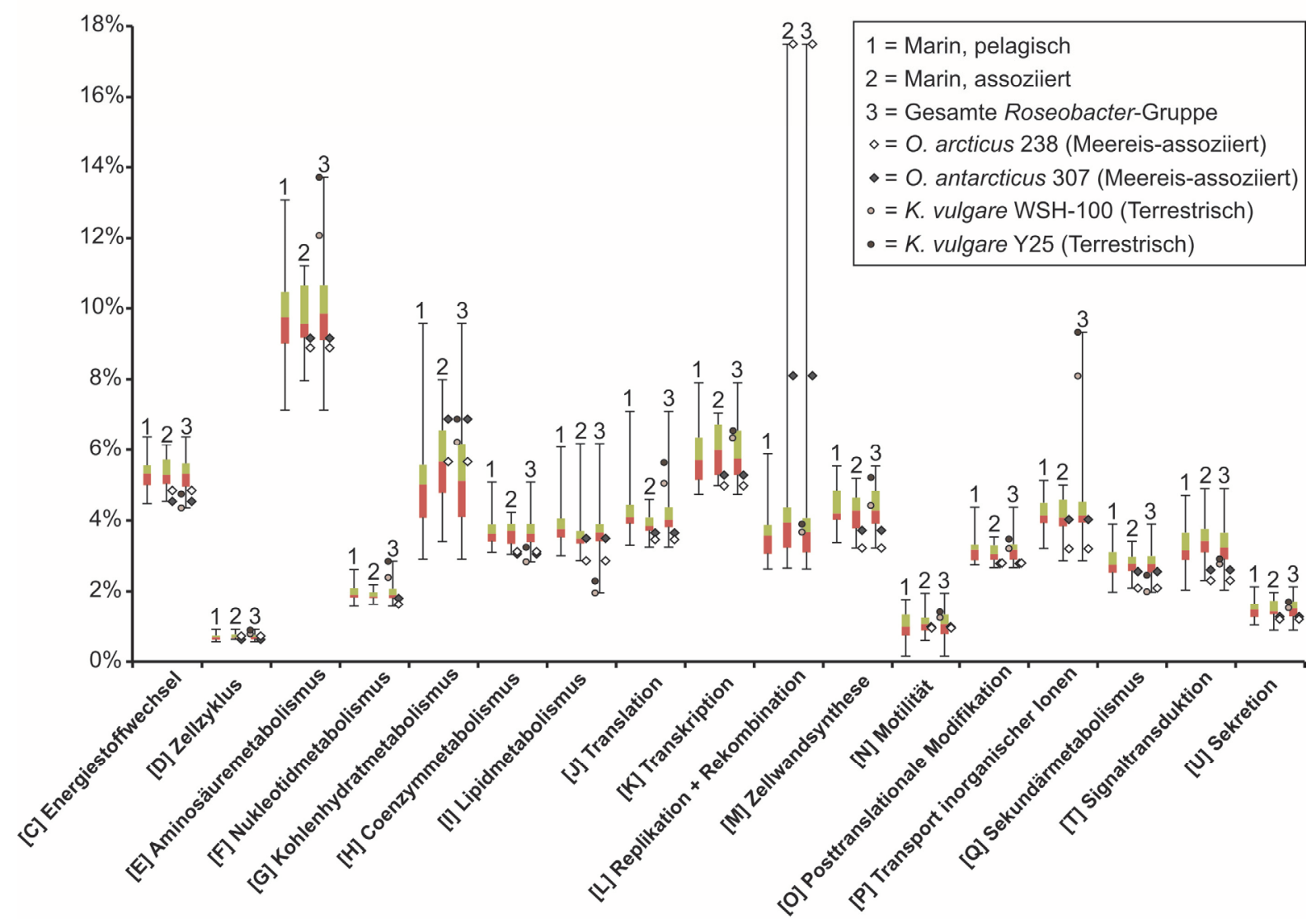

Abb. 7 Anteile an Genen verschiedener COG-Kategorien in Roseobacter-Vertretern unterschiedlicher Lebensweise

Die Schwankungsbereiche der Anteile an Genen (in \%) verschiedener COG-Kategorien (siehe 2.9.3) in den Genomen pelagisch (1) und assoziiert lebender (2) mariner Roseobacter-Vertreter sowie der gesamten Roseobacter-Gruppe (3) sind jeweils als Boxplots dargestellt. Zusätzlich sind die entsprechenden Werte der Octadecabacter-Vertreter als Rauten, und die der terrestrischen Ketogulonicigenium Vertreter als Kreise dargestellt. 


\subsubsection{Phylogenie}

\subsubsection{Multilokus Sequenzanalysen (MLSA)}

Multilokus Sequenzanalyse (MLSA) ist eine Methode zur phylogenetischen Differenzierung nah verwandter Organismen, basierend auf multiplen phylogenetischen Markern (Martens et al. 2008). Typischerweise werden hierfür Sequenzen mehrerer meist proteinkodierender Gene, welche in allen Vergleichsorganismen jeweils genau ein Ortholog aufweisen, konkateniert. Proteinkodierende Gene sind in der Regel weniger stark konserviert als rRNA-Gene (Palys, Nakamura \& Cohan 1997; Palys et al. 2000). Daher wird durch diesen Ansatz eine höhere phylogenetische Auflösung erreicht als durch die Verwendung von 16S rRNA-Gensequenzen (Thompson et al. 2005). Durch Verwendung vieler unterschiedlicher Marker wird zudem die hohe Variabilität von proteinkodierenden Sequenzen ausgeglichen und die Zuverlässigkeit der resultierenden Stammbäume erhöht. Die Kenntnis des Core-genoms der Roseobacter Gruppe (siehe 3.1.1) ermöglichte es, die maximale Zahl geeigneter Marker für phylogenetische Untersuchungen basierend auf MLSA heranzuziehen, wobei Escherichia coli K-12 MG1655 sowie Parvarcula bermudensis HTCC2503 als Referenzen dienten (siehe 2.10.7).

Es wurde ein Satz von 166 Genen pro Organismus ermittelt, welche in jedem der Vergleichsorganismen einzigartige Orthologe aufwiesen. Die konkatenierten Aminosäure-alignments der entsprechenden Genprodukte resultierten in einem soliden Neighbor-Joining Stammbaum, dessen Verzweigungen hohe Bootstrap-Werte aufwiesen und größtenteils durch MaximumLikelihood-Berechnungen reproduzierbar waren (Abb. 8). Der Stammbaum bestätigt und erweitert die Ergebnisse von Newton et al. (2010), welche auf einer kleineren Gruppe aus 32 Roseobacter-Genomen und nur 69 ausgewählten Proteinsequenzen basierten. Demnach lassen sich die sequenzierten Roseobacter-Vertreter prinzipiell in fünf Untergruppen einteilen, wobei die Octadecabacter-Stämme in Untergruppe 4 fallen. Im Vergleich zu Newton et al., welche dieser Gruppe neben den Octadecabacter-Stämmen auch Loktanella vestfoldensis SKA53, Loktanella sp. CCS2 sowie Oceanicola granulosus zurechneten, konnten fünf weitere Vertreter dieser Gruppe zugewiesen werden: Loktanella sp. SE62, Thalassiobium sp. R2A62, Wenxinia marina DSM24838 und interessanterweise die beiden terrestrischen Ketogulonicigenium vulgare Stämme WSH-001 und Y25. Die beiden K. vulgare Stämme zweigen innerhalb der Untergruppe 4 tief ab, bilden aber dennoch ein stabiles Cluster gemeinsam mit W. marina DSM 24838 und O. granulosus HTCC2516. 
Insgesamt konnten den durch Newton et al. beschriebenen Untergruppen vierzehn neue Vertreter zugewiesen werden, wodurch sich neue Sequenzcluster abzeichnen, ohne die Integrität der Untergruppen grundsätzlich zu verändern (Abb. 8). Es gibt lediglich eine Abweichung in Bezug auf Rhodobacteraceae sp. HTCC2083, welcher anhand der neuen

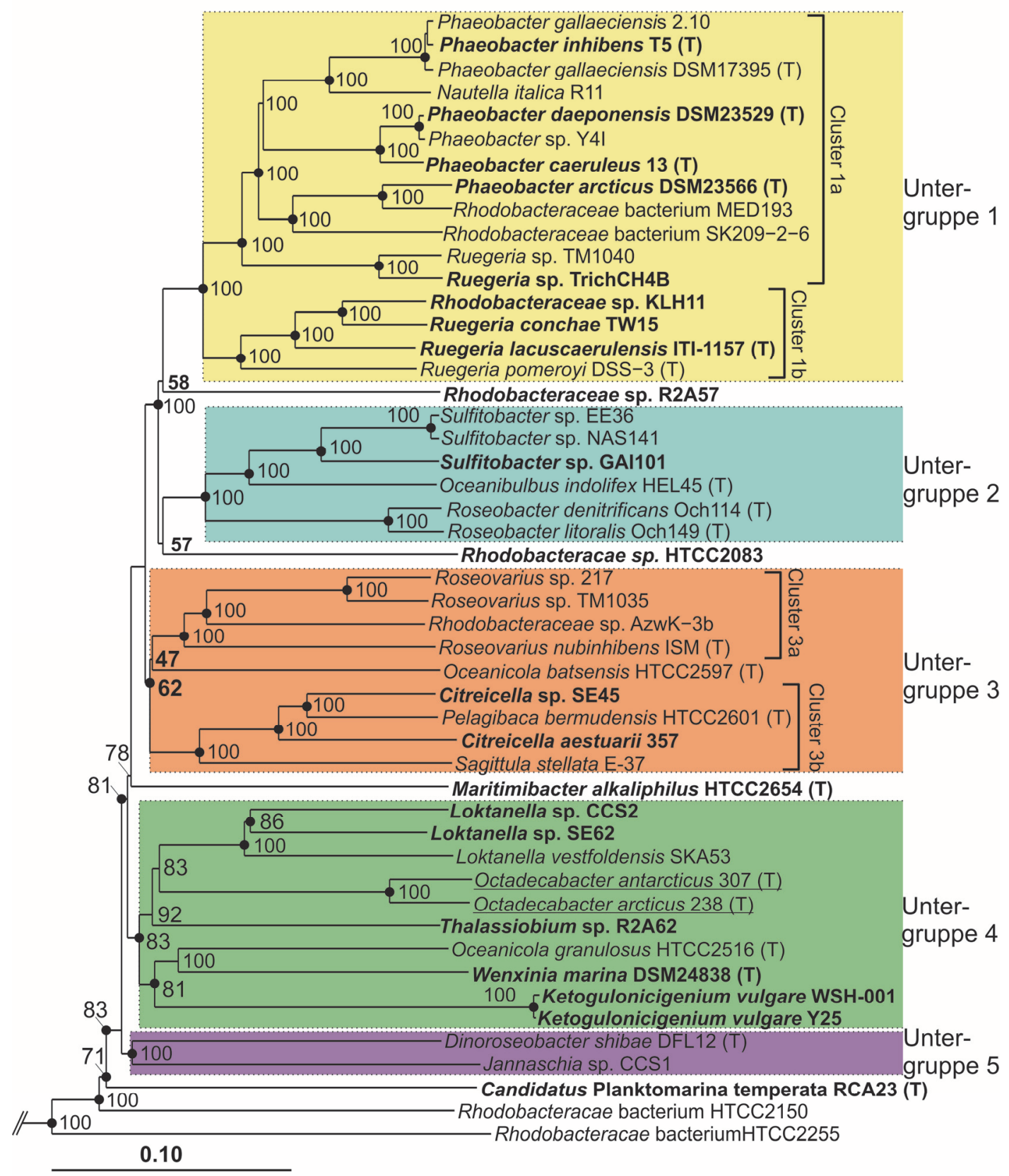

Abb. 8 MLSA-basierte Phylogenie der Roseobacter-Gruppe

Dargestellt ist ein Neighbor-Joining Baum aus konkatenierten Aminosäure-Sequenzen von 166 Genprodukten, welche in allen Roseobacter-Genomen sowie den Referenzen E. coli K12 MG1655 und P. bermudensis HTCC2503 Orthologe, aber keine Paraloge aufwiesen. Für sämtliche Verzweigungen sind Bootstrap-Werte angegeben. Verzweigungen, welche sich durch Maximum-Likelihood Berechnungen reproduzieren ließen, sind durch schwarze Punkte gekennzeichnet. Die ursprünglich durch Newton et al. (2010) definierten RoseobacterUntergruppen sind farblich hinterlegt und beschriftet. Darüber hinaus wurden in Untergruppen 1 und 3 stabile Subcluster identifiziert und ebenfalls beschriftet. Organismen welche frühere Analysen von Newton et al. ergänzen oder deutlich von ihnen abweichen sind fett beschriftet. Typenstämme sind durch $(\mathrm{T})$ markiert. Als outgroup diente E. coli K12 MG1655. 
Daten, im Gegensatz zu Newton et al., nicht zweifelsfrei der Untergruppe 2 zugeordnet werden kann. Die entsprechende Verzweigung des Stammbaums weist einen vergleichsweise niedrigen Bootstrap-Wert von 57\% auf und ist nicht durch Maximum-LikelihoodBerechnungen reproduziert worden. Untergruppen 1 und 3 lassen sich jeweils in zwei eindeutige Sequenzcluster $(1 \mathrm{a}+1 \mathrm{~b}$ bzw. $3 \mathrm{a}+3 \mathrm{~b})$ unterteilen. Cluster 1a besteht hauptsächlich aus Vertretern des Genus Phaeobacter, beinhaltet jedoch auch Nautelle italica R11 sowie die Bakterienstämme TM1040 und TrichCH4B, welche bislang dem Genus Ruegeria zugeordnet wurden. Die Typstämme der beiden Ruegeria-Arten $R$. lacuscaerulensis und $R$. pomeroyi fallen jedoch in das deutlich abzugrenzende Cluster 1b. Im Gegensatz zu den übrigen Untergruppen weist Untergruppe 3 einen relativ niedrigen Bootstrap-Wert von $62 \%$ auf. Die Integrität dieser Untergruppe wird jedoch durch Maximum-Likelihood-Berechnungen unterstützt. Die Zugehörigkeit von Oceanicola batsensis zu Cluster 3a ist jedoch aufgrund des sehr niedrigen Bootstrap-Wertes von $47 \%$ unsicher.

Die Organismen Rhodobacteraceae sp. R2A57, Rhodobacteraceae sp. HTCC2083 und Maritimibacter alkaliphilus HTCC2654 bilden zwischen den Untergruppen 1-4 eigene Abzweigungen. Sie sind demnach mit diesen Untergruppen relativ nah verwandt, auch wenn sie keiner von ihnen eindeutig zugewiesen werden können. Im Gegensatz hierzu fällt „Candidatus Planktomarina temperata“ RCA23, ebenso wie die noch unklassifizierten Rhodobacteraceae-Stämme HTCC2150 und HTCC2255, nicht in die Nähe der übrigen Roseobacter-Vertreter. Somit weichen diese Organismen auf Proteinsequenz-Ebene erheblich von den übrigen Roseobacter-Vertretern ab.

\subsubsection{16S + 23S rRNA-Gensequenzvergleiche}

Um die durch Multilokus Sequenzanalysen ermittelten Verwandtschaftsverhältnisse (siehe 3.1.3.1) mit Ergebnissen traditioneller rRNA-basierter Phylogenie in Relation setzen zu können, wurden die verfügbaren $16 \mathrm{~S}$ und 23S rRNA-Gensequenzen der Vergleichsstämme für weitere Stammbaumberechnungen herangezogen. Basierend auf ribosomalen RNAGensequenzen berechnete phylogenetische Stammbäume (Abb. 9) wurden zu großen Teilen ähnliche Verwandtschaftsverhältnisse ermittelt wie durch Multilokus Sequenzanalysen (siehe 3.1.3.1), allerdings mit geringeren Bootstrap-Werten.

Untergruppen 1 und 2, sowie die Cluster $1 \mathrm{a}$ und $1 \mathrm{~b}$ sind auf rRNA-Gensequenzebene rekonstruierbar. Die übrigen Untergruppen zeigen auf rRNA Sequenzebene allerdings eine 

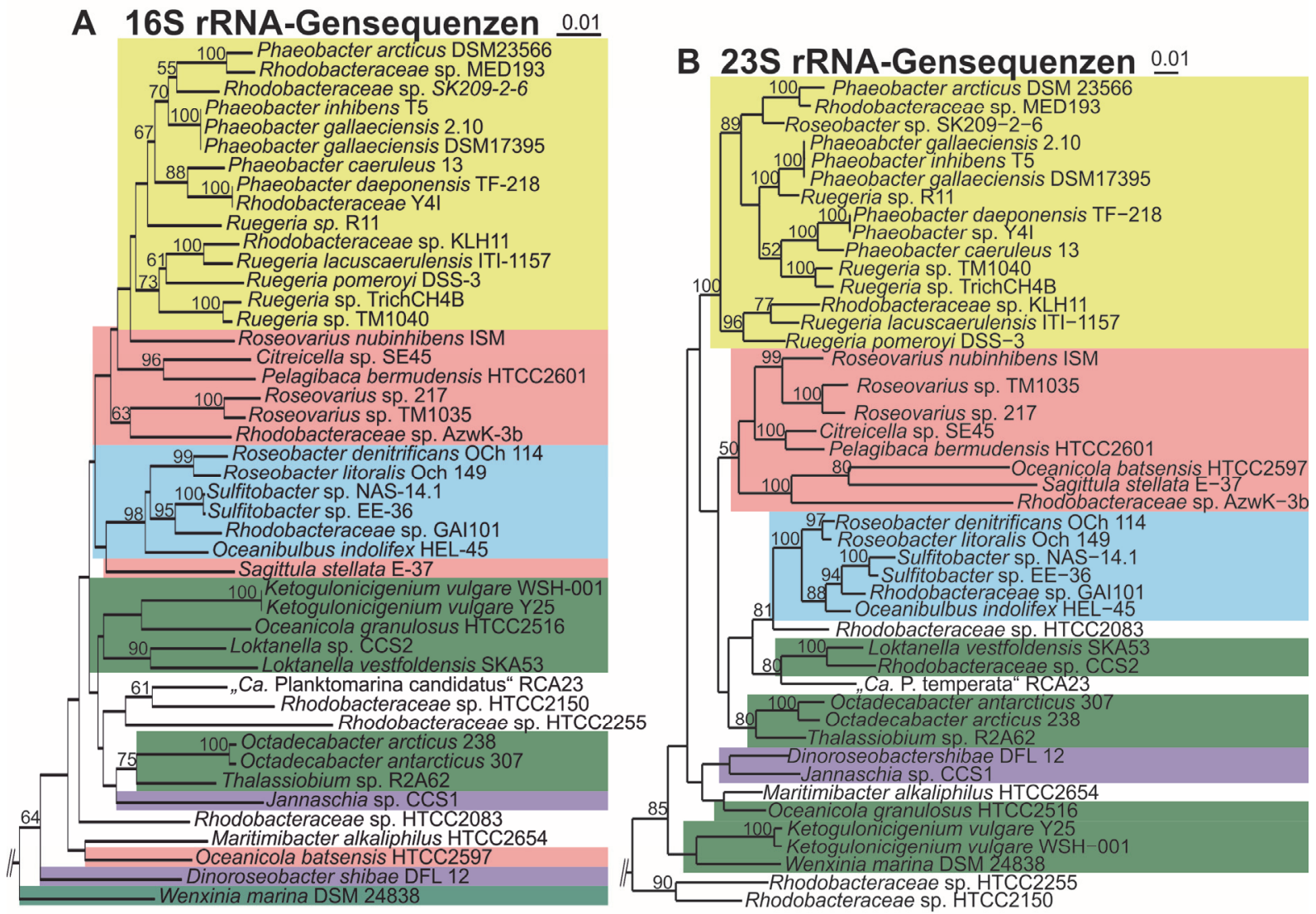

Untergruppe (MLSA-basiert):

\section{Abb. 9 Phylogenetische Stammbäume basierend auf rRNA-Gensequenzen}

Die dargestellten Bäume wurden mittels des Neighbor-Joining Algorithmus berechnet. Bootstrap-Werte über $50 \%$ sind an den entsprechenden Verzweigungen angegeben. A) Stammbaum basierend auf $16 \mathrm{~S}$ rRNAGensequenzen. B) Stammbaum basierend auf 23S rRNA-Gensequenzen. Als outgroup diente jeweils E. coli K12 MG1655. Zugehörigkeit zu MLSA-basierten Roseobacter-Untergruppen (siehe 3.1.3.1) ist durch entsprechende Farbmarkierung gekennzeichnet.

deutlich erhöhte Heterogenität. Dies gilt in besonderem Maße für die Mitglieder von Untergruppe 3, welche in den auf $16 \mathrm{~S}$ und $23 \mathrm{~S}$ rRNA-Gensequenzen basierenden Stammbäumen mit niedrigen Bootstrap-Werten stellenweise weit verteilt sind. Die Beziehungen innerhalb der Untergruppe 4 waren insoweit rekonstruierbar, dass die Octadecabacter-Stämme in rRNA-Gensequenzbasierten Stammbäumen (Abb. 9a+b), ebenso wie im MLSA-Stammbaum (Abb. 8), eine nahe Verwandtschaft zu Thalassobium sp. R2A62 und eine etwas entferntere Verwandtschaft zu Loktanella-Vertretern aufweisen. Nicht rekonstruierbar war jedoch die Zusammengehörigkeit dieser Vertreter mit K. vulgare, W. marina und O. granulosus. Untergruppe 5, bestehend aus Dinoroseobacter shibae DFL 12 und Jannaschia sp. CCS1, konnte auf Basis von 23S rRNA-Gensequenzen zuverlässig rekonstruiert werden (Bootstrap $>70 \%$, Abb. 9a), nicht jedoch auf Basis von 16S rRNAGensequenzen (Abb. 9b). 
„Ca. Planktomarina temperata“ RCA23 sowie Rhodobacteraceae sp. HTCC2150 und HTCC2255 zeigen auf rRNA-Sequenzebene eine deutlich geringere Divergenz zu den übrigen Roseobacter-Vertretern als auf MLSA-Ebene. Insbesondere „Ca. P. temperata, RCA23 zeigt auf rRNA-Ebene relativ nahe Verwandtschaften zu Octadecabacter, Loktanella und Thalassiobium.

\subsubsection{Vergleiche auf Basis der Gesamtgenomsequenzen}

Als Vergleichswerte zur Bestimmung der Sequenzähnlichkeiten von Vergleichsorganismen auf Gesamtgenomebene wurden BLAST-basierte durchschnittliche Nukleotididentitäten (Average nucleotide identity based on BLAST, ANIb) sowie Korrelationskoeffizienten der Tetramerzusammensetzungen der Vergleichsstämme herangezogen (siehe 2.10.6). Diese Werte können analog zu den bislang üblichen DNA/DNA-Hybridisierungswerten (Wayne et al. 1987) genutzt werden, um Art-Zugehörigkeiten zu ermitteln (Richter \& Rosselló-Móra 2009). Die Vergleichswerte wurden, wie in Math\&Meth beschrieben, Clusteranalysen unterzogen (Abb. 10). ANIb-Werte von über 96\% bzw. Tetramer-Korrelationskoeffizienten von über 0,999 deuten darauf hin, dass es sich bei den Vergleichs-Organismen um dieselbe Spezies handelt (Richter \& Rosselló-Móra 2009). Solche Fälle sind in Abb. 10 durch rote Umrandung markiert und im Folgenden aufgelistet. Sämtliche Ähnlichkeitswerte sind in Tab. DA54 und Tab. DA55 (digitaler Anhang) aufgeführt.

Wie zu erwarten, erfüllten die beiden K. vulgare Stämme WSH-001 und Y25 die Kriterien für gemeinsame Artzugehörigkeit. Des Weiteren sind Sulfitobacter sp EE-36 und Sulfitobacter sp. NAS-141 einer gemeinsamen Art zuzuordnen. Phaeobacter sp. Y4I ist aufgrund der hohen Ähnlichkeiten zu P. daeponensis DSM23529 der Art P. daeponensis zuzuordnen. Zwar erfüllt auch Phaeobacter caerulensis 13 auf Ebene der Tetranukleotid-Häufigkeiten das Kriterium für Artgleichheit mit Phaeobacter sp. Y4I (Abb. 10B), jedoch wird dies durch die Ergebnisse anderer phylogenetische Ansätze (Abb. 8, Abb. 9,Abb. 10A) nicht unterstützt. Überraschenderweise sind auch P.gallaeciensis DSM17395, P.gallaeciensis 2.10 und Phaeobacter inhibens $\mathrm{T} 5$ potentiell zu gemeinsamen Arten zusammenzufassen. Dies ist deshalb überraschend, weil es sich bei P. gallaeciensis DSM17395 und P. inhibens T5 um Typstämme zweier bereits beschriebener Arten handelt. Die beobachtete Artgleichheit wird jedoch auch durch entsprechend niedrige phylogenetische Distanzen auf MLSA- und rRNAGensequenzebene unterstützt (Abb. 8+Abb. 9). 
Der ANIb-basierte Stammbaum (Abb. 10A) spiegelt zu großen Teilen die durch MLSA ermittelten Verwandtschaftsverhältnisse (siehe 3.1.3.1) wider. Untergruppen 1 und 2 werden durch diesen Stammbaum vollständig rekonstruiert. Untergruppe 3 ist jedoch aufgespalten in die Cluster 3a und 3b sowie O. batsensis HTCC2597. Die größten Heterogenitäten weisen die Vertreter der Untergruppen 4 und 5 auf. Die auf Tetramer-Korrelationskoeffizienten basierende Clusterung (Abb. 10B) zeigt jedoch nur geringe Übereinstimmungen mit MLSAoder rRNA-Gensequenz-basierten Verwandtschaftsverhältnissen.
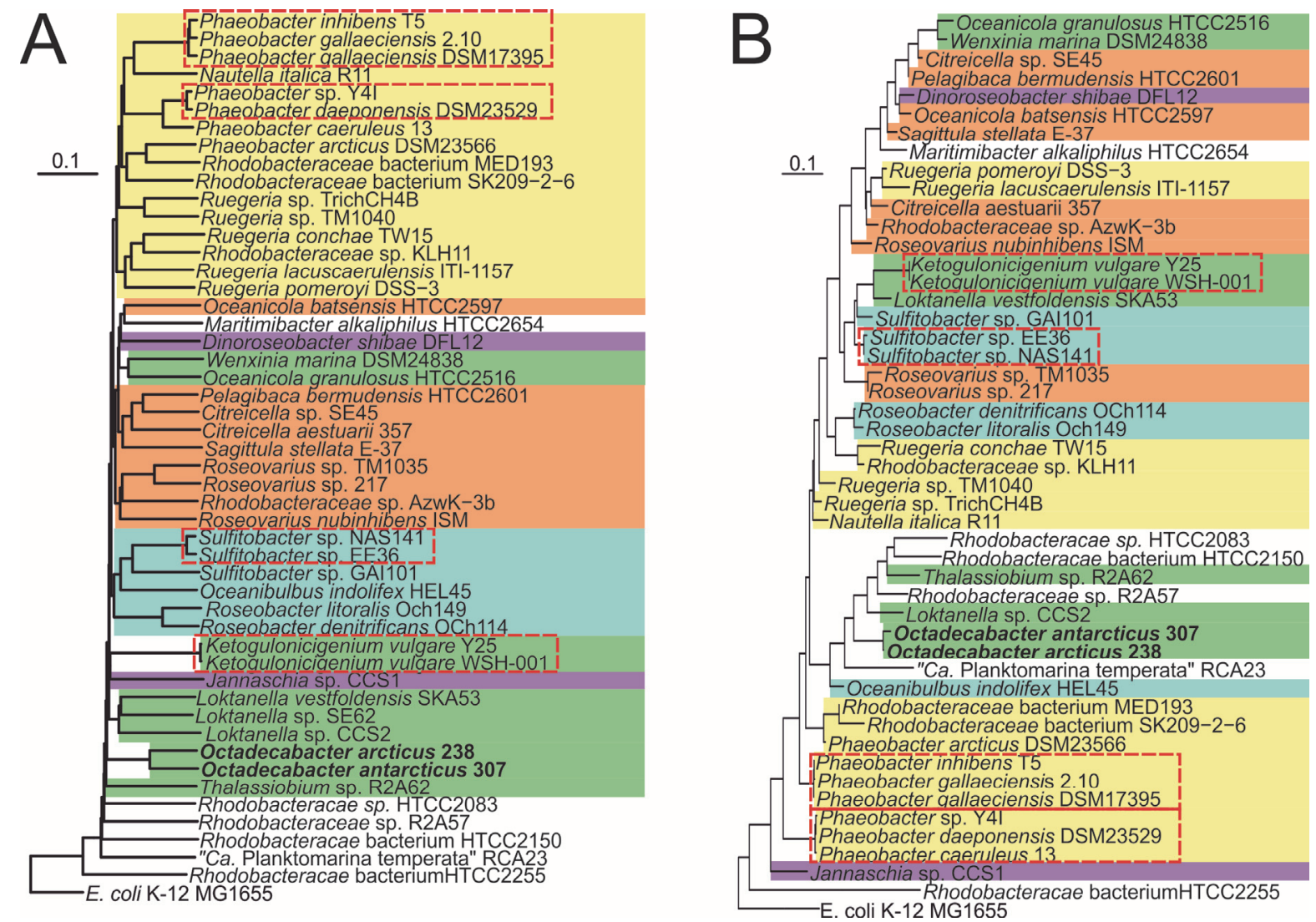

Abb. 10 Verwandtschaftsverhältnisse zwischen Roseobacter-Vertretern basierend auf Gesamtgenomvergleichen.

Abgebildet sind Neighbor-Joining Stammbäume basierend auf Distanzmatrizen, welche anhand der Ergebnisse von Analysen der Jspecies Software (www.imedea.uib.es/jspecies/) erstellt wurden (siehe 2.10.6). Organismen, welche Ähnlichkeitskriterien für Artgleichheit erfüllen (Richter \& Rosselló-Móra 2009), sind durch rote gestrichelte Linien umrandet. A) Stammbaum beruhend auf BLAST-basierten durchschnittlichen Nukleotididentitäten (ANIb). B) Stammbaum beruhend auf den Korrelationskoeffizienten der Tetranukleotid-häufigkeiten in den verschiedenen Vergleichsgenomen. 


\subsection{Spezielle Betrachtung des Genus Octadecabacter}

\subsubsection{Biogeographie des Genus Octadecabacter}

In arktischen sowie antarktischen Habitaten wurden Vertreter des Genus Octadecabacter bereits häufig in unabhängigen Studien nachgewiesen (Tab. 8), was darauf hindeutet, dass es sich um allochthone Vertreter der Polargebiete handelt. Die phylogenetischen Daten dieser Studien wurden genutzt, um den ungefähren Anteil an Octadecabacter-Vertretern in verschiedenen Standorten zu berechnen (Tab. 8). Dabei zeigte sich, dass die entsprechenden Schätzungen je nach Studie, Probenort und Untersuchungsmethode stark schwanken können.

Tab. 8 Anteile von Octadecabacter-Vertretern in polaren Habitaten

\begin{tabular}{|c|c|c|c|c|c|c|}
\hline $\begin{array}{l}\text { Polar- } \\
\text { Region }\end{array}$ & Habitat & Methode & $\begin{array}{c}\text { Anteil an } \\
\text { Gesamt- } \\
\text { population }\end{array}$ & $\begin{array}{c}\text { Anteil an } \\
\text { Proteobacteria }\end{array}$ & $\begin{array}{c}\text { Anteil an } \\
\text { Alpha- } \\
\text { proteobacteria }\end{array}$ & Referenz \\
\hline Arktis & Packeis & 16S-Genbank & $20 \%$ & $75 \%$ & $100 \%$ & $\begin{array}{c}\text { (Brown \& } \\
\text { Bowman } \\
\text { 2001) }\end{array}$ \\
\hline Arktis & Packeis & 16S-Genbank & $5-8 \%$ & $5-10 \%$ & $36-86 \%$ & $\begin{array}{l}\text { (Brinkmeyer } \\
\text { et al. 2003) }\end{array}$ \\
\hline Arktis & Packeis & 16S-Genbank & n.b. & $3 \%$ & $6 \%$ & $\begin{array}{l}\text { (Collins, } \\
\text { Rocap \& } \\
\text { Deming } \\
\text { 2010) }\end{array}$ \\
\hline Arktis & Packeis & $\begin{array}{c}\text { 16S-Amplikon- } \\
\text { Sequenzierung (454) }\end{array}$ & $2,2 \%$ & $3,3 \%$ & $57 \%$ & $\begin{array}{l}\text { (Bowman et } \\
\text { al. 2012) }\end{array}$ \\
\hline Arktis & Packeis & Isolate & $9 \%$ & $15 \%$ & $100 \%$ & $\begin{array}{l}\text { (Junge et al. } \\
\text { 2002) }\end{array}$ \\
\hline Arktis & Packeis & Isolate & $25 \%$ & $30 \%$ & $42 \%$ & $\begin{array}{l}\text { (Brinkmeyer } \\
\text { et al. 2003) }\end{array}$ \\
\hline Sub-Arktis & $\begin{array}{l}\text { Oberflächen- } \\
\text { wasser }\end{array}$ & 16S-Genbank & $0,5 \%$ & $1,5 \%$ & $2 \%$ & $\begin{array}{l}\text { (Zeng et al. } \\
\text { 2012) }\end{array}$ \\
\hline Sub-Arktis & $\begin{array}{l}\text { Oberflächen- } \\
\text { wasser }\end{array}$ & GTA Capsid-Genbank & n.b. & n.b. & ca. $11 \%$ & $\begin{array}{l}\text { (Fu et al. } \\
\text { 2010) }\end{array}$ \\
\hline Antarktis & Packeis & 16S-Genbank & $0 \%$ & $0 \%$ & $0 \%$ & $\begin{array}{c}\text { (Brown \& } \\
\text { Bowman } \\
2001)\end{array}$ \\
\hline Antarktis & Packeis & 16S-Genbank & $0-1 \%$ & $0-1 \%$ & $0-14 \%$ & $\begin{array}{l}\text { (Brinkmeyer } \\
\text { et al. 2003) }\end{array}$ \\
\hline Antarktis & Packeis & 16S-Genbank & n.b. & n.b. & $14 \%$ & $\begin{array}{l}\text { (Ghiglione } e t \\
\text { al. 2012) }\end{array}$ \\
\hline Antarktis & Packeis & Isolate & $9 \%$ & $10 \%$ & $38 \%$ & $\begin{array}{l}\text { (Brinkmeyer } \\
\text { et al. 2003) }\end{array}$ \\
\hline Antarktis & $\begin{array}{l}\text { Oberflächen- } \\
\text { wasser }\end{array}$ & 16S libraries & $1,7 \%$ & $2,3 \%$ & $5,2 \%$ & $\begin{array}{c}\text { (Grzymski et } \\
\text { al. 2012) }\end{array}$ \\
\hline Antarktis & $\begin{array}{l}\text { Oberflächen- } \\
\text { wasser }\end{array}$ & Isolate+16S-libaries & $4 \%$ & $15 \%$ & $20 \%$ & $\begin{array}{c}\text { (Murray \& } \\
\text { Grzymski } \\
\text { 2007) }\end{array}$ \\
\hline Antarktis & $\begin{array}{l}\text { Oberflächen- } \\
\text { wasser }\end{array}$ & $\begin{array}{l}\text { MEGAN/Metagenom- } \\
\text { Fosmid-Enden }\end{array}$ & n.b. & n.b. & $12 \%$ & $\begin{array}{c}\text { (Grzymski et } \\
\text { al. 2012) }\end{array}$ \\
\hline
\end{tabular}


So wird dieser Anteil durch kultivierungsabhängige Untersuchungen höher eingeschätzt (9$25 \%$ ) als durch kultivierungsunabhängige (0-20\%). Dies reflektiert die generell hohe Kultivierbarkeit der Roseobacter-Gruppe (Kirchman 2008) und deutet an, dass sich Octadecabacter-Vertreter gut an die relativ hohen Nährstoffkonzentrationen gängiger Isolierungsmedien anpassen können. Für eine zuverlässige Bestimmung der tatsächlichen Populationsverhältnisse nativer Bakteriengemeinschaften sind kultivierungsunabhängige Ansätze jedoch weitaus besser geeignet (Hugenholtz, Goebel \& Pace 1998; Schmidt 2006).

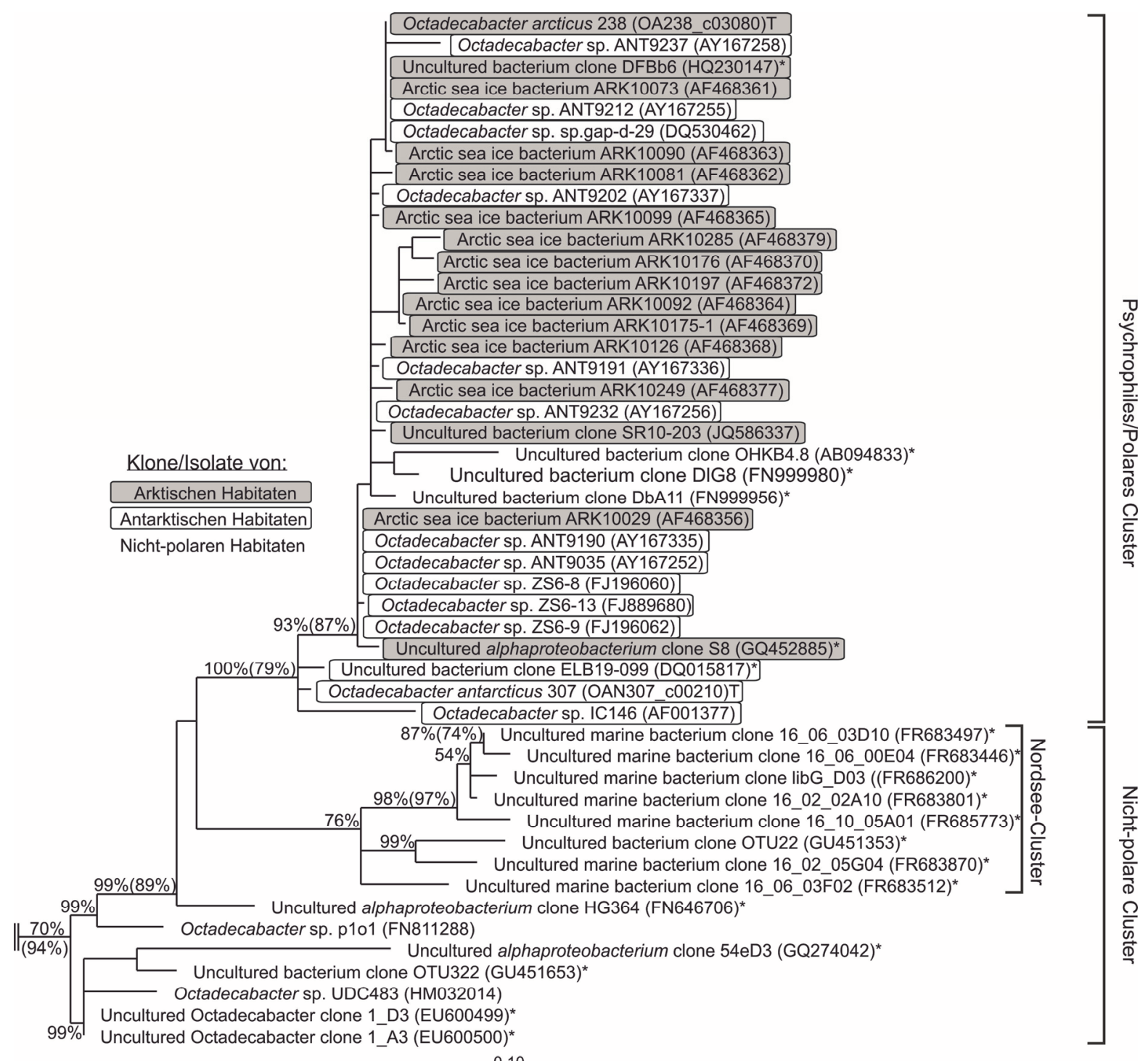

Abb. 11 Phylogenetische Beziehungen zwischen Octadecabacter-Vertretern unterschiedlicher geographischer Standorte

Dargestellt ist ein Ausschnitt aus einem Neighbor-Joining Stammbaum basierend auf 16S rRNA-Gensequenzen repräsentativer Vertreter der Roseobacter-Gruppe sowie aller verfügbaren Octadecabacer-Vertreter. Der gesamte Stammbaum ist in Abb. A1 (Anhang) wiedergegeben. NCBI Accession-Nummern sind in Klammern hinter den jeweiligen Stamm- bzw. Klonbezeichnungen angegeben. Klone sind durch einen Asterisk (*) gekennzeichnet. Typenstämme einer Spezies sind durch ein „T" gekennzeichnet. Bootstrap-Werte über $50 \%$ sind an den entsprechenden Verzweigungen angegeben. 16S rRNA-Gensequenzen von Methylococcus capsulatus und Thiothrix nivea (NCBI-ACC-Nr: AJ563935 + L40993) dienten als Outgroup. 
Doch auch zwischen verschiedenen kultivierungsunabhängigen Untersuchungen schwanken die geschätzten Octadecabacter-Anteile sehr stark, was auf einen großen Einfluss regionaler und saisonaler Unterschiede schließen lässt (Tab. 8). In arktischem Packeis stellen Octadecabacter schätzungsweise 2-20\% der Bakteriengemeinschaft und machen meist den Großteil der vorhandenen Alphaproteobacteria aus, während sie in Meerwasser derselben Polarregion nur schwach vertreten waren ( $0,5 \%$ der Bakteriengemeinschaft). In antarktischem Packeis ist dagegen der Octadecabacter-Anteil mit 0-1\% der Bakteriengemeinschaft und 014\% der Alphaproteobacteria deutlich geringer als in der Arktis, während er in antarktischem Meerwasser mit 2-4\% der Bakteriengemeinschaft und 5-20\% der Alphaproteobacteria etwas erhöht ist (Tab. 8).

Das Vorkommen von Vertretern des Genus Octadecabacter beschränkt sich größtenteils auf die Polarregionen. Dennoch lassen sich mittlerweile auch außerhalb der Polarregionen eine Reihe von Sequenzen, sowohl von Klonen aus 16S rRNA-Genbanken als auch von einer wachsenden Zahl an Isolaten, diesem Genus zuordnen (Abb. 11). Dennoch bilden 16S rRNAGensequenzen von Octadecabacter-Stämmen der Arktis und der Antarktis ein gemeinsames phylogenetisches Cluster, welches sich mit hohen Bootstrap-Werten eindeutig von den meisten aus nicht-polaren Habitaten stammenden Octadecabacter-Sequenzen abgrenzt. Das bedeutet, dass die Octadecabacter-Vertreter der beiden räumlich getrennten Polargebiete auf 16S rRNA-Sequenz-Ebene untereinander einen höheren Grad an Verwandtschaft aufweisen, als zu potentiellen Vertretern in den wärmeren Regionen zwischen den Polen. Lediglich drei nicht-polare Klon-Sequenzen sind in diesem Cluster enthalten, welche allesamt aus kalten Umgebungen stammen: Zwei Sequenzen, welche im Winter von Ciliaten aus dem Atlantischen Ozean gewonnen wurden (NCBI-Acc: FN999980 + FN999956) und eine, welche aus Tiefsee-Sediment stammt (NCBI-Acc: AB094833). Die übrigen nicht-polaren Sequenzen bilden mindestens zwei eigenständige phylogenetische Cluster mit ebenfalls hohen Bootstrap-Werten von 76\% bzw. 99\%. Eines dieser Cluster, bestehend aus acht Sequenzen, scheint ausschließlich aus Vertretern aus der Nordsee zu bestehen.

\subsubsection{Genomplastizität der Octadecabacter-Stämme}

\subsubsection{Genomische Inseln und Regionen erhöhter Genomplasitizität}

Der Begriff Genomplastizität bezeichnet die Wandlungs- bzw. Anpassungsfähigkeit eines Genoms und wird meist in Bezug auf horizontalen Gentransfer verwendet. Ein Indikator für 
horizontalen Gentransfer sind sogenannte genomische Inseln. Hierbei handelt es sich um klar abgegrenzte Bereiche eines Genoms, welche sowohl in Basen als auch in GenZusammensetzung vom Großteil des übrigen Genoms sowie der Genome nah verwandter Stämme abweichen. Solche Genomabschnitte können durch Insertion von Fremd-DNA resultieren und sind beispielsweise aufgrund abweichender Basen-Zusammensetzung (z.b über Tetranucleotid-Häufigkeiten oder GC-Gehalt) oder abweichendem genetischen Dialekt (Codon-Usage) zu identifizieren. Mithilfe der Software-Tools SIGI-HMM und IslandPathDIMOB der Islandviewer-Plattform (http://www.pathogenomics.sfu.ca/islandviewer) wurden auf den Chromosomen beider Organismen mehrere potentielle genomische Inseln identifiziert: 35 mit einer Gesamtgröße von 469.100 bp in Octadecabacter arcticus 238 und 28 mit einer Gesamtgröße von 544.622 bp in Octadecabacter antarcticus 307. Auch die Plasmide der Octadecabacter-Stämme wurden mittels IslandViewer analysiert. Auf pOAR160 wurden drei und auf pOAR118 ein von der Norm abweichender Abschnitt ermittelt. Diese sind möglicherweise auf Rekombinationsereignisse zwischen verschiedenen Replikons zurückzuführen. Allerdings ist anzumerken, dass die geringe Größe dieser Replikons eine zuverlässige Bestimmung abweichender Sequenzabschnitte stark beeinträchtigt.

Visualisierungen der Orthologen-Verteilung beider Octadecabacter-Genome lassen große zusammenhängende Bereiche erkennen, welche in Vergleichsorganismen nur wenige Orthologe mit zudem relativ geringen Sequenzidentitäten aufweisen (Abb. 12). In solchen Regionen konzentrieren sich somit Art bzw. Stamm-spezifische Gene, was ebenfalls als Hinweis auf genomische Inseln gedeutet werden kann. Im Sinne eines systematischen Vorgehens wurden Regionen erhöhter Genomplastizität (RGPs) (Abb. 12) definiert, für die gleichzeitig mehrere Kriterien gelten mussten: Das Vorhandensein einer oder mehrerer Bereiche mit positiver IslandViewer-Vorhersage, starke Schwankungen des GC-Gehaltes und eine geringe Dichte an Orthologen in den Vergleichsstämmen. Plasmide wurden generell als RGPs definiert. In O. arcticus treten 19 (Oar-RGP 1-19), und in O. antarcticus 17 (Oan-RGP 1-17) solcher Regionen auf. Viele der charakteristischen Eigenschaften beider Octadecabacter-Stämme (siehe 3.2.3-3.2.4) befinden sich in diesen Regionen.

Eine detaillierte Auflistung und Beschreibung sämtlicher Regionen ist in Tab. DA56 (digitaler Anhang) zu finden. 


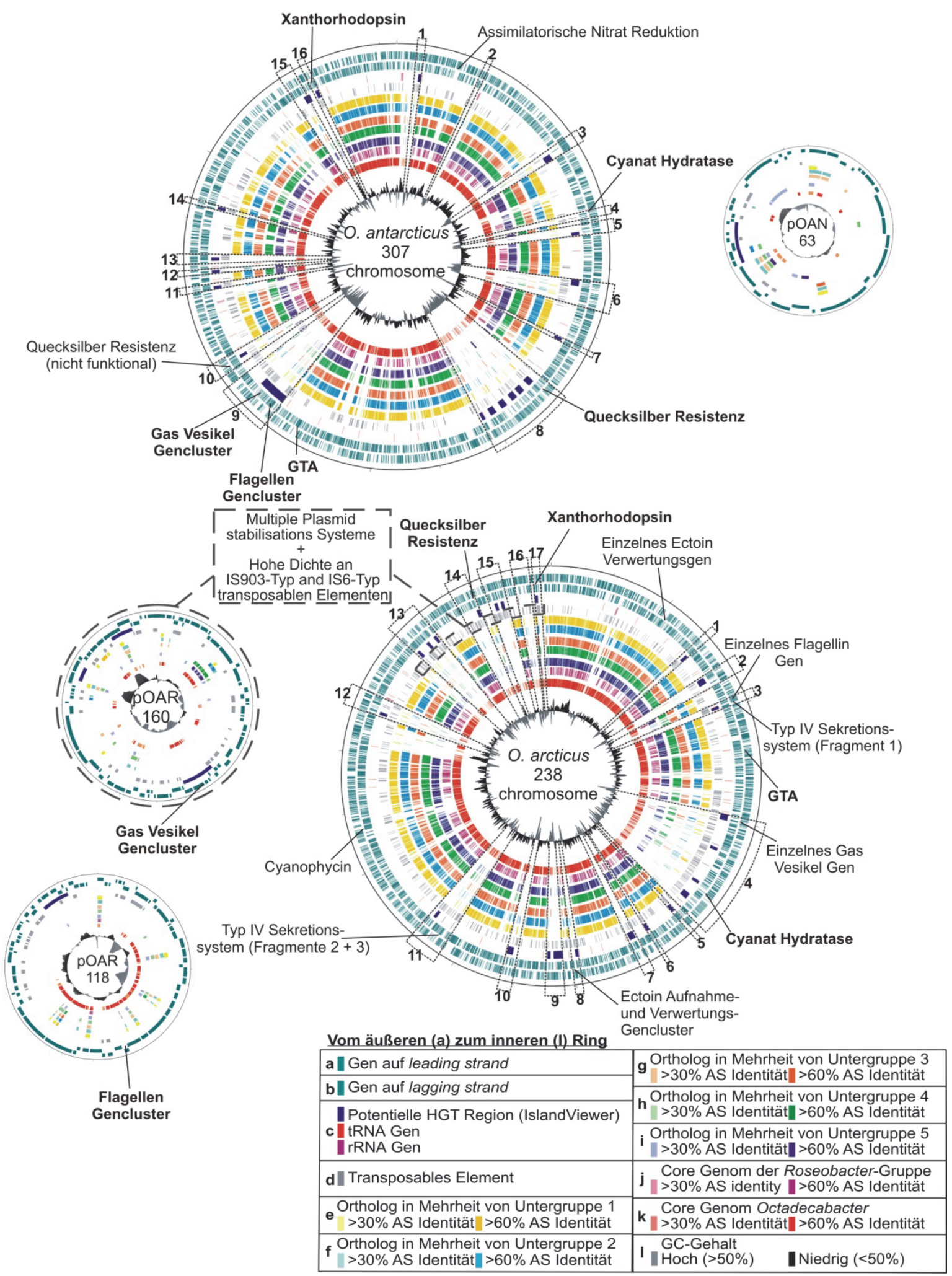

\section{Abb. 12 Detailierte zirkuläre Darstellung der Octadecabacter Genome}

Regionen erhöhter Genomplastizität (RGPs) sind auf den jeweiligen Chromosomen durch gepunktete Linien markiert und durchnummeriert. Ebenfalls dargestellt sind protein-kodierende Gene, IslandViewer Vorhersagen potentieller Islands, rRNA-Gene, transposable Elemente (TEs), Orthologe zu Genen anderer RoseobacterStämme sowie Schwankungen im GC-Gehalt (siehe 2.10). Die Vergleichsstämme wurden zu Untergruppen 1-5 (siehe 3.1.3) zusammengefasst. Die Positionen verschiedener Merkmale, welche auf horizontalen Gentransfer oder intragenomsiche Rekombinationsereignisse hindeuten, sind entsprechend beschriftet. Merkmale, welchen beiden Octadecabacter-Stämmen gemein sind, sind durch fette Beschriftung markiert. 


\subsubsection{Transposable Elemente}

Von den 4683 Protein-kodierenden Genen im Genom von O. arcticus, sind 912 konservierte Bestandteile von transposablen Elementen (TEs), während es in O. antarcticus 361 von insgesamt 4492 Protein-kodierenden Genen sind. Die hohe Dichte an TE-assoziierten Genen in diesen Organismen ist nicht nur einzigartig innerhalb der Roseobacter-Gruppe (Tab. 7, 3.1.1), sondern auch allgemein für bakterielle Organismen sehr ungewöhnlich. Ein großer Teil der TE-assozierten Gene und Pseudogene konnte durch BLAST-Vergleiche mit der ISFinderDatenbank (Siguier et al. 2006) charakterisierten Familien und Untergruppen zugeordnet

Tab. 9 Klassifikation der Transposablen Elemente von O. arcticus und O. antarcticus anhand der ISFinder-Datenbank

\begin{tabular}{|c|c|c|c|c|c|c|c|}
\hline \multirow[b]{2}{*}{ Familie/Typ } & \multicolumn{3}{|c|}{ OAR } & \multicolumn{3}{|c|}{$\mathrm{OAN}$} & \multirow{2}{*}{$\begin{array}{c}\text { Häufigkeit in } \\
\text { Roseobacter- } \\
\text { Gruppe }^{c}\end{array}$} \\
\hline & $\mathrm{CDS}$ & Pseudo & Gesamt & $\mathrm{CDS}$ & Pseudo & Gesamt & \\
\hline $\mathrm{IS}^{\mathrm{a}}$ & 177 & 30 & 207 & 137 & 49 & 186 & 26 \\
\hline IS4 & 0 & 0 & 0 & 1 & 1 & 2 & 2 \\
\hline $\mathrm{IS}^{\mathrm{a}}$ & 44 & 19 & 63 & 34 & 8 & 42 & 14 \\
\hline IS6 & 25 & 4 & 29 & 12 & 3 & 15 & 7 \\
\hline IS10 & 7 & 8 & 15 & 0 & 0 & 0 & 0 \\
\hline IS 21 & 11 & 0 & 11 & 13 & 4 & 17 & 8 \\
\hline IS30 & 45 & 17 & 62 & 8 & 0 & 8 & 11 \\
\hline IS66 & 66 & 15 & 81 & 2 & 1 & 3 & 14 \\
\hline IS91 & 22 & 5 & 27 & 12 & 0 & 12 & 6 \\
\hline IS110 & 17 & 4 & 21 & 33 & 39 & 72 & 9 \\
\hline IS200/IS605 & 38 & 2 & 40 & 14 & 0 & 14 & 31 \\
\hline IS204/IS1001/IS1096/IS1165 & 0 & 2 & 2 & 0 & 0 & 0 & 0 \\
\hline IS256 & 72 & 21 & 93 & 9 & 3 & 12 & 3 \\
\hline IS481 & 33 & 3 & 36 & 1 & 16 & 17 & 9 \\
\hline IS630 & 73 & 10 & 83 & 2 & 3 & 5 & 4 \\
\hline IS116/IS110/IS902 & 1 & $\mathbf{0}$ & 1 & 0 & 0 & 0 & 0 \\
\hline IS1182 & 0 & 0 & 0 & 1 & 14 & 15 & 5 \\
\hline IS 1380 & 1 & 0 & 1 & 2 & 0 & 2 & 0 \\
\hline IS1595 & 33 & 1 & 34 & 20 & 3 & 23 & 12 \\
\hline ISAs1 & 28 & 2 & 30 & 0 & 0 & 0 & 0 \\
\hline ISL3 & 29 & 10 & 39 & 0 & 0 & 0 & 0 \\
\hline P4-Integrase & 1 & $\mathbf{0}$ & 1 & 0 & 0 & 0 & 11 \\
\hline ISNCY & 1 & 2 & 3 & 0 & 0 & 0 & 8 \\
\hline Oar-RGP4/Oan-RGP8-Integrase ${ }^{b}$ & 6 & 1 & 7 & 5 & 1 & 6 & \\
\hline Unbekannt $^{\mathrm{b}}$ & 182 & 107 & 289 & 55 & 120 & 175 & \\
\hline
\end{tabular}

Familien, welche auf einen der beiden Octadecabacter Stämme beschränkt sind, wurden fett hervorgehoben CDS = Coding Sequence (funktionales Gen); Pseudo = Pseudogen (nicht funktionales Gen)

${ }^{a}$ mehrere verschiedene Untergruppen dieser Familie sind repräsentiert

${ }^{b}$ keine Verwandten Elemente in ISfinder-Datenbank vorhanden

${ }^{c}$ Anzahl der Vergleichstämme ausserhalb des Genus Octadecabacter, welche nah verwandte TEs aufweisen 
werden. Es zeigte sich, dass die TEs in den Genomen der Octadecabacter-Stämme nicht nur zahlreich, sondern auch hochdivers sind (Tab. 9). Die TEs von O. arcticus 238 lassen sich 21 verschiedenen Familien zuordnen, während die Elemente von O. antarcticus 16 verschiedenen Familien zugehörig sind. Diese hohe Diversität an TEs in den Genomen der Octadecabacter-Stämme ist bemerkenswert, da sie auf unterschiedliche Herkünfte der verschiedenen Elemente und somit häufigen horizontalen Gentransfer hindeuten könnte.

Ein hoher Anteil der TE-assoziierten Gene und Pseudogene (296 in O. arcticus bzw. 181 in O. antarcticus) ließen sich keiner bereits charakterisierten Familie zuordnen und repräsentieren somit neue Gruppen von transposablen Elementen. Hierzu gehört auch eine Gruppe von Integrasen welche mit nahezu identischer Sequenz in Region Oar-RGP 4 von O. arcticus und Oan-RGP 8 von O. antarcticus vorkommen (Oar-RGP4/Oan-RGP8-Integrase, siehe 3.2.2.1). Manche Familien, darunter IS3 und IS5, deren Vertreter in beiden Octadecabacter-Genomen vorkommen, sind in der ISFinder-Datenbank zusätzlich in Untergruppen eingeteilt. Jeweils vier dieser Untergruppen sind in den OctadecabacterStämmen repräsentiert: Untergruppen IS150, IS407, IS51 und IS3 der Familie IS3 sowie Untergruppen IS903, IS247, IS1031 und IS5 der Familie IS5. Insgesamt acht Familien von TEs waren auf jeweils einen der beiden Octadecabacter-Stämme beschränkt (Tab. 9).

Um zu prüfen, ob ein Zusammenhang zwischen mutmaßlichen Rekombinations-Ereignissen und verschiedenen Gruppen an TEs besteht, wurde die Verteilung der einzelnen Gruppen an TEs über die Octadecabacter-Genome untersucht. Die meisten der in Tab. 9 aufgelisteten Elemente sind relativ gleichmäßig über die Genome der beiden Octadecabacter Stämme verteilt. Fünf Gruppen an Elementen wiesen jedoch in mindestens einem der Stämme regionale Anhäufungen auf: Untergruppe IS3 der Familie IS3, Untergruppe IS903 der Familie IS5, Familien IS6 und IS256 sowie die Oar-RGP4/Oan-RGP8-Integrasen (Abb. 13).

Transposable Elemente der Untergruppe IS3 (Familie IS3) sind in O. arcticus relativ gleichmäßig über das Genom verteilt, während sie in $O$. antarcticus ausschließlich auf einen Genomabschnitt beschränkt sind, der sich auf weniger als die Hälfte des Chromosoms erstreckt. Umgekehrt sind Elemente der Untergruppe IS903 (Familie IS5), in O. antarcticus gleichmäßig über das Genom verteilt, in O. arcticus jedoch hauptsächlich in den Regionen Oar-RGP 13-17 sowie auf dem Plasmid pOAR160 zu finden. Elemente der Familie IS6 sind in beiden Octadecabacter-Stämmen auf einen Bereich im letzten Achtel des Chromosoms (relativ zum Replikationsursprung) konzentriert. In O. arcticus 238 erstreckt sich dieser Bereich über Oar-RGP 14 bis Oar-RGP 17, während er in O. antarcticus, abgesehen von 


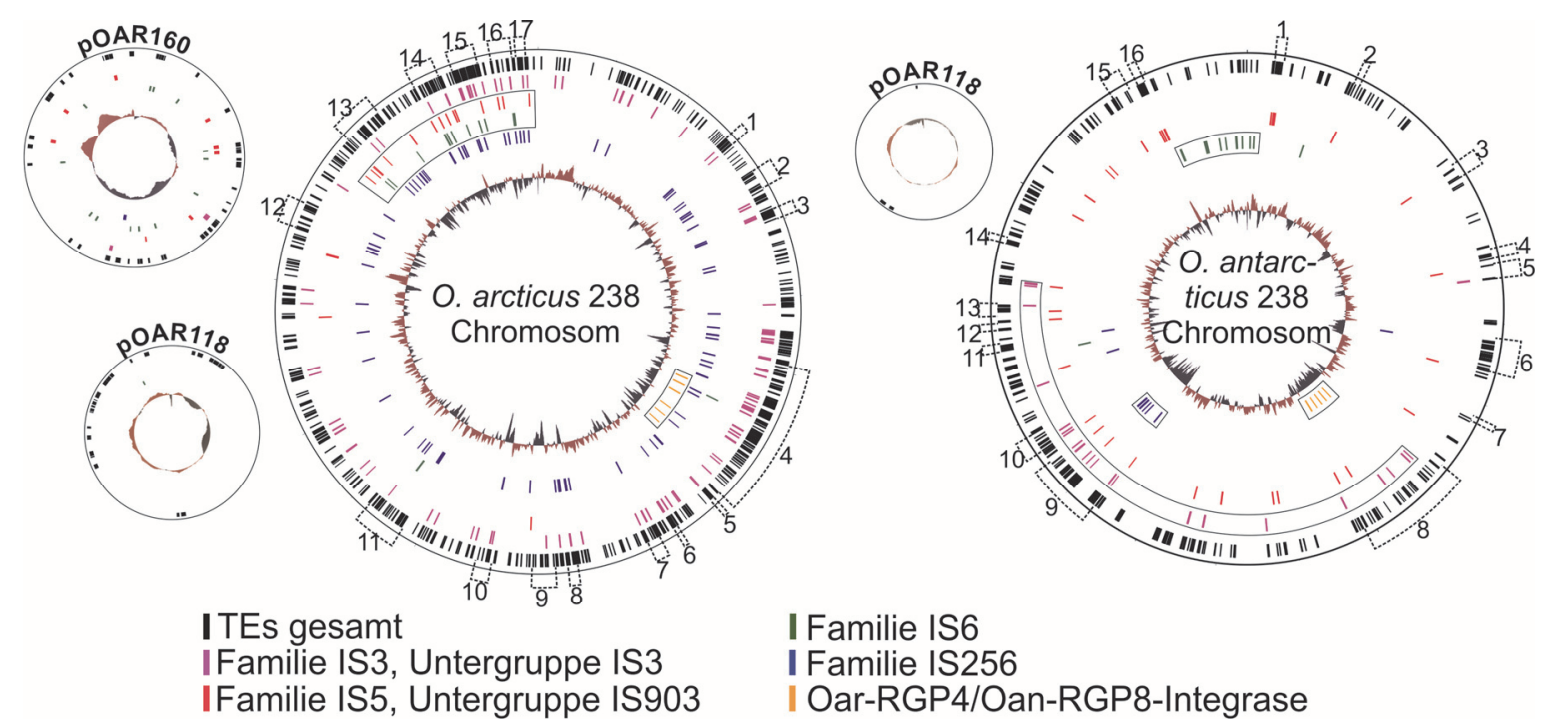

Abb. 13 Regionale Anhäufung einiger Gruppen von transposablen Elementen (TEs) in den Genomen von $O$. arcticus 238 und $O$. antarcticus 307

Abgebildet sind zirkuläre, nicht maßstabsgetreue, Repräsentationen der Octadecabacter-Genome. GC-Plots sind als ringförmige Graphen im Inneren der kreisförmigen Genomdarstellungen angezeigt. Die Positionen und Nummern von RGPs (siehe 3.2.2.1) sind ausserhalb der Kreise markiert. Das Vorkommen von Genen verschiedener Gruppen von TEs ist durch verschiedene Farben dargestellt. Es sind deutliche regionale Anhäufungen einiger TE-Gruppen zu erkennen.

Oan-RGP 16, nur konservierte Genomabschnitte umfasst. In beiden Fällen ist jedoch eine Region enthalten, welche ein Xanthorhodopsin-Gencluster aufweist (siehe 3.2.2.1+3.2.5). In O. arcticus sind IS6-Elemente auch auf Plasmid pOAR160 stark vertreten. Die Tatsache, dass IS6- und IS903 (Familie IS5)-ähnliche Elemente in O. arcticus sowohl im selben Abschnitt des Chromosoms, als auch auf Plasmid pOAR160 gehäuft vorkommen, deutet auf vergangene Rekombinations-Ereignisse zwischen diesen Genom-Bereichen hin. Transposable Elemente der Familie IS256 konzentrieren sich in O. antarcticus deutlich in Region Oan-RGP 9, welche in diesem Organismus Gasvesikel- und Flagellen-Gencluster enthält (siehe 3.2.2.1, 3.2.4.2+3.2.4.3), während sie in O. arcticus gleichmäßig über das Genom verteilt sind. Auch in O. arcticus ist ein einzelnes Element dieser Familie in der Umgebung des GasvesikelGenclusters vorhanden, welches sich in diesem Organismus jedoch auf dem Plasmid pOAR160 befindet.

\subsubsection{Pseudogene}

Beide Octadecabacter-Stämme enthalten, verglichen mit anderen Vertretern der RoseobacterGruppe, eine ungewöhnliche hohe Zahl an Pseudogenen (Tab. 7, 3.1.1). Um zu untersuchen, ob dies ausschließlich auf die Aktivität von transposablen Elementen (TEs) zurückzuführen 
ist, wurden sämtliche Pseudogene sowie deren Genumgebung im Einzelnen überprüft (Tab. $10)$.

Der überwiegende Teil an Pseudogenen in beiden Octadecabacter-Stämmen (262 von 411 in O. arcticus bzw. 273 von 361 in O. antarcticus) ist Bestandteil eines transposablen Elements. Dies war zu erwarten, da solche Elemente aufgrund ihrer hohen Kopienzahl in den Octadecabacter-Genomen, sowie der Fähigkeit vieler TEs in trans aktiviert zu werden (Mahillon, Léonard \& Chandler 1999), einem niedrigeren evolutionärem Druck ausgesetzt sein sollten als andere Gene. Von den übrigen Pseudogenen ist ein hoher Anteil in O. arcticus (77 von 411) und ein niedriger Anteil in O. antarcticus (9 von 361) durch die Insertion eines transposablen Elements fragmentiert worden. Dies deutet darauf hin, dass einige der TEs in den Octadecabacter-Stämmen noch aktiv sind und, vor allem in O. arcticus, auch Stoffwechsel-relevante Gene beeinträchtigen können. Die restlichen Pseudogene sind nicht direkt auf den Einfluss transposabler Elemente zurückzuführen. Die Zahl dieser Pseudogene ist mit 72 in O. arcticus und 81 in O. antarcticus noch immer höher als die Gesamtzahl an Pseudogenen der meisten Roseobacter, abgesehen von Phaeobacter arcticus DSM23566 (102 Pseudogene) und Phaeobacter caeruleus 13 (81 Pseudogene).

Tab. 10 Pseudogene in $O$. arcticus und $O$. antarcticus

\begin{tabular}{|c|c|c|c|c|}
\hline & \multicolumn{2}{|c|}{ O. arcticus 238} & \multicolumn{2}{|c|}{ O. antarcticus 307} \\
\hline & Anzahl & Anteil an Genom ${ }^{\mathrm{a}}$ & Anzahl & $\begin{array}{l}\text { Anteil an } \\
\text { Genom }^{\text {a }}\end{array}$ \\
\hline Pseudogene gesamt: & 411 & $8,0 \%$ & 361 & $7,37 \%$ \\
\hline $\begin{array}{l}\text { davon Bestandteil } \\
\text { eines TE }\end{array}$ & 262 & $5,1 \%$ & 273 & $5,57 \%$ \\
\hline $\begin{array}{l}\text { durch Insertion } \\
\text { eines TE fragmentiert }\end{array}$ & 77 & $1,5 \%$ & 9 & $0,18 \%$ \\
\hline restliche Pseudogene & 72 & $1,4 \%$ & 81 & $1,65 \%$ \\
\hline
\end{tabular}

\subsubsection{Genom-alignments}

Es wurden paarweise Genom-alignments (siehe 2.10.2) von Octadecabacter antarcticus 307 gegen Octadecabacter antarcticus 238 erstellt und mit entsprechenden Genom-alignments von Roseobacter denitrificans Och114 gegen Roseobacter litoralis Och149 und Nautella italica R11 gegen Phaeobacter gallaeciensis DSM17395 verglichen (Abb. 14). Diese Organismenpaare wurden für Vergleichs-alignments ausgewählt, weil sie auf Multilokus Sequenzanalyse-Ebene (MLSA) sowie auf Ebene der durchschnittlichen Nukleotididentitäten 

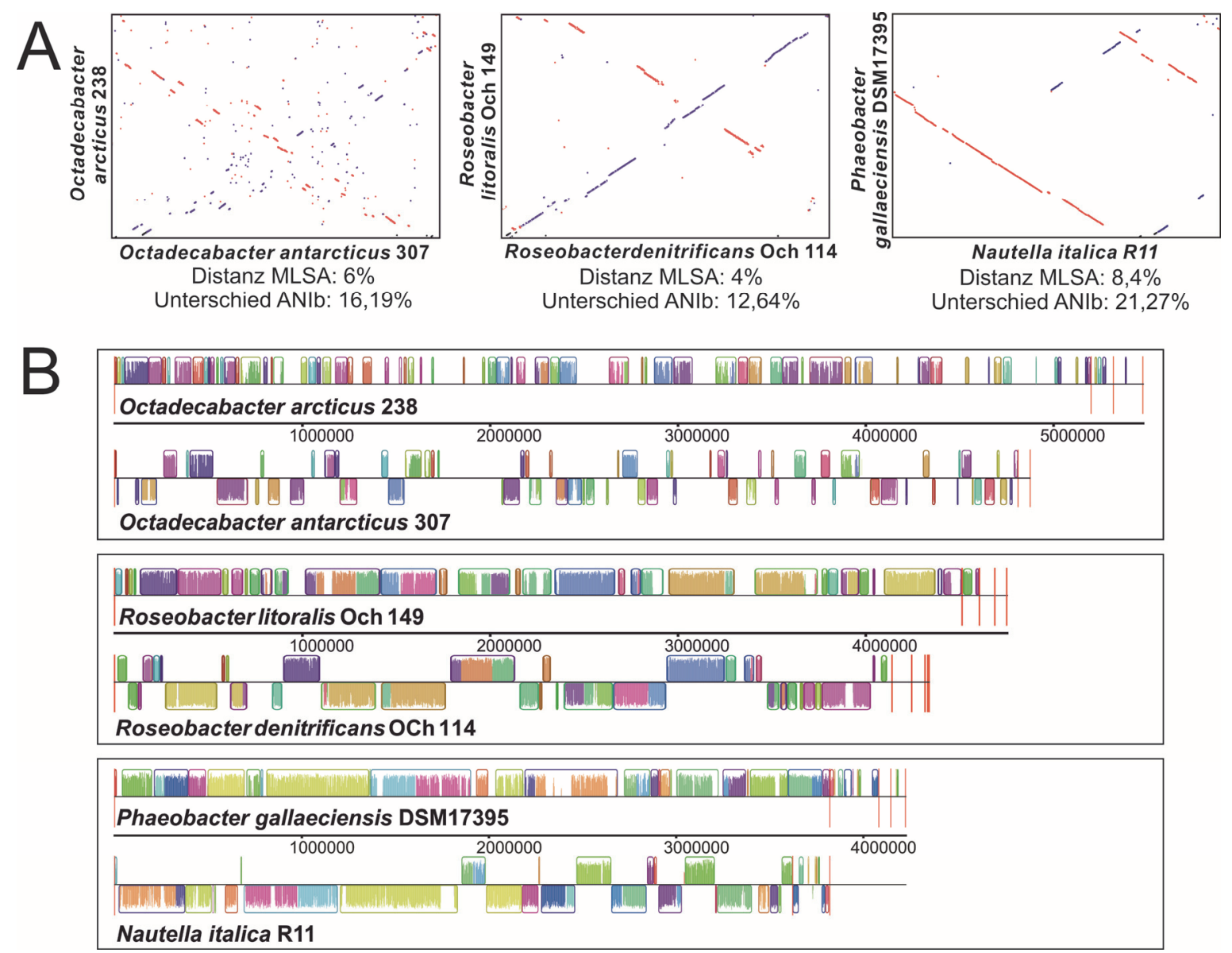

Abb. 14 Genomalignments der Octadecabacter-Stämme sowie verschiedener Vergleichsorganismen

A) MUMmer-Plots basierend auf Nukleotid-Sequenzen. Lineare Bereiche repräsentieren zusammenhängende übereinstimmende Genomabschnitte. Rote Färbung deutet auf identische Orientierung der Abschnitte in beiden Vergleichsgenomen hin, während blaue Färbung Inversionen anzeigt. Die entsprechenden phylogenetischen Distanzen auf MLSA- sowie ANIb-Ebene (siehe 3.1.3) sind für jedes Organismenpaar angegeben. Zusätzliche Vergleiche zwischen weiteren Roseobacter-Vertretern sind in Abb. A2 (Anhang) dargestellt. B) Graphische Darstellung der Mauve-alignments. Farbige Boxen repräsentieren zusammenhängende Genomabschnitte. Die Füllung der Boxen stellt den jeweiligen Grad an Übereinstimmung dar. Die Position der Boxen oberhalb bzw. unterhalb der Grenzlinien, zeigt die relative Orientierung der Abschnitte in den jeweiligen Vergleichsorganismen an. Es zeigt sich das die Genome der Octadecabacter-Stämme eine deutlich geringere Syntenie aufweisen als vergleichbare Organismen mit ähnlichen phylogenetischen Verhältnissen.

(ANIb) ähnliche phylogenetische Distanzen (Abb. $8+$ Abb. 10) zeigten wie die beiden Octadecabacter-Stämme (siehe 3.1.3), und die entsprechenden Genomsequenzen zudem nur sehr wenige bzw. keine Lücken aufwiesen. Ausserdem wurden P. gallaeciensis DSM17395 und N. italica R11, ähnlich wie die beiden Octadecabacter-Stämme, an nahezu entgegengesetzten Standorten des Erdglobus isoliert (Tab. DA01, digitaler Anhang). Die Octadecabacter-Genome zeigten im Vergleich zu den anderen verwandten RoseobacterStämmen eine extrem hohe Divergenz (Abb. 14). Dies äußerte sich besonders deutlich in NUCmer-Plots (Abb. 14a) welche bei den Octadecabacter-alignments nur sehr kurze 
übereinstimmende (linear dargestellte) Bereiche mit einer sehr diffusen Verteilung aufwiesen (Abb. 14a). Sowohl R. litoralis und R. denitrificans als auch P. gallaeciensis und N. italica wiesen weitaus höhere Syntenien und zudem eine gleichmässigere Verteilung und Orientierung Übereinstimmender Genomabschnitte auf (Abb. 14). Mauve-Plots verdeutlichten, dass dennoch teilweise sehr hohe Sequenz-Übereinstimmung zwischen Teilabschnitten beider Octadecabacter-Genome vorhanden sind (Abb. 14b). Diese sind jedoch in Form kleiner Regionen weit über die entsprechenden Genome verteilt. Zudem weisen diese Regionen zwischen den Octadecabacter-Genomen weitaus mehr Inversionen auf, als das bei alignments von $R$. denitrificans gegen $R$. litoralis bzw. $N$. italica gegen P. gallaeciensis der Fall ist.

\subsubsection{Unterschiede zwischen $\boldsymbol{O}$. arcticus und $\boldsymbol{O}$. antarcticus}

\subsubsection{Cyanophycin-Gencluster in $O$. arcticus}

O. arcticus 238 besitzt ein innerhalb der Roseobacter-Gruppe kaum verbreitetes Gencluster, welches die Synthese sowie den Abbau von Cyanophycin kodiert (Abb. 15). Cyanophycin ist ein nicht-ribosomal synthetisiertes, verzweigtes und wasserunlösliches Polymer des Isodipeptids $\beta$-Aspartat-Arginin ( $\beta$-Asp-Arg) (Berg et al. 2000; Berg 2003). Das Enzym Cyanophycin-Ligase katalysiert sowohl die Synthese des ß-Asp-Arg-Monomers als auch dessen Polymerisierung. In Cyanobakterien liegt dieses Enzym als Homodimer, bestehend aus zwei identischen CphA-Untereinheiten, vor (Ziegler et al. 1998). In anderen Organismen kann es jedoch auch als Heterodimer vorkommen, bestehend aus einer CphA-Untereinheit und einer CphA-ähnlichen Untereinheit $\left(\mathrm{CphA}^{\circ}\right)$ (Füser \& Steinbüchel 2007). Die

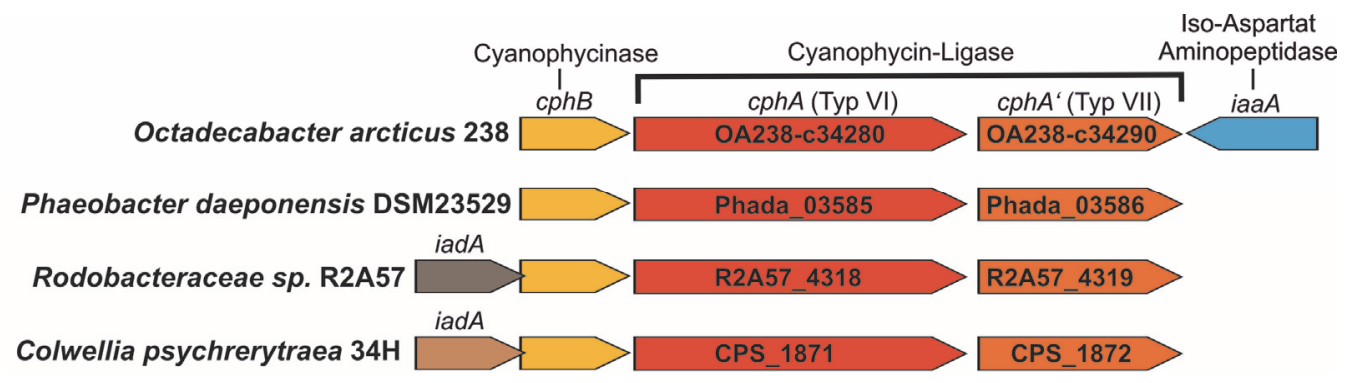

Abb. 15 Cyanophycin-Gencluster mit Typ VI Cyanophycin-Ligase

Identische Farben kennzeichnen Orthologe zwischen den Vergleichsstämmen. Cyanophycin-Ligase-Gene sind jeweils mit dem entsprechenden locus tag beschriftet. In O. arcticus ist die assoziierte Iso-Aspartyl Peptidase vom IaaA-Typ, während sie bei Rhodobacteraceae sp. R2A57 und C. psycherythraea 34H dem IadA-Typ angehört. 


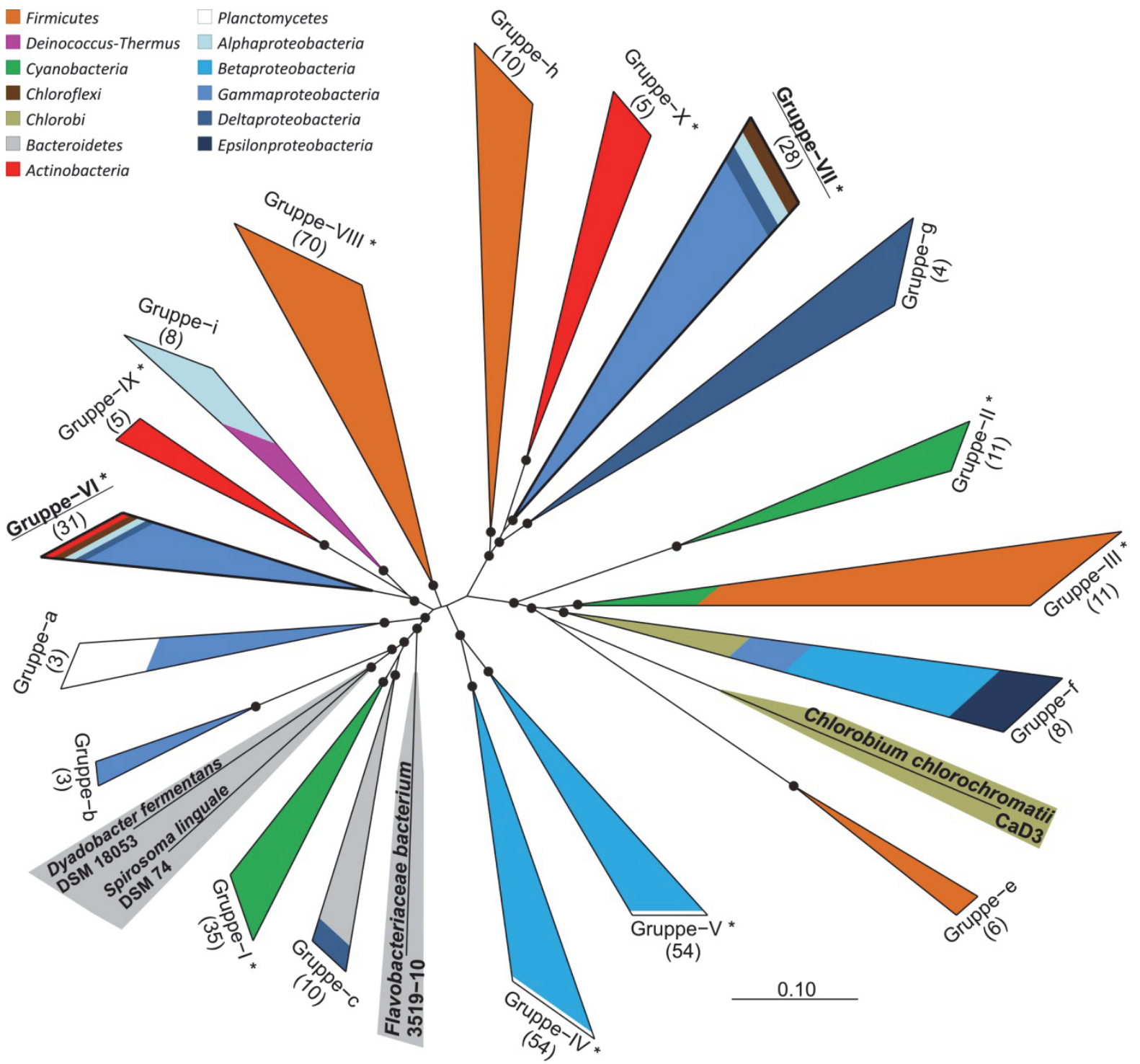

Abb. 16 Diversität bakterieller Cyanophycin-Ligasen

Neighbor-Joining Baum basierend auf Proteinsequenzen. Gruppen die aus mehr als drei Sequenzen bestehen und Bootstrap-Werte von über $70 \%$ aufweisen, sind als geschlossene Gruppen dargestellt. Gruppen die prinzipiell bereits durch Füser et al. (2007) beschrieben wurden, sind mit einem Asterisk $\left.*^{*}\right)$ markiert und entsprechend mit römischen Zahlen durchnummeriert. Neu entdeckte Gruppen sind mit den Kleinbuchstaben a-i beschriftet. Die Anzahl an Sequenzen pro Gruppe ist jeweils in Klammern angegeben. Die relativen Anteile unterschiedlicher Bakterien-Taxa, die in den verschiedenen Gruppen vertreten sind, wurden durch verschiedene Farbmarkierungen dargestellt. Verzweigungen mit Bootstrap-Werten über 50\% sind mit schwarzen Punkten markiert. Gruppen VI und VII, welche Cyanophycin-Ligase-gene von O. arcticus 238 beinhalten, sind Fett hervorgehoben. Eine genaue Auflistung aller im Stammbaum enthaltenen Sequenzen befindet sich in Tab. DA57 (digitaler Anhang).

Organisation des entsprechenden Genclusters von O. arcticus 238 (Abb. 15) legt nahe, dass es sich bei der Cyanophycin-Ligase dieses Organismus um ein Heterodimer handelt. Ähnliche Gencluster sind auch in Phaeobacter daeponensis DSM23529 und Rhodobacteraceae sp. R2A57 vorzufinden. Cyanophycin ist nicht anfällig für die Aktivität der meisten Proteinasen und Peptidasen. Der Abbau dieses Polymers geschieht durch Cyanophycinasen $(\mathrm{CphB})$ und Iso-Aspartyl Peptidasen (IadA bzw. IaaA) (Füser \& Steinbüchel 2007). Solche AbbauEnzyme sind ebenfalls im Cyanophycin-Gencluster von $O$. arcticus 238 vertreten (Abb. 15). 
Das Produkt des cphA-Gens von O. arcticus wies hohe Sequenzähnlichkeiten $(>70 \%) \mathrm{zu}$ Cyanophycin-Ligasen von Mycobacterium marinum M, Acinetobacter sp. ADP1, Colwellia psycherythraea 34H sowie Francisella tularensis Schu 4 auf. Diese bilden Gruppe-VI der von Füser und Steinbüchel etablierten zehn Gruppen von Cyanophycin-Ligasen (I-X) (Füser \& Steinbüchel 2007). Da jedoch in der Zwischenzeit die Zahl öffentlich verfügbarer Sequenzen stark gestiegen ist, und um eine korrekte phylogenetische Einteilung der OctadecabacterCyanophycin-Ligase sicherzustellen, wurde die NCBI-nr Datenbank per BLAST-Analysen nach weiteren Cyanophycin-Ligase-ähnlichen Proteinsequenzen durchsucht. Die so ermittelten Proteinsequenzen wurden in einem phylogenetischen Stammbaum integriert (Abb. 16).

Tab. 11 Liste der Gruppe-VI Cyanophycin Ligasen und der zugehörigen Organismen.

\begin{tabular}{|c|c|c|}
\hline Organismus & NCBI-Acc & Herkunft \\
\hline Acinetobacter sp. ADP1 & CAG68152 & Strand der Iriomote-jima Insel, Japan \\
\hline Mycobacterium marinum $\mathrm{M}$ & YP_001850711 & San Francisco, Kalifornien, USA \\
\hline Colwellia psychrerythraea $34 \mathrm{H}$ & YP_268601 & Arktisches Sediment \\
\hline Francisella tularensis SCHU 4 & YP_170103 & Ohio, USA \\
\hline Octadecabacter arcticus 238 & ZP_05067667 & Arktisches Meereis \\
\hline Rhodobacteraceae sp. R2A57 & - & Meerwasser, Aquina Bucht, Oregon, USA \\
\hline Phaeobacter daeponensis DSM23529 & - & Strand von Daeopo, Südkorea \\
\hline Francisella novicida FTE & ZP_03057450 & Mauspassage von Stamm U112 \\
\hline Francisella novicida U112 & YP_898752 & Patient, Ogden Bucht, Utah, USA \\
\hline Francisella novicida GA99-3548 & ZP_04990001 & Loisiana, USA \\
\hline Francisella tularensis WY96-3418 & YP_001122090 & Wyoming, USA \\
\hline Francisella novicida FTG & ZP_03247111 & genaue Herkunft nicht ermittelbar \\
\hline Francisella tularensis MA00-2987 & ZP_03665784 & Martha's Vineyard, Massachusetts, USA \\
\hline Francisella tularensis FSC 198 & YP_667235 & Slovakei \\
\hline Francisella tularensis FSC033 & ZP_04986699 & Georgia, USA \\
\hline Francisella tularensis FSC147 & YP_001891929 & Alma-Ata-Region, Kazakhstan \\
\hline Francisella tularensis MA00-2987 & ZP_05247730 & Martha's Vineyard, Massachusetts, USA \\
\hline Francisella novicida GA99-3549 & ZP_04988557 & Kalifornien, USA \\
\hline Francisella tularensis URFT1 & ZP_06558955 & Frankreich \\
\hline Francisella tularensis FTNF002-00 & YP_001428312 & Frankreich \\
\hline Francisella tularensis OSU18 & YP_763387 & Red Rock, Oklahoma, USA \\
\hline Francisella tularensis 257 & ZP_04983545 & Moskau, Russland \\
\hline Francisella tularensis LVS & YP_513553 & Europa \\
\hline Francisella tularensis FSC200 & ZP_02274705 & genaue Herkunft nicht ermittelbar \\
\hline Francisella tularensis FSC022 & ZP_04985201 & Japan \\
\hline Francisella philomiragia ATCC 25015 & ZP_04755870 & Brigham City, Utah, USA \\
\hline Francisella philomiragia ATCC 25017 & YP_001678220 & Bear River Refuge, Utah, USA \\
\hline Francisella philomiragia ATCC 25015 & ZP_05249534 & Brigham City, Utah, USA \\
\hline Congregibacter litoralis KT71 & ZP_01104810 & Bei Helgoland, Deutschland \\
\hline gamma proteobacterium NOR5-3 & ZP_05125957 & Sylt, Deutschland \\
\hline Plesiocystis pacifica SIR-1 & ZP_01912973 & Japan \\
\hline Acinetobacter sp. ADP1 & YP_045974 & Strand der Iriomote-jima Insel, Japan \\
\hline Herpetosiphon aurantiacus ATCC 23779 & YP_001543393 & Minnesota, USA \\
\hline
\end{tabular}


Zwar bleiben die durch Füser und Steinbüchel etablierten Gruppen mit hohen BootstrapWerten bestehen, jedoch existieren noch einige weitere Gruppen und es zeigte sich, dass Cyanophycin-Ligasen in weitaus vielfältigeren Organismen verbreitet sind als bisher angenommen. Entsprechende Gencluster sind in Bakterien neun verschiedener Phyla zu finden. Am häufigsten wurden solche Gencluster in Genomen von Vertretern des Phylums Firmucutes, insbesondere der Klasse Clostridia, nachgewiesen. Die Cyanophycin-LigaseSequenzen mehrerer Gruppen (insbesondere Gruppen VI und VII sowie Gruppe f) stammen trotz hoher Sequenz-Übereinstimmungen von Vertretern sehr unterschiedlicher bakterieller Taxa (Abb. 16), was auf eine Übertragung dieser Eigenschaft durch horizontalen Gentransfer hindeutet.

Die Vertreter der Gruppe-IV beinhalten neben O. arcticus auch Ligasen aus Organismen der Phyla Actinobacteria, Chloroflexi und Deltaproteobacteria, hauptsächlich aber aus Vertretern der Gammaproteobacteria (Tab. 11). Dazu gehört auch Colwellia Psycherythraea, eine weitere psychrophile arktisch-marine Bakterienart, deren Vertreter auch häufig in Meereis vorzufinden sind. Die übrigen Organismen, welche eine Gruppe-VI Cyanophycin-Ligase besitzen, stammen allesamt aus der nördlichen Hemisphäre. Die meisten der Isolate, in denen diese Ligase nachgewiesen wurde, gehören den nah verwandten bakteriellen Krankheitserregern Francisella tularensis, Francisella novicida und Francisella philomiragia an, welche fast ausschließlich in der nördlichen Hemisphäre auftreten (Keim, Johansson \& Wagner 2007). Aufgrund hoher Sequenzübereinstimmungen wird F. novicida als Unterart von F. tularensis betrachtet, doch die Zusammenführung dieser Taxa ist bislang noch umstritten (Huber et al. 2010; Johansson et al. 2010).

Obwohl die Herkunft entsprechender Isolate für ein endemisches Vorkommen von Gruppe-VI Cyanophycin-Ligasen auf der nördlichen Erdhalbkugel hindeuten (Tab. 11), zeigten Screenings von marinen Metagenombanken der GOS und AntarcticAquatic Metagenomprojekte (siehe 2.11), dass diese Gruppe an Cyanophycin-Ligasen durchaus auch in der südlichen Hemisphäre vorzufinden ist (Abb. 17). In marinen Habitaten waren diese Cyanophycin-Ligasen allerdings hauptsächlich auf Polargebiete beschränkt. Marine Habitate in temperaten bis tropischen Regionen wiesen nur selten Cyanophycin-Ligasen dieses Typs auf. 


\section{Cyanophycin-Ligasen vorhanden; davon Typ VI: $\quad$ Isolate mit Typ VI Cyanophycin-Ligase: \\ $90 \% \bigcirc 30 \% \bigcirc 20 \% \bigcirc 10 \% \bigcirc 5 \% \bigcirc 2 \% \bigcirc 0 \% \quad x$ Isolat Roseobacter-Gruppe \\ Keine Cyanophycin-Ligase vorhanden \\ \& Isolat andere bakterielle Gruppe}
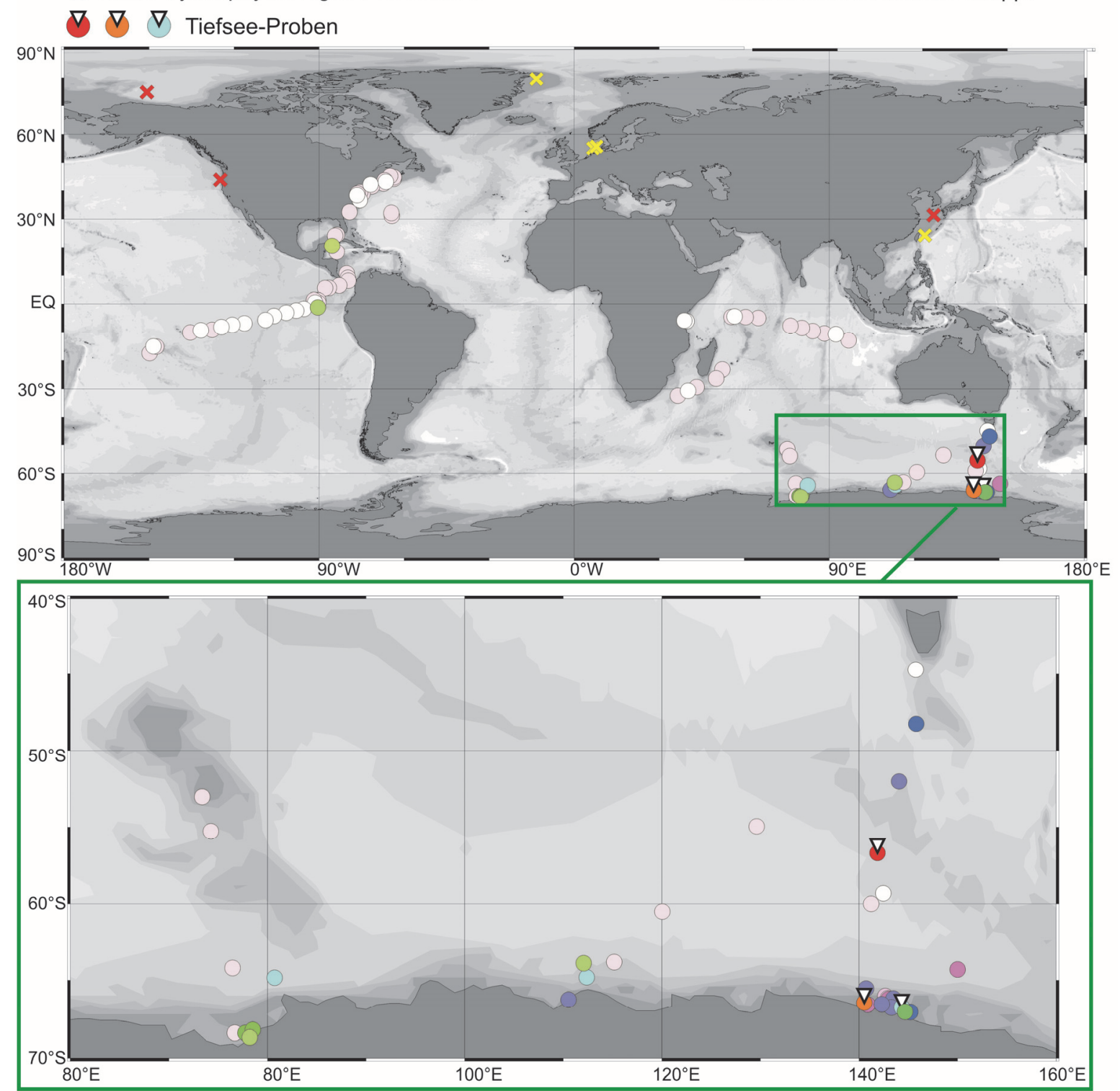

Abb. 17 Biogeographie von Gruppe-VI Cyanopycin-Ligasen in marinen und Eis-assoziierten Standorten Die Abbildungen wurden mit Ocean Data View (ODV) Version 3.3.2 (AWI, Bremerhaven) erstellt. Es wurden nur marine und Eis-assoziierte Standorte berücksichtigt. Probenorte von Metagenomen, welche Sequenzen von Cyanophycin-Ligasen aufwiesen, sind durch farbige Kreise repräsentiert. Durch unterschiedliche Färbung dieser Kreise ist der jeweilige Anteil an Typ VI Cyanophycin-Ligasen an den gesamten Cyanophycin-Ligasen des jeweiligen Metagenoms gekennzeichnet. Weiße Kreise kennzeichnen Probenorte von Metagenomen, welche keine Sequenzen von Cyanophycin-Ligasen aufwiesen. Metagenome aus Tiefseeproben sind mit weißen Dreiecken markiert. Kreuze markieren Isolierungsorte von marinen Organismen welche Typ VI CyanophycinLigase Gene besitzen. Die Farbe der Kreuze zeigt an, ob es sich bei dem Isolat um einen Vertreter der Roseobacter-Gruppe oder einen Vertreter einer anderen bakteriellen Gruppe handelt. 


\title{
3.2.3.2 Assimilatorische Nitrat-Reduktion in O. antarcticus
}

O. antarcticus besitzt, im Gegensatz zu O. arcticus (siehe 3.2.3.1), keine Gene für die Synthese von Stickstoff-Speicherpolymeren. Stattdessen konnte jedoch ein Gencluster der assimilatorischen Nitrat-Reduktion identifiziert werden. Dieses Gencluster beinhaltet die Bestandteile eines Nitrat ABC-Transporters, bestehend aus einem extrazellulärem SubstratBindeprotein, einer Permease und einer ATPase, sowie einer Nitrit-Reduktase, bestehend aus zwei Untereinheiten und einer Nitrat-Reduktase.

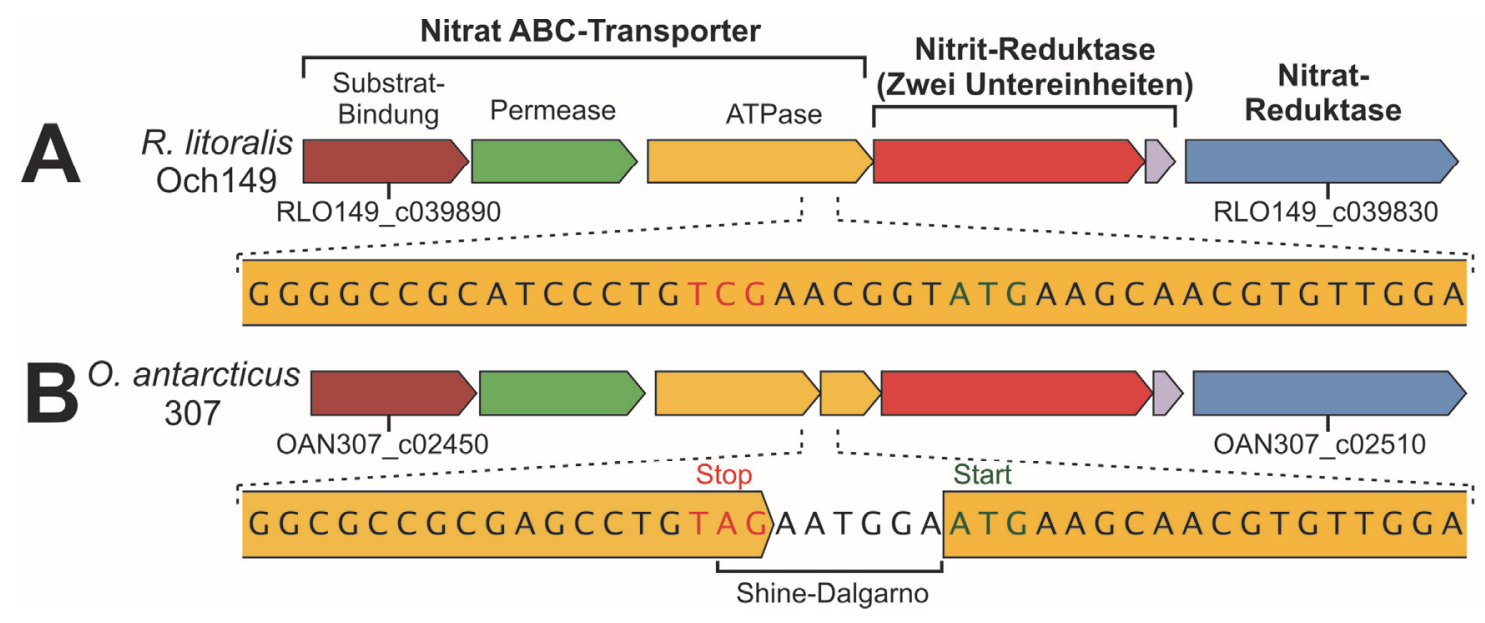

\begin{abstract}
Abb. 18 Gencluster der assimilatorischen Nitrat-Redukion in $\boldsymbol{R}$. litoralis und $\boldsymbol{O}$. antarcticus
Orthologe zwischen $O$. antarcticus und $R$. litoralis sind durch identische Färbung der jeweiligen Gensymbole gekennzeichnet. Das jeweils erste und letzte Gen der dargestellten Gencluster sind mit den entsprechenden locus tags beschriftet. Die Funktion der einzelnen Genprodukte ist jeweils für $R$. litoralis angegeben. Die Basenfolge in der unmittelbaren Umgebung der Punkmutation, welche in O. antarcticus zu einer Unterbrechung der ATPase Untereinheit des Nitrat-Transporters führte, ist für beide Vergleichsorganismen angegeben. A) Gencluster der assimilatorischen Nitrat-Reduktion in R. litoralis. B) Gencluster der assimilatorischen NitratReduktion in O. antarcticus.
\end{abstract}

Diese Eigenschaft ist innerhalb der Roseobacter-Gruppe weit verbreitet. 21 der 48 bislang sequenzierten Roseobacter-Genome, darunter Vertreter aller 5 Untergruppen (siehe 3.1.3), weisen das entsprechende Gencluster auf. Der Aufbau des Genclusters ist dabei stark konserviert und entspricht grundsätzlich der in Abb. 18A dargestellten Organisation. In O. antarcticus ist jedoch, anders als bei allen anderen Roseobactern, das Gen der ATPase Untereinheit des Nitrat-Transporters unterbrochen. Der Grund hierfür ist eine Punktmutation in Base 1262 dieses Gens, wodurch das Triplet TCG, welches für Serin kodieren würde, in das Stop-Codon TAG umgewandelt wurde. Dennoch ist der Nitrat-Transporter hierdurch nicht zwangsläufig inaktiviert. Die Punktmutation unterbricht das Gen in einem Bereich, der einer Shine-Dalgarno-Sequenz gleicht, und nur wenige Basen stromaufwärts eines potentiellen Start-Codons. Somit können sowohl das vordere als auch das hintere Fragment dieses Gens 


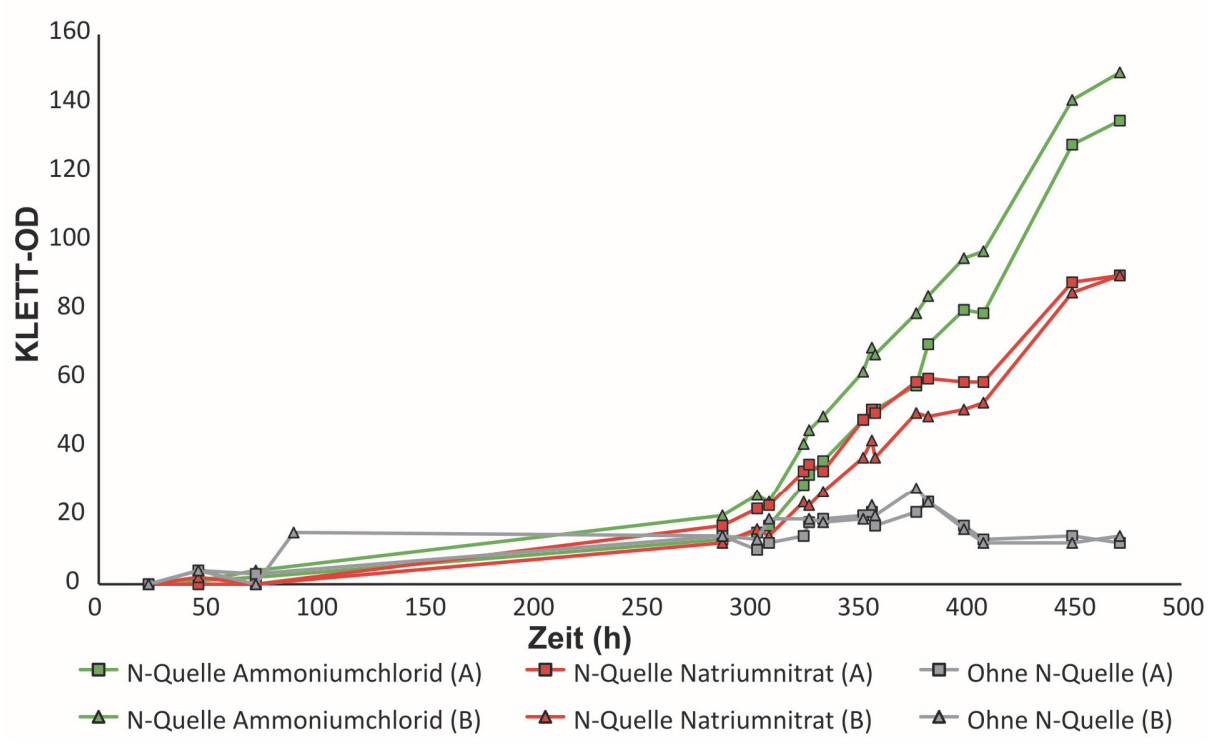

Abb. 19 Wachstum von $O$. antarcticus mit verschiedenen Stickstoffquellen

Als Basis-Medium diente gepuffertes MB2216-Medium (pH 7.5) mit geringer Zugabe von Hefeextrakt, aber ohne Zugabe von Pepton (siehe 2.2.1). Als Kohlenstoffquelle diente Glucose. Es wurden verschiedene Ansätze durchgeführt mit Ammoniumchlorid (Positivkontrolle) oder Natriumnitrat als Stickstoffquelle (N-Quelle) bzw. ohne Stickstoffquelle (Negativkontrolle). Alle Ansätze wurden in zwei Parallelen durchgeführt (A und B). Wachstum wurde durch Trübungsmessung mittels eines Klett-Summerson Photometers verfolgt. Für jede Kultur ist die Optische Dichte (OD in Klett-Einheiten) gegen die Zeit (in Stunden) aufgetragen.

translatiert werden. Um die Befähigung zur Nitrat-aufnahme zu überprüfen, wurden Wachstumsversuche mit $O$. antarcticus in Medien mit oder ohne Zugabe einer Stickstoffquelle (Ammoniumchlorid oder Natriumnitrat) durchgeführt (Abb. 19). Als Basismedium diente modifiziertes SWC-Medium in dem Pepton als vorwiegende Kohlenstoff-Quelle durch Glucose ersetzt und die Menge an zugegebenen Hefeextrakt als Vitaminquelle stark reduziert wurde (siehe 2.2.1).

O. antarcticus zeigte in Medien, welche Nitrat als hauptsächliche Stickstoff-Quelle enthielten, ein deutlich stärkeres Wachstum als in Medien ohne zugesetzte Stickstoffquelle. Das Wachstum war gegenüber solchen Kulturen, welche mit Ammonium als hauptsächlicher Stickstoff-Quelle wuchsen, nur geringfügig eingeschränkt. Dies deutet darauf hin, dass O. antarcticus in der Lage ist Nitrat aufzunehmen und als Stickstoffquelle zu nutzen.

\subsubsection{Ectoin-Aufnahme und Verwertung}

Im Gegensatz zu O. antarcticus besitzt $O$. arcticus ein Gencluster für die Aufnahme und den Abbau von Ectoin, einem kompatiblen Solut, das als Osmo- und Cryoprotektant dienen kann. Ähnliche Gencluster sind auch in einigen anderen Roseobacter-Vertretern zu finden. 
Insgesamt zwölf der 49 untersuchten Roseobacter-Stämme tragen Gene für die Aufnahme von Ectoin, während nur sieben Vertreter das Potential zur Ectoin-Verwertung besitzen. Die entsprechenden Organismen unterscheiden sich jedoch größtenteils im Typ des assoziierten Ectoin-Transporters. In $O$. arcticus ist dies ein ABC-Transporter des ehu-Typs. Die Expression dieses Typs an Ectoin- Transportern wird in Sinorhizobium meliloti durch die Verfügbarkeit von exogenem Ectoin aktiviert (Jebbar et al. 2005) und kommt nur in insgesamt 4 Roseobacter-Stämmen vor, von denen zudem nur zwei zur Verwertung von Ectoin befähigt sind. Die meisten (neun von zwölf) der zur Aufnahme von Ectoin befähigten RoseobacterStämme besitzen dagegen TRAP-Transporter des tea-Typs. Hierbei handelt es sich um eine Art von Ectoin-Transporter, welcher ebenfalls in Halomonas elongata zu finden ist und dort durch Schwankungen der Osmolarität aktiviert wird (Grammann, Volke \& Kunte 2002). In Wachstumsversuchen konnte gezeigt werden, dass O. arcticus in der Lage ist, Ectoin als hauptsächliche Kohlenstoff- und Energiequelle zu nutzen (Abb. 20).

Im Gegensatz zu O. antarcticus, dem entsprechende Gencluster fehlen, wies $O$. arcticus bei Zugabe von Ectoin als hauptsächlicher Kohlenstoff- und Energiequelle ein deutlich stärkeres Wachstum auf als in Ansätzen ohne zusätzliche Kohlenstoffquelle. Allerdings war das Wachstum deutlich weniger stark ausgeprägt als bei Ansätzen mit Pepton oder Glucose als hauptsächlicher Kohlenstoffquelle.

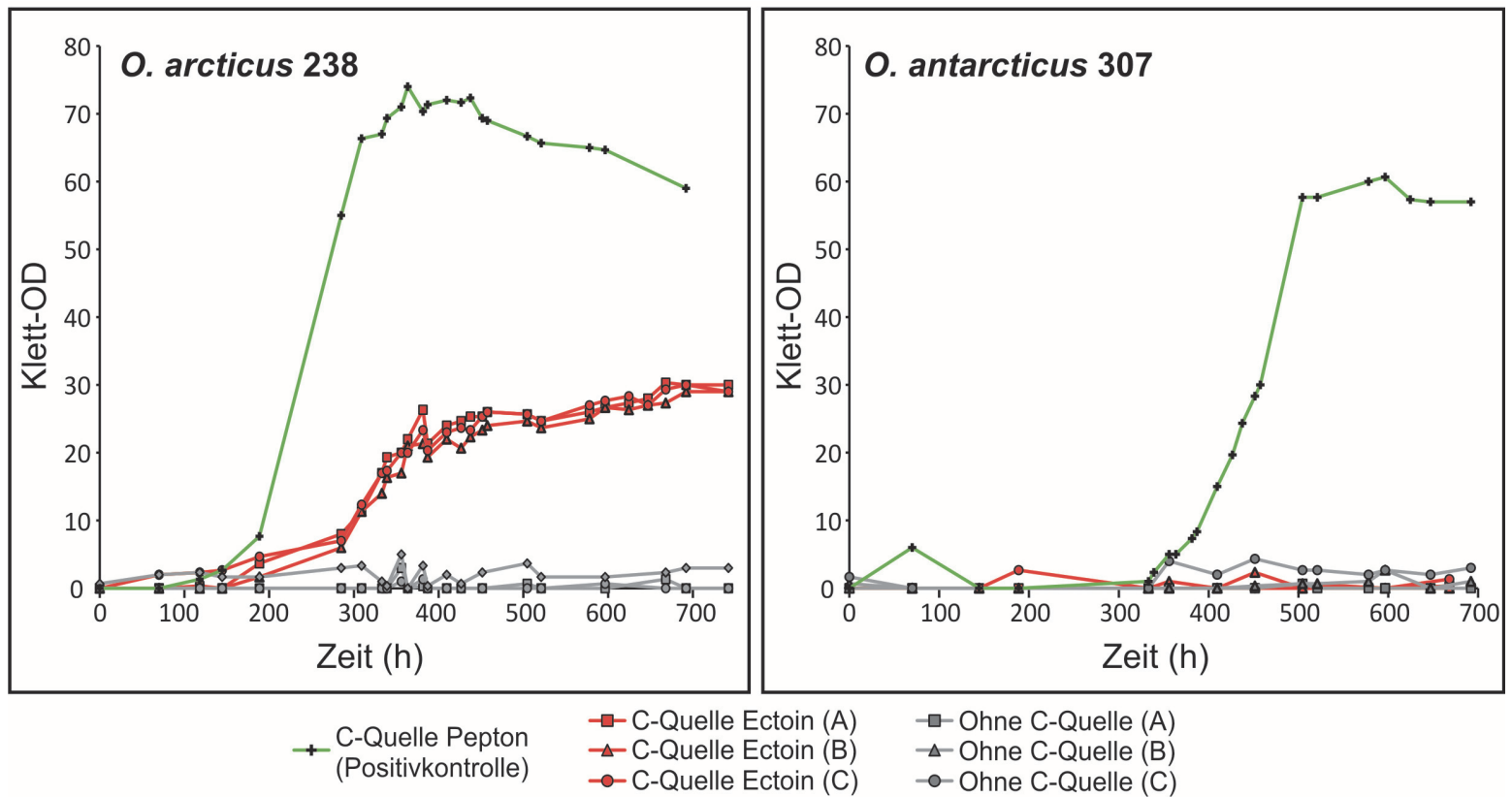

Abb. 20 Wachstum von Octadecabacter-Kulturen mit Ectoin als hauptsächlicher Kohlenstoffquelle Als Basis-Medium diente gepuffertes SWC-Medium ( $\mathrm{pH}$ 7.5) mit geringer Zugabe von Hefeextrakt aber ohne Zugabe von Pepton (siehe 2.2.1). Es wurden verschiedene Ansätze durchgeführt mit Pepton (Positivkontolle) oder Ectoin als Kohlenstoffquelle (C-Quelle) bzw. ohne Kohlenstoffquelle (Negativkontrolle). Ansätze mit Ectoin sowie Negativkontrollen wurden in drei Parallelen durchgeführt (A, B und C). Wachstum wurde durch Trübungsmessung mittels eines Klett-Summerson Photometers verfolgt. Für jede Kultur ist die Optische Dichte (OD in Klett-Einheiten) gegen die Zeit (in Stunden) aufgetragen. 


\subsubsection{Ribulose-1,5-Bisphosphat-Carboxylase/Oxygenase(RuBisCO)-ähnliches Gen}

O. antarcticus weist ein Gen auf, welches ein Ribulose-1,5-BisphosphatCarboxylase/Oxygenase (RuBisCO)-ähnliches Protein kodiert (OAN307_c00690). Orthologe dieses Gens sind nur in sechs anderen Roseobacter-Genomen zu finden: Citreicella sp. SE45, Jannaschia sp. CCS1, O. granulosus HTCC2516, P. bermudensis HTCC2601 Rhodobacteraceae sp. MED193 und „Ca. P. marina” RCA23. Die höchste Ähnlichkeit, sowohl in der Aminosäuresequenz als auch in der Organisation der näheren Genumgebung, wies das entsprechende Ortholog von „Ca. P. marina“ RCA23 auf (Abb. 21). In O. arcticus ist kein Ortholog dieses Gens vorhanden.

BLAST-Analysen zeigten eine nahe Verwandtschaft zu dem Swissprot-Eintrag Q8KBL4, einem Protein aus Chlorobium tepidum DSM12025. Funktionelle Analysen dieses Proteins hatten ergeben, dass es nicht an einer Fixierung von Kohlenstoff beteiligt ist, aber dafür wahrscheinlich eine Rolle im Sulfat-Metabolismus und der osmotischen Stress-Antwort spielt (Hanson \& Tabita 2001). Diese Art von RuBisCO-ähnlichen Proteinen wird als Typ IV RuBisCo oder RuBisCO-Like Protein (RLP) bezeichnet (Tabita et al. 2007).

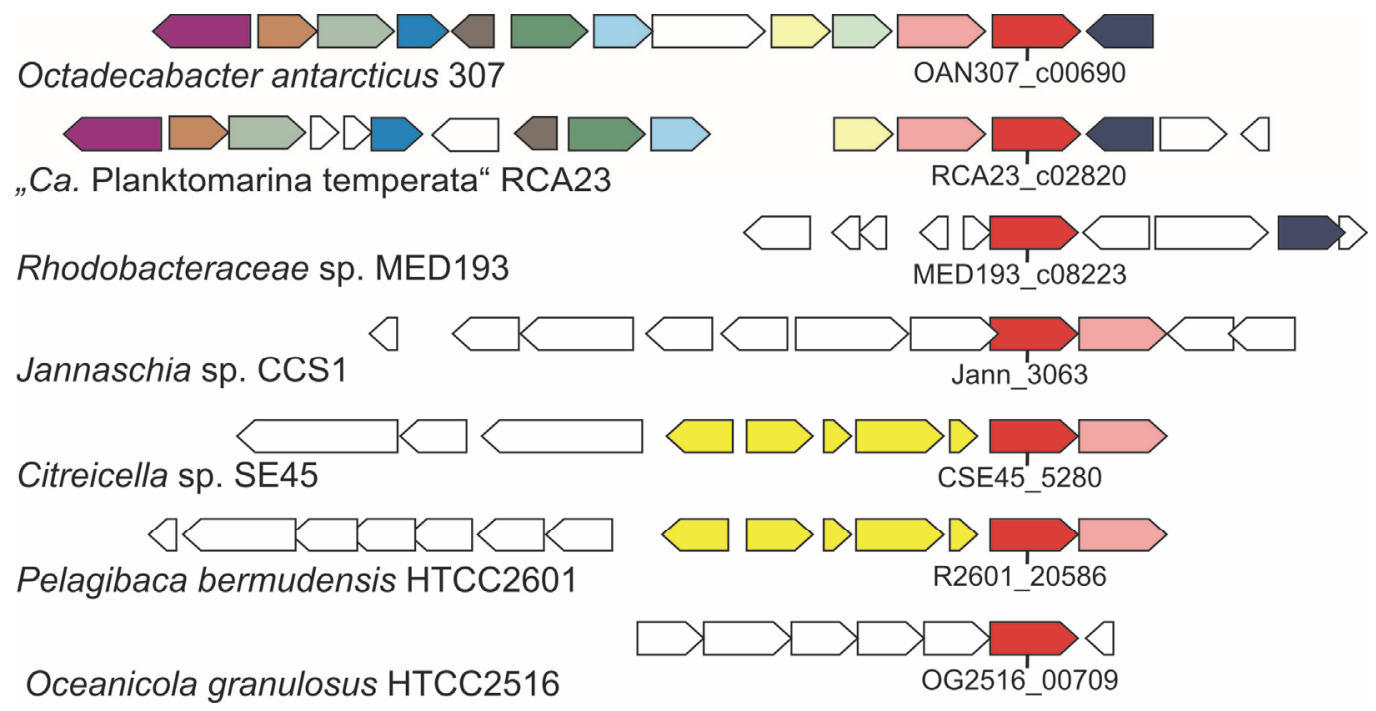

Abb. 21 Gencluster RuBisCO-ähnlicher Gene in Roseobacter-Vertretern

Gene, welche keine Orthologe zu den entsprechenden Genclustern der Vergleichsstämme aufwiesen, sind in Weiß dargestellt Andere Farben kennzeichnen Orthologe zwischen den Vergleichsstämmen. RuBisCO-ähnliche Gene sind in Rot dargestellt und mit dem jeweils entsprechenden locus tag beschriftet. 


\subsubsection{Typ IV-Sekretionssystem in O. arcticus}

O. arcticus besitzt 3 Gencluster, welche einem Typ IV Sekretionssystem zuzuordnen sind (Abb. 22). Vertreter dieses vielseitigen Sekretionssystems sind in verschiedenen bakteriellen Organismen als Mechanismen der Konjugation, der natürlichen Transformation oder der Übertragung von Effektoren nachgewiesen worden (Cascales \& Christie 2003; Fronzes, Christie \& Waksman 2009; Wallden, Rivera-Calzada \& Waksman 2010). Typ IV Sekretionssysteme können somit entweder Instrumente des horizontalen Gentransfers oder Merkmale der Pathogenität sein. Entsprechende Gencluster sind in 18 der 49 RoseobacterVergleichsstämme zu finden, fehlen jedoch in O. antarcticus 307 und „Ca. P. temperata“ RCA23.

Im Gegensatz zu den anderen Roseobacter-Stämmen, welche Typ IV Sekretionssysteme aufweisen, sind in $O$. arcticus die entsprechenden Gencluster auf verschiedene Genomregionen verteilt. Da die Gencluster in O. arcticus zudem von transposablen Elementen flankiert werden, ist dies vermutlich auf intragenomische Rekombinationsereignisse zurückzuführen. Das erste Gencluster, bestehend aus den Genen von VirB2-VirB5, VirB8, zwei putativen lytischen Transglycosilasen sowie zwei konservierten hypothetischen Proteinen, befindet sich im Bereich von Oar-RGP 3. Dieses Gencluster ist aufgrund von zwei Punktmutationen in virB4 und einer Insertion eines transposablen Elements in virB8 defekt. Die

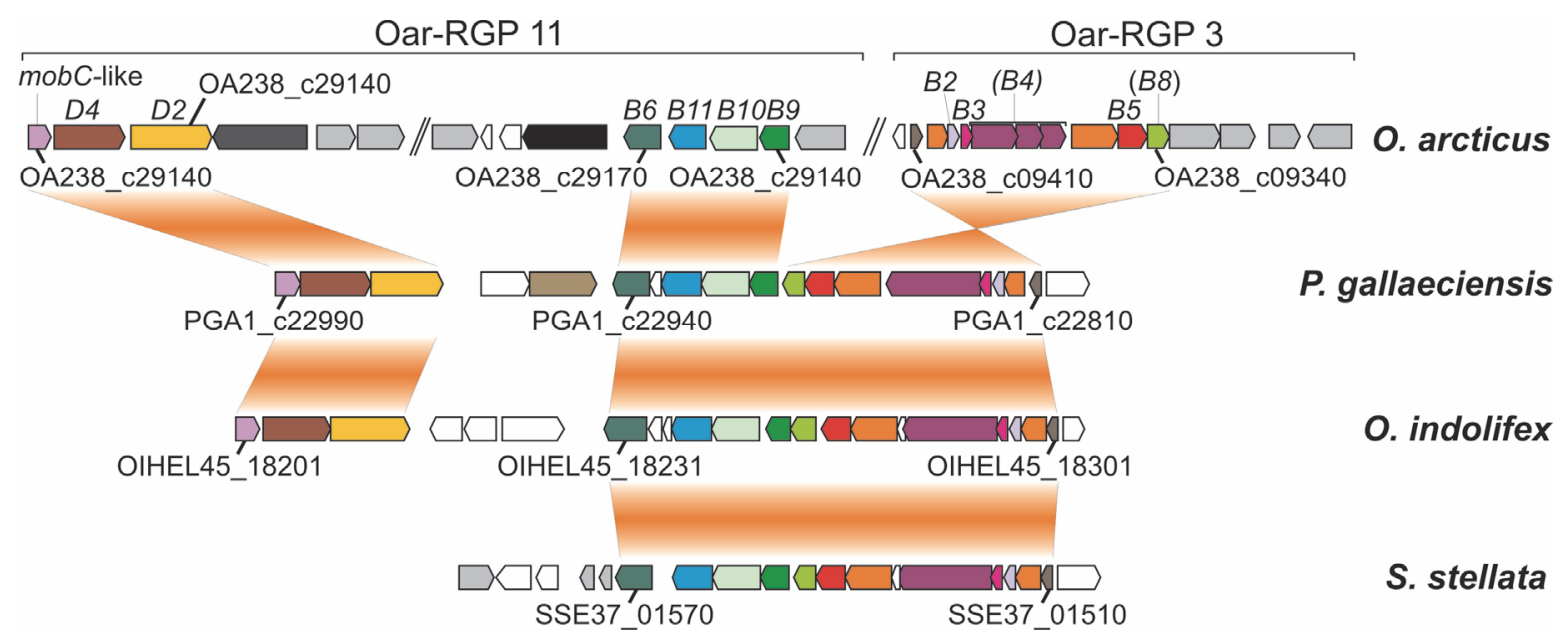

\footnotetext{
Abb. 22 Gencluster der Typ IV Sekretionssysteme in $O$. arcticus 238 und ausgewählten Vergleichsorganismen

Graue und schwarze Färbung kennzeichnet jeweils Transposasen und Rekombinasen. Weiße Färbung kennzeichnet Gene, welche keine Orthologe in den entsprechenden Genclustern der Vergleichsstämme aufwiesen. Alle anderen Farben markieren Orthologe zwischen Vergleichsstämmen. Die Typ IV Sekretionssystemgene virB2-B11 und virD2-D4 sind jeweils für O. arcticus mit B2-B11 bzw D2-D4 beschriftet. Beschriftungen in Klammern weisen auf Pseudogene in O. arcticus hin. Die jeweils ersten und letzten Gene zusammengehöriger Gencluster sind mit den entsprechenden locus tags beschriftet.
} 


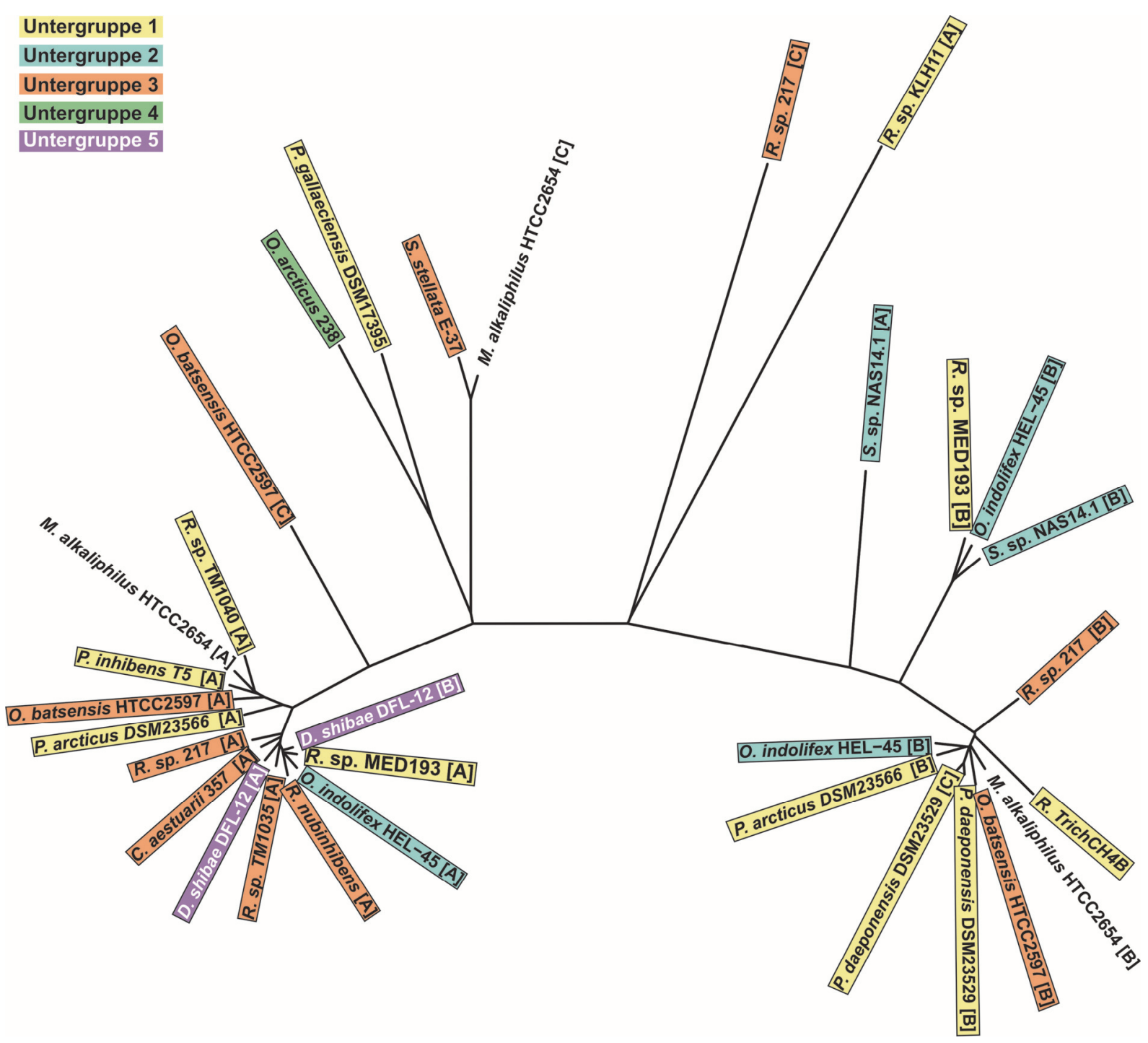

Abb. 23 Phylogenie von Typ IV-Sekretionssystemen in Vertretern der Roseobacter-Gruppe

Dargestellt ist ein ungewurzelter Neighbor-Joining Stammbaum, basierend auf den Aminosäuresequenzen der Genprodukte VirB9-11. Einige Vergleichsorganismen besitzen mehrere Paraloge dieser Gene. In diesen Fällen sind die jeweiligen Paraloge in eckigen Klammern mit A-C gekennzeichnet. Zugehörigkeit zu einer der MLSAbasierten Roseobacter-Untergruppen ist durch farbige Hinterlegung gekennzeichnet.

anderen beiden Gencluster befinden sich in einigem Abstand zueinander im Bereich von OarRGP 11. Ein Gencluster kodiert die Proteine VirB6 und VirB9-VirB10, während das andere Gencluster VirD2, VirD4 sowie ein MobC-ähnliches Protein kodiert. Phylogenetische Analysen dieser Sekretionssysteme, basierend auf Aminosäuresequenzen der Genprodukte VirB9-11, ergaben keinen direkten Zusammenhang mit der MLSA-basierten Phylogenie der Roseobacter-Gruppe (Abb. 23). 


\subsubsection{Charakteristische Gemeinsamkeiten zwischen $\boldsymbol{O}$. arcticus und $\boldsymbol{O}$. antarcticus}

\subsubsection{Gene Transfer Agents (GTAs)}

Gene Transfer Agents (GTAs) sind keine spezifische Eigenschaft der OctadecabacterStämme, sondern ein Merkmal, das der Großteil der Roseobacter-Gruppe teilt (Newton et al. 2010), und dementsprechend nicht in einer Region erhöhter Genomplastizität (RGP) lokalisiert (Abb. 12). Es handelt sich dabei um Phagen-ähnliche Partikel, welche zufällige Fragmente des Wirtsgenoms verpacken und in nah verwandte Bakterien einschleusen können (Lang, Zhaxybayeva \& Beatty 2012). Entsprechende Gencluster sind in 43 der 49 sequenzierten Roseobacter-Vertretern vorhanden und stark konserviert (Abb. 24). Organismen, welche kein entsprechendes Gencluster aufweisen, sind Rhodobacteraceae sp. R2A57, HTCC2255, KLH11 sowie Thalassobium sp. R2A62. Rhodobacteraceae sp. HTCC2083 und "Cand. P. temperata" RCA23 besitzen ebenfalls keine vollständigen GTA Gencluster. Diese beiden Organismen weisen jedoch Genfragmente auf, welche darauf hindeuten, das GTAs in den Vorfahren dieser Stämme noch vorhanden waren (Abb. 24).

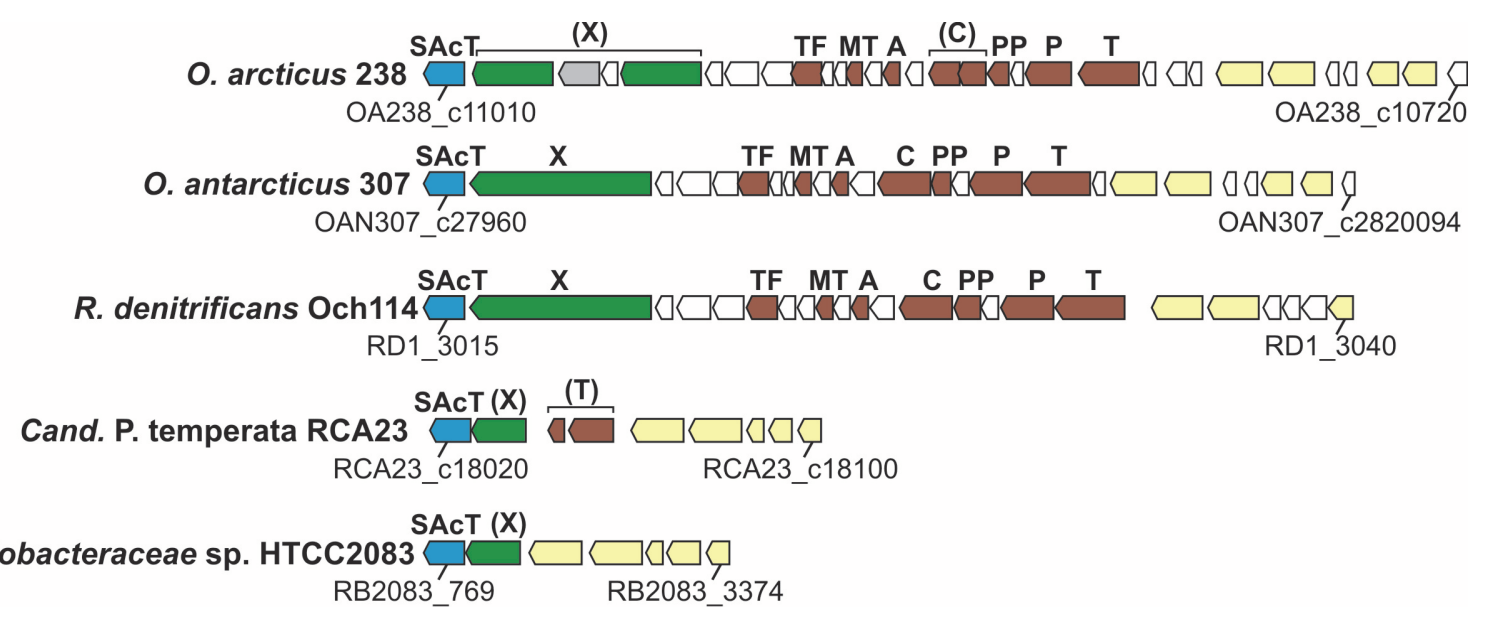

Abb. 24 Gene Transfer Agent (GTA)-Gencluster und Umgebung in verschiedenen Roseobacter-Vertretern GTA-Gencluster befinden sich häufig in der Umgebung eines konservierten Serin-O-Acetyl Transferase(SAcT)-Gens (blau). Das erste Gen des GTA-Clusters (X) kodiert ein großes hypothetisches Protein unbekannter Funktion und ist grün dargestellt. Dieses Gen ist in Rhodobacteraceae sp. HTCC2083 und Cand. P. temperata RCA23 fragmentiert. In O. arcticus ist ein transposables Element in dieses Gen inseriert (grau). Die charakterisierten Bestandteile des Genclusters, Schwanzfaser Protein (TF), primäres Schwanzprotein (MT), Kopf-Schwanz-Adaptor (A), primäres Capsid (C), Kopf-Protease (PP), Portal-Protein (P) und Terminase (T), sind in braun dargestellt. Pseudogene sind dadurch markiert, dass die Beschriftungen in Klammern gesetzt wurden. Konservierte Wirts-Gene (mit Ausnahme von sacT) sind in Gelb dargestellt. Das erste und das letzte Gen der einzelnen Gencluster sind jeweils mit dem entsprechenden Locus tag beschriftet. 


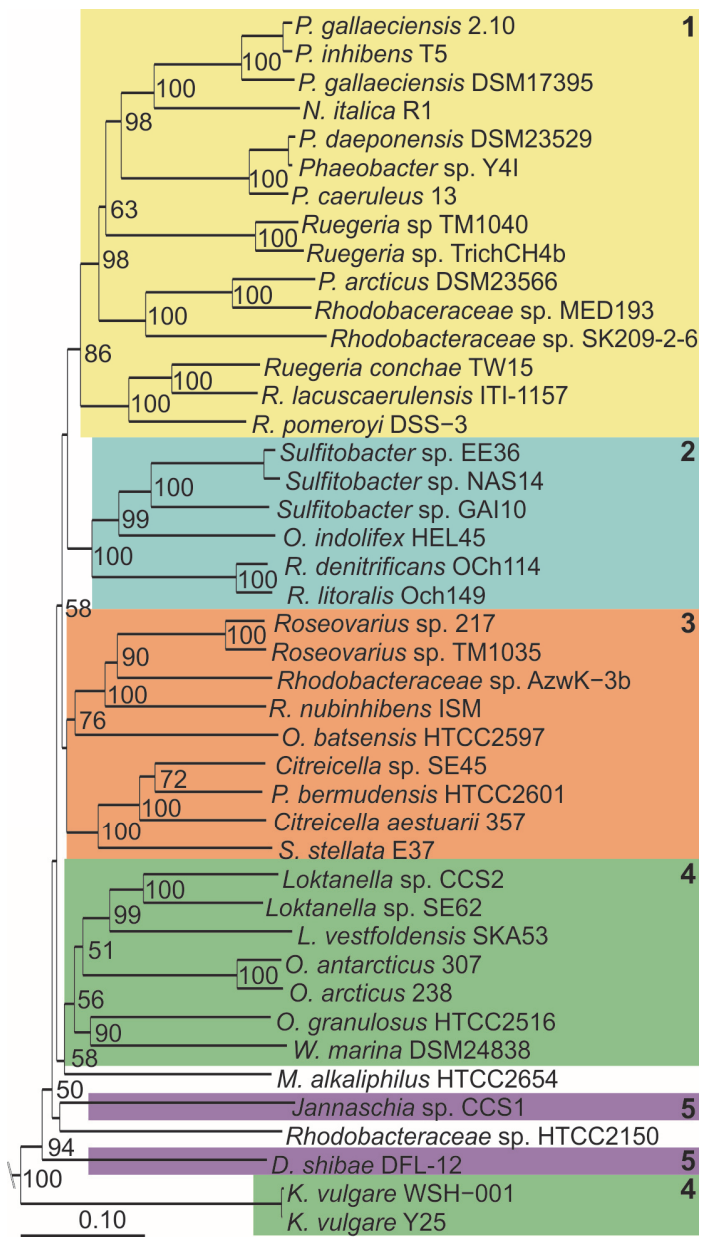

Abb. 25 Neighbor-Joining-Baum von GTA-Genprodukten in Vertretern der Roseobacter-Gruppe Bootstrap-Werte über $50 \%$ sind an den entsprechenden Verzweigungen angegeben. Farbmarkierungen und Nummerierungen weisen auf die Untergruppenzugehörigkeit der entsprechenden Organismen hin (siehe 3.1.3.1)
Die Aminosäure-Sequenzen konservierter GTA-Genprodukte wurden konkateniert und für phylogenetische Analysen verwendet (siehe 2.10.7). Es zeigte sich, dass die Verwandtschaftsverhältnisse der GTAGencluster in den verschiedenen Roseobacter-Vertretern weitestgehend die durch Multilokus Sequenzanalysen (MLSA) des Core-Genoms (siehe 3.1.3.1) ermittelte Phylogenie der Roseobacter-Gruppe widerspiegelt (Abb. 25). Abweichungen gab es lediglich in Bezug auf die beiden terrestrischen K. vulgare-Stämme, welche laut GTA-Phylogenie deutlich von den übrigen Vertretern der Untergruppe 4 abzugrenzen sind, sowie in Bezug auf Jannaschia sp. CCS1 und D. shibae DFL12, welche in GTA-Sequenzvergleichen, im Gegensatz zu Core-GenomVergleichen, keine gemeinsame Gruppe bilden.

\subsubsection{Flagellen}

Obwohl O. arcticus 238 und $O$. antarcticus 307 als unbeweglich beschrieben wurden (Gosink, Herwig \& Staley 1997), sind in beiden Genomen drei zusammengehörige Gencluster zu finden, welche für Flagellen-Synthese kodieren. In $O$. arcticus befinden sich die Gencluster auf dem Plasmid pOAR118 (Oar-RGP 18) während sie in O. antarcticus auf dem Chromosom in Region Oan-RGP 9 zu finden sind. Die Reihenfolge der Gencluster unterscheidet sich in den beiden Octadecabacter-Stämmen etwas, die einzelnen Cluster sind jedoch in beiden Organismen nahezu identisch aufgebaut (Abb. 26). 


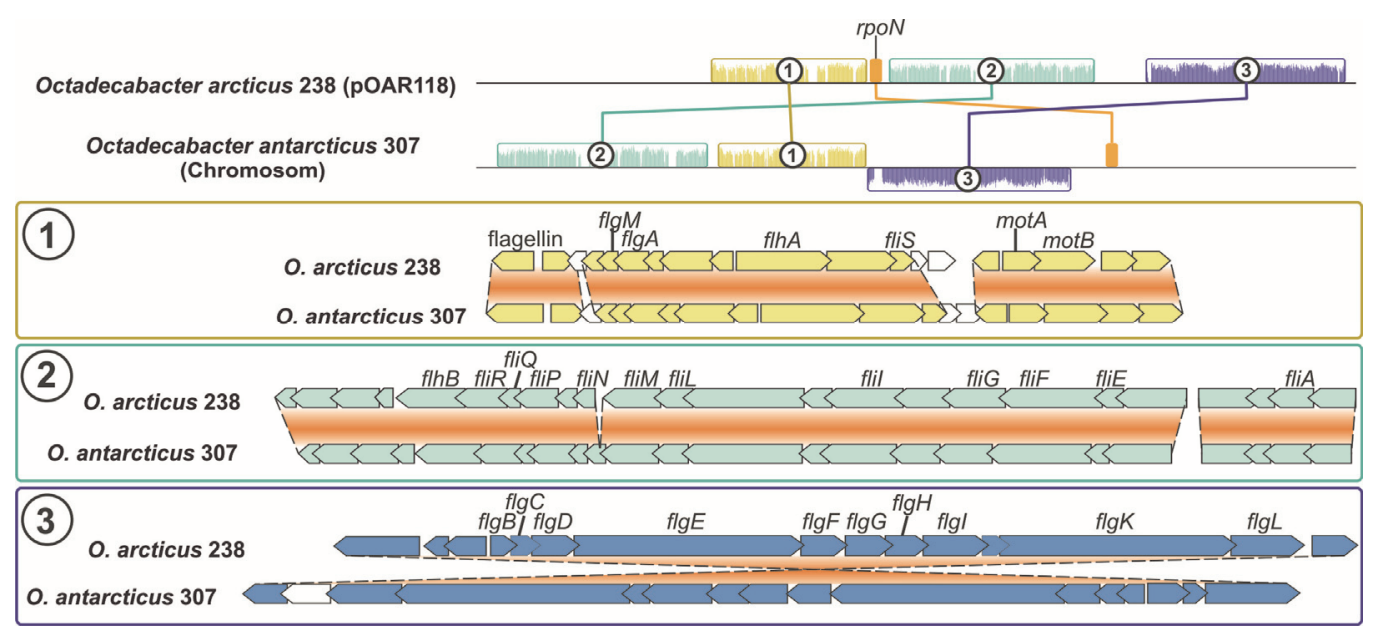

Abb. 26 Flagellen-Gencluster in $\boldsymbol{O}$. arcticus 238 und $\boldsymbol{O}$. antarcticus 307.

Die obere Abbildung stellt die relative Orientierung der drei Flagellengencluster beider OctadecabacterVertreter dar. Die Organisation der einzelnen Flagellengencluster ist darunter abgebildet. Hypothetische Gene sind weiß dargestellt. Alle anderen Farben deuten auf Orthologe in den Octadecabacter-Vertretern hin. Dargestellt ist der Genombereich zwischen den locus tags OA238_118p0200-118p0780 (O. arcticus 238) und OAN307_c29440-c30060 (O. antarcticus 307).

BLAST-Vergleiche (siehe 2.9.3) zeigten, dass die Produkte der Flagellen-Synthesegene beider Octadecabacter-Stämme in ihren Aminosäure-Sequenzen stark von denen der meisten motilen Roseobacter-Vertretern abweichen. Für eine genauere Analyse wurden 15 Flagellengene (flgA, flgB, flgC, flgD, flgF, flgG, flgH, flgI, flhA, flhB, fliE, fliI, fliL, fliQ, und $f l i R)$ identifiziert, welche in allen Flagellen-Gencluster besitzenden Roseobactern vorhanden waren. Die Aminosäuresequenzen der entsprechenden Genprodukte wurden konkateniert und phylogenetischen Analysen unterzogen (siehe 2.10.7). Die resultierenden Stammbäume bestätigten, dass die Flagellen-Gencluster der Octadecabacter-Stämme von der Norm der bisher sequenzierten Roseobacter-Stämme abweichen (Abb. 27). So zeichnen sich zwei eindeutig umgrenzte Typen an Flagellen-Genclustern ab. Der Großteil (85\%) der FlagellenCluster der Roseobacter-Gruppe fällt in Typ I. Dieser Typ lässt sich desweiteren in zwei deutliche Unterkategorien einteilen. Typ Ia, welcher innerhalb der Roseobacter-Gruppe am stärksten verbreitet ist, und Typ Ib, welcher Gencluster von Sulfitobacter sp. NAS141 + EE36, Oceanibulbus indolifex HEL45, Oceanicola batsensis HTCC2597 sowie Oceanicola granulosus HTCC2516 beinhaltet. Das Genom von O. granulosus HTCC2516 beinhaltet sowohl Gencluster des Typs Ia als auch des Typs Ib. Die Gencluster der OctadecabacterStämme fallen hingegen in Typ II, welcher zudem Gencluster der Roseobacter-Vertreter Roseovarius sp. TM1035, Loktanella vestfoldensis SKA53, Rhodobacteraceae sp. HTCC2083, und Cand. Planktomarina temperata RCA23 enthält. Sowohl Roseovarius sp. TM1035 als auch Rhodobacteraceae sp. HTCC2083 besitzen zusätzlich ein zweites 
Gencluster vom Typ I. Weitere Vertreter des Typs II sind diverse Rhodobacter sphaeroides Stämme, sowie mehrere Vertreter des SAR11-Clusters. Interessanterweise weist Typ II der Flagellen-Gencluster eine nähere Verwandtschaft zu Genclustern der Gammaproteobacteria als zu solchen des Typs I auf.

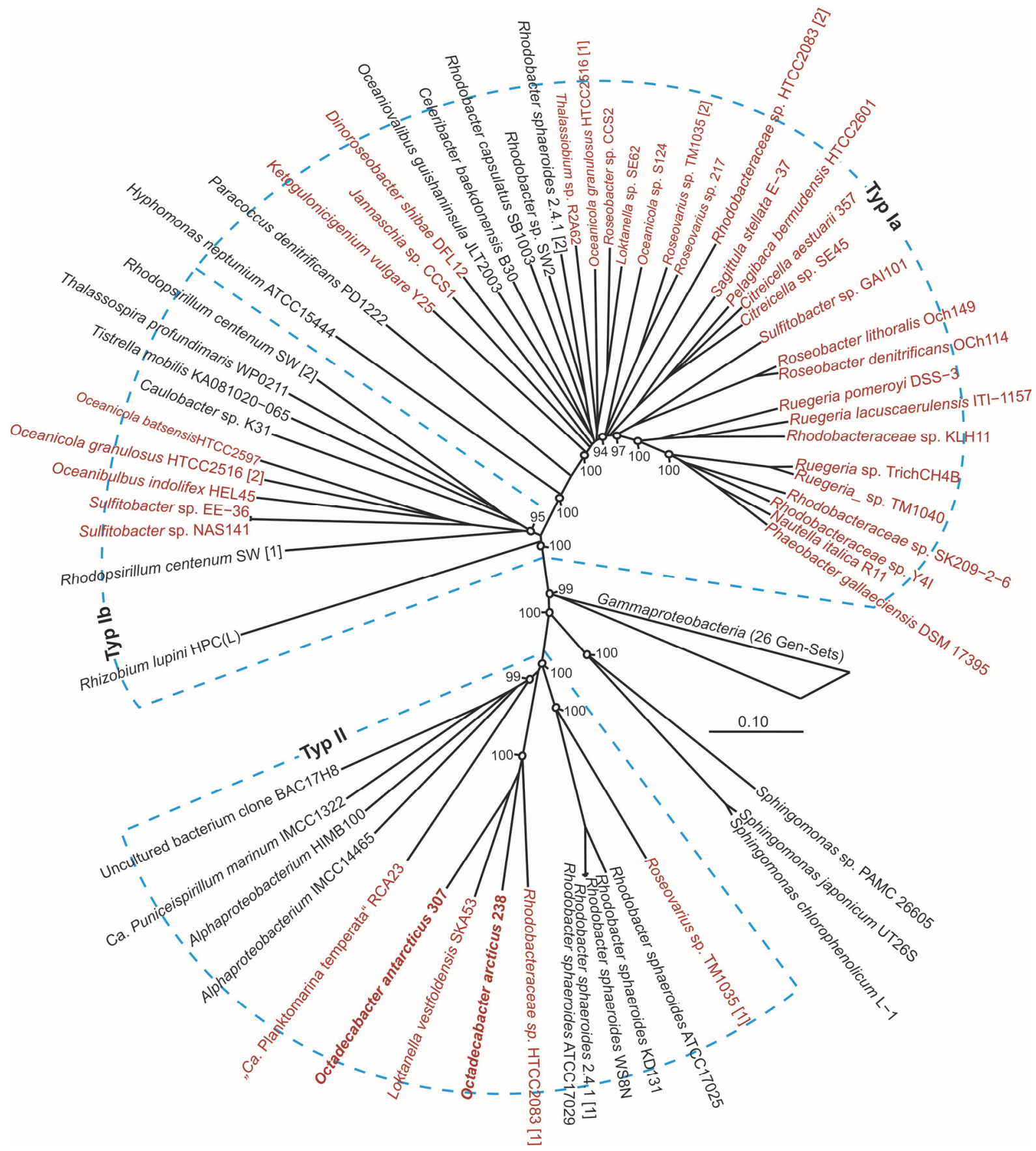

Abb. 27 Phylogenie der Flagellen-Gencluster in Vertretern der Roseobacter-Gruppe und verwandten Organismen.

Vertreter der Roseobacter-Gruppe sind in roter Schrift dargestellt. Vertreter anderer AlphaproteobacteriaGruppen sind in schwarzer Schrift dargestellt. Repräsentanten der Gammaproteobacteria wurden aus Gründen der Übersichtlichkeit kollabiert. Für ausgewählte Verzweigungen wurden Bootstrap-Werte angegeben (durch Kreise markiert). Drei verschiedene Flagellentypen (Typ Ia, Typ Ib und Typ II) sind anhand der phylogenetischen Beziehungen ersichtlich. Diese Flagellentypen sind blau umkreist und entsprechend beschriftet. 


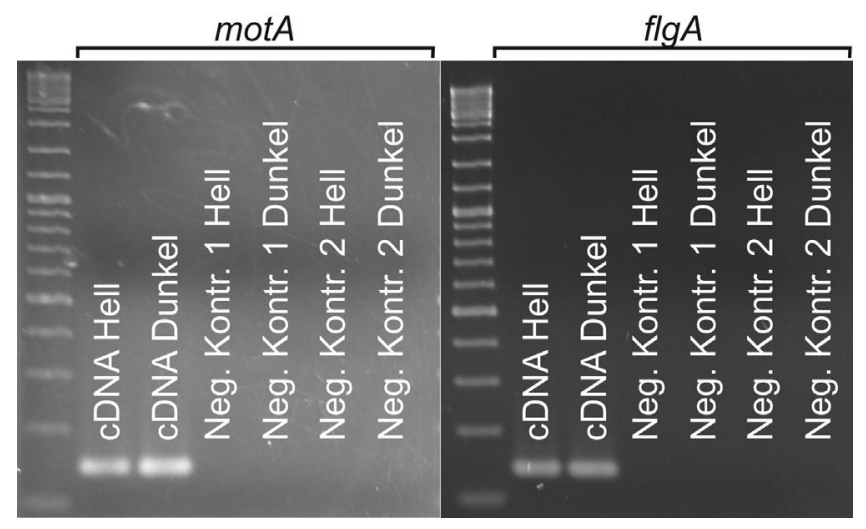

\begin{abstract}
Abb. 28 RT-PCR mit Flagellin-spezifischen Primern
Transcripte der Flagellengene motA und $f l g A$ wurden durch spezifische PCRs nachgewiesen (siehe 0). MatrizencDNA wurde aus RNA-Extrakten von O. arcticus 238-Kulturen, welche mit Licht (Hell) bzw. bei Dunkelheit (Dunkel) angezogen wurden erzeugt. Es wurden jeweils zwei Negativkontrollen durchgeführt: Eine Kontrolle wurde mit einem RNA-Aliquot durchgeführt, welches wie ein Ansatz der cDNA-Synthese behandelt wurde, jedoch ohne Zugabe von reverser Transkriptase (Neg. Kontr. 1). Bei der anderen Kontrolle wurde unverdünntes RNA-Extrakt ohne weitere Behandlung als Matrize eingesetzt (Neg. Kontr. 2). Als Positivkontrolle diente Chromosomale DNA von O. arcticus 238 (nicht abgebildet).
\end{abstract}

Durch RT-PCRs konnten Transkripte der Flagellengene mot $A$ und $f l g A$ in $O$. arcticus nachgewiesen werden (Abb. 28). Versuche, diese Flagellen durch Anfärbung unter dem Lichtmikroskop sichtbar $\mathrm{zu}$ machen (siehe 2.2.5) waren jedoch nicht erfolgreich. Verschiedene Motilitäts-Nachweise (siehe 2.2.5) fielen ebenfalls negativ aus (Tab. 12).

In Bezug auf „Ca. Planktomarina temperata“ RCA23 sind ursprünglich ähnliche Beobachtungen gemacht worden. Die Zellen dieses Bakteriums wiesen, wie auch die der Octadecabacter-Stämme, unter dem Phasenkontrast-Mikroskop deutliche Zuckungen auf, jedoch keine gerichtete Fortbewegung (Giebel, H.-A., persönliches Gespräch). Zunächst war unklar ob die beobachteten Zuckungen auf eine generelle Beweglichkeit des Organismus zurückzuführen waren, in späteren Tests konnte jedoch schließlich die Motilität dieses Organismus nachgewiesen werden (Voget, Vollmers et al. 2013).

Tab. 12 Ergebnisse verschiedener Motilitäts-Tests mit $O$. arcticus 238 und $O$. antarcticus 307

\begin{tabular}{cc}
\hline Ansatz & Beobachtung \\
\hline Weich-Agar Stichkulturen in Kultur-Röhrchen & Wachstum nur innerhalb des Einstichs. Kein \\
Punktförmige Inokulation von Weich-Agar- & Eindringen von Zellen in das umgebende Medium \\
Platten & Kompakte, kreisförmige Kolonien ohne \\
Beobachtungen mittels Phasen-Kontrast- & schwarmförmige Ausbreitung \\
Mikroskopie & Deutliches Zucken der Zellen zu sehen, jedoch keine \\
\end{tabular}




\subsubsection{Gasvesikel}

In beiden Octadecabacter-Genomen konnten Gencluster der Gasvesikel-Synthese identifiziert werden (Abb. 29a). In O. antarcticus befindet sich das Gencluster auf dem Chromosom in Region Oan-RGP 9, während es in O. antarcticus auf dem Plasmid pOAR160 enthalten ist. Gasvesikel-Bildung ist eine charakteristische Eigenschaft des Genus Octadecabacter (Gosink, Herwig \& Staley 1997). Heterotrophe Organismen mit der Befähigung zur GasvesikelBildung sind für die meisten marinen Habitate sehr ungewöhnlich, in Meereis jedoch häufiger vorzufinden. Entsprechend weist der überwiegende Teil der bislang sequenzierten Roseobacter-Vertreter keine Homologe zu Genen dieses Clusters auf. Einzige Ausnahmen stellen die zwei Loktanella-Stämme CCS2 und SE-62 dar (Abb. 29b). Loktanella CCS2 weist ein einzelnes $g v p K$ aber keine weiteren Gasvesikel-Gene auf. Loktanella SE-62 besitzt hingegen auch weitere Gasvesikel-Gene in einem zusammenhängenden Cluster. BLASTVergleiche zeigten jedoch, dass diese Gene nur sehr geringe Sequenzähnlichkeiten zu den entsprechenden Genen in $O$. arcticus und $O$. antarcticus aufweisen. Stattdessen ähneln sie stark entsprechenden Gasvesikel-Genen in Rhodobacter capsulatus BS1003. In Loktanella sp.

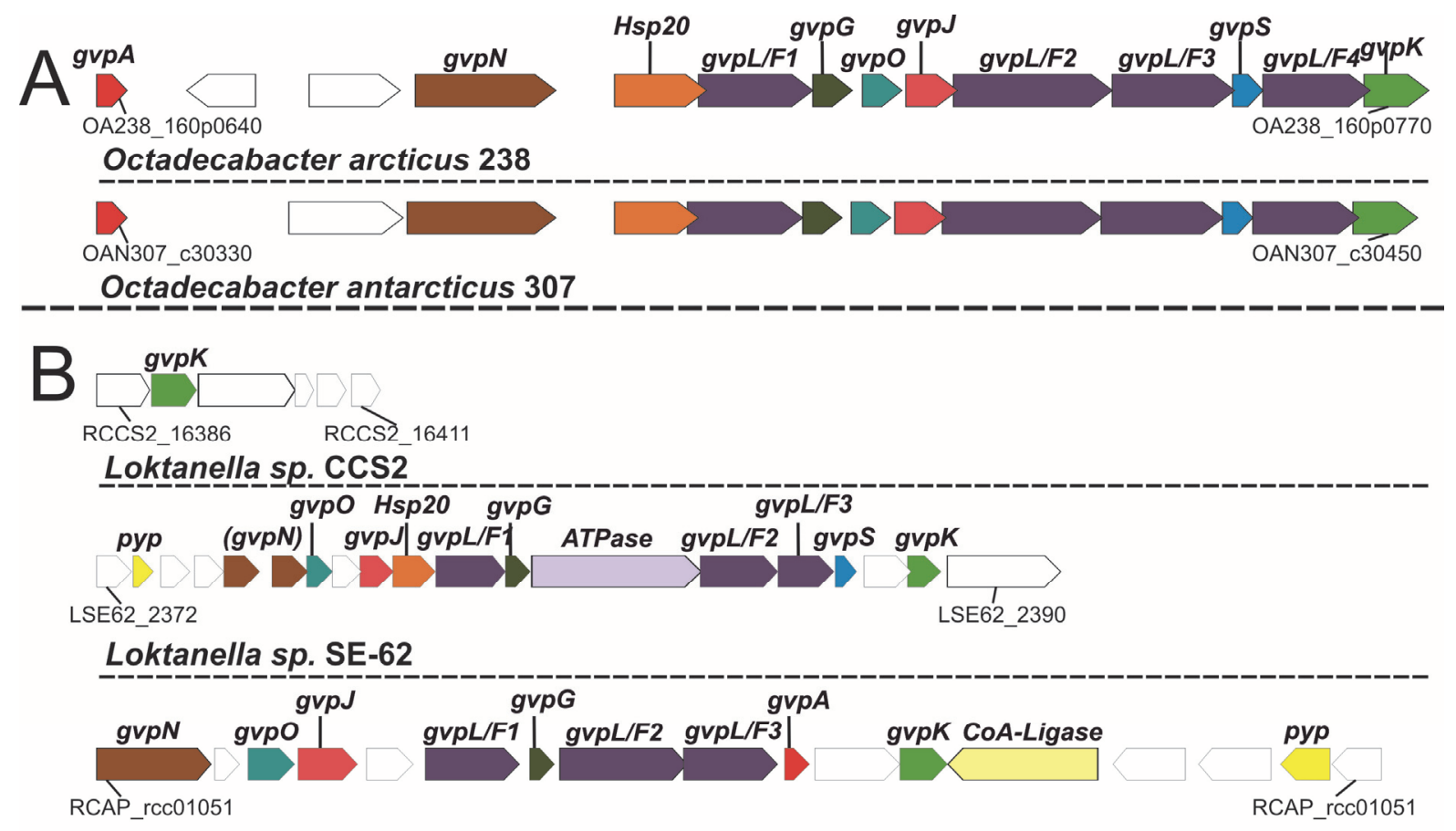

Rhodobacter capsulatus SB1003

\section{Abb. 29 Gasvesikel-Gencluster in beiden Octadecabacter-Stämmen}

a) Gasvesikel-Gencluster der Octadecabacter-Stämme. b) Gasvesikel-Gencluster in Loktanella-Stämmen und Rhodobacter capsulatus SB1003. Gene mit homologer Funktion sind durch identische Färbung gekennzeichnet. Hypothetische Proteine sind in Weiß dargestellt. Trotz funktioneller Übereinstimmung weisen die GasvesikelGenprodukte von $R$. capsulatus und Loktanella nur sehr geringe Sequenz-Übereinstimmungen mit den entsprechenden Produkten der Octadecabacter-Stämme auf. Das jeweils erste und letzte Gen jedes der dargestellten Gencluster ist mit dem entsprechenden locus tag beschriftet. 
SE-62 ist zudem, ebenso wie in R. capsulatus SB1003, ein pyp (yellow photoactive protein)Gen (Kyndt et al. 2004) eng mit diesem Cluster assoziiert (Abb. 29b). Die Gencluster von $O$. arcticus und $O$. antarcticus sind nahezu identisch aufgebaut, unterscheiden sich aber eindeutig von den Genclustern der Loktanella-Stämme und R. capsulatus. Die OctadecabacterGencluster beinhalten Homologe zu sämtlichen 8 Genen ( $g v p A J S$, gvpLF, gvpG, gvpO und gvpK), welche in Halobacterium salinarum PHH1 als essentiell für Gasvesikel-Bildung identifiziert wurden. Darüber hinaus sind Gene des Chaperons GvpN, eines HSP20Hitzeschock-Proteins und eines weiteren konservierten hypothetischen Proteins enthalten.

\subsubsection{Quecksilber-Resistenz}

Auf den Chromosomen beider Octadecabacter-Stämme sind nahezu identische QuecksilberResistenz-Gencluster vorhanden (Abb. 30). Diese Cluster beinhalten Gene des Regulators MerR, des Quecksilber-Transporters MerTPF und der Quecksilber-Reduktase MerA. Während im Genom von O.arcticus nur eine Version des Clusters in Oar-RGP 14 vorhanden ist, besitzt $O$. antarcticus eine intakte Kopie in Oan-RGP 8 und eine defekte in Oan-RGP 10, welche eine Rasterschubmutation im Transporter-Gen merT aufweist. Ähnliche QuecksilberResistenz-Gencluster konnten in 10 der 49 übrigen Roseobacter-Vertretern gefunden werden.

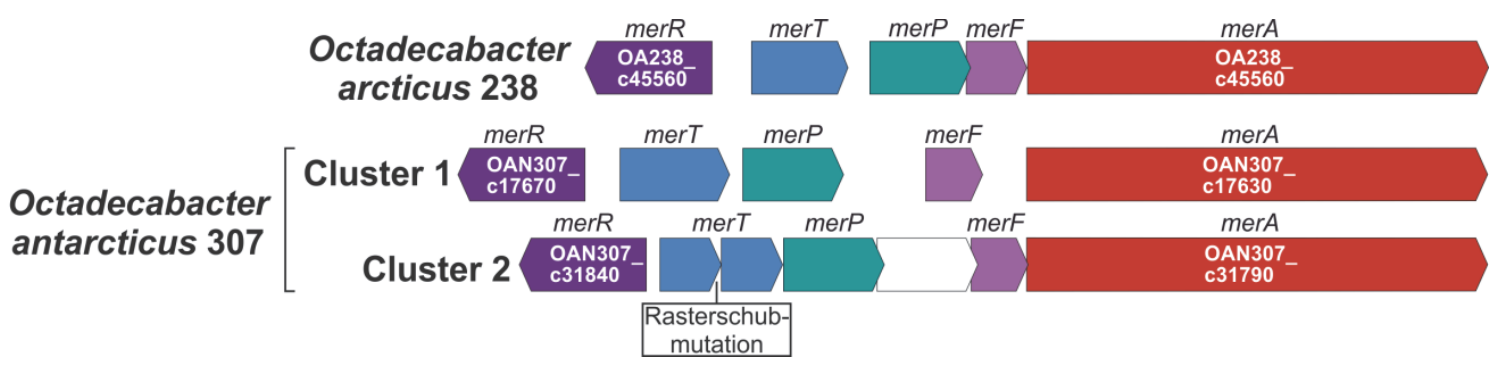

Abb. 30 Schwermetall-Resistenz-Gencluster in den Octadecabacter-Stämmen

Homologe Gene sind durch identische Färbung gekennzeichnet. Hypothetische Proteine sind in Weiß dargestellt. Für das jeweils erste und letzte Gen des Clusters ist der entsprechende locus tag angegeben.

Bei vorläufigen Wachstumsversuchen mit verschiedenen Schwermetallkonzentrationen (siehe 2.2.4) wiesen die Octadecabacter-Stämme bei Quecksilber Konzentrationen bis $5 \mu \mathrm{M}$ nahezu uneingeschränktes Wachstum auf. Mit verzögertem Wachstum waren beide Stämme in der Lage, bis hin zu Quecksilber Konzentrationen von $10 \mu \mathrm{M}$ eingeschränkt zu wachsen. In Tab. DA58 (digitaler Anhang) sind die Ergebnisse der Schwermetall-Wachstumsversuche im Einzelnen aufgelistet. 


\subsubsection{Kohlenmonoxid-Oxidation}

Beide Octadecabacter-Stämme weisen jeweils zwei cox-ähnliche Gencluster auf (Locus tags OA238_c17740-c17760 + OA238_c20690-c20670 in O. arcticus bzw. OAN307_c32790c32810 + OAN307_c07520-c07540 in O. antarcticus). Solche Gencluster werden in nah verwandten Organismen mit Kohlenmonoxid-Oxidation in Verbindung gebracht (Cunliffe 2010). Jeweils eines der Cluster (Locus tags OA238_c20690-c20670 in O. arcticus 238 bzw. OAN307_c32790-c32810 in O. antarcticus 307) ist dem BMS-typ zuzuordnen, dessen Genprodukte nur eine niedrige Affinität $\mathrm{zu}$ Kohlenmonoxid aufweisen und das im überwiegenden Teil der Roseobacter-Vertreter vorhanden ist (Cunliffe 2010; Newton et al. 2010; Voget, Vollmers et al. 2013). Dieses Cluster ist in beiden Octadecabacter-Stämmen in regulären Genomabschnitten (ausserhalb von RGPs) lokalisiert. Das zweite Cluster, welches dem hochaffinen OMP-Typ zuzuordnen ist (Cunliffe 2010) ist hingegen nur in wenigen Roseobacter-Vertretern vorhanden, und in O. arcticus in Region Oar-RGP4 und in $O$. antarcticus in Region Oan-RGP 3 lokalisiert.

\subsubsection{Rhamnose Aufnahme- und Verwertungssystem}

Sowohl in $O$. arcticus als auch O. antarcticus wurde das Gencluster rhaKMQPTSRDI identifiziert, welches die Aufnahme und Verwertung des Zuckers Rhamnose kodiert. Dieses Cluster ist in zehn weiteren Roseobacter-Vertretern, darunter mehrere Organismen der

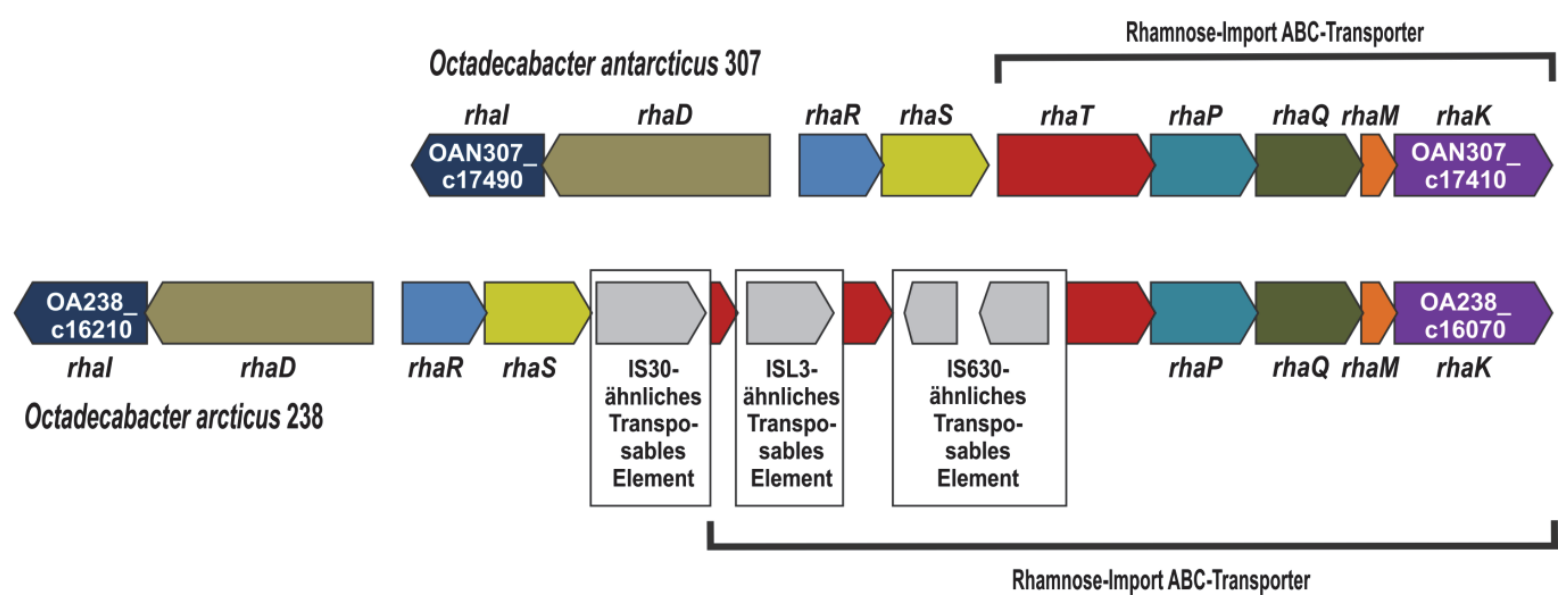

Abb. 31 Rhamnose-Import- und Verwertungs-Gencluster in $\boldsymbol{O}$. arcticus 238 und $\boldsymbol{O}$. antarcticus 307 Oben das Gencluster in O. antarcticus 307, unten das Gencluster von O. arcticus 238. Gene von transposablen Elementen sind in Grau dargestellt. Die übrigen Farben kennzeichnen Orthologe zwischen den beiden Octadecabacter-Stämmen. Für das jeweils erste und letzte Gen des Clusters sind die entsprechenden locus tags angegeben. 
Untergruppen 2, 4 und 5 (siehe 3.1.3.1), vorhanden (Tab. DA03 und Tab. DA04, digitaler Anhang). Dieses Gencluster ist in seinem prinzipiellen Aufbau in beiden OctadecabacterStämmen identisch (Abb. 31). Jedoch ist in O. arcticus das Gen rhaT durch die Insertion von 3 verschiedenen transposablen Elementen unterbrochen. Dieses Gen kodiert das ATPBindungsprotein des Rhamnose-ABC-Transporters RhaTPQMK.

Um zu überprüfen, ob hierdurch die Fähigkeit von O. arcticus 238 Rhamnose als Kohlenstoffund Energiequelle aufzunehmen, beeinträchtigt ist, wurden Wachstumskurven beider Octadecabacter-Stämme in verschiedenen Nährmedien aufgenommen (siehe 2.2.3): einerseits mit Pepton und andererseits mit Rhamnose als hauptsächlicher Kohlenstoff-Quelle. $O$. antarcticus 307 wuchs in Rhamnose-haltigem Medium, während O. arcticus 238 in Rhamnose-haltigem Medium so gut wie kein Wachstum aufwies (Abb. 32). Daher ist die Unfähigkeit von $O$. arcticus 238 Rhamnose effektiv zu verwerten wahrscheinlich auf den defekten Rhamnose-Transporter dieses Organismus zurückzuführen.

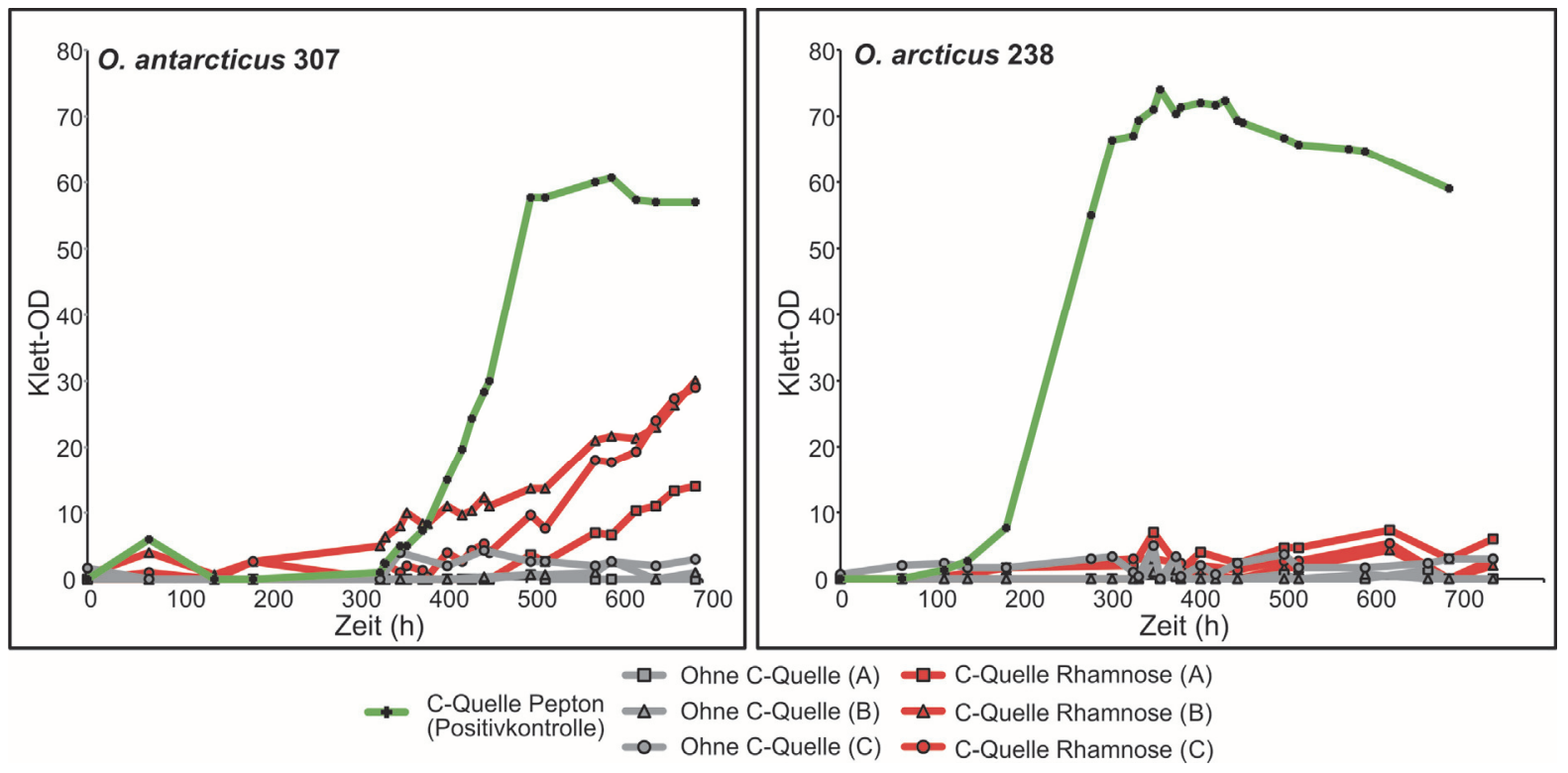

Abb. 32 Rhamnose-Verwertung in den Octadecabacter-Stämmen

Als Basis-Medium diente gepuffertes SWC-Medium ( $\mathrm{pH} 7.5)$ mit geringer Zugabe von Hefeextrakt aber ohne Zugabe von Pepton (siehe 2.2.1). Es wurden verschiedene Ansätze durchgeführt mit Pepton (Positivkontrolle) oder Rhamnose als Kohlenstoffquelle (C-Quelle) bzw. ohne Kohlenstoffquelle (Negativkontrolle). Ansätze mit Rhamnose sowie Negativkontrollen wurden in drei Parallelen durchgeführt (A, B und C). Wachstum wurde durch Trübungsmessung mittels eines Klett-Summerson Photometers verfolgt. Für jede Kultur ist die Optische Dichte (OD in Klett-Einheiten) gegen die Zeit (in Stunden) aufgetragen.

\subsubsection{Cyanat-Hydratase}

Cyansäure (CHNO) ist ein Abfallprodukt einiger Industriezweige, kann aber auch als Nebenprodukt verschiedener Stoffwechselvorgänge gebildet werden (Dubey \& Holmes 1995; 
Scanlan et al. 2009). Diese Substanz ist für die meisten Organismen toxisch (Stark 1965; Qian et al. 2011), kann aber durch das Enzym Cyanat-Hydratase (CynS) in einer Bicarbonatabhängigen Reaktion in Kohlenstoffdioxid und Ammonium umgewandelt werden (Johnson \& Anderson 1987). Diverse marine Organismen sind in der Lage exogene Cyansäure aufzunehmen und mit Hilfe von CynS als Stickstoff-Quelle zu nutzen (Kamennaya \& Post 2011). In beiden Octadecabacter-Genomen konnten Gencluster des Cyansäure-Abbaus (Locus tags: OA238_c17620-OA238_c17670 bzw. OAN307_c10320-OAN307_c10370), welche eine Cyanat-Hydratase CynS, ein konserviertes hypothethisches Protein, einen Bicarbonat-Transporter und einen Transkriptions-Regulator kodieren, identifiziert werden.

Es konnten jedoch keine Aufnahme-Systeme für exogene Cyansäure in den OctadecabacterGenomen identifiziert werden, was darauf hindeutet, dass dieses Gencluster in den Octadecabacter-Stämmen ausschließlich zur Detoxifizierung endogener Cyansäure dient. Da dieser Stickstoffhaltige Stoff auf diese Weise jedoch wieder dem eigenen Stoffwechsel zugeführt werden kann, anstatt ihn zu Entgiftungszwecken auszuscheiden, ist davon auszugehen, dass die Cyanat-Hydratasen auch den Stickstoff-Metabolismus der Octadecabacter-Stämme beeinflussen.

\subsubsection{Weitere Gemeinsamkeiten}

$\mathrm{Zu}$ den noch nicht aufgezählten Eigenschaften beider Octadecabacter-Stämme zählt die Veranlagung zur Synthese und Nutzung der Speicherstoffe Polyhydroxybutyrat (PHB) und Polyphosphat. Transporter für die Aufnahme der potentiellen Stickstoffquellen Ammonium, Harnstoff, Spermidin, Putrescin sowie einer Vielzahl an Aminosäuren und kleiner Peptide sind diesen Organismen ebenfalls gemein. Auch wurden betABCI-Gencluster, welche die Synthese des kompatiblen Soluts Betain aus Cholin kodieren (Pocard et al. 1997; Cánovas et al. 2000), sowie eine Vielzahl an putativen Betain/Cholin-Transportern gefunden. Beide Organismen besitzen Gene für Sialinsäure-Synthasen sowie diverse ExopolysaccharidBiosynthese-Proteine und Polysaccharid-Exporter, was auf die Befähigung beider Organismen hindeutet, Exopolymere zu bilden. Diverse Fettsäure- und Sterol-Desaturasen, welche eine Anpassung der Membranfluidität ermöglichen, sind ebenfalls in den Octadecabacter-Genomen kodiert. Alle eben genannten Eigenschaften sind in Genomanalysen psychrophiler Bakterien als wichtige Anpassungen an kalte Habitate identifiziert worden (Medigue et al. 2005; Methé et al. 2005). Jedoch ist keine dieser 
Eigenschaften spezifisch für den Genus Octadecabacter, sondern im Gegenteil in den meisten Vertretern der Roseobacter-Gruppe vorzufinden (Tab. DA03+Tab. DA04, digitaler Anhang). Zusätzlich zu den eben erwähnten Eigenschaften besitzen beide Octadecabacter-Stämme jedoch eine relativ hohe Anzahl an UV-induzierten DNA-Reparatursystemen (fünf in O. arcticus, sieben in O. antarcticus; Tab. DA03+Tab. DA04, digitaler Anhang).

Nicht im Octadecabacter Pan-Genom enthalten sind Homologe der Eis-bildenden Proteine von Colwellia sp. SLW5 (Raymond, Fritsen \& Shen 2007), oder der Polyketid-artigen Fettsäure-synthasen von Colwellia psychrerythraea 34H (Methé et al. 2005), welche als spezielle Anpassungen an Meereishabitate beschrieben wurden.

\subsubsection{Xanthorhodopsine}

\subsubsection{Phylogenie der Xanthorhodopsine}

Sowohl die Genome beider OctadecabacterStämme, als auch das eines weiteren Roseobacter-Vertreters, HTCC2255 weisen Gencluster auf, welche für die Synthese von Rhodopsinen kodieren. Diese Eigenschaft war bislang noch nicht in Vertretern der Roseobacter-Gruppe beobachtet worden. BLAST-Vergleiche deuten darauf hin, dass das Opsin von HTCC2255 den Proteorhodopsinen zuzuordnen ist, während die Octadecabacter-Opsine der Xanthorhodopsin-Gruppe angehörig sind. Diese Gruppenzugehörigkeiten konnten durch detailierte phylogenetische Analysen bestätigt werden (Abb. 33).

Hierbei zeigte sich jedoch, dass die Xanthorhodopsin-Gruppe sich in zwei große Untergruppen, im Folgenden als

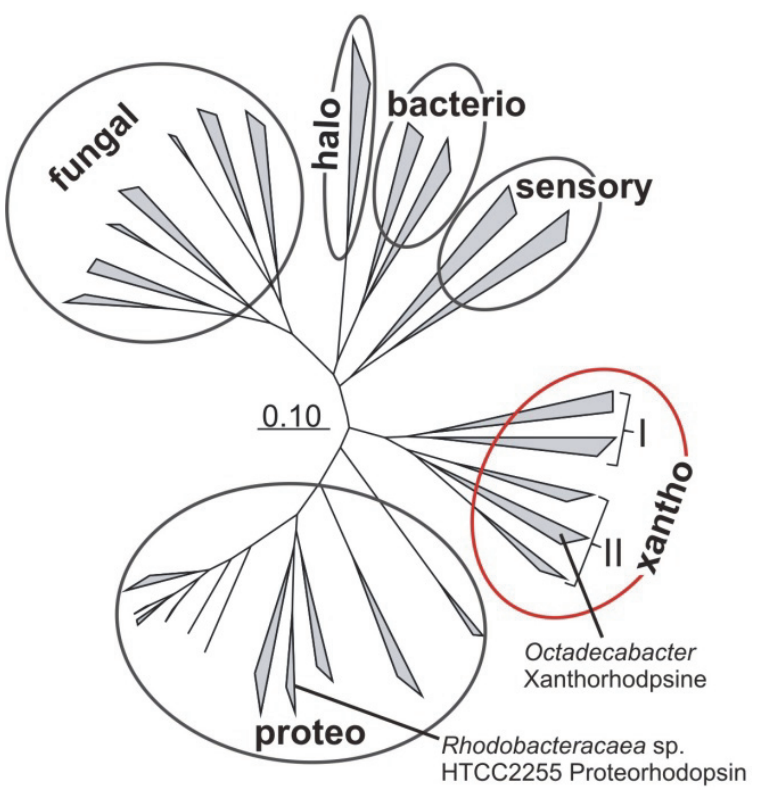

Abb. 33 Phylogenie mikrobieller Rhodopsine Der dargestellte Neighbor-Joining Stammbaum gibt grob die phylogenetischen Verhältnisse zwischen mikrobiellen Rhodopsinen wieder. Die verschiedenen Rhodopsintypen sind markiert und beschriftet. Die Position der Octadecabacter-Xanthorhodopsine und des HTCC2255 Proteorhodopsins sind zusätzlich angegeben. Eine Liste der im Stammbaum enthaltenen Sequenzen ist Tab. DA59 (digitaler Anhang) zu entnehmen

Untergruppen I und II bezeichnet, einteilen lässt. Diese Einteilung wird durch hohe Bootstrap-Werte von 95\% (Untergruppe I) und 92\% (Untergruppe II) unterstützt. Ferner 
konnten die beiden Untergruppen anhand robuster Hidden-Markov-Modelle voneinander abgegrenzt werden. Untergruppe I umfasst die beiden bislang einzigen funktionell charakterisierten Xanthorhodopsine: Die Rhodopsine von Salinibacter ruber M31 und Gloeobacter violaceus PCC 7421. Dieser Untergruppe sind bislang 9 bekannte Rhodopsinsequenzen zuzuordnen. Hierzu gehört auch das nennenswerte und distinkte Cluster der Actinorhodopsine(Sharma et al. 2009), dessen Vertreter ausschließlich in Actinobacteria aus Süßwasser-Habitaten auftreten. Die Rhodopsine der beiden Octadecabacter Stämme dagegen gehören in Untergruppe II und sind somit von den bisher charakterisierten Xanthorhodopsinen abzugrenzen. Der Untergruppe II sind mehr als 16 bekannte Sequenzen zuzuordnen, darunter ein Cluster, welches in Dinoflagellaten, also marinen Eukaryoten, vorzufinden ist (Slamovits et al. 2011). Bislang ist jedoch noch kein Vertreter dieser Untergruppe funktionell charakterisiert worden.

Betrachtet man die Hintergrundinformationen, der in der NCBI-nr Datenbank hinterlegten Xanthorhodopsin-Sequenzen, so zeichnet sich ein Zusammenhang zwischen der jeweiligen Xanthorhodopsin-Untergruppe und der Herkunft des entsprechenden Organismus oder Klons ab (Abb. 34). So stammen mit Ausnahme von Thioalkalimicrobium cyclicum ALM1 alle Vertreter der Untergruppe II von marinen Mikroorganismen. Sechs Vertreter stammen von psychrophilen oder psychrotoleranten Organismen aus den Polargebieten: Polarella glacialis

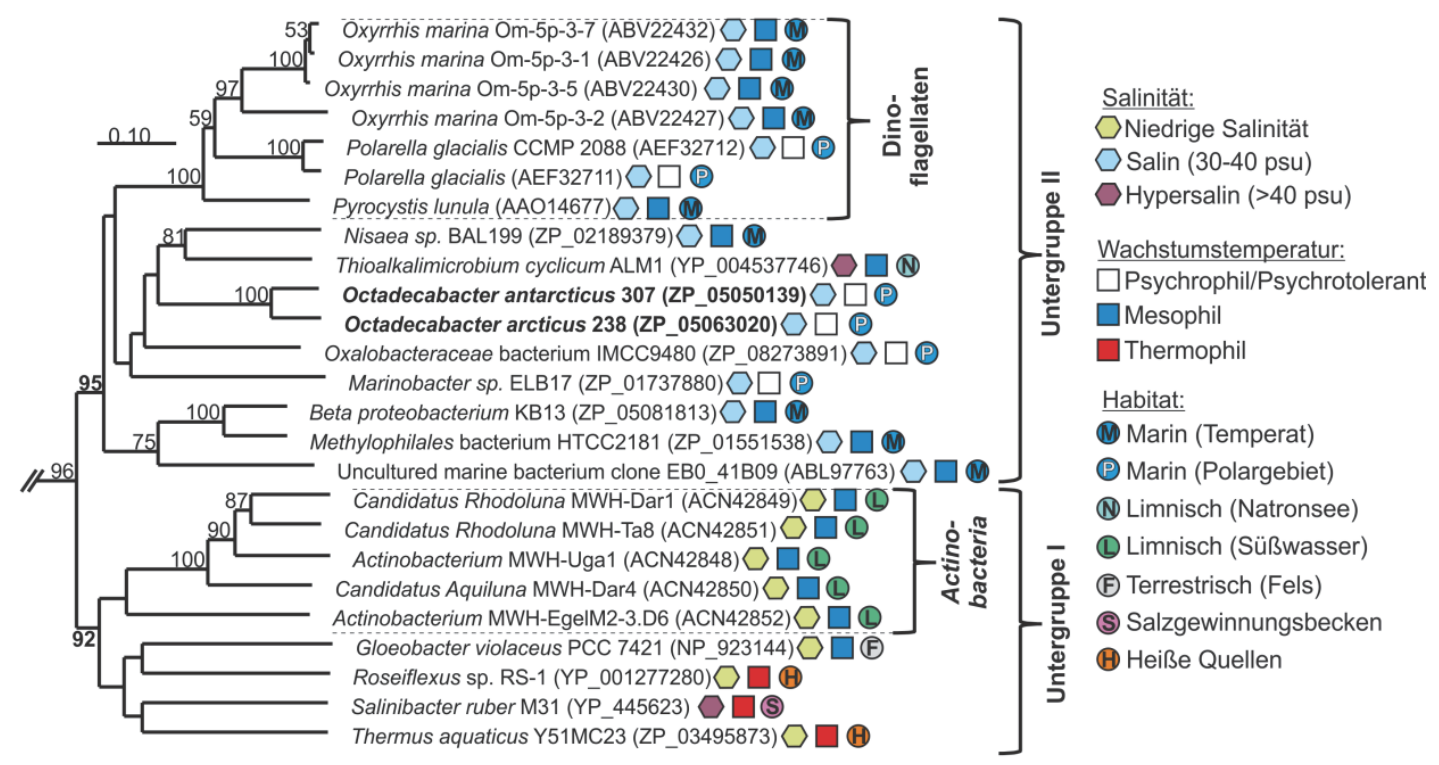

\section{Abb. 34 Habitat-Bevorzugung und detaillierte Phylogenie der Xanthorhodopsin Untergruppen}

Detaillierte, gewurzelte Darstellung des Xanthorhodopsin-Zweigs des Rhodopsinstammbaums von Abb. 33. Die Octadecabacter-Xanthorhodopsine sind fett beschriftet. Als outgroup diente die Gruppe der fungalen Rhodopsine. Die Xanthorhodopsin Untergruppen I und II sowie Subcluster aus Actinobakterien bzw. Dinoflagellaten sind durch Klammern gekennzeichnet. Die Lebensweise der entsprechenden Organismen ist durch verschiedene Symbole dargestellt. Für jedes Rhodopsin ist die entsprechende NCBI-Acc in runden Klammern angegeben. 
CCMP 2088, Octadecabacter antarcticus 307, Octadecabacter arcticus 238, Oxalobacteraceae bacterium IMCC9480 und Marinobacter sp, ELB17. Die restlichen Vertreter dieser Untergruppe stammen von mesophilen Organismen.

Im Gegensatz dazu stammt kein einziger Vertreter der Xanthorhodopsin Untergruppe I aus einer marinen Umgebung. Die entsprechenden Organismen sind meso- bis thermophil und mit Ausnahme von Salinibacter ruber (Anton et al. 2002) stammen alle aus Habitaten mit niedrigen Salinitäten. (Rippka, Waterbury \& Cohen-Bazire 1974; Madigan et al. 2005; Sharma et al. 2009). Gloeobacter violaceus PCC 7421 wurde zwar aus einem terrestrischen Habitat isoliert (Rippka, Waterbury \& Cohen-Bazire 1974), da jedoch die entsprechenden Isolierungs- und Kultivierungsmedien Salzkonzentrationen des Süßwassers aufwiesen, kann von einer niedrigen Salztoleranz ausgegangen werden.

\subsubsection{Biogeographie der Xanthorhodopsine}

Zahlreiche Metagenome verschiedener aquatischer Umgebungen wurden auf den Anteil und die Diversität von Rhodopsinen hin überprüft (Abb. 35, Abb. 36). Hierbei wurde vor allem den relativen Anteilen der beiden Xanthorhodopsin-Untergruppen Aufmerksamkeit gewidmet. Allgemein zeigte sich, dass Typ I Rhodopsine in aquatischen Habitaten weit verbreitet sind. Die am stärksten vertretenen Gruppen waren meist Proteo- und Xanthorhodopsine. Metagenome welche auf 454-Pyrosequenzierung beruhten (Abb. 36), wiesen allgemein einen niedrigeren Anteil an Gesamt-Rhodopsinen auf als solche, die auf Sanger-Sequenzierung beruhten (Abb. 35). Dies lässt sich durch den cloning-bias, die ungleichmäßige Repräsentation verschiedener Bakteriengruppen in Klon-Bibliotheken, welcher bei der Sanger-Methode auftreten kann, erklären. Dennoch waren die relativen Anteile der verschiedenen Rhodopsin-Gruppen an den Gesamt-Rhodopsin-Sequenzen bei beiden Sequenzierungsmethoden ähnlich.

In marinen Habitaten stellten Proteorhodopsine den deutlich stärksten Anteil (durchschnittlich 98\%) an den detektierten Rhodopsin-Sequenzen. Xanthorhodopsine machten hier durchschnittlich weniger als $2 \%$ aus und waren in vielen Proben nicht vertreten. Allerdings gab es vereinzelt starke Schwankungen im Xanthorhodopsin-Anteil (von 0 bis 7\% im offenen Ozean und von $0-14 \%$ in Küstengebieten). Dies betraf Vertreter beider Untergruppen.

In Süßwasserseen, heißen Quellen, hypersalinen Habitaten und sogar in Gletscher- und Schelf-Eis waren Xanthorhodopsine beider Untergruppen generell zahlreicher vertreten als im 

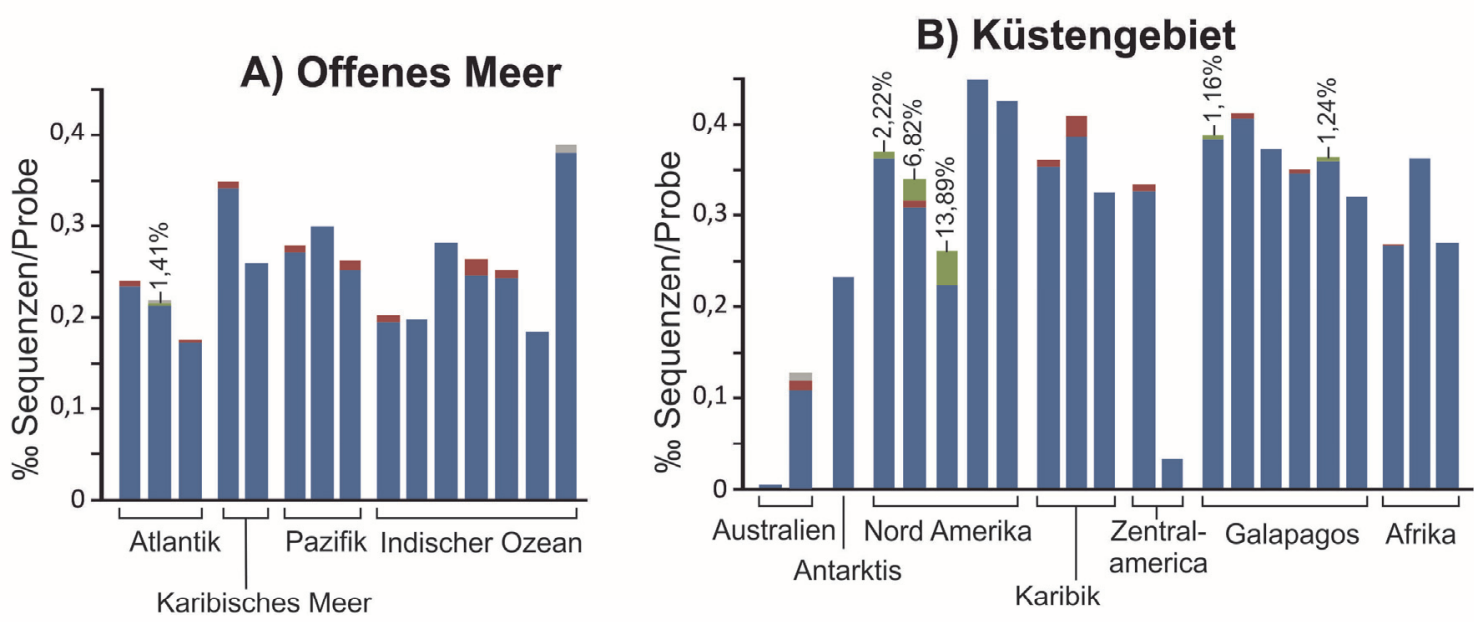

C) Süßwasser

D) Heisse

E) Hypersalin
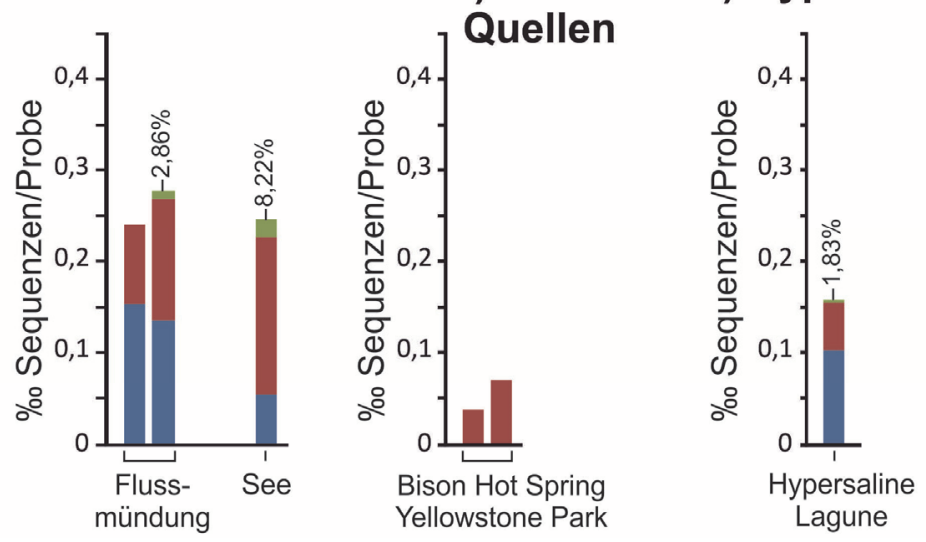

Abb. 35 Anteil von Rhodopsin-Gensequenzen in Sanger-Sequenzierungs-basierten Metagenomen Die Anteile von Proteorhodopsinen und Xanthorhodopsinen der Untergruppen I und II an den Gesamtsequenzen der jeweiligen Metagenome sind durch Farbmarkierungen dargestellt. Der relative Anteil von Xanthorhodopsinen der Untergruppe II an den Rhodopsinen verschiedener Standorte ist (sofern vorhanden) durch entsprechende Beschriftung angezeigt.

Meer. Häufig stellten sie in diesen nicht-marinen Habitaten die am stärksten vertretene Gruppe, noch vor den Proteorhodopsinen.

In Seen, Flüssen und heißen Quellen dominierten Xanthorhodopsine der Untergruppe II mit Anteilen an den Gesamt-Rhodopsinen von meist über 50\%. Untergruppe II war mit Anteilen von $0-14 \%$ in Seen und Flüssen sowie $0-25 \%$ in heißen Quellen vertreten.

In warmen hypersalinen Habitaten waren Xanthorhodopsine in stark variierenden, aber zum Teil bedeutenden, Anteilen von 7-88\% enthalten. In drei von vier hypersalinen Metagenomen dominierte Untergruppe I die Xanthorhodopsin-Fraktion. Mit zunehmender Salinität nahm jedoch der Anteil an Xanthorhodopsinen zugunsten von Bakterio- und Halorhodopsinen ab.

Organic Lake, ein flacher hypersaliner See auf dem antarktischen Kontinent mit extrem niedrigen durchschnittlichen Wassertemperaturen (Franzmann et al. 1987; Yau et al. 2011), waren Xanthorhodopsine der Untergruppe II auffällig stark vertreten (19-86\%). Dieser See 

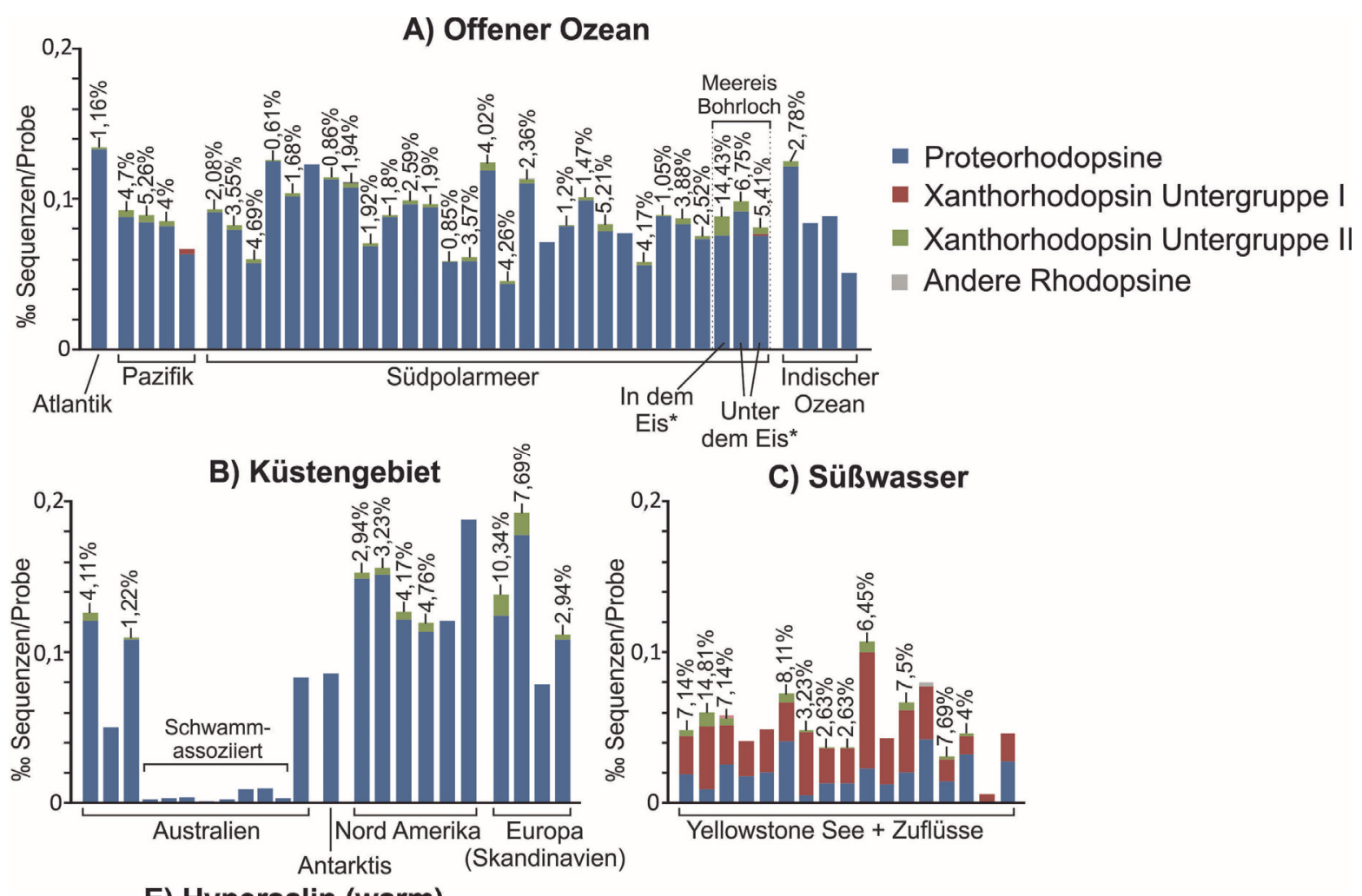

E) Hypersalin (warm)

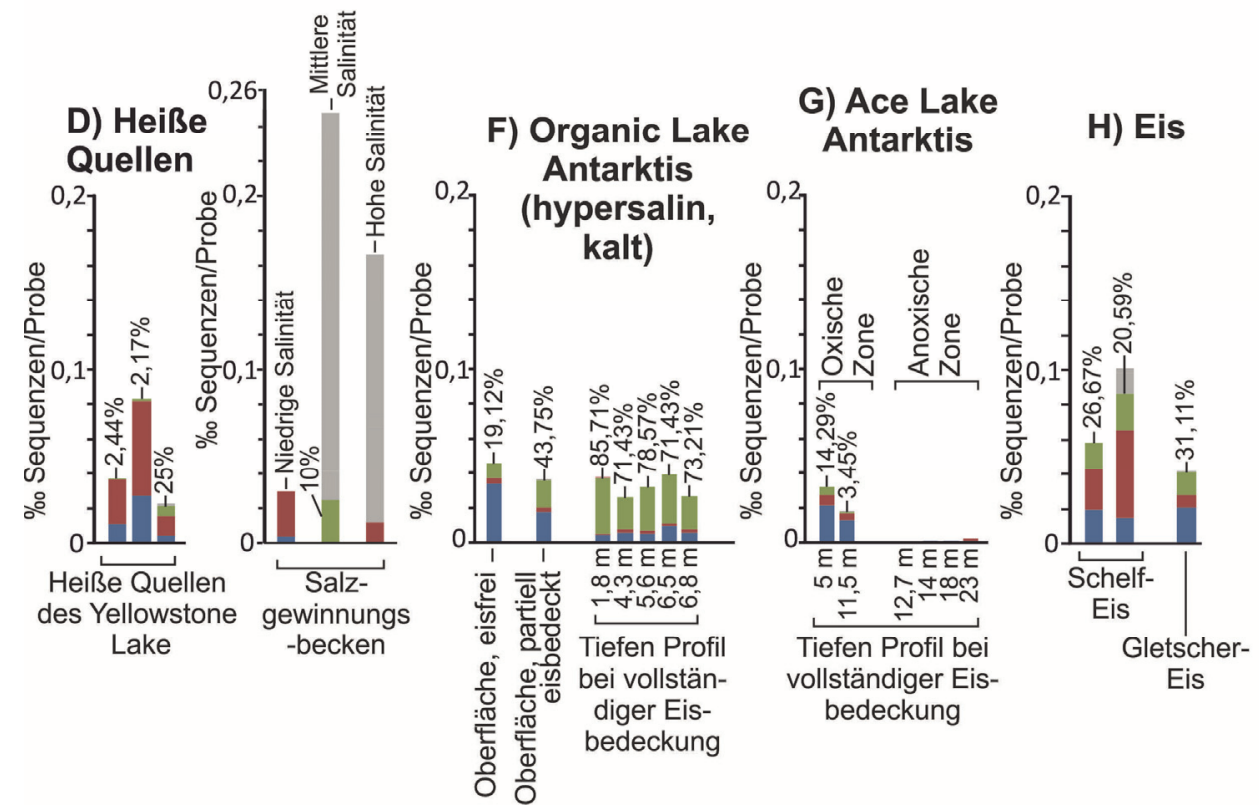

Abb. 36 Anteil von Rhodopsin-Gensequenzen in 454-Sequenzierungs-basierten Metagenomen

Die Anteile von Proteorhodopsinen und Xanthorhodopsinen der Untergruppen I und II an den Gesamtsequenzen der jeweiligen Metagenome sind durch Farbmarkierungen dargestellt. Der relative Anteil von Xanthorhodopsinen der Untergruppe II an den Rhodopsinen verschiedener Standorte ist (sofern vorhanden) durch entsprechende Beschriftung angezeigt. * Ein Loch wurde durch $3 \mathrm{~m}$ dickes marines Packeis gebohrt und anschließend wurde das Wasser auf Höhe der Eisschicht („In dem Eis“") und unterhalb der Eisschicht („Unter dem Eis“) beprobt (Jeff Hoffman, persönliches Gespräch).

wurde mehrmals zu verschiedenen Zeitpunkten mit unterschiedlicher Eisbedeckung beprobt. Es zeichnete sich ab, dass der Anteil von Untergruppe II mit zunehmender Eisbedeckung zunimmt. 
In Ace Lake, ebenfalls ein Antarktischer See allerdings mit niedrigeren Salzkonzentrationen und höheren Durchschnittstemperaturen als Organic Lake, waren Rhodopsine hauptsächlich in den oberen Wasserschichten (5-12 m) zu finden. Hier überwiegte wieder der Anteil der Proteorhodopsine. Xanthorodopsine waren nur zu 28-33\% vertreten, wobei der Anteil von Untergruppe I überwiegte. In tieferen anoxischen Schichten dieses Sees ( $>12 \mathrm{~m}$ Tiefe) waren Rhodopsine kaum noch nachzuweisen.

In Gletscher- und Schelfeis waren Xanthorhodopsine die bedeutendste Rhodopsin-Gruppe. In arktischem Schelfeis war Untergruppe II stärker vertreten als Untergruppe I, während es im Eis eines alpinen Gletschers des Schneeferners (Deutschland) (Simon et al. 2009) umgekehrt war.

\subsubsection{Funktionelle Analysen der Xanthorhodopsine}

\subsection{Sequenzbasierte Analysen}

\section{Genomgebung}

Xanthorhodopsine der Untergruppen I und II unterscheiden sich grundsätzlich in der Organisation der entsprechenden Genumgebungen (Abb. 37). Die Vertreter der Untergruppe II sind stets eng mit einem konservierten Gencluster bestehend aus crtE, crtI. crtB, $\operatorname{crt} Y$ und blh assoziiert. Diese Gene stellen einen Stoffwechselweg zur Gewinnung von Retinal aus Geranylgeranyl-diphosphat (Armstrong 1997; Sabehi et al. 2005) dar und sind auch in einem großen Teil der Proteorhodopsin-kodierenden Genome als konserviertes Gencluster zu finden(McCarren \& DeLong 2007).

\section{Protonenpumpen-Aktivität und Energiekonservierung}

Die Octadecabacter-Rhodopsine besitzen Äquivalente sämtlicher konservierter Aminosäuren, welche in Bacterio-, Proteo- und in Salinibacter-Xanthorhodopsin als funktionelle Bestandteile der Protonentranslokation identifiziert wurden (Balashov 2000; Beja et al. 2000; Balashov et al. 2005) (Abb. A3, Anhang). Dies deutet darauf hin, dass es sich um lichtgetriebene Protonenpumpen handelt.

\section{$\underline{\text { Keto-Carotenoid-Bindung }}$}

Die Octadecabacter-Rhodopsine wurden auch auf ihre Fähigkeit hin überprüft, Ketocarotenoide zu binden. Imasheva et al. gelang es in dem Xanthorhodopsin von S. ruber 


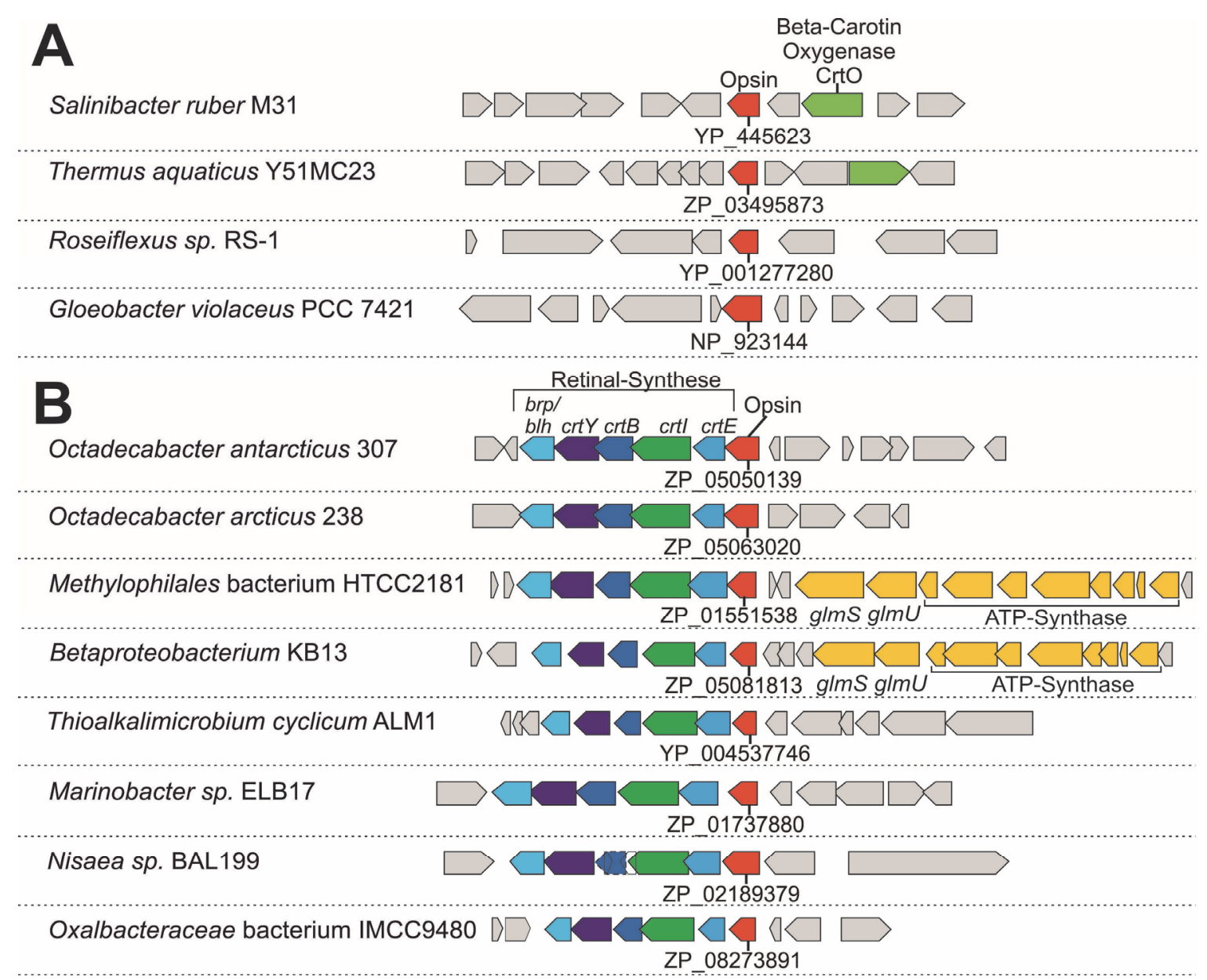

\section{Abb. 37 Vergleich der Genumgebungen von Xanthorhodopsinen der Untergruppen I und II}

Nicht dargestellt sind die Vertreter des Actinorhodopsin-Clusters (Untergruppe I) und des Eukaryotenassoziierten Rhodopsin-Clusters (Untergruppe II), da hierfür keine Genominformationen verfügbar waren. A) Gen-Umgebungen von Xanthorhodopsinen der Untergruppe I. Es sind keine gemeinsamen Gencluster zu erkennen. B) Gen-Umgebungen von Xanthorhodopsinen der Untergruppe II. Gene, welche Enzyme der Retinal-Synthese und Gene die Opsine kodieren, sind in allen Vergleichsorganismen in konservierten Genclustern organisiert. In Nisaea sp. BAL199 ist $c r t B$ vorhanden, jedoch nicht annotiert. Dies ist durch die gestrichelte Darstellung des Gensymbols markiert. Die stattdessen fälschlicherweise annotierten ORFs sind durch transparente Symbole dargestellt.

die funktionellen Bestandteile der Keto-Carotenoid-Bindestelle zu bestimmen (Imasheva et al. 2009). Diese besteht aus 16 Aminosäuren welche über die Transmembranhelices E und F verteilt sind. Als unentbehrlich für Keto-Carotenoid-Bindung gilt ein Glycin-Rest an Sequenzposition 156 (Gly (156) $_{\text {) }}$ des Salinibacter-Xanthorhodopsins (Balashov et al. 2010). Wird dieses durch ein Tryptophan ersetzt, verliert das Protein die Befähigung, Ketocarotenoide zu binden (Imasheva et al. 2009). Die übrigen Aminosäure-Reste dieser Bindestelle sind jedoch offenbar nicht alle essentiell, da das ebenfalls Keto-Carotenoidbindende Xanthorhodopsin von $G$. violaceus nur 11 hiervon an den entsprechenden alignment-Positionen teilt (Abb. 38). Experimentelle Daten existieren hierfür jedoch leider 
noch nicht. Generell ist diese Bindestelle unter Vertretern der Untergruppe I hochkonserviert.

Diese besitzen durchschnittlich 12 äquivalente oder 10 identische Aminosäuren an den entsprechenden alignment-Positionen. Alle Untergruppe I-Xanthorhodopsine besitzen einen

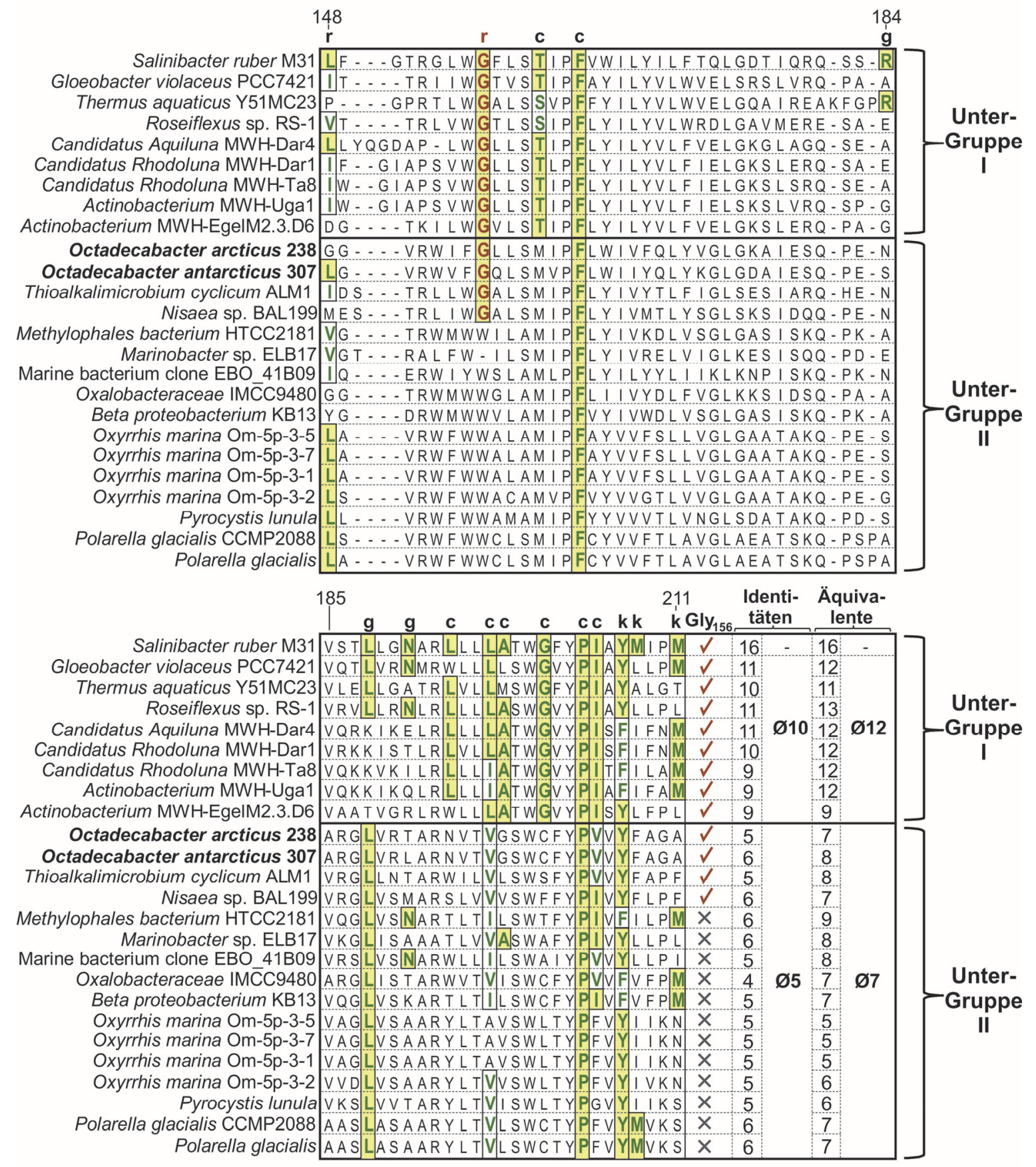

Abb. 38 Potentielle Keto-Carotenoid-Bindestellen in verschiedenen Xanthorhodopsinen

Die entsprechende Aminosäureposition ist für $S$. ruber-Xanthorhodopsin oberhalb der alignments angegeben. Alignment-Positionen, welche laut Imasheva et al. (2009) in S. ruber-Xanthorhodopsin an der Bindung von Keto-Carotenoiden beteiligt sein könnten, sind durch die Buchstaben c, g, k und $\mathrm{r}$ markiert, welche direkten Kontakt zu unterschiedlichen Bestandteilen des Keto-Carotenoids repräsentieren (c, Polyen-Seitenkette [chain]; g, Glucosid; k, Keto-Gruppe; r, Ring). Äquivalente Aminosäuren an solchen Positionen sind umrandet und durch farbige Schrift gekennzeichnet. Aminosäureidentitäten sind zusätzlich gelb hervorgehoben. Aminosäuren, welche dem Gly ${ }_{156}$ des Salinibacter Xanthorhodopsins entsprechen, sind in roter Schrift dargestellt. Die Summe der Aminosäureäquivalente bzw. -identitäten in den einzelnen Organismen bzw. deren Mittelwerte in den einzelnen Xanthorhodopsin-Untergruppen sind rechts angegeben. 
zu Gly156 homologen Glycin-Rest. In Vertretern der Untergruppe-II waren dagegen nur an 5 Positionen der Keto-Carotenoid-Bindestelle gleichartige und nur an 7 Positionen ähnliche Aminosäuren zu Salinibacter-Xanthorhodopsin zu finden. Die meisten Rhodopsine der Untergruppe-II tragen zudem ein Tryptophan anstelle von $\mathrm{Gly}_{156}$, was effektiv die Befähigung zur Keto-Carotenoid-Bindung ausschließt. Ausgenommen hiervon sind die Rhodopsine von O. arcticus, O. antarcticus, T. cyclicum und Nisaea sp. BAL199 (Abb. 38). Diese unterscheiden sich jedoch von dem Großteil der Untergruppe-I Vertretern an den entsprechenden alignment-positionen von Thr160, Leu194, Leu197, Ala198, Gly201 und Ile205 des Salinibacter-Xanthorhodopsins. Diese Aminosäuren, welche in Vertretern der Untergruppe I größtenteils konserviert sind, sind in S. ruber daran beteiligt, die sperrige Polyen-Seitenkette solcher Keto-Carotenoide wie Salinixanthin zu beherbergen.

\subsection{Experimentelle Analysen}

\section{$\underline{\text { Heterologe Expression und Spektraleigenschaften }}$}

Die Octadecabacter Opsingene wurden zum Zweck der heterologen Expression in E. coliZellen eingebracht. Die resultierenden rekombinanten E. coli-Stämme wiesen nach Zugabe von Retinal eine charakteristische rötliche Färbung auf. Da diese Färbung bei den Kontrollstämmen nicht auftrat, deutet diese Färbung auf die Anwesenheit von funktionalem Rhodopsin in den Zellmembranen hin. Zudem konnten durch Western-Blot-Analysen Opsine
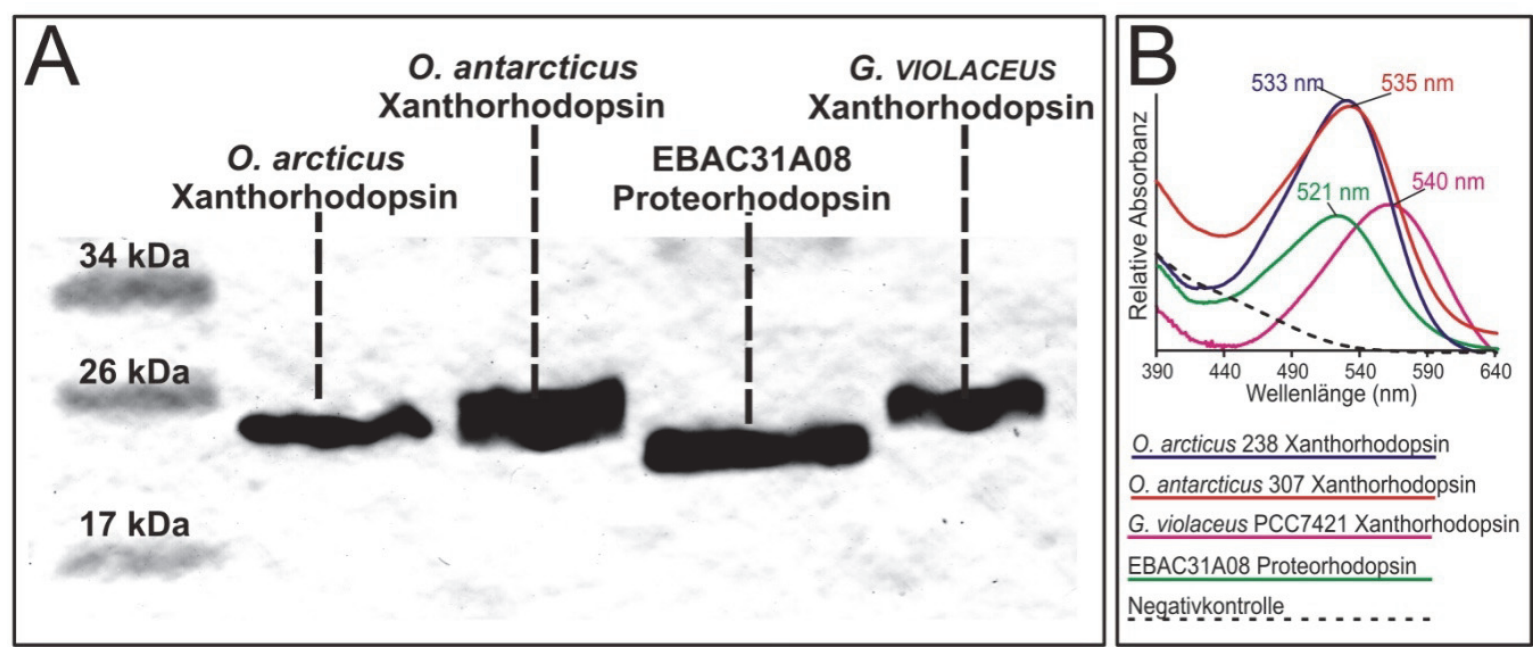

Abb. 39 Western-Blots und Spektralanalysen heterolog exprimierter Rhodopsine

A) Western-Blots heterolog exprimierter Rhodopsine. Als Größenstandard diente „PageRuler ${ }^{\mathrm{TM}}$ Prestained Protein Ladder" von Thermo Fisher Scientific Inc. (Waltham, MA, USA). Die den Banden entsprechenden Molekulargewichte stimmen mit den erwarteten Sequenzlängen der Rhodopsine überein. B) Differenz-Spektren rhodopsinhaltiger Membranfragmente nach Zugabe von $10 \mu \mathrm{M}$ Retinal. Spektren verschiedener Rhodopsintypen sind durch unterschiedliche Farben gekennzeichnet. Für jeden Rhodopsintyp ist das jeweilige Absorptionsmaximum angegeben. 
in den Membranfraktionen von Lysaten der entsprechenden Zellsuspensionen nachgewiesen werden (Abb. 39A). Spektralanalysen der Membranfragment-Suspensionen erbrachten Absorptionsmaxima von $533( \pm 1) \mathrm{nm}$ für das O. arcticus-Rhodopsin, und $535( \pm 1) \mathrm{nm}$ für das O.antarcticus-Rhodopsin (Abb. 39B). Diese Werte liegen über dem des ReferenzProteorhodopsins von EBAC31A08 $(512 \pm 1 \mathrm{~nm})$ aber unter denen der Untergruppe I Xanthorodopsine von Gloeobacter violaceus $(540 \pm 1 \mathrm{~nm})$ und S. ruber $(560 \mathrm{~nm})$ (Lanyi \& Balashov 2008).

\section{Protonenpumpenaktivität und Energiekonservierung}

Rhodopsin-vermittelte Protonenpumpenaktivität wurde anhand sensitiver Messungen geringfügiger pH-Wert-Änderungen in nährstofffreien Suspensionen rekombinanter, Rhodopsin-exprimierender E. coli-Zellen nachgewiesen (siehe 2.12.7). Rhodopsine befördern unter Lichteinfluss Protonen aus den Zellen in das umliegende Medium, was eine Erhöhung des Membranpotentials und eine vorübergehende sehr geringfügige $\mathrm{pH}$-Wert-Absenkung des umliegenden Mediums bewirkt. Endet die Beleuchtung, so fließen die Protonen entsprechend des Membranpotentials zurück in die Zellen, wodurch der $\mathrm{pH}$-Wert des umliegenden Mediums wieder geringfügig ansteigt. Suspensionen rekombinanter E. coli-Stämme, welche

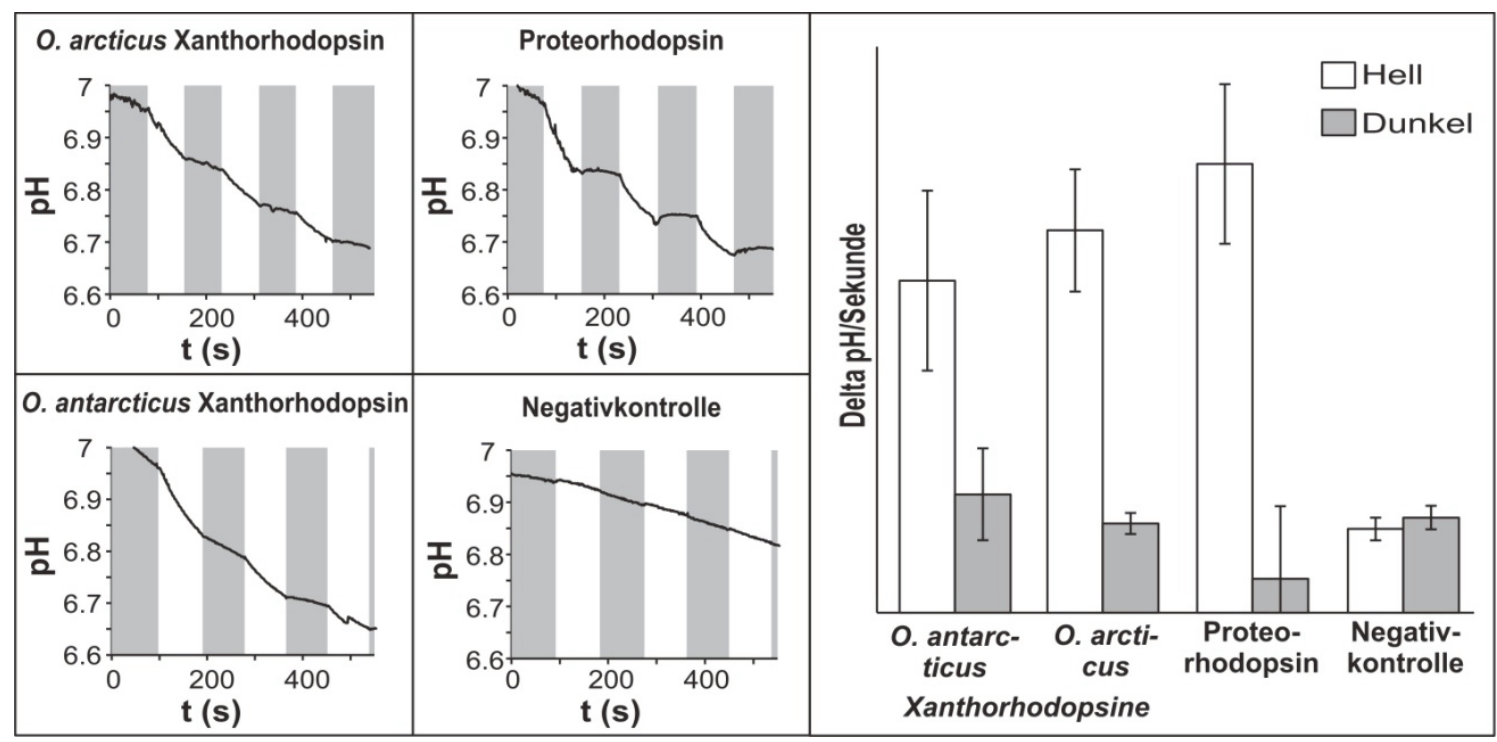

Abb. 40 Protonenpumpenaktivitäten heterolog exprimierter Rhodopsine

Lichtabhängige pH-Wert-Änderungen rekombinanter E. coli-Zellsuspensionen. Links: Kurvendiagramme, welche Änderungen des pH-Wertes im Laufe der Versuchszeit darstellen. Beleuchtungsintervalle sind durch einen hellen Hintergrund, Dunkelintervalle durch einen grauen Hintergrund dargestellt. Eine andauernde Ansäurerung des Mediums war in allen Suspensionen, inklusive der Negativkontrolle, zu beobachten. Zellsuspensionen, welche Rhodopsine exprimierten, zeigten jedoch lichtabhängige Veränderungen der Ansäuerungsrate, welche in den Negativkontrollen nicht zu beobachten waren. Rechts: Durchschnittliche Ansäuerungsrate der verschiedenen rekombinanten Zellsuspensionen während Beleuchtungs- bzw. Dunkelintervallen. Die Ansäuerungsrate ist als Veränderung des pH-Wertes pro Sekunde angegeben. Fehlerindikatoren zeigen den jeweiligen Standardfehlerbereich an. 
Octadecabacter-Xanthorhodopsine exprimierten, zeigten lichtabhängige Veränderungen in der Ansäuerungs-Rate (Abnahme des pH-Wertes pro Sekunde, $\Delta \mathrm{pH}$ ) (Abb. 40). Bei Wechsel von Dunkelheit zu Beleuchtung war die Ansäuerungsrate erhöht, während sie umgekehrt bei Wechsel von Beleuchtung zu Dunkelheit erniedrigt war. Da solche Fluktuationen bei den Negativkontrollen nicht auftraten, sind die Änderungen der Ansäuerungsrate auf die Aktivität von Rhodopsinen zurückzuführen, welche in den Membranen der Expressions-Zellen im Überschuss vorhanden sind. Unabhängig vom Beleuchtungszustand war aber in allen Suspensionen, inklusive der Negativkontrolle, eine geringe aber stetige Ansäuerung des Mediums $\mathrm{zu}$ beobachten (Abb. 33). Dies ist vermutlich auf Lösung atmosphärischen Kohlendioxids und somit Bildung von Kohlensäure im ungepufferten Suspensionsmedium zurückzuführen.

Native Octadecabacter-Kulturen wiesen bei Wachstumsversuchen mit Nährstoffkonzentrationen von 10-1\% keinen deutlichen lichtabhängigen Wachstumsvorteil auf (Abb.A4, Anhang). Bei Nährstoffkonzentrationen $<1 \%$ wurde weder bei Licht noch bei Dunkelheit Wachstum festgestellt. Somit konnte Rhodopsin-vermittelte Energiekonservierung in den Octadecabacter-Kulturen nicht beobachtet werden. Dennoch waren Transkripte der Opsingene mittels RT-PCR in RNA-Extrakten klar nachweisbar (Abb. 41).

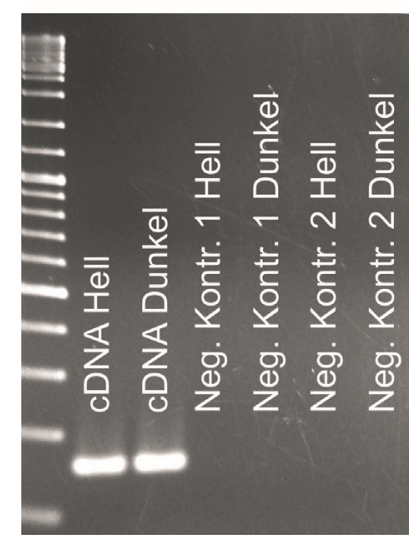

\begin{abstract}
Abb. 41 Nachweis der Expression von Xanthorhodopsinen in nativen Octadecabacter-Kulturen Transcripte von Opsingenenwurden durch spezifische PCRs nachgewiesen (siehe 0). Matrizen-cDNA wurde aus RNA-Extrakten von $O$. arcticus 238-Kulturen welche mit Licht (Hell) bzw. bei Dunkelheit (Dunkel) angezogen wurden. Es wurden jeweils zwei Negativkontrollen durchgeführt: Eine Kontrolle wurde mit einem RNA-Aliquot durchgeführt, welches wie ein Ansatz der cDNA-Synthese behandelt wurde, jedoch ohne Zugabe von reverser Transkriptase (Neg. Kontr. 1). Bei der anderen Kontrolle wurde unverdünntes RNA-Extrakt ohne weitere Behandlung als Matrize eingesetzt (Neg. Kontr. 2). Als Positivkontrolle diente Chromosomale DNA von O. arcticus 238 (nicht abgebildet).
\end{abstract}




\section{$\underline{\text { Keto-Carotenoid-Bindung }}$}

Spektralanalysen nach Zugabe von Salinixanthin $\mathrm{zu}$ heterolog exprimierten RhodopsinSuspensionen zeigten, dass die Xanthorhodopsine der Octadecabacter-Stämme nicht dazu befähigt sind, das Keto-carotenoid Salinixanthin zu binden. (Abb. 42). Die für Salinixanthinbindung charakteristischen Peaks bei $456 \mathrm{~nm}, 480 \mathrm{~nm}$ und $512 \mathrm{~nm}$ (Imasheva et al. 2009; Balashov et al. 2010) traten nur bei der Positivkontrolle Gloeobacter-Xanthorhodopsin auf, nicht aber bei Octadecabacter-Xanthorhodopsin.
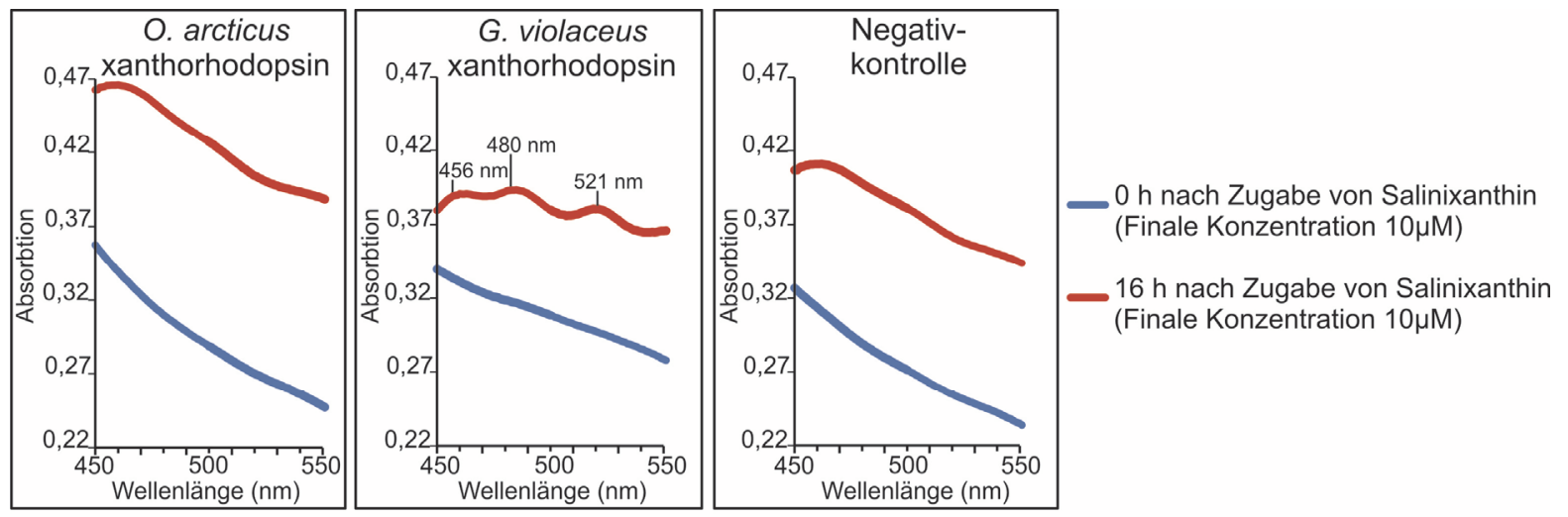

Abb. 42 Versuche zur Keto-Carotenoid Bindefähigkeit von Untergruppe I- und Untergruppe II-Xanthorhodopsinen

Dargestellt sind Differenz-Spektren, welche Veränderungen der Absorpionsmaxima verschiedener Rhodopsinhaltiger Membranfragment-Suspensionen zu verschiedenen Zeitpunkten nach Zugabe von $10 \mu \mathrm{M}$ Salinixanthin aufzeigen. Das Differenzspektrum von $G$. violaceus Xanthorhodopsin weist eine Zunahme der Absorption bei $456 \mathrm{~nm}, 480 \mathrm{~nm}$ und $521 \mathrm{~nm}$ auf, was auf die Bindung von Salinixanthin hindeutet (Imasheva et al. 2009)

\subsection{Zusatzergebnis: Erste Betrachtung des marinen Myxobakterienclusters (MMC) durch Sequenzanalysen von Fosmid-Klonen}

Vertreter der Ordnung Myxococcales (auch als Myxobakterien bekannt) galten lange Zeit ausschließlich als terrestrische Organismen. Der gelegentliche Nachweis von Myxobakterien in limnischen oder marinen Habitaten wurde meist dadurch erklärt, dass terrestrische Vertreter in diese Habitate ausgespült wurden. Schließlich wies Stevens et al. (2005) durch DGGEAnalysen einen der Ordnung Myxococcales zuzuordnenden Phylotyp in diversen marinen Oberflächensedimenten nach. Nah verwandte Sequenzen dieses Phylotyps waren weltweit in zahlreichen Klonbanken mariner Sedimente nachweisbar, jedoch nie in terrestrischen oder limnischen Habitaten (Brinkhoff, Vollmers et al. 2012). Diese Sequenzen bildeten eine gemeinsame phylogenetische Gruppe welche als MMC (marines Myxobakteriencluster) bezeichnet wurde. Die Biogeographischen Analysen von Brinkhoff et al. legen nahe, dass es 
sich bei dieser Gruppe um Organismen marinen Ursprungs handelt, welche zudem in marinen Sedimenten von hoher ökologischer Bedeutung sein können. Ein Isolat, dass dieser Gruppe zugeordnet werden konnte, existiert jedoch bislang noch nicht. Durch PCR-basierte Screenings einer aus Sedimenten des deutschen Wattenmeeres erstellten Fosmidbank konnten zwei Klone (MMCf1 und MMCf2) identifiziert werden, welche 16S Sequenzen von Vertretern des MMC beinhalteten (Vollmers 2007; Brinkhoff, Vollmers et al. 2012). Um einen ersten Einblick in die genetische Ausstattung dieser Gruppe zu erhalten, wurden die entsprechenden Fosmide subkloniert (siehe 2.6), sequenziert (siehe 2.8) und analysiert (Brinkhoff, Vollmers et al. 2012). MMCf1 trug ein 37,1 kb insert mit 24 proteinkodierenden ORFs und MMCf2 ein 40,7 kb insert mit 31 proteinkodierenden ORFs. Die entsprechenden Annotationen sowie die nächsten Homologe dieser ORFs in öffentlichen Proteindatenbanken sind in Tab. A60 (digitaler Anhang) aufgeführt. Direkte Sequenzvergleiche zwischen beiden Fosmiden ergaben einen ca $32 \mathrm{~kb}$ langen überlappenden Bereich, der jeweils 20 Gene mit einer Sequenzübereinstimmung von bis zu $94 \%$ umfasste. Durch bidirektionale BLASTAnalysen (siehe 2.10.3) konnten zahlreiche Orthologe zu Sorangium cellulosum So ce 56 und Haliangium ochraceum DSM14365 nachgewiesen werden (Abb. A5, Anhang). Diese Orthologe machten 14 von 23 Genen (61\%) in MMCf1 und 15 von 30 Genen (50\%; Vergleichsorganismus $S$. cellulosum) bzw. 14 von 30 Genen (47\%; Vergleichsorganismus $H$. ochraceum) in MMCf2 aus. Ungefähr die hälfte dieser Gene wies jedoch bei BLASTVergleichen mit der Trembl-Datenbank höhere Sequenzübereinstimmungen mit Homologen in marinen Organismen als mit entsprechenden Genen in terrestrischen Myxobakterien auf (Tab. A60, digitaler Anhang). Beide Fosmide wiesen jeweils ein einzelnes 16S rRNA-Gen auf, welches nicht mit einem vollständigen rRNA- Operon verbunden war und keine benachbarten tRNA- oder rRNA-Gene aufwies. 


\section{Diskussion}

\subsection{Allgemeine Genomvergleiche}

\subsubsection{Phylogenetische Vergleiche}

Die in dieser Arbeit untersuchten Genomsequenzen ermöglichten eine polyphasische Herangehensweise der phylogenetischen Einordnung der teilweise sehr nah verwandten Roseobacter-Vertreter (siehe 3.1.3). Hierdurch konnten die Komplexität der Verwandtschaftsbeziehungen innerhalb der Roseobacter-Gruppe aufgezeigt, sowie verschiedene sequenzierte Roseobacter-Vertreter einander verwandtschaftlich auf Art-Ebene zugeordnet werden. Die beobachtete Artgleichheit der beiden Phaeobacter gallaeciensis Stämme mit Phaeobacter inhibens T5 (siehe 3.1.3.3) erscheint zwar sehr überraschend, deckt sich jedoch mit Ergebnissen unabhängiger Untersuchungen durch Mitarbeiter der AG Simon (ICBM, Carl-von-Ossietzky-Universität, Oldenburg) in Kooperation mit der Deutschen Sammlung für Mikroorganismen und Zellkulturen GmbH (DSMZ, Braunschweig). Demnach scheint in mehreren internationalen Stammsammlungen ein falscher Organismus als Typstamm der Art P. gallaeciensis hinterlegt zu sein, was in einer bald erscheinenden Publikation aufgearbeitet werden soll (Thorsten Brinkhoff, persönliches Gespräch).

Obwohl sich phylogenetische Vergleiche basierend auf Tetramer-Korrelationskoeffizienten als Kriterium zur Unterscheidung sehr nah verwandter Bakterienarten bewährt haben (Richter \& Rosselló-Móra 2009), scheint diese Methode bei höheren phylogenetischen Distanzen wenig zuverlässig zu sein (siehe 3.1.3.3, Abb. 10B). Die ANIb-Analysen zeigen dagegen mehr Übereinstimmungen zu den durchgeführten Marker-basierten phylogenetischen Analysen (siehe 3.1.3.3, Abb. 10A), allerdings fehlen bootstrap-Werte, um die Zuverlässigkeit der entsprechenden Ergebnisse einschätzen zu können. Die durchgeführten MLSABerechnungen, basierend auf 166 einzigartigen Genen des Roseobacter-Coregenoms (siehe 3.1.2 + 3.1.3.1), ermöglichen eine besonders genaue phylogenetische Einteilung und sind als zuverlässiger einzustufen als entsprechende rRNA-Gensequenzanalysen (siehe 3.1.3.2) (Palys et al. 2000; Rajendhran \& Gunasekaran 2011). Durch die große Menge an Sequenzinformation verschiedener unabhängiger phylogenetischer Marker wird der Einfluss einzelner Artefakte (z. B. horizontal übertragener Gene oder schlecht alignbarer Sequenzbereiche) minimiert, was sich in hohen Bootstrap-Werten äußert. Prinzipiell konnten die bereits durch Newton et al. (2010) auf der Grundlage von nur 69 konservierten 
Proteinsequenzen beschriebenen Untergruppen 1-5 bestätigt werden. Vergleichende Analysen basierend auf rRNA-Genen und allgemeiner Nukleotid-Zusammensetzung (siehe 3.1.3.2+3) sowie genereller Genomeigenschaften (Abb. 43), zeigen jedoch, dass diese Untergruppen unterschiedliche Maße an Heterogenität aufweisen.

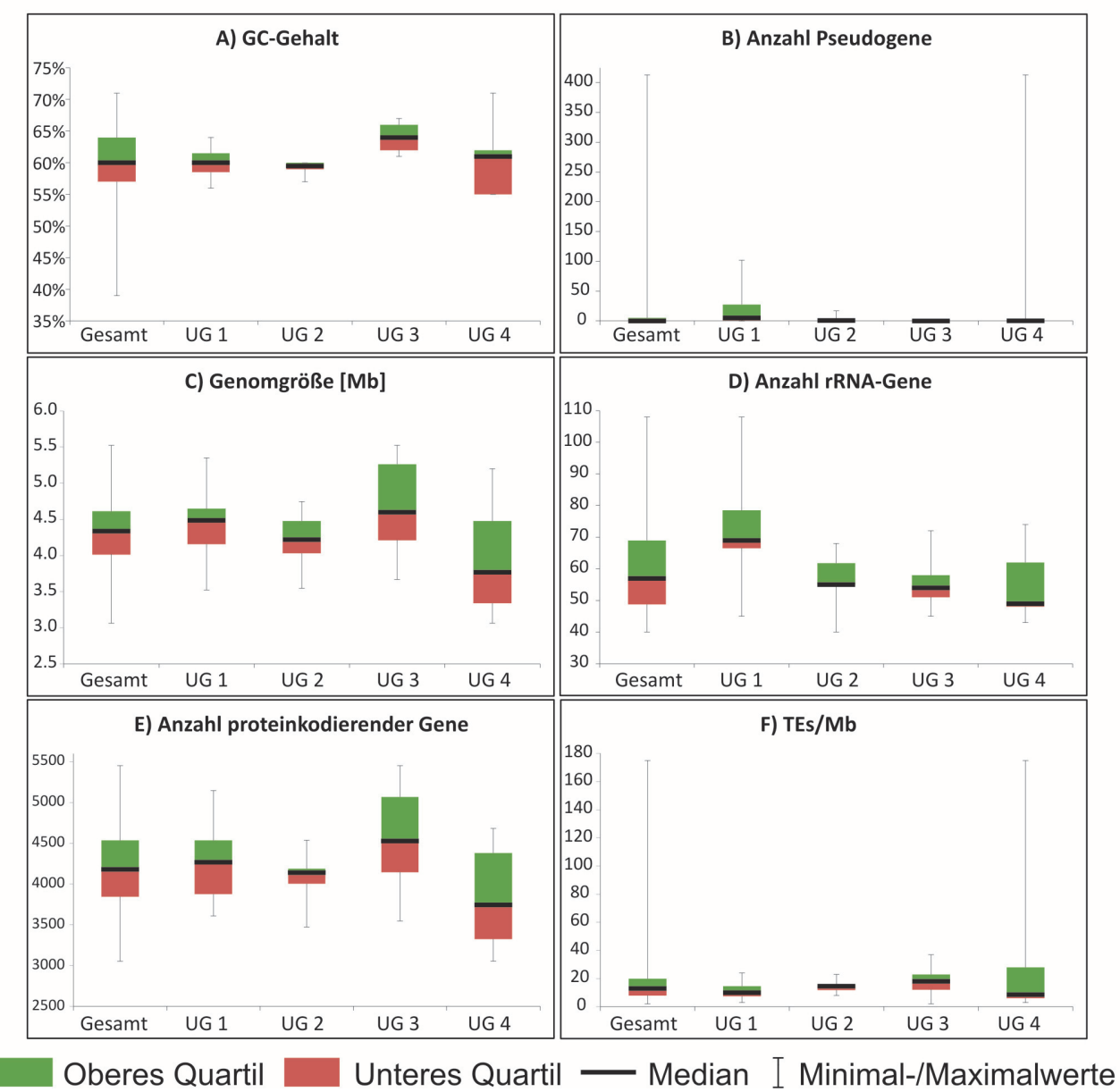

Abb. 43 Vergleich allgemeiner Genomeigenschaften zwischen MLSA-basierten Roseobacter Gruppen

Die Abbildungen basieren auf den Daten in Tab. 7 (3.1.1). Die Verteilung der Werte für GC-Gehalt (A), Genomgröße (B), Anzahl kodierender Gene (C), Anzahl Pseudogene (D), Anzahl an RNA Genen (E) und Dichte an TEs (F) innerhalb der Roseobacter-Gruppe ist jeweils für die gesamte Gruppe sowie für jede einzelne Untergruppe (UG) als Boxplot dargestellt. Untergruppe 5 ist nicht dargestellt, da die Anzahl der entsprechenden Vergleichsgenome für statistische Analysen nicht ausreichte.

Untergruppe 1, welche hauptsächlich aus Vertretern der Gattungen Phaeobacter und Ruegeria besteht, wird bislang durch die meisten Genomsequenzen repräsentiert. Diese Untergruppe ist sehr homogen und lässt sich auf verschiedenen phylogenetischen Ebenen, wie rRNA Gensequenz-Analysen oder durchschnittlicher BLAST-basierter Nukleotididentitäten (ANIb), zuverlässig rekonstruieren (siehe Abb. $9+$ Abb. 10A, 3.1.3). Auch in Bezug auf ihren GCGehalt (Abb. 43C) weichen Vertreter der Untergruppe 1 vergleichsweise wenig voneinander ab. Trotz der allgemeinen Homogenität dieser Untergruppe sind ihre Vertreter phylogenetisch 
tief verzweigt und vielfältig (Abb. 8, 3.1.3.1). Zudem weisen die entsprechenden Organismen eine recht hohe Diversität mariner Habitate auf. Sie sind weltweit sowohl im Freiwasser, als auch Sediment-, Algen- oder Biofilm-assoziiert vorzufinden (Tabelle DA01, digitaler Anhang). Auffällig ist die Unterteilung in zwei deutlich getrennte phylogenetische Cluster. Cluster 1a beinhaltet hauptsächlich Phaeobacter-Stämme, enthält jedoch auch die beiden Bakterien-Stämme TM1040 und TrichCH4b, welche bislang der Gattung Ruegeria zugeschrieben wurden. Die Typenstämme zweier Arten dieser Gattung, R. lacuscaerulensis ITI-1157 und $R$. pomeroyi DSS-3, fallen jedoch in Cluster 1b. Daher ist es fragwürdig ob TM1040 und TrichCH4b tatsächlich der Gattung Ruegeria zuzuordnen sind. Die scheinbar irrtümliche Zuordnung mag mit der allgemein problematischen Taxonomie dieser Gattung zusammenhängen. So sind verschiedene Vertreter bereits mehrfach umbenannt worden und die Zusammenlegung der Taxa Ruegeria und Silicibacter zu einem gemeinsamen Genus ist bis heute umstritten (Martens et al. 2006; Muramatsu et al. 2007; Yi, Lim \& Chun 2007). Diese Unsicherheiten basieren $\mathrm{zu}$ großen Teilen auf dem niedrigen Auflösungsvermögen 16S rRNA Gensequenz-basierter phylogenetischer Ansätze, einem Problem das durch die MLSA-Methodik umgangen werden kann.

Auch Untergruppe 2 ist größtenteils auf verschiedenen phylogenetischen Ebenen rekonstruierbar. In Bezug auf GC-Gehalt und Größe ihrer Genome weisen Vertreter dieser Gruppe ebenfalls nur geringe Schwankungen auf (Abb. 43A+C).

Rhodobacteraceae sp. HTCC2083 scheint jedoch, anders als durch Newton et al. (2010) angenommen, nicht direkt dieser Untergruppe zuzuordnen $\mathrm{zu}$ sein. Hierauf deuten der niedrige Bootstrap-Wert auf MLSA-Ebene, sowie die unsichere Zuordnung auf rRNA-Genund ANIb-Ebene, hin (Abb. $9+$ Abb. 10A, 3.1.3). Da dieser Organismus zudem auf MLSAEbene sehr tief abzweigt (Abb. 8, 3.1.3.1) ist anzunehmen, dass er eine weitere bislang nicht beschriebene Untergruppe repräsentiert.

Untergruppe 3 ist heterogener als die zuvor genannten Untergruppen. Auf der Ebene von 16S rRNA Gensequenzvergleichen (Abb. 9A, 3.1.3.2) lässt sich diese Gruppe in Bezug auf zwei ihrer Vertreter, Oceanicola batsensis HTCC2597 und Sagittula stellata E-37, nicht vollständig rekonstruieren. Da die phylogenetischen Verzweigungen von O. batsensis HTCC2597 innerhalb von Untergruppe 3 auf MLSA-Ebene relativ niedrige bootstrap-Werte aufweisen (47\% bzw. 62\%; Abb. 8, 3.1.3.1) und zudem auf ANIb- und 16S rRNA-Gensequenz-Ebene ebenfalls nicht rekonstruierbar sind (Abb. 9A+Abb. 10A, 3.1.3), ist die Zugehörigkeit dieser 
Art zu Untergruppe 3 sehr unsicher. Die Zugehörigkeit von S. stellata E-37 ist dagegen auf MLSA-Ebene eindeutig und wird zudem durch ANIb-Vergleiche und 23S rRNAGensequenzanalysen bestätigt (Abb. $8+$ Abb. 9B, 3.1.3).

Untergruppe 4 weist eine besonders große Heterogenität auf. Zwar wird die Zusammengehörigkeit dieser Untergruppe auf MLSA-Ebene durch hohe bootstrap-Werte unterstützt, auf den Ebenen von rRNA-Gensequenzanalysen sowie ANIb-Vergleichen (siehe 3.1.3), bildeten ihrer Vertreter jedoch kein zusammenhängendes Cluster. Hierbei ist jedoch zu berücksichtigen, dass die entsprechenden rRNA-Gensequenzbasierten Stammbäume bereits bei frühen Verzweigungen niedrige bootstrap-Werte von $<50 \%$ aufweisen. Dies deutet darauf hin, dass die phylogenetische Auflösung einzelner rRNA-Gensequenzen nicht ausreicht, um die Verwandtschaftsbeziehungen zwischen Vertretern dieser Untergruppe zuverlässig darzustellen. Die Zuverlässigkeit der auf ANIb-Vergleichen basierenden Clusteranalysen lässt sich mangels bootstrap-Werten nicht beurteilen. Allgemein zeigen die Differenzen zwischen den verschiedenen phylogenetischen Vergleichsmethoden jedoch, dass die Verwandschaftsbeziehungen zwischen Vertretern der Untergruppe 4 komplexer sind, als zwischen Vertretern anderer Roseobacter-Untergruppen.

Auch in Bezug auf prinzipielle Genomeigenschaften wie GC-Gehalt, Genomgröße und Anzahl an RNA-Genen (Abb. 43) weisen die Vertreter dieser Untergruppe eine hohe Variabilität auf. Ebenso divers sind ihre Habitate, welche nicht nur Salzwiesen, Meerwasser und Meeressedimente unterschiedlicher klimatischer Regionen, sondern auch den extremen Lebensraum Meereis und sogar terrestrische Habitate umfassen. Dies spricht für eine hohe Adaptivität dieser Untergruppe, welche möglicherweise in einer allgemein erhöhten Genomdynamik begründet sein könnte. Da die Genomsequenzen dieser Untergruppe jedoch fast ausschließlich in Form von draft-Genomen mit hoher contig-Zahl vorliegen, lässt sich diese Hypothese nicht durch direkte Genom-alignments überprüfen.

Untergruppe 5 besteht aus nur zwei Organismen, welche auf MLSA-Ebene sehr weit voneinander abzweigen und auch auf anderen phylogenetischen Ebenen kaum Ähnlichkeiten aufweisen (siehe 3.1.3). Daher sind, obwohl diese Organismen vermutlich von einem gemeinsamen entfernten Vorfahren abstammen, die phylogenetische Zusammengehörigkeit und das Verwandtschaftsverhältnis innerhalb dieser Untergruppe nicht annähernd so eng wie zwischen Vertretern der anderen Roseobacter-Untergruppen. Das deutet darauf hin, dass diese beiden Vertreter jeweils eigene, voneinander abzugrenzende, Untergruppen repräsentieren. 
Durch Analysen weiterer Genomsequenzen nah verwandter Organismen könnten Unterschiede oder Gemeinsamkeiten zwischen diesen hypothetischen neuen Untergruppen deutlicher hervortreten. Somit zeigen diese Organismen eine Lücke in der genomischen Abdeckung der Roseobacter-Gruppe auf, welche durch zukünftige Sequenzierprojekte geschlossen werden sollte.

Die Rhodobacteraceae Stämme R2A57, HTCC2083, HTCC2510 und HTCC2255 sowie die Organismen Maritimibacter alkaliphilus HTCC2654 und „Ca.Planktomarina temperata“ RCA23 sind auf MLSA-Ebene keiner zusammenhängenden Gruppe sequenzierter Roseobacter-Vertreter eindeutig zuzuordnen. Sie repräsentieren somit jeweils potentiell eigene Untergruppen, welche jedoch bislang nicht ausreichend durch entsprechende Genomsequenzen abgedeckt sind, um ihre jeweilige Diversität und Heterogenität abschätzen zu können. Zwei dieser Organismen repräsentieren bedeutende, bislang fast ausschließlich aus 16s rRNA Gensequenz-Ebene nachgewiesene, Roseobacter-Cluster. „Ca. P. temperata“ RCA23 repräsentiert den sog. Roseobacter Clade Affiliated (RCA)-Cluster (Voget, Vollmers et al. 2013), während HTCC2255 eine nahe Verwandtschaft zu dem sog. NAC11-7-Cluster aufweist (Newton et al. 2010). Diese beiden Cluster sind weltweit in marinen Habitaten hoch abundant (Selje, Simon \& Brinkhoff 2004; Buchan, Gonzalez \& Moran 2005), und daher für eine umfassende Beschreibung mariner Roseobacter-Populationen unerlässlich.

\subsubsection{Zusammenhänge zwischen Genomeigenschaften und Habitat bzw.}

\section{Lebensweise}

Die hier präsentierten Genomanalysen deuten auf erniedrigte Genomgrößen in marinen Organismen mit pelagischer Lebensweise im Vergleich zu partikel- bzw. eukaryotenassoziierter Lebensweise hin. Dementsprechend sind auch marine Vertreter der Myxococcales, welche die größten der bekannten prokaryotischen Genome aufweisen (Reichenbach 1999; Schneiker et al. 2007), fast ausschließlich auf Partikeln und in Sedimenten vorzufinden (Brinkhoff, Vollmers et al. 2012). Somit scheint auf freilebende marine Organismen ein Selektionsdruck zu herrschen, der kleine Genome begünstigt. Genomreduktion (bzw. genomic streamlining) wurde für diverse ubiquitäre aber schwer zu kultivierende marine Organismen, darunter Vertreter des SAR11-Clusters, als mögliche nährstoff- und energiekonservierende Anpassung beschrieben (Giovannoni et al. 2005; Woyke et al. 2009). Daher könnten die 
relativ geringen Genomgrößen von Roseobacter-Vertretern des Freiwassers auf eine geringere Verfügbarkeit von Nährstoffen bei pelagischer Lebensweise hindeuten. Auch der niedrigere Anteil an Genen der COG-Kategorie G (Kohlenhydratmetabolismus) in pelagischen Vertretern (Abb. 7, 3.1.2) könnte mit einer solchen Nährstofflimitierung zusammenhängen. Dies lässt sich beispielsweise durch die im Freiwasser im Vergleich zu Sedimenten, Meereis und Biofilmen erhöhten Diffusionsraten erklären, welche den Abbau von Makromolekülen durch Exoenzyme stark erschweren. Zudem können Organismen-assoziierte RoseobacterVertreter, im Gegensatz zu freilebenden, eventuell direkt von Stoffwechsel-Ausscheidungen ihrer Wirte profitieren. Zugleich könnte der Genomgehalt auch die Komplexität und Wechselhaftigkeit des entsprechenden Lebensraumes widerspiegeln und somit darauf hindeuten, dass das marine Freiwasser einen stabileren und weniger komplexen Lebensraum darstellt, als Biofilme, Sedimente oder Wirtsorganismen. Dies wird durch den durchschnittlich höheren Anteil an Genen der COG-Kategorie $\mathrm{T}$ (Signaltransduktion) in assoziiert lebenden Roseobacter Vertretern unterstützt, welcher für eine komplexe Interaktion innerhalb der Bakteriengemeinschaften partikel- oder wirtsassoziierter Habitate spricht.

Die Kopienzahlen von rRNA und tRNA Genen sind in Vertretern der RoseobacterUntergruppe $1 \mathrm{im}$ Durchschnitt höher als bei anderen Roseobacter-Vertretern (Abb. 43D). Verschiedene Studien brachten Kopienzahlen von rRNA-Genen mit der ökologischen Strategie von Bakterien in Verbindung: Organismen mit einer hohen Zahl an rRNA Operons wiesen höhere Wachstumsraten bei optimalen Nährstoffkonzentrationen und eine schnellere Adaption an wechselnde Umweltbedingungen auf, als solche mit einer geringen Anzahl an Operons (Klappenbach, Dunbar \& Schmidt 2000; Stevenson \& Schmidt 2004). Dies könnte auf einen opportunistischen Lebensstil von Vertretern der Roseobacter-Untergruppe 1 hindeuten.

Die auf gene content-Analysen basierende Clusterung der Roseobacter-Vergleichsstämme (siehe 3.1.2) zeichnet die phylogenetischen Verhältnisse zwischen diesen Organismen teilweise nach (Abb. 44). Dies ist besonders deutlich bei Untergruppe 1 der Fall. Die spezifische genetische Ausstattung von Vertretern dieser Untergruppe scheint somit, trotz der sehr diversen Habitate der entsprechenden Isolate, deutlich stärker durch phylogenetische Abstammung als durch äußere Einflüsse geprägt $\mathrm{zu}$ sein. Bei den Vertretern anderer Roseobacter-Untergruppen sind zwar ebenfalls Zusammenhänge, aber auch mehrere deutliche Abweichungen, zwischen Phylogenie und genetischer Ausstattung ersichtlich. Diese Abweichungen scheinen mit Unterschieden in Lebensweise und Habitat und daher mit individuellen Nischenadaptionen in Zusammenhang zu stehen. 


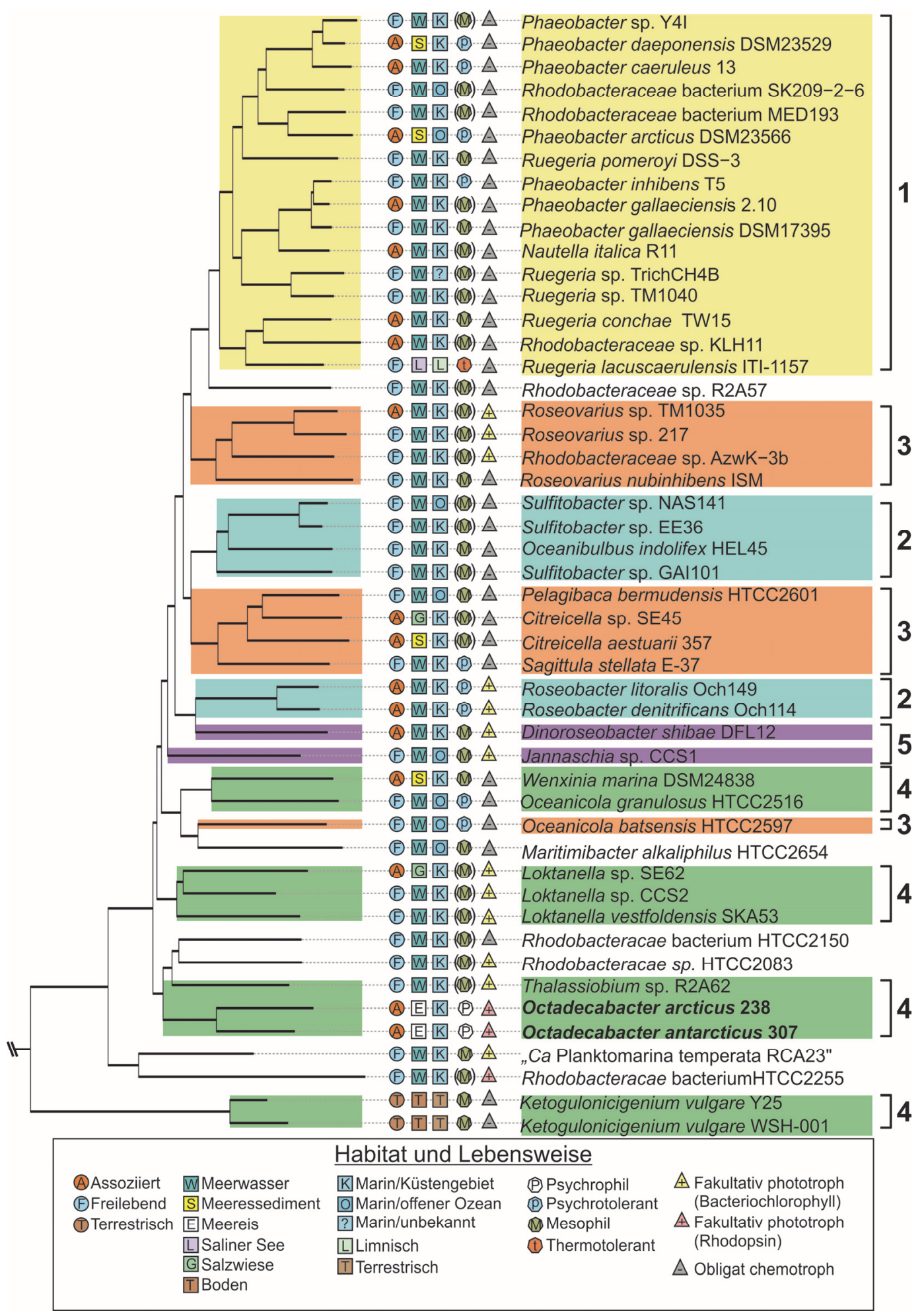

Abb. 44 Zusammenhang zwischen MLSA-basierter Phylogenie, gene content Analysen und Lebensweise verschiedener Roseobacter-Vertreter

Dargestellt ist ein gene content-Baum der Roseobacter-Gruppe (siehe 3.1.2). Zugehörigkeiten zu MLSAbasierten phylogenetischen Untergruppen (siehe 3.1.3.1) sind durch unterschiedliche Farbhinterlegung und entsprechende Nummerierung markiert. Spezifische Eigenschaften von Lebensweise und Habitat der Vergleichsorganismen sind durch verschiedene Symbole gekennzeichnet. Symbole in Klammern deuten auf Eigenschaften hin, welche in Genomdatenbanken (www.genomesonline.org) angegeben wurden, aber nicht in entsprechenden Publikationen nachvollziehbar sind. 
So sind marine und terrestrische Roseobacter-Vertreter in gene content-Analysen deutlich voneinander abzugrenzen, obwohl dies auf phylogenetischer Ebene nicht der Fall ist.

Untergruppen 2, 3, 4 und 5 zeigen ebenfalls auf gene content-Ebene eine höhere Diversität als auf phylogenetischer Ebene. Roseobacter denitrificans Och114 und Roseobacter litoralis Och149, welche phylogenetisch der Roseobacter-Untergruppe 2 zugehörig sind, lassen sich in ihrer genomischen Ausstattung deutlich von den übrigen Vertretern dieser Untergruppe unterscheiden, und weisen stattdessen große Ähnlichkeiten zu dem phylogenetisch nur sehr entfernt verwandten Organismus Dinoroseobacter shibae DFL12 (Untergruppe 5) auf (Abb. 44). Auch hier ist ein deutlicher Zusammenhang mit ökologischer Nischenadaption zu erkennen. So sind R. denitrificans Och114 und $R$. litoralis Och149 ebenso wie D. shibae DFL12 Eukaryoten-assoziierte Lebensformen, welche der phototrophen Ernährung fähig sind. Die übrigen Vertreter von Untergruppe 2 sind jedoch freilebend und obligat chemotroph. Interessanterweise unterscheiden sich die Vertreter „Ca. P. temperata“ RCA23 und Rhodobacteraceae sp. HTCC2255, welche mit den hoch abundanten RoseobacterClustern RCA bzw NAC11-7 assoziiert sind (siehe 4.1.1), in ihrer Genomausstattung deutlich von allen anderen marinen Roseobacter-Vertretern (Abb. 44). Im Fall des Isolats HTCC2255 lässt sich dies zwar möglicherweise zum Teil auf E. coli Kontaminationen der Sequenzdaten zurückführen (Ottesen et al. 2011). Im Fall von „Ca. P. temperata“ RCA23 sind solche Kontaminationen jedoch ausgeschlossen. Somit weist zumindest dieser Organismus im Vergleich $\mathrm{zu}$ den übrigen bislang sequenzierten Roseobacter-Vertretern tatsächlich einzigartige genetische Adaptionen auf. Dies ist vor allem deshalb bedeutend, weil sowohl der RCA- als auch der NAC11-7-Cluster häufig die Mehrheit natürlicher RoseobacterPopulationen stellen. Somit ist das genetische Potential natürlicher Roseobacter-Populationen durch die bisherigen Genomsequenzen wahrscheinlich nicht repräsentativ erfasst. Um diese Wissenslücke zu schließen, müssen weitere Vertreter der RCA- und NAC11-7-Cluster sequenziert werden.

\subsubsection{Genomische Flexibilität der Roseobacter-Gruppe}

Die Genomvergleiche der Roseobacter-Gruppe (siehe 3.1.1) unterstreichen die Bedeutung von horizontalem Gentransfer (HGT) für diese Gruppe. Das Coregenom der 49 untersuchten Roseobacter-Vertreter nimmt nur einen geringen Teil (14-25\%) der jeweiligen Genome ein (siehe Tab. A5, Anhang), was viel Freiraum für individuelle Adaptionen lässt. Entsprechend 
reichhaltig und divers ist das flexible Genom der Roseobacter-Gruppe. Hierdurch wird die physiologische Vielfalt widergespiegelt, welche es Vertretern der Roseobacter-Gruppe ermöglicht, unterschiedlichste marine Lebensräume zu besiedeln (Moran et al. 2007; Newton et al. 2010).

Die natürliche Umgebung der Octadecabacter-Stämme stellt ein unter den Vergleichsorganismen einzigartiges Habitat dar, zudem zweigen beide Vertreter in phylogenetischen Stammbäumen der Roseobacter-Gruppe tief ab. Aus diesem Grund war zu erwarten, dass sich die Octadecabacter-Vertreter in zahlreichen spezifischen genetischen Merkmalen von den übrigen Roseobacter-Vertretern abgrenzen würden. Der Großteil des Octadecabacter-Pangenoms wird jedoch auch von phylogenetisch weit entfernten Roseobacter-Vertretern geteilt. Jedes der Vergleichsgenome teilt allerdings einen völlig anderen Satz an Genen mit dem Octadecabacter-Pangenom (Tab. DA03 + Tab DA04, digitaler Anhang). Der Anteil an Genen, welcher ausschließlich von den beiden Octadecabacter-Vertretern geteilt wird, ist dagegen mit nur $2 \%$ der jeweiligen Genome verschwindend gering. All dies deutet darauf hin, dass sich die Gattung Octadecabacter innerhalb der Roseobacter-Gruppe weniger durch einzigartige, Octadecabacter-spezifische Merkmale, sondern mehr durch eine einzigartige Zusammenstellung von Merkmalen eines allgemeinen Roseobacter-Genpools abgrenzt.

Dies scheint, in unterschiedlichem Maße, auch für andere Roseobacter-Vertreter zu gelten. Viele Eigenschaften des flexiblen Genoms dieser Gruppe sind in mehreren verschiedenen Roseobacter-Vertretern konserviert, ohne dass in der Verteilung dieser Eigenschaften ein direkter phylogenetischer Zusammenhang erkennbar wäre (Abb. 45). Dies deckt sich mit früheren Untersuchungen der physiologischen und genetischen Vielfalt dieser Gruppe (Buchan, Gonzalez \& Moran 2005; Newton et al. 2010). Beispiele für solche Eigenschaften sind verschiedene Mechanismen der phototrophen Ernährung, der assimilatorischen NitratReduktion, der Kohlenmonoxid-Oxidation sowie Cyanat-Hydratasen. Dies deutet darauf hin, dass die einzelnen Vertreter dieser Gruppe per HGT vernetzt sind. Prinzipiell können also auch phylogenetisch entfernte Vertreter der Roseobacter-Gruppe auf einen gemeinsamen Pool aus akzessorischen Genen zurückgreifen.

Es ist anzunehmen, dass ein solcher Austausch von Genmaterial die Adaptivität von Bakterienpopulationen erhöht und sie somit befähigt, sich schneller in neuen oder veränderten Lebensräumen zu behaupten. 


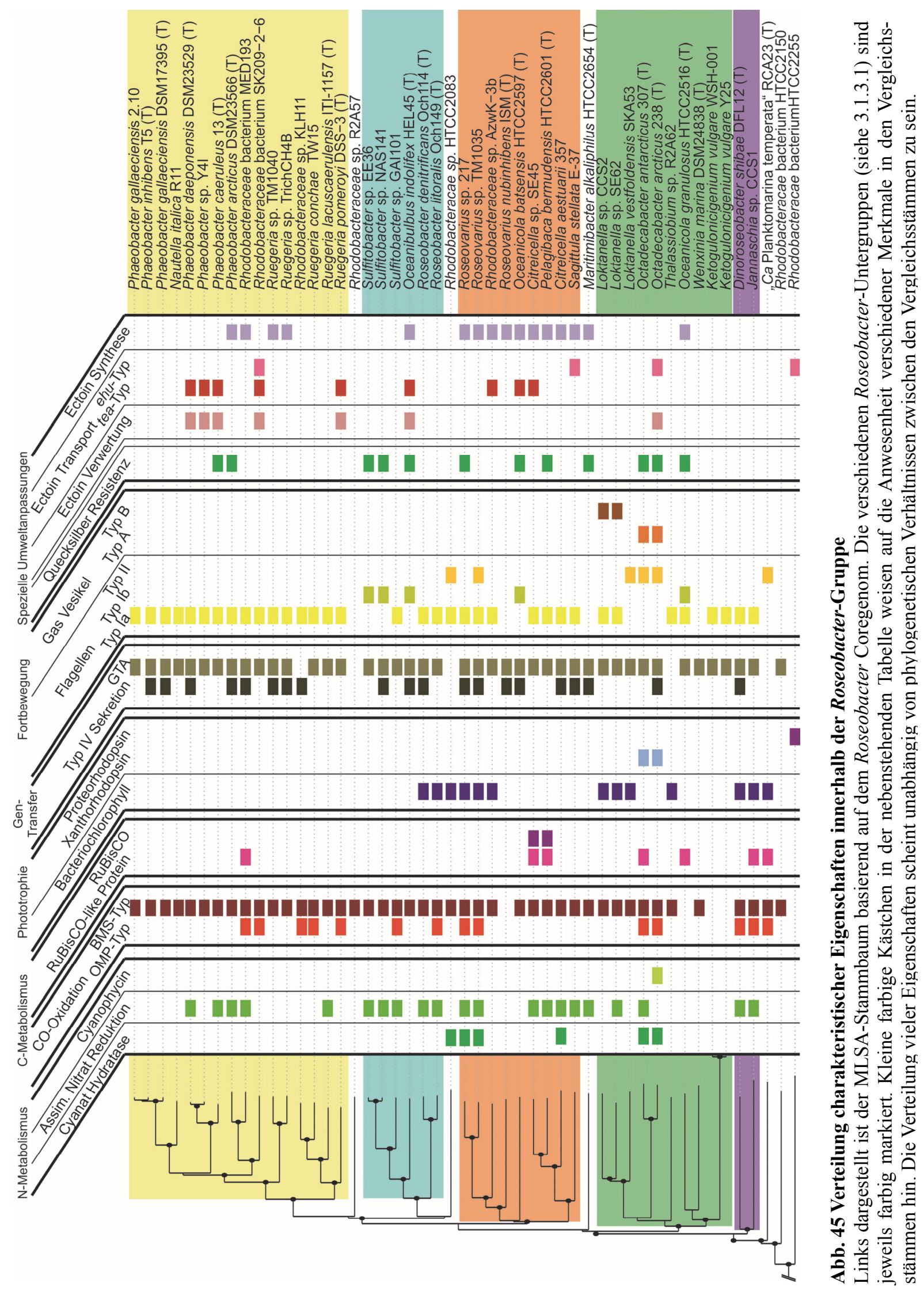


Ein wirkungsvolles Instrument des horizontalen Gentransfers stellen Gene Transfer Agents (GTAs, siehe 3.2.4.1) (Solioz \& Marrs 1977; Lang \& Beatty 2000) dar, Phagen-ähnliche Partikel welche in den Genomen fast aller Roseobacter-Vertreter kodiert werden (Abb. 45).

Die hohe Verbreitung der GTA-Gencluster lässt auf eine wichtige Bedeutung dieser Eigenschaft für die Roseobacter-Gruppe schließen. Am Beispiel von Silicibacter pomeroyi DSS-3 wurde die Funktion von GTAs als Mechanismen der Übertragung von genetischem Material zwischen nah verwandten Bakterienstämmen bereits experimentell bestätigt (Biers et al. 2008). Bislang wurden jedoch noch keine Untersuchungen über die Übertragungsweite von GTAs zwischen verschiedenen Vertretern der Roseobacter-Gruppe veröffentlicht. Somit ist es unklar, ob GTA-vermittelte Transduktion nur zwischen Bakterienstämmen derselben Spezies, oder auch zwischen Vertretern zweier nah verwandter Genera möglich ist. Zwar gibt es Hinweise darauf, dass die Zugabe von GTAs zu komplexen Bakteriengemeinschaften die Übertragungsfrequenz bestimmter Eigenschaften auch zwischen Vertretern verschiedener Phyla deutlich erhöht (McDaniel et al. 2010), doch es ist nicht sicher, ob dies ausschließlich auf die Aktivität der jeweils zugegebenen GTAs zurückzuführen ist. Auf Ebene der Aminosäuresequenz spiegelt die Phylogenie der Roseobacter-GTAs fast vollständig die MLSA-basierten Verwandtschaftsverhältnisse der Roseobacter-Gruppe wieder (Abb. 25, 3.2.4.1 und Abb. 8, 3.1.3.1). Sollten GTAs eine Übertragung genetischer Merkmale über Artbzw. Gattungsgrenzen hinweg ermöglichen, so wäre nicht anzunehmen, dass die entsprechenden Proteinsequenzen in solch hohem Maße art- und gattungsspezifisch konserviert wären. In diesem Fall könnten GTA-Gencluster teilweise oder vollständig durch horizontal übertragene Homologe aus anderen Vertretern ersetzt werden.

Eine hohe Wirtsspezifität dieser Phagen-ähnlichen Partikel würde die enge Bindung zwischen MLSA- und GTA-Phylogenie erklären. Eine GTA-vermittelte Genübertragung auf weit entfernt verwandte Organismen wäre dadurch stark eingeschränkt und würde, über einen Selektionsdruck auf funktionaler Ebene, letztlich zu einer art- bzw. gattungsspezifischen Konservierung der GTA-Gene führen. Aus diesem Grund ist es naheliegend anzunehmen, dass GTA-vermittelter Gentransfer nur zwischen sehr nah verwandten Roseobacter-Stämmen möglich ist (bzw. GTAs nur eine geringe phylogenetische Übertragungsweite aufweisen).

Diese Annahme wird dadurch unterstützt, dass gene content-Stammbäume der Roseobacter Gruppe (siehe 3.1.2), trotz der teilweise erheblichen Unterschiede in Lebensweise und Habitat zwischen verwandten Organismen, zu großen Teilen ebenfalls mit der MLSA-basierten Phylogenie übereinstimmen (Abb. 44). Sollte ein vollkommen uneingeschränkter Gentransfer zwischen sämtlichen Vertretern der Roseobacter-Gruppe möglich sein, so wäre zu erwarten, 
dass die individuelle Genausstattung einzelner Vertreter weniger von phylogenetischer Abstammung und mehr mit Habitat und Lebensweise zusammenhängt. Demnach scheinen für verschiedene Untergruppen distinkte Genpools zu existieren, und HGT scheint in erster Linie zwischen Vertretern derselben Untergruppe, Gattung oder Art stattzufinden.

Die oben erwähnte flickenartigen Verteilung mehrerer konservierter Gencluster über phylogenetisch relativ weit entfernte Taxa (Abb. 45) zeigt jedoch, dass es durchaus auch Überlappungen zwischen den Genpools der einzelnen Untergruppen gibt. Hierfür könnten zusätzliche Mechanismen des HGT verantwortlich sein, welche eine höhere phylogenetische Übertragungsweite erlauben, aber innerhalb der Roseobacter-Gruppe weniger stark verbreitet sind als GTAs. Typ-IV Sekretionssysteme können unter anderem dem Gentransfer zwischen Organismen dienen (siehe 3.2.3.5) (Wallden, Rivera-Calzada \& Waksman 2010). Gencluster, welche Typ-IV Sekretionssysteme kodieren, sind in 20 der 49 Roseobacter-Vertreter konserviert (Abb. 45). Anders als bei GTAs ist jedoch kein eindeutiger Zusammenhang zwischen der Phylogenie dieser Sekretionssysteme und der MLSA-basierten Phylogenie der Roseobacter-Gruppe zu erkennen (Abb. 23, 3.2.3.5). Somit scheint auf diesen Merkmalen, im Gegensatz zu GTAs, kein Selektionsdruck bezüglich Taxon-spezifischer Konservierung zu lasten. Die Annahme, dass diese Sekretionssysteme auch über relativ weite phylogenetische Distanzen hinweg einen Gentransfer ermöglichen, wird durch bislang unveröffentlichte experimentelle Ergebnisse unterstützt. So berichtete PD Dr. Jörn Petersen (DSMZ, Braunschweig) von dem Nachweis eines durch Typ-IV Sekretionssysteme vermittelten Gentransfers zwischen den weit entfernt verwandten Roseobacter-Vertretern D. shibae DFL-12 und P. gallaeciensis DSM17395 (Tagungsbeitrag, Klausurtagung des TRR 51 Januar 2013, Wolfenbüttel). Es ist anzunehmen, dass sich gattungs- und artfremde Merkmale, einmal in das Genom eines Roseobacter-Vertreters aufgenommen, anschließend mithilfe von GTAs zügig innerhalb nah verwandter Roseobacter-Populationen verbreiten können. Die Tatsache, dass Typ-IV Sekretionssysteme in Roseobacter-Vertretern weitaus seltener vorzufinden sind als GTAs, deckt sich zudem mit der oben erwähnten Beobachtung, dass HGT zwischen phylogenetisch entfernten Taxa seltener aufzutreten scheint als zwischen nah verwandten Taxa.

In O. arcticus 238 sind zwar prinzipiell alle entsprechenden Gene eines Typ-IV Sekretionssystems vorhanden, jedoch ist dieses Gencluster durch intragenomische Rekombination stark fragmentiert (siehe 3.2.3.5). Daher ist davon auszugehen, dass dieses Merkmal im besagten Stamm nicht funktional ist. Allerdings ist es unwahrscheinlich, dass die Fragmentierung dieses Genclusters entwicklungsgeschichtlich lange zurück liegt, da aufgrund 
natürlicher Selektion funktionslose Gene mit der Zeit deletiert würden. Daher ist davon auszugehen, dass nah verwandte Octadecabacter-Stämme derselben Population noch entsprechende unfragmentierte Gencluster aufweisen. Inwiefern GTAs und Typ-IV Sekretionssysteme in den Pangenomen der entsprechenden Populationen konserviert sind, wird sich jedoch erst mit größerer Sicherheit sagen lassen, wenn weitere Genome nah verwandter Isolate sequenziert wurden.

\subsubsection{Methodische Aspekte der Roseobacter Genomvergleiche}

Bei der Interpretation der in dieser Arbeit dargelegten Genomvergleiche sind einige wichtige methodische Aspekte sowie einige Besonderheiten in den untersuchten Vergleichsgenomen zu berücksichtigen. Je nach Referenzorganismus ergaben reziproken BLAST-Analysen teilweise etwas unterschiedliche Orthologenzahlen. Vergleicht man also die Roseobacter-Gruppe ausgehend von den Octadecabacter-Vertretern, ergibt sich ein etwas anderes Bild als wenn ähnliche Vergleiche beispielsweise ausgehend von Dinoroseobacter shibae DFL-12 durchgeführt werden. $\mathrm{Zu}$ einem Teil ist dies durch evalue- und Identitäts-cutoffs bedingt. So gibt es immer wieder Grenzfälle, in denen die entsprechenden Vertrauenswerte eines BLAST-Treffers von unterschiedlichen Organismen ausgehend, jeweils über oder unter den gewählten cutoffWerten liegen. Der hauptsächliche Grund für die Diskrepanzen in den Orthologenzahlen liegt jedoch in der Methodik des reziproken BLASTs selbst. Durch diese Methode werden nur solche Gene als potentielle Orthologe identifiziert, welche in bidirektionalen BLASTAnalysen den jeweils besten Treffer darstellen, während Paraloge nicht berücksichtigt werden (siehe 2.10.3). Folglich wird die Gesamtzahl an potentiellen Orthologen zwischen verschiedenen Vergleichsgenomen durch diese Methode eher unterschätzt, wodurch die resultierenden Vergleichswerte etwas variieren können. Die Unterschiede sind in der Regel jedoch nicht schwerwiegend. Beispielsweise ergeben sich in Bezug auf das Coregenom der 49 untersuchten Roseobacter-Vertreter bei unterschiedlichen Referenzorganismen lediglich Abweichungen von bis zu 15 Genen (bei einer durchschnittlichen Coregenomgröße von 750 Genen, Tab. A5, Anhang). Gene content-Analysen (siehe 3.1.2) werden hierdurch nicht beeinträchtigt, da singletons nicht in die entsprechenden Charaktermatrizen mit aufgenommen wurden (siehe 2.10.5). Die Bestimmung art- und gattungsspezifischer Gene in den Octadecabacter-Vertretern wird durch diesen Umstand jedoch gravierend beeinflusst. Diese beiden Organismen weisen zahlreiche transposable Elemente (TEs) auf, welche in der über- 
wiegenden Zahl der Fälle auch in anderen Roseobacter-Vertretern zu finden sind (Tab. 9, 3.2.2.2). In den Octadecabacter-Stämmen ist die Kopienzahl solcher Elemente allerdings um ein vielfaches höher als in anderen Roseobacter-Vertretern. Die entsprechenden Paraloge werden somit zumeist fälschlicherweise als art- bzw. gattungsspezifische Merkmale bestimmt, was $\mathrm{zu}$ hohen Anteilen (20-23\%) von vermeintlich einzigartigen Genen in den Octadecabacter-Genomen führt. Zwar ist die extreme Anzahl der TEs in diesen Organismen tatsächlich einzigartig innerhalb der Roseobacter-Gruppe, die entsprechenden TE-assoziierten Gene sind es jedoch nicht. Somit sind TE-assoziierte Gene von dem Anteil vermeintlich artbzw. gattungsspezifischer Gene in den Octadecabacter-Genomen abzuziehen. Die entsprechend korrigierten Anteile liegen mit 9-15\% deutlich niedriger als die nicht korrigierten, und geben ein wahrscheinlich realitätsgetreueres Abbild der physiologischen Eigenheiten der Octadecabacter-Vertreter wieder (Tab. DA03 + Tab. DA04, digitaler Anhang).

Auch die Qualität der Genomsequenzen beeinflusst vergleichende Analysen zwischen den Roseobacter-Vertretern. Aus Kosten- und Zeitgründen wird immer häufiger auf finishing und polishing (siehe 2.9) von Genomsequenzen verzichtet. Stattdessen werden bakterielle Genome in Form von Rohsequenzen (draft-Genome) veröffentlicht, welche noch zahlreiche Lücken aufweisen. Lücken in assemblies entstehen meist in sogenannten repeat-Regionen (Schatz, Delcher \& Salzberg 2010), also Bereichen, welche mit sehr ähnlicher Sequenz mehrfach über das Genom verteilt, vorkommen. Solche Bereiche werden häufig durch TEs oder rRNA-Gencluster gebildet und somit lässt sich ohne Lückenschluss nicht mit absoluter Sicherheit sagen, wie viele Kopien dieser Elemente in den jeweiligen Genomen enthalten sind. So ist es durchaus möglich, dass einige Roseobacter-Vertreter eine höhere Zahl an TEs oder rRNA Genclustern beinhalten als angenommen. Zudem können draft-Genome noch zahlreiche Sequenzierfehler beinhalten, welche dazu führen können, dass prinzipiell funktionale Gene fälschlicherweise als Pseudogene klassifiziert werden. Aber auch vermeintlich vollständige Genomsequenzen, welche ausschließlich auf 454Pyrosequenzierung beruhen, wie die von Ketogulonicigenium vulgare WSH-001, weisen in sog. homopolymer-stretches (drei oder mehr aufeinanderfolgende identische Nukleotide) häufig Sequenzierfehler auf (Margulies et al. 2005).

Ebenfalls zu berücksichtigen ist, dass das draft-Genom von Rhodobacteraceae sp. HTCC2255 einige Contigs aufweist, welche womöglich auf einer Kontamination des Sequenzieransatzes durch E. coli beruhen (Ottesen et al. 2011). Die Identifikation von Elementen des Roseobacter-Coregenoms in diesem Organismus sollte dadurch nicht 
wesentlich beeinträchtigt worden sein, da die zusätzlichen fremden Genomabschnitte im Falle einer Kontamination bei BLAST-Analysen konservierter Roseobacter housekeeping-Gene keinen bidirektionalen besten Treffer ergeben sollten. Bei Vergleichen der allgemeinen Genomausstattung (z.B. gene content-Bäume) könnten die Unterschiede und Eigenheiten dieses Organismus durch eine solche Kontamination jedoch schwerwiegender erscheinen als sie es tatsächlich sind.

\subsection{Spezifische Betrachtung der Octadecabacter-Stämme}

\subsubsection{Erhöhte Genomplastizität der Octadecabacter Stämme}

Beide untersuchten Octadecabacter-Stämme weisen eine außerordentliche Genomplastizität auf. Vor allem in Genomorganisation und -struktur sind enorme Unterschiede zu sehen (siehe 3.2.2). Dies deckt sich mit früheren DNA/DNA-Hybridisierungsversuchen von Gosink et al. (1997), scheint aber nicht mit den Ähnlichkeiten dieser Organismen auf verschiedenen Sequenzebenen (siehe 3.1.3) vereinbar zu sein.

Es ist in hohem Maße unwahrscheinlich, dass zwei getrennte Bakterienpopulationen über einen längeren Zeitraum hinweg unabhängig voneinander, ähnliche oder identische Sequenzmutationen anhäufen. Sollte also die Divergenz in Aufbau und Struktur der Octadecabacter-Genome auf die räumliche Trennung dieser Organismen und somit auf eine unabhängige evolutionäre Entwicklung zurückzuführen sein, so müsste sich dies auch auf anderen phylogenetischen Ebenen widerspiegeln. Durch vergleichbare Genom-alignments repräsentativer Roseobacter-Stämme konnte jedoch gezeigt werden, dass die strukturellen Unterschiede zwischen den Octadecabacter-Genomen deutlich höher sind, als die entsprechenden Distanzen auf Sequenzebene vermuten lassen (3.2.2.4). In diesen alignments wiesen die Genome der Vergleichsorganismen selbst bei höheren Sequenzunterschieden weitaus mehr strukturelle Syntenien auf als die Octadecabacter-Vertreter, unabhängig davon, ob die entsprechenden Stämme aus nahe gelegenen oder global entgegengesetzten Standorten stammen (Abb. 14, 3.2.2.4 + Abb. A2, Anhang).

Daher ist vielmehr davon auszugehen, dass $O$. arcticus und $O$. antarcticus anfälliger sind für intragenomische Rekombinationsereignisse als andere Roseobacter-Vertreter. In Anbetracht der außergewöhnlichen Dichte an transposablen Elementen (TEs) in diesen Organismen (siehe 3.2.2.2), sind Häufungen solcher Rekombinationsereignisse nicht verwunderlich. Viele TEs weisen in den Octadecabacter-Genomen zahlreiche Kopien auf, welche weit über die 
jeweiligen Replikons verteilt sind (Tab. 9, 3.2.2.2). Diese Elemente stellen somit repetitive Bereiche mit nahezu vollständiger Sequenzidentität dar, welche als Ausgangspunkte für homologe Rekombination dienen können. In diversen Organismen konnten verschiedentliche Inversionen, Deletionen, Duplikationen und Translokationen größerer Genomabschnitte auf solch Homologie-basierte Rekombinationsereignisse zwischen identischen TEs zurückgeführt werden (Gray 2000; Mieczkowski, Lemoine \& Petes 2006; Petrosino et al. 2006; Braumann, van den Berg \& Kempken 2008). Während die durchschnittliche Dichte an TEs in Genomen der Roseobacter-Gruppe bei ca. 18 TEs/Megabase liegt (Tab. 7, Abb. 5, 3.1.1), ist dieser Wert bei beiden Octadecabacter-Vertretern um das vier- bis achtfache erhöht. Entsprechend ist zu erwarten, dass TE-basierte homologe Rekombinationsereignisse in beiden OctadecabacterStämmen mit deutlich höherer Wahrscheinlichkeit und Häufigkeit auftreten als in anderen Roseobacter-Vertretern. Zudem wird intragenomische Rekombination auch unabhängig von Sequenzhomologien durch sogenannte ,alternative Transposition“ (Gray 2000) ermöglicht. Dieser Begriff bezeichnet die gleichzeitige Beteiligung zweier in unterschiedlichen Genomabschnitten lokalisierter TEs an derselben Transpositionsreaktion, was zu einem Austausch der jeweils benachbarten Regionen führen kann (Zhang \& Peterson 1999; Zhang \& Peterson 2004). Die hohe Kopienzahl mehrerer TEs in beiden Octadecabacter Genomen (Tab. 9, 3.2.2.2) deutet darauf hin, dass diese TEs funktional sind und häufige TranspositionsAktivität aufweisen. Somit kann es in beiden Octadecabacter-Genomen auch zu alternativen Transpositions-Ereignissen kommen.

Es ist anzunehmen, dass beide erwähnten TE-basierten Rekombinationsmechanismen auch das Potential für HGT in Octadecabacter-Populationen drastisch erhöhen. Dies könnte im Meereis von besonderer Bedeutung sein, da Meereis als potentieller hot spot für HGT gilt, der reich an extrazellulärer DNA ist (Collins \& Deming 2011a; Collins \& Deming 2011b). DNAFragmente, welche z. B. mittels Transduktion oder Transformation aus fremden Quellen aufgenommen wurden, müssen jedoch meist in ein natives Replikon integrieren, um stabil repliziert werden $\mathrm{zu}$ können und dem Abbau durch Nukleasen zu entgehen. Die Wahrscheinlichkeit für die Integration heterologer DNA-Abschnitte allein mittels illegitimer (nicht-homologer) Rekombination (Ehrlich 1989) ist extrem niedrig (de Vries \& Wackernagel 2002). Bereits kurze Sequenzbereiche (ab 183 bp) mit hoher Sequenzübereinstimmung können jedoch als „rekombinatorische Anker“ bzw. Ausgangspunkt für homologe Rekombinationsereignisse dienen, wodurch die Wahrscheinlichkeit für die Integration flankierender heterologer Genomabschnitte mittels anschließender illegitimer Rekombination um bis das $10^{5}$-fache erhöht wird (de Vries \& Wackernagel 2002; Prudhomme, Libante \& 
Claverys 2002). Die meisten der in den Octadecabacter-Genomen identifizierten TEs weisen nah verwandte Orthologe in beiden Isolaten auf (Tab. 9, 3.2.2.2), und sind zudem in hoher Dichte über beide Genome verteilt. Somit ist die Anwesenheit geeigneter rekombinatorischer Anker auf den meisten DNA Fragmenten, welche zwischen den Octadecabacter-Stämmen transferiert werden könnten, gegeben. Die extrem hohe Diversität an TEs in den Octadecabacter-Genomen spricht zudem dafür, dass häufig genetisches Material auch aus vielfältigen anderen Quellen aufgenommen wurde. Aufgrund ihrer Befähigung zur Transposition besitzen TEs eine höhere Wahrscheinlichkeit in ein neues Wirtsgenom zu integrieren als andere genetische Elemente. Solche neu aufgenommenen TEs könnten anschließend als rekombinatorische Anker für die Integration weiterer fremder DNAFragmente fungieren und somit auch das Potential für art- bzw. gattungsübergreifenden Gentransfer erhöhen. Diese Hypothese würde auch die regionale Anhäufung von Elementen einiger TE-Familien in begrenzten Genomabschnitten (Abb. 13, 3.2.2.2) erklären.

Die auf Basis mehrerer Faktoren systematisch definierten „Regionen erhöhter Genomplastizität“ (RGPs, 3.2.2.1) sind als rekombinatorische hot spots anzusehen. In diesen Regionen ist die Dichte an TEs und somit die Wahrscheinlichkeit für Homologie-basierte oder TE-vermittelte Rekombinationsereignisse meist deutlich erhöht. Anhand spezifischer Gencluster lassen sich in den Octadecabacter-Genomen verschiedene Rekombinationsereignisse zwischen RGPs nachvollziehen, sowohl innerhalb des Chromosoms (z. B. Fragmentierung des Typ-IV Sekretionssystems in O. arcticus, siehe 3.2.3.5 bzw. Duplikation des Quecksilber-Resistenzclusters in O. antarcticus, siehe 3.2.4.4), als auch zwischen verschiedenen Replikons (z. B. Duplikationen einzelner Gene der Flagellen- und GasvesikelGencluster in O. arcticus, Abb. 12, 3.2.2.1). In O. arcticus sind zudem im Bereich der RGPs 13-17, sowie auf dem Plasmid pOAR160 weitere konkrete Hinweise für den Austausch von genetischem Material zwischen chromosomalen und Plasmid-lokalisierten Genomabschnitten zu finden. Ein deutlicher Hinweis ist die regionale Anhäufung von IS6- und IS903-ähnlichen TEs in den genannten chromosomalen Genomabschnitten sowie auf pOAR160 (Abb. 13, 3.2.2.2). Desweiteren sind im Bereich der RGPs 13-17 mehrere Toxin/Antitoxin PlasmidStabilisierungssysteme enthalten, von denen eines fast vollständige Sequenzidentität zu einem entsprechenden System auf Plasmid pOAR160 aufweist (Tab. DA56, digitaler Anhang).

Die zahlreichen als potentielle genomische Inseln identifizierten Bereiche in den Chromosomen beider Octadecabacter-Stämme (Abb. 12, 3.2.2.1) weisen ebenfalls auf ein hohes Potential für horizontalen Gentransfer (HGT) hin. Wie im Folgenden erläutert, ist davon auszugehen, dass die tatsächliche Anzahl genomischer Inseln durch die verwendeten 
bioinformatische Vorhersage-Methoden (siehe 2.10.4) stark unterschätzt wird. Diese Vorhersagen basieren auf signifikanten Abweichungen verschiedener Messgrößen (beispielsweise der codon usage oder des GC-Gehalts) von genomischen Mittelwerten (Langille, Hsiao \& Brinkman 2008). Durch die hohe Zahl der transposablen Elemente (TEs) in diesen Organismen werden jedoch sowohl die Durchschnittswerte als auch die Varianz der jeweiligen Messgrößen beeinflusst. Dies kann dazu führen, dass einige Bereiche nicht mehr als signifikant abweichend gewertet werden. So sind auch abseits der durch bioinformatische Analysen identifizierten genomischen Inseln diverse Gencluster $\mathrm{zu}$ finden, welche wahrscheinlich durch HGT übertragen wurden. Beispiele hierfür sind das Cyanophycin Gencluster von O.arcticus 238 und die Gene der assimilatorischen Nitrat-Reduktion in O. antarcticus 307 (siehe 3.2.3.1+2 und Abb. 12, 3.2.2.1).

Durch die oben genannten Faktoren lassen sich die extremen Unterschiede in Struktur sowie Zusammensetzung der Genome der beiden phylogenetisch nah verwandten OctadecabacterStämmen erklären. Doch auch die vergleichsweise hohe Divergenz zwischen den phylogenetischen Distanzen auf MLSA- und rRNA-Gensequenz-Ebene (siehe Abb. 8+9, 3.1.3) ist wahrscheinlich als Ausdruck erhöhter Genomplastizität zu sehen. Obwohl die geringe Auflösung 16S rRNA-Gensequenz-basierter Phylogenie in Bezug auf sehr nah verwandte Spezies bereits häufig berichtet wurde (Palys, Nakamura \& Cohan 1997; Gevers et al. 2005; Thompson et al. 2005), sind 16S rRNA-basierte Stammbäume prinzipiell verlässlich und größtenteils vergleichbar mit MLSA-basierten Methoden (Adekambi \& Drancourt 2004; Soria-Carrasco et al. 2007). Allerdings weisen 16S rRNA-Gene signifikant niedrigere evolutionäre Substitutionsraten auf, als proteinkodierende Gene (Palys, Nakamura \& Cohan 1997; Palys et al. 2000). Entsprechend sollten sich erhöhte Mutationsraten in proteinkodierenden Genen weitaus früher und stärker ausprägen als in rRNA-Genen. Demnach deuten die unterschiedlichen phylogenetischen Distanzen zwischen den Octadecabacter-Stämmen auf rRNA-Ebene und MLSA-Ebene darauf hin, dass sich die beiden Octadecabacter-Stämme, möglicherweise aufgrund erhöhter Mutationsraten, innerhalb eines relativ kurzen Zeitraumes auseinander entwickelten. Der ungewöhnlich hohe Anteil an Pseudogenen in beiden Octadecabacter-Stämmen deutet auf eine solche erhöhte Mutationsrate hin (siehe 3.2.2.3). Somit scheinen die beiden Octadecabacter-Stämme entweder anfälliger für Sequenzmutationen oder in ihrem natürlichen Habitat stärker mutagenen Einflüssen ausgesetzt zu sein als andere Roseobacter-Vertreter. Saisonal erhöhte UV-Strahlungen (McKenzie et al. 2007) und Schwermetall-Konzentrationen (Ebinghaus et al. 2002; Ariya et al. 2004) in den Polarregionen könnten solche mutagenen Einflüsse darstellen. 


\subsubsection{Rückschlüsse auf die Biogeographie bipolar verbreiteter Organismen}

Arktis und Antarktis unterscheiden sich in mehreren Faktoren wie dem Ausmaß terrestrischer, limnischer und anthropogener Einflüsse sowie den verschiedenen durchschnittlichen Jahrestemperaturen grundsätzlich voneinander (Ghiglione et al. 2012) (Siehe 1.2). Auch die beiden Octadecabacter-Stämme lassen sich in mehreren prägnanten Merkmalen voneinander unterscheiden (siehe 3.2.3). Es liegt daher nahe, die genetischen Unterschiede zwischen arktischen und antarktischen Octadecabacter-Vertretern mit unterschiedlichen Umwelteinflüssen ihres jeweiligen Habitats in Verbindung zu setzen. Auf der ausschließlichen Grundlage der wenigen sequenzierten polaren Roseobacter-Vertreter sind jedoch noch keine verlässlichen Rückschlüsse auf unterschiedliche Lebensbedingungen in den nördlichen und südlichen Polargebieten möglich.

16S rRNA-Gensequenzanalysen zeigten, dass psychrophile Octadecabacter-Stämme beider Pole eine deutlich nähere Verwandtschaft zueinander aufweisen, als zu mesophilen Octadecabacter-Vertretern in temperaten und warmen Habitaten (siehe 3.2.1). Dies spricht gegen eine unabhängige Entwicklung und deutet vielmehr auf eine direkte Verbindung zwischen den Bakteriengemeinschaften beider Polargebiete hin. Zudem weisen die beiden Octadecabacter-Stämme, abgesehen von offenkundigen Unterschieden in Genomstruktur und -organisation (siehe 3.2.2.1 und 3.2.2.4), erstaunlich viele Gemeinsamkeiten auf. So sind beispielsweise Gasvesikel, Rhodopsin und Flagellengencluster der Octadecabacter-Vertreter beider Polarregionen fast identisch, aber dennoch prinzipiell verschieden von entsprechenden Genclustern der meisten anderen Roseobacter-Vertreter. Dies deutet auf einen gemeinsamen Genpool arktischer und antarktischer Octadecabacter-Populationen hin. Sämtliche Unterschiede in der Genom-Ausstattung beider Octadecabacter-Stämme lassen sich hingegen durch deren extrem hohe Genomplastizität erklären (siehe 4.2.1), einer Eigenschaft, welche gleichzeitig auch die auffälligste Gemeinsamkeit dieser Organismen darstellt (siehe 4.2.3). Keines der prägnanten genetischen Merkmale, in denen sich O.arcticus 238 und O. antarcticus 307 unterscheiden, ist ausschließlich auf Organismen des nördlichen bzw. des südlichen Polargebiets beschränkt. So sind Homologe sowohl der Gene der assimilatorischen Nitrat-Reduktion von O. antarcticus (siehe 3.2.3.2) als auch der Cyanophycin-Ligase und des Typ IV Sekretionssystems von O.arcticus (siehe 3.2.3.1 bzw. 3.2.3.5) prinzipiell in Organismen beider Polargebiete nachweisbar. Das genomische Potential der Bakteriengemeinschaften beider Polarregionen scheint somit grundsätzliche Ähnlichkeiten aufzuweisen. 
Es wurde bereits über mögliche Übertragungswege von Bakterien zwischen den Polen spekuliert (Staley \& Gosink 1999). Am naheliegendsten erscheint ein Transport polarer Organismen über die Wassermassen kalter Tiefenströmungen wie dem North Atlantic Deep Water oder dem Antarctic Bottom Water (NADW bzw. AABW; Brix \& Gerdes 2003). Diese Tiefenströmungen entstehen in den Polargebieten und erstrecken sich über den Äquator hinaus in die Gewässer der jeweils anderen Erdhalbkugel. Das NADW bildet sogar eine direkte Verbindung zwischen den Wassermassen beider Polargebiete (Brix and Gerdes 2003). Ein Kritikpunkt solcher Hypothesen ist die extrem lange Transferzeit von mehreren hundert Jahren, die vergeht, bis Wasser von einem Pol zum anderen gelangt (Staley \& Gosink 1999). Allerdings ist nicht auszuschließen, dass heterotrophe polare Organismen während solcher Transferzeiten in den Wassermassen von Tiefenströmungen überleben und sogar wachsen können. Der durch die charakteristischen Gasvesikel bedingte erhöhte Auftrieb von Octadecabacter-Vertretern (siehe 3.2.4.1) scheint zwar auf den ersten Blick gegen einen Transport über Tiefsee-Wassermassen zu sprechen. Allerdings sind Gasvesikel allgemein sehr empfindlich gegenüber Druckveränderungen und kollabieren irreversibel sobald der Wasserdruck zu sehr ansteigt (Pfeifer 2012). Wenn also Octadecabacter-Vertreter durch absinkende Tiefenströmungen ausreichend weit mitgerissen würden, wäre aufgrund der veränderten Druckverhältnisse die Ausbildung von Gasvesikeln nicht mehr möglich. Somit besäßen die entsprechenden Bakterienzellen keinen erhöhten Auftrieb mehr, der ein Aufsteigen in höhere und wärmere Wassermassen bewirken könnte.

Die Annahme einer direkten Verbindung zwischen den Populationen beider Polarregionen wird durch kürzlich von Ghiglione et al. (2012) veröffentlichte, auf 16S rRNA-Amplikonsequenzierung basierende Strukturanalysen globaler Bakteriengemeinschaften unterstützt. Zwar ließen sich durch die genannten Analysen arktische und antarktische Bakteriengemeinschaften in ihrer Zusammensetzung prinzipiell voneinander abgrenzen, jedoch wiesen die Populationen der beiden Polargebiete untereinander stets höhere Ähnlichkeiten auf, als zu angrenzenden Meeresregionen. Zudem sind die durch Ghiglione et al. dargestellten Unterschiede zwischen arktischen und antarktischen Bakteriengemeinschaften allgemein geringer ausgeprägt als zwischen den Sommer- und Wintergemeinschaften der jeweiligen Polarregion. Das bedeutet, dass saisonale Schwankungen einen stärkeren Einfluss auf die Artenzusammensetzung dieser Gebiete haben als geographische Unterschiede.

Die Tatsache, dass arktische und antarktische Bakteriengemeinschaften sich dennoch prinzipiell unterscheiden lassen, deutet allerdings auch auf grundsätzliche Unterschiede in den 
Lebensbedingungen beider Polarregionen hin. Die wenigen bislang verfügbaren Genomsequenzen polarer Organismen (www.genomesonline.org) reichen jedoch nicht aus und sind zudem $\mathrm{zu}$ divers, um entsprechende unterschiedliche Adaptionen durch gene content-Analysen aufzuzeigen. Zudem ist nicht auszuschließen, dass genetische Unterschiede zwischen den entsprechenden nördlichen und südlichen Bakteriengemeinschaften nicht in der Exklusivität, sondern vor allem in der Häufigkeit und Expressionsstärke verschiedener Merkmale zu suchen sind. Daher sind Metagenom- und Metatranskriptomanalysen geeignetere Mittel, um spezifische genetische Anpassungen an arktische bzw. antarktische Habitate aufzuzeigen, als Genomanalysen einzelner Organismen.

\subsubsection{Generelle Adaptionen an Polargebiete bzw. Meereishabitate}

Mehrere Merkmale beider Octadecabacter-Stämme lassen sich als generelle Anpassungen an polare bzw. Meereishabitate interpretieren. Das auffälligste Merkmal dieser Organismen ist die hohe Zahl und Diversität der TEs. Wie bereits in Abschnitt 4.2.1 diskutiert, sind hierdurch die Genomplastizität und somit auch das Potential für HGT in beiden OctadecabacterStämmen stark erhöht. Da Meereishabitate als potentielle hot spots für HGT gelten (Kiko 2010; Collins \& Deming 2011a; Collins \& Deming 2011b), ist anzunehmen, dass genomische Rekombination für die Meereis-bewohnenden Octadecabacter-Stämme von höherer Bedeutung ist als für andere Roseobacter-Vertreter. Die damit zusammenhängende genomische Flexibilität und erhöhte ökologische Adaptivität könnte in den sich jahreszeitlich drastisch verändernden polaren Lebensräumen (Takahashi et al. 2010; Ghiglione et al. 2012; Ghiglione \& Murray 2012) einen entscheidenden Selektionsvorteil bieten und erklären, wie sich die hohe Dichte an TEs trotz ersichtlicher negativer Auswirkungen (beispielsweise die Inaktivierung des Rhamnose-Verwertungs-Genclusters in O. arcticus, siehe 3.2.4.6) in beiden räumlich getrennten Octadecabacter-Populationen erhalten konnte. Somit könnten Octadecabacter-Vertreter aus Meereishabitaten eine starke Triebkraft der genomischen Diversität der gesamten Roseobacter-Gruppe darstellen.

Die Belastung mit UV-Licht ist in polaren Habitaten im Vergleich zu anderen Erdregionen erhöht (Karsten et al. 1998). Dies äußert sich bei den Octadecabacter-Stämmen in der relativ hohen Zahl an UV-Reparatursystemen (siehe 3.2.4.8) und könnte zudem eine Erklärung für die erhöhte Mutationsrate (siehe 3.2.2.3 und 4.2.1) in beiden Octadecabacter-Vertretern darstellen. 
Quecksilber-Emissionen belasten weltweit verschiedene Ökosysteme (Hylander \& Goodsite 2006). Entsprechend sind Resistenzmechanismen, wie die Befähigung zur QuecksilberReduktion, in vielfältigen Organismen unterschiedlicher Lebensräume zu finden (Osborn et al. 1997; Mindlin et al. 2005; Møller et al. 2012). Da jedoch sowohl die Arktis als auch die Antarktis als Senken für atmosphärisches Quecksilber gelten, was in diesen Gebieten zu saisonal erhöhten Quecksilber-Konzentrationen führt (Ebinghaus et al. 2002; Ariya et al. 2004; Poulain et al. 2007), könnten entsprechende Resistenzmechanismen in polaren Habitaten von besonderer Bedeutung sein. Diese Annahme wird durch die Tatsache unterstützt, dass Quecksilberresistenz Gencluster in allen drei polaren Roseobacter-Vertretern Phaeobacter arcticus DSM23566, O. arcticus 238 sowie O. antarcticus 307 konserviert sind, aber nur wenige andere Vertreter der Roseobacter-Gruppe entsprechende Orthologe aufweisen.

Es ist davon auszugehen, dass Speicherstoffe im Meereis allgemein eine sehr wichtige Rolle einnehmen. Sowohl niedrige Diffusionsraten im Meereis und kältebedingte erniedrigte Substratbindeaffinitäten bakterieller Enzyme als auch die extremen Übergänge zwischen verschiedenen Lebensbedingungen (vor allem bei der Bildung oder Schmelze des Meereises) und die damit verbundenen notwendigen Umstellungen des Metabolismus, können die Verfügbarkeit von Nährstoffen für Meereisorganismen vorrübergehend stark einschränken (Thomas \& Dieckmann 2002). Die Kohlenstoff-Speichersubstanz Polyhydroxybuttersäure (PHB) und der Phosphat-Speicherstoff Polyphosphat sind beiden Octadecabacter-Stämmen gemein, aber auch in vielen anderen Roseobacter-Vertretern zu finden (Tab. DA03+Tab. DA04, digitaler Anhang). Daher sind diese Speicherstoffe, auch wenn sie zweifelsohne in Meereishabitaten von großer Bedeutung sind, nicht spezifisch für Bewohner polarer Habitate. Anders verhält sich dies beim Cyanophycin-Gencluster von O. arcticus 238 (siehe 3.2.3.1). Metagenomanalysen deuten darauf hin, dass die Befähigung zur Cyanophycin-Synthese für marine Organismen eher untypisch ist. In Polarregionen ist die Häufigkeit entsprechender Gene, insbesondere von Cyanopycin-Ligasen des Typs VI, jedoch deutlich erhöht. Dies könnte vor allem mit saisonalen Nährstoff-Schwankungen in den Polarregionen zusammenhängen, da Stickstoff ein signifikanter limitierender Faktor für die heterotrophe Biomasse-Produktion polarer mariner Bakteriengemeinschaften im Sommer sein kann (Ortega-Retuerta, Jeffrey \& Joux 2012). Anstelle eines Stickstoff-Speicherpolymers, besitzt O. antarcticus 307 die Befähigung zur assimilatorischen Nitrat-Reduktion und ist daher in der Lage zusätzliche anorganische Stickstoffquellen zu nutzen (siehe 3.2.3.2). Desweiteren besitzen beide Octadecabacter-Stämme Cyanat-Hydratasen kodierende Gene (siehe 3.2.3.1), 
welche im weiteren Sinne ebenfalls am Stickstoffmetabolismus beteiligt sind. Dies deutet auf eine besonders Wachstums-limitierende Rolle von Stickstoff in polaren Lebensräumen hin.

Die Befähigung von O. arcticus, Ectoin aufzunehmen und zu verwerten, ist vor allem in Bezug auf das Meereishabitat dieses Organismus vorteilhaft. Aufgrund der sich während der Formation und des Schmelzens von Meereis drastisch ändernden Salinitäten ist anzunehmen, dass kompatible Solute für Organismen dieses Lebensraumes von großer Bedeutung sind. Interessanterweise scheint die Aufnahme von Ectoin in O. arcticus jedoch nicht primär der Osmoregulation, sondern vielmehr der Energie- und Kohlenstoffversorgung zu dienen. Hierfür spricht die Art des Ectoin-Transporters, welcher in O. arcticus dem ehu-Typ angehört. Da die Aktivität dieser Art von Transportern durch die Verfügbarkeit des Substrats reguliert wird, ist die Aufnahme von Ectoin nicht zwangsläufig von osmotischen Bedingungen abhängig. Es ist anzunehmen, dass dieses kompatible Solut in der natürlichen Umgebung von O.arcticus vor allem dann in großen Mengen zur Verfügung steht, wenn es durch Ectoinbildende Organismen aktiv ausgeschieden wird. Dies ist jedoch vor allem dann zu erwarten, wenn die Osmolarität drastisch abnimmt und eine hohe intrazelluläre Ectoin-Konzentration somit die Überlebensfähigkeit einschränken würde. Zwar ist es denkbar, dass die Expression des ehu-Typ Transporters in O. arcticus in Abhängigkeit von der Osmolarität reguliert wird, jedoch würde dies keine schnelle Reaktion auf plötzliche Veränderungen erlauben. Zum Zwecke der Osmoregulation erscheinen Ectoin-Transporter des tea-Typs, wie sie in den meisten zur Ectoin-Aufnahme befähigten Roseobacter-Vertretern vorliegen, weitaus besser geeignet. Ein Vorteil ergibt sich in O. arcticus somit vielmehr dadurch, dass dieser Organismus ein zusätzliches und in seinem natürlichen Habitat erwartungsgemäß häufig vorkommendes Substrat nutzen kann.

Die Xanthorhodopsine der Octadecabacter-Stämme (siehe 3.2.5) stellen nachweislich spezifische Anpassungen an die Eis-assoziierten Habitate dieser Organismen dar. Da diese im Fokus besonders intensiver Untersuchungen standen, werden die entsprechenden Befunde im nachfolgenden Abschnitt gesondert diskutiert.

\subsubsection{Xanthorhodopsine: Ökologie und Funktion}

\subsubsection{1 Ökologie der Xanthorhodopsine}

Phylogenetische Analysen der in der NCBI-nr Datenbank hinterlegten Rhodopsin-Sequenzen zeigen eindeutig eine Unterteilung der Xanthorhodopsin-Gruppe in zwei Untergruppen 
(Abb. 34, 3.2.5.1) (Vollmers et al. 2013). Eine solche Unterteilung ist bislang noch nicht beschrieben worden, jedoch lassen die hohen Bootstrap-Werte dieser Untergruppen, sowohl in Neighbor-Joining- als auch in Maximum-Likelihood-Analysen, an diesem Befund keine Zweifel aufkommen. Die Xanthorhodopsin-Untergruppe I beinhaltet unter anderem die beiden ursprünglich beschriebenen Xanthorhodopsine von G. violaceus und S. ruber und ist somit bereits funktional charakterisiert worden (Balashov \& Lanyi 2007; Balashov et al. 2010). Allerdings ist, trotz der größeren Zahl an entsprechenden Isolaten, noch kein Vertreter der Xanthorhodopsin Untergruppe II detailliert untersucht worden. Die Analysen der Octadecabacter-Rhodopsine stellen somit stellvertretend auch eine Charakterisierung der gesamten Xanthorhodopsin-Untergruppe II dar. Eine einfache phylogenetische Differenzierung solcher Merkmale wäre wohl wenig bemerkenswert, wenn sie nicht mit Unterschieden in Funktion und Ökologie einhergehen würde. Einer der Gründe dafür, dass die Existenz von Xanthorhodopsin-Untergruppen vormals noch nicht beschrieben wurde, könnte sein, dass solche funktionalen und ökologischen Unterschiede bislang nicht festgestellt wurden. Bei genauer Betrachtung der entsprechenden Isolate und Klone zeichnen sich jedoch deutliche Trends bezüglich der Habitate, in denen die jeweiligen Untergruppen typischerweise vorzukommen scheinen, ab (Abb. 46 und Abb. 34, 3.2.5.1).

Die Herkunftsverteilung dieser Klone und Isolate impliziert, dass Untergruppe I bevorzugt in meso- bis thermophilen Organismen diverser, vorwiegend limnischer, Habitate vorkommt, während es sich bei Untergruppe II primär um eine Eigenschaft meso- bis psychro-philer, mariner Organismen handelt. Bemerkenswert ist die Häufung von Vertretern der Untergruppe II in den Polargebieten. Da Isolate jedoch nicht notwendigerweise charakteristisch für ihre entsprechenden Habitate sein müssen, ist es notwendig, die tatsächlichen Abundanzen durch kultivierungsunabhängige Methoden zu überprüfen. Metagenomsequenzierung ist hierfür ein besonders geeignetes Mittel. Durch diese Methode wird die Beeinflussung der

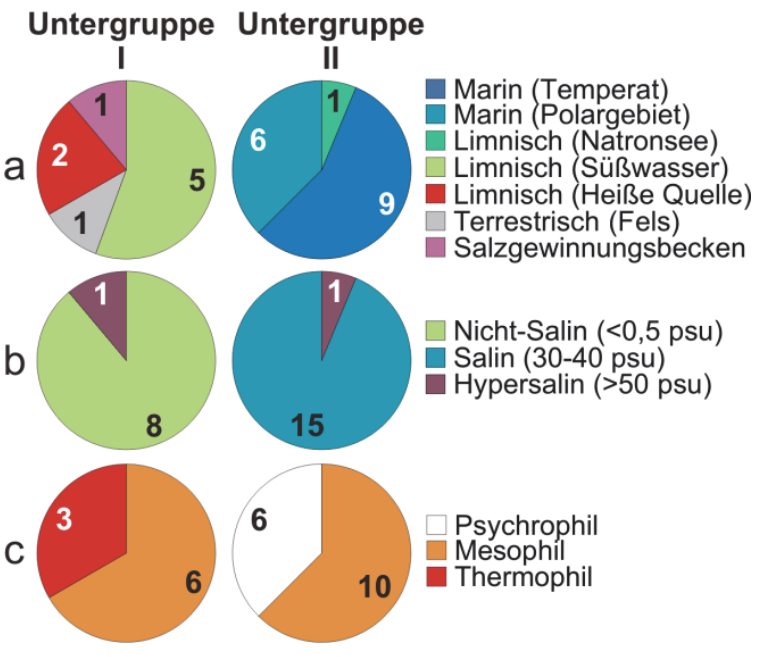

Abb. 46 Vergleich der Lebensbedingungen von Organismen mit Xanthorhodopsinen der Untergruppe I oder II

Dargestellt ist jeweils die Anzahl der Vertreter aus verschiedenen Habitaten mit unterschiedlichen Lebensbedingungen. a) Habitate b) Habitate eingeteilt nach Salinität. c) Habitate eingeteilt nach TemperaturOptima der jeweils dominanten Organismen. 
relativen Verhältnisse innerhalb einer Umweltprobe minimiert. Entsprechend konnten Metagenomanalysen die oben genannten Vermutungen teilweise bestätigen (Abb. 46 und Abb. 35+36, 3.2.5.2). Xanthorhodopsin-Sequenzen der Untergruppe I traten besonders zahlreich in heißen Quellen und in Süßwasser-Habitaten wie Flüssen und Seen auf. Allerdings waren dort auch Sequenzen der Untergruppe II vorzufinden, wenn auch in relativ geringem Maße. Demnach scheinen hohe Temperaturen und niedrige Salinitäten das Auftreten von Vertretern der Untergruppe II nicht prinzipiell auszuschließen. Auch in Metagenomen aus hypersalinen Habitaten war Untergruppe I stark vertreten, jedoch wiesen diese Metagenome bezüglich der relativen Rhodopsin-Anteile sehr hohe Schwankungen auf. Es handelte sich bei den betreffenden Habitaten um eine hypersaline Lagune und drei verschiedene Becken einer Salzgewinnungsanlage mit unterschiedlichen Salzkonzentrationen. Diese vier Habitate sind allesamt ursprünglich durch Meerwasser geprägt worden. In den flachen Becken der Lagune und der Salzgewinnungsanlage erwärmt sich jedoch das Meerwasser unter Sonneneinstrahlung schnell, was $\mathrm{zu}$ erhöhten Verdunstungsraten und somit steigenden Salinitäten führt. So entwickeln sich extreme Lebensbedingungen, welche im zunehmenden Maße halo- und thermophile Organismen, vornehmlich Archaeen, begünstigen. Dieser Umstand spiegelt sich in den ermittelten Rhodopsin-Verhältnissen wider: Der Proteorhodopsin-Anteil nimmt mit steigender Salinität ab, während archaeelle Bacterio- und Halorhodopsine immer dominanter werden (Abb. 36, 3.2.5.2). Das bedeutet, dass solche Habitate ohne Kenntnis der genauen Wassertemperatur und des Salzgehaltes schwer zu vergleichen sind. Jedoch sind solche Parameter für die Metagenome der Salzgewinnungsbecken nicht dokumentiert.

Interessanterweise scheinen jedoch Vertreter der Untergruppe II, anders als durch die Verhältnisse der Xanthorhodopsin-tragenden Klone und Isolate angedeutet (Abb. 46), nicht bevorzugt in marinen Organismen aufzutreten (Abb. 47). Tatsächlich sind beide Xanthorhodopsin-Untergruppen in limnischen Umgebungen weitaus zahlreicher vorzufinden als in marinen. Dennoch sind beide Untergruppen in geringen und regional schwankenden Anteilen in Meerwassern vorzufinden, wobei es keinen Unterschied machte, ob küstennahe Regionen untersucht wurden, oder der offene Ozean (Abb. 47). Xanthorhodopsine der Untergruppe II erreichten die höchsten Anteile in Eis-assoziierten Habitaten und auch in Meerwasser-Proben war ihr Anteil in der direkten Umgebung von Meereis deutlich erhöht (Abb. 36A, 3.2.5.2). In Organic Lake stieg der Anteil dieser Untergruppe mit zunehmender 


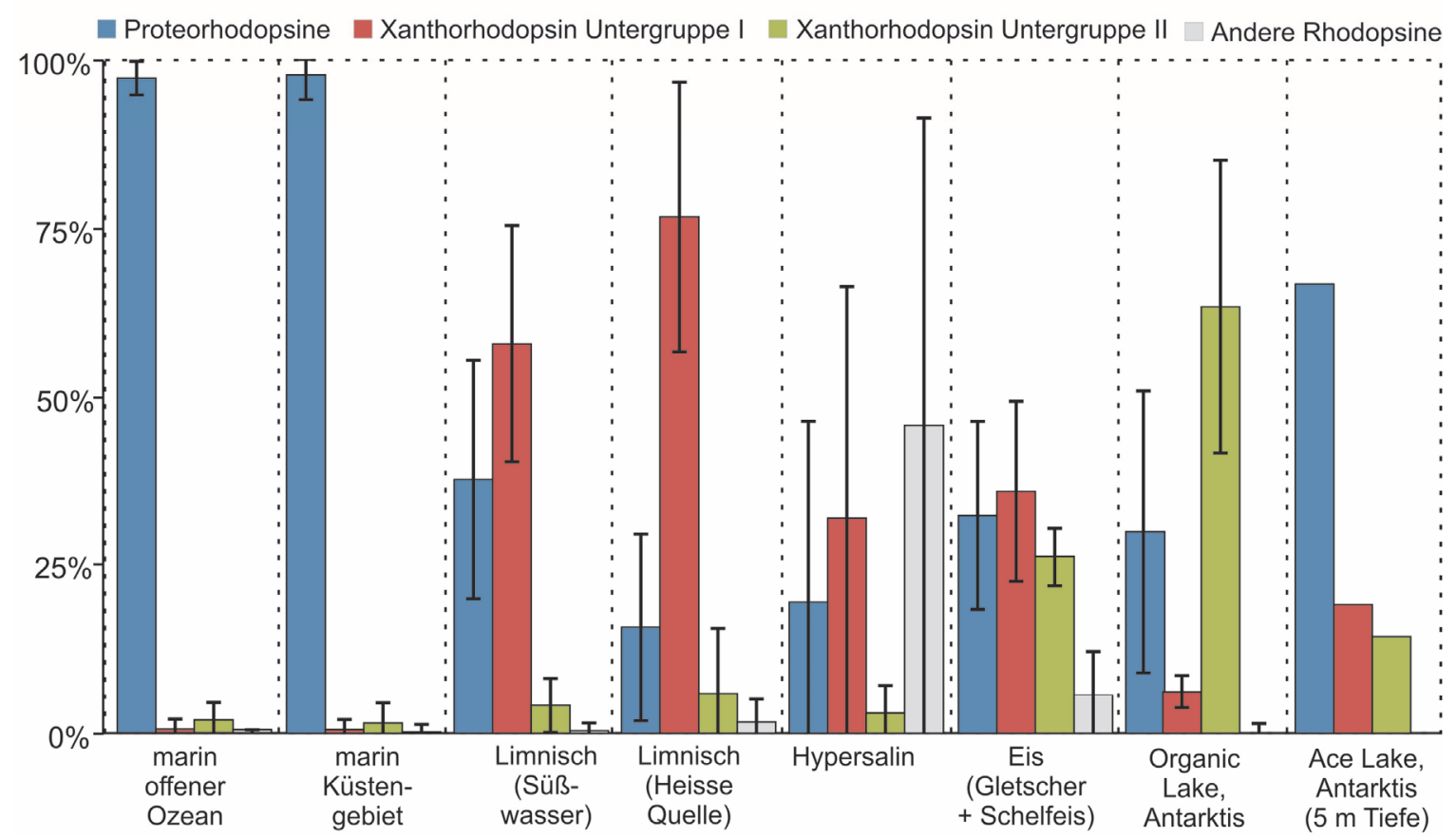

Abb. 47 Zusammenfassung der relativen Rhodopsin-Anteile in verschiedenen Habitaten

Es sind die durchschnittlichen Anteile verschiedener mikrobieller Rhodopsine an den Gesamt-Rhodopsinen unterschiedlicher Habitate dargestellt. Schwarze senkrechte Balken geben den jeweiligen Standardfehlerbereich wieder. Die Rhodopsin-Verhältnisse in Ace Lake werden nur durch eine Probe repräsentiert, da es sich hierbei um die einzige oberflächennahe Probe dieses Standortes handelt. Sämtliche andere Proben von Ace Lake stammen aus dem tiefergelegenen anoxischen Bereich dieses Sees und waren daher nicht direkt vergleichbar.

Eisbedeckung (Abb. 36F, 3.2.5.2). Dies deutet darauf hin, dass der Anteil an Xanthorhodopsinen der Untergruppe II direkt mit dem Vorhandensein von Eis zusammenhängt. Dennoch waren in mehreren Proben des ganzjährig mit Eis bedeckten Antarktischen Sees Ace Lake (Burch 1988), kaum Xanthorhodopsine nachweisbar. Allerdings handelt es sich bei Ace Lake um einen stark stratifizierten, meromiktischen See mit einer deutlich höheren Wassertiefe als Organic Lake. Nur in die oberen Meter dieses Sees dringt genügend Licht um Photosynthese bzw. photoheterotrophe Ernährung zu ermöglichen, weshalb sich ab ca. $12 \mathrm{~m}$ Wassertiefe eine deutliche anoxische Schicht ausbildet (Lauro et al. 2011). Die meisten Proben des Ace Lake Metagenoms stammen jedoch aus Wassertiefen $\geq 12 \mathrm{~m}$, daher sind in diesen Proben keine hohen Anteile an Rhodopsinen zu erwarten. In der obersten beprobten Wasserschicht dieses Sees $(5 \mathrm{~m})$ konnte immerhin ein deutlich höherer relativer Anteil an Untergruppe II-Xanthorhodopsinen identifiziert werden als in sämtlichen nicht Eisassoziierten Metagenomen (Abb. 47). Sowohl Ace Lake als auch Organic Lake sind durch marine Bedingungen geprägt worden. Organic Lake entstand vor etwa 6000 Jahren in Folge sinkender Meeresspiegel aus abfließendem Meerwasser (Franzmann et al. 1987), während Ace Lake ursprünglich aus einem Süßwassersee hervorging, der zwischenzeitlich durch Meer- 
wasser überspült wurde (Rankin et al. 1996). Demgegenüber sind die Probenstandorte des arktischen Schelfeis- (Varin et al. 2010) und insbesondere des alpinen Gletschereismetagenoms (Simon et al. 2009) nicht direkt durch marine Habitate beeinflusst worden. Auch diese Metagenome weisen deutlich erhöhte Anteile an Untergruppe II Xanthorhodopsinen auf (Abb. 47), was deutlich belegt, dass es sich hierbei um Eis-, nicht um Meerwasser-assoziierte Merkmale handelt. Daher lassen die hier vorgelegten Metagenomanalysen insgesamt darauf schließen, dass Xanthorhodopsine der Untergruppe II vor allem Eis-assoziierten Organismen einen Selektionsvorteil bieten.

Auffällig ist, dass Xanthorhodopsine im Allgemeinen an beiden Enden sowohl des Salinitätsspektrums, als auch des Temperaturspektrums mikrobieller Gemeinschaften vorzufinden sind. Sie stellen sowohl in eiskalten als auch in sehr heißen Umgebungen die dominante Rhodopsin-Gruppe, und sind sowohl in Süßwasser als auch in hypersalinen Habitaten zahlreich vertreten. Die Tatsache, dass eines der Xanthorhodopsin-tragenden Isolate aus einem Natronsee stammt, lässt zudem auch ein breites $\mathrm{pH}$-Spektrum vermuten. Das könnte darauf hindeuten, dass Xanthorhodopsine, im Gegensatz zu Proteorhodopsinen, welche hauptsächlich unter stabilen marinen Umweltbedingungen Selektionsvorteile zu bringen scheinen, an stark schwankende Umweltbedingungen angepasst sind. Dieser Aspekt ist vor allem für das Meereis-Habitat der Octadecabacter-Vertreter, mit seinen extremen zeitlichen und räumlichen Salinitäts- und Temperatur-Gradienten, von großer Bedeutung. Leider war es nicht möglich, den Einfluss solcher Umweltbedingungen auf die Aktivität verschiedener Rhodopsine direkt in Zellkulturen $\mathrm{zu}$ messen, da sowohl die pH-Messung, als auch die Integrität der Bakterienzellen durch eben diese Faktoren entscheidend beeinträchtigt werden. Durch Flash-Photolyse-Techniken (Sasaki \& Spudich 1998) ließen sich Aktivitätsspektren von Rhodopsinen auch in Membranfragmentsuspensionen bestimmen, jedoch stand diese Methode im Rahmen der vorliegenden Doktorarbeit nicht zur Verfügung.

Obwohl Xanthorhodopsine auf Sequenzebene enge Verwandtschaftsbeziehungen aufweisen, sind die zugehörigen Organismen sehr divers. Diese Organismen sind acht verschiedenen bakteriellen Klassen aus sechs bakteriellen Phyla zuzuordnen und beinhalten zudem auch noch eine Gruppe von eukaryotischen Organismen. Das lässt darauf schließen, dass dieses Merkmal häufig durch horizontalen Gentransfer auch zwischen phylogenetisch sehr unterschiedlichen Organismen übertragen wird. Die konservierte Genumgebung von Xanthorhodopsinen der Untergruppe II, welche das Opsin-Gen und mehrere Gene der Retinalsynthese in einem kompakten Cluster vereint (Abb. 37, 3.2.5.3) begünstigt die Übertragung funktionaler Rhodopsine. Ohne kovalent gebundenes Retinal sind Opsine nicht photoaktiv 
und somit nicht funktional (Spudich \& Jung 2005). Durch die Zusammenfassung von Opsinund Retinalsynthese zu einem gemeinsamen Gencluster würde ein einziges GentransferEreignis ausreichen, um ein funktionales Rhodopsin zu übertragen. Die Wahrscheinlichkeit eines solchen Ereignisses liegt höher als die Wahrscheinlichkeit der Übertragung funktional zusammengehöriger aber räumlich getrennter Gen-Loci durch multiple unabhängige Gentransfers (Lawrence \& Roth 1996; Sharma, Spudich \& Doolittle 2006). Der hohe Grad an Konservierung der Untergruppe II-Xanthorhodopsin-Gencluster deutet zudem darauf hin, dass dieses Merkmal vor nicht sehr langer Zeit durch die entsprechenden Organismen aufgenommen wurde. Denn ist ein solches Gencluster einmal in das Genom integriert, kann es sich im Laufe der Zeit durch Rekombinationsereignisse verändern und auch auf verschiedene Genomregionen verteilen.

Untergruppe I-Xanthorhodopsine besitzen hingegen keine entsprechende konservierte Genumgebung. Allerdings bilden sämtliche Isolate, welche Xanthorhodopsine der Untergruppe I beherbergen, auch unabhängig von diesem Merkmal Carotenoide aus. Salinibacter ruber bildet das Carotenoid Salinixanthin vermutlich primär zur Stabilisierung der Membran und zum Schutz vor starker Sonneneinstrahlung (Lutnaes, Oren \& LiaaenJensen 2002). Auch Vertreter der Actinobacteria und des Genus Thermus sind für die Bildung von Carotenoiden bekannt (Brock \& Freeze 1969; Yokoyama et al. 1996; Klassen 2010; Romero et al. 2012). Gloeobacter violaceus PCC 7411 und Roseiflexus sp. RS-1 bilden Chlorophyll bzw. Bacteriochlorophyll (Nakamura et al. 2003; van der Meer et al. 2010). Vermutlich sind in den entsprechenden Organismen die Retinal-Synthesegene des ursprünglichen Xanthorhodopsin-Genclusters in bereits vorhandene Carotenoid-SyntheseGencluster integriert, bzw. teilweise durch diese funktional ersetzt worden. In Folge dessen könnte sich schließlich auch die Befähigung der Untergruppe I-Xanthrorhodopsine ausgebildet haben, zusätzliche Carotenoide als Antennenpigmente zu binden. Dies lässt darauf schließen, dass die weitere horizontale Übertragung von Untergruppe I-XanthorhodopsinGenen größtenteils auf Organismen beschränkt sein wird, welche ebenfalls bereits Carotenoid-Synthesewege besitzen.

\subsubsection{Funktion der Xanthorhodopsine}

Die Untergruppe II-Xanthorhodopsine der beiden Octadecabacter-Stämme fungieren als lichtgetriebene Protonenpumpen. Hierauf deuten bereits vergleichenden Analysen der 
entsprechenden Aminosäure-Sequenzen hin (siehe 3.2.5.3). So sind an den entsprechenden alignment-Positionen Äquivalente aller Aminosäuren vorhanden, welche in Bacterio- und Proteorhodopsinen als funktionelle Bestandteile des Protonentransports beschrieben wurden (Balashov 2000; Beja et al. 2000; Balashov et al. 2005). Anhand heterologer Expressionskulturen konnte lichtabhängige Protonentranslokation für die Xanthorhodopsine von O. arcticus und $O$. antarcticus auch experimentell nachgewiesen werden (Abb. 40, 3.2.5.3). Für die nah verwandten Xanthorhodopsine der Untergruppe I ist eine solche Funktion ebenfalls bekannt (Balashov et al. 2005; Kawanabe et al. 2009), daher ist anzunehmen, dass diese Funktion allen Xanthorodopsinen gemein ist. Der so erzeugte Protonengradient kann zur Energiekonservierung genutzt werden, wodurch vorhandene Nährstoffe vermehrt anabolischen Stoffwechselwegen zugeführt werden können.

Transkriptionsanalysen zeigten, dass die Opsin-Gene in beiden Octadecabacter-Stämmen sowohl bei Licht als auch bei Dunkelheit exprimiert werden (Abb. 41, 3.2.5.3). Das Fehlen einer sichtbaren Pigmentierung könnte auf eine geringe Expressionsrate zurückzuführen sein. Auch Vibrio sp. AND4 weist keine sichtbare Pigmentierung auf und besitzt dennoch bei Nährstoffmangel einen Überlebensvorteil aufgrund des von diesem Organismus gebildeten Proteorhodopsins (DeLong \& Beja 2010; Gomez-Consarnau et al. 2010).

Dass die Octadecabacter-Stämme unter den getesteten Bedingungen dennoch keinen deutlichen lichtabhängigen Wachstumsvorteil aufwiesen, ist nicht ungewöhnlich. Für diverse Proteorhodopsin-bildende Organismen konnte ein solcher Wachstumsvorteil bislang noch nicht nachgewiesen werden (DeLong \& Beja 2010; Irene Wagner-Döbler, persönliches Gespräch). Bei einigen Organismen vermittelte Proteorhodopsin lediglich während extremer Hungerperioden einen Wachstums- bzw. Überlebensvorteil (Gomez-Consarnau et al. 2007; Gomez-Consarnau et al. 2010). In mehreren Fällen wurde beobachtet, dass die Aktivität von Rhodopsinen direkt mit der Aktivität der Atmungskette zusammenhängt und sogar durch diese gehemmt wird (Walter et al. 2007). Es ist daher anzunehmen, dass es sich bei dem Xanthorhodopsin der Octadecabacter-Vertreter nicht um einen allgemein wachstumsfördernden Mechanismus, sondern vielmehr um einen Überlebensmechanismus handelt, welcher nur unter widrigen Lebensbedingungen an Bedeutung gewinnt. Dies könnte unter anderem in den Adaptionsphasen während der Bildung oder des Schmelzens von Meereis (Thomas \& Dieckmann 2002) der Fall sein. Eine ähnliche Rolle könnten Xanthorhodopsine auch in anderen Organismen einnehmen. Die Untergruppe I-Xanthorhodopsin-bildenden Bakterien G. violaceus und Roseiflexus RS-1 besitzen zusätzlich zu dem Xanthorhodopsinvermittelten Protonentransport noch weitere effiziente Mechanismen der photoheterotrophen 
Ernährung: Photosynthese mittels Chlorophyll bzw. anoxygene Photosynthese mittels Bacteriochlorophyll (Nakamura et al. 2003; van der Meer et al. 2010). Daher ist auch für diese Organismen nicht anzunehmen, dass Xanthorhodopsin primär zur Energiegewinnung während der Wachstumsphase benötigt wird. Da G. violaceus als Fels-assoziierter Organismus (Rippka, Waterbury \& Cohen-Bazire 1974) voraussichtlich des Öfteren mit Austrocknung und Roseiflexus RS-1 (Madigan et al. 2005) in heißen Quellen mit starken Temperaturgradienten konfrontiert ist, könnte Xanthorhodopsin als Überlebensmechanismus auch für diese Organismen von Bedeutung sein.

\subsection{Diskussion der Zusatzergebnisse: Erste Einblicke in die Genomausstattung von Vertretern des marinen Myxobakterienclusters (MMC)}

Die in dieser Doktorarbeit präsentierten Sequenzanalysen zweier Fosmide einer marinen Metagenombank (siehe 3.3), ermöglichen einen ersten Einblick in die Eigenschaften einer weiteren beudeutsamen und global verbreiteten marinen Bakteriengruppe: Dem marinen Myxobakteriencluster (MMC; Brinkhoff, Vollmers et al. 2012)

Die auf den Fosmiden MMCf1 und MMCf2 enthaltende Sequenzeninformation ist tatsächlich auf marine Myxobakterien zurückzuführen. Hierauf deuten nicht nur $16 \mathrm{~S}$ rRNAGensequenzanalysen (Vollmers 2007; Brinkhoff, Vollmers et al. 2012) hin, sondern auch die Tatsache, dass beide Fosmide über 50\% der jeweils enthaltenen Gene als Orthologe mit sequenzierten Myxobakterien teilen (Abb. A5, Anhang). Eine evolutionäre Anpassung an marine Habitate wird dadurch ersichtlich, dass ungefähr die Hälfte der eben genannten Orthologe in den MMC-Fosmiden eine höhere Sequenzübereinstimmung zu entsprechenden Homologen in marinen Organismen als $\mathrm{zu}$ anderen, ausschließlich terrestrischen Myxobakterien (Tab. DA60, digitaler Anhang; Brinkhoff, Vollmers et al. 2012) aufweisen. Da sich die Orthologe zwischen beiden MMC-Fosmiden zwar sehr ähneln, aber auch geringfügige Sequenzunterschiede aufweisen, ist davon auszugehen, dass die entsprechenden Fosmid-inserts von zwei verschiedenen Stämmen derselben Bakterien-Art stammen.

Die Tatsache, dass die 16S rRNA-Gene der inserts von MMCf1 und MMCf2 nicht mit vollständigen oder partiellen rRNA-Operons verbunden sind, ist bemerkenswert und grenzt die Vertreter des MMC von den bislang sequenzierten Myxobakterien ab. Alleinstehende 16S Gene wurden bereits in verschiedenen Bakterien und Archaeen beobachtet, stellen aber eher Ausnahmen als den Normalfall dar (Boyer, Flechtner \& Johansen 2001). 
Die auf den Fosmiden enthaltene Sequenzinformation reicht zwar nicht aus, um tiefgehende Rückschlüsse auf die Lebensweise mariner Myxobakterien zu erlauben, insbesondere da Vertreter der Myxococcales allgemein sehr komplex sind und die größten bekannten bakteriellen Genome aufweisen (Reichenbach 1999; Schneiker et al. 2007). Dennoch ermöglichen sie einen interessanten ersten Einblick in die Genomeigenschaften dieser Organismen. 


\section{Zusammenfassung}

Die in dieser Arbeit präsentierten Genomanalysen erweitern das Wissen um das genomische Potential der Roseobacter-Gruppe und zeigen mögliche Adaptionen an ökologische Nischen innerhalb mariner Lebensräume auf. In den polaren Meereisorganismen Octadecabacter arcticus 238 und $O$. antarcticus 307 konnten neue Eigenschaften identifiziert werden, welche bislang nicht in Vertretern der Roseobacter-Gruppe beschrieben wurden und wahrscheinlich Anpassungen an polare bzw. Meereis-assoziierte Lebensräume darstellen.

Ein besonderes Highlight dieser Analysen ist die Charakterisierung einer neuen Untergruppe von Xanthorhodopsinen in den Octadecabacter-Vertretern. Diese neue XanthorhodopsinUntergruppe unterscheidet sich von den bisher beschriebenen Xanthorhodopsinen in ihrer mangelnden Befähigung zur Keto-Carotenoid-Bindung und ihrer vorwiegenden Verbreitung in Organismen Eis-assoziierter Habitate. Die Analysen weisen zudem darauf hin, dass diese lichtgetriebenen Protonenpumpen nicht primär zur Energiegewinnung während der Wachstumsphase benötigt werden. Vielmehr scheint es sich um einen Überlebensmechanismus für extreme Umweltbedingungen, wie sie auch im Meereis herrschen, zu handeln (Vollmers et al. 2013).

Für beide polare Octadecabacter-Vertreter wurde eine ungewöhnlich hohe Genomplastizität festgestellt. Hierbei scheint es sich um eine Anpassung an das einzigartige Meereishabitat dieser Organismen zu handeln, welches als hot spot für horizontalen Gentransfer (HGT) gilt. Zudem bietet diese Genomplastizität eine Erklärung für die zahlreichen genomischen Unterschiede zwischen den Octadecabacter-Stämmen, welche in direktem Widerspruch zu der nahen Verwandtschaft dieser Organismen auf 16S rRNA-Gensequenzebene stehen.

Trotz dieser Unterschiede weist die genetische Ausstattung von O. arcticus und O. antarcticus auffällige Übereinstimmungen auf, welche auf einen gemeinsamen exklusiven Genpool von Octadecabacter-Vertretern beider Polargebiete hindeuten. Dies wird durch 16S rRNA-basierte phylogenetische Analysen von Octadecabacter-Vertretern verschiedener Habitate unterstützt. Somit scheint zwischen Bakteriengemeinschaften beider Polarregionen eine direkte Verbindung zu existieren. Von den Polargebieten ausgehende Tiefenströmungen, welche sich über beide Hemisphären erstrecken, könnten diese Verbindung darstellen (Vollmers et al. 2013). 
Anhand der bislang verfügbaren Genomsequenzen wurden Verwandtschaftsbeziehungen sowie allgemeine Unterschiede zwischen Vertretern der Roseobacter-Gruppe auf vielfältigen Ebenen untersucht. Die Ergebnisse dieser Analysen geben wertvolle Einblicke in unterschiedliche Nischenadaptionen zwischen nah verwandten Roseobacter-Vertretern und in die Bedeutung von horizontalem Gentransfer für diese Gruppe (Voget, Vollmers et al. 2013; Vollmers et al. 2013). Zudem bieten sie eine Grundlage für die vereinfachte Einteilung und Analyse zukünftiger Roseobacter-assoziierter Genom- und Metagenomsequenzen. So trugen die in dieser Arbeit präsentierten phylogenetischen Analysen des Genus Octadecabacter bereits dazu bei, ein kürzlich gewonnenes Nordsee-Isolat (AG Simon, ICBM, Oldenburg; noch nicht veröffentlicht) als nicht-polaren Octadecabacter-Stamm zu identifizieren.

Als zusätzliches Ergebnis konnten erste Einblicke in die Genomausstattung von Vertretern des weltweit verbreiteten aber bislang unkultivierten marinen Myxobakterienclusters (MMC) gewonnen werden (Brinkhoff, Vollmers et al. 2012). 


\section{Ausblick}

1) Die Beziehungen zwischen bipolar verbreiteten Organismen beider Polarregionen sollten weiter untersucht werden. Hierfür böten sich unter anderem Genomsequenzierungen weiterer arktischer und antarktischer Octadecabacter-Isolate an. Dadurch ließe sich feststellen, ob Struktur und Zusammensetzung der Genome von Octadecabacter-Vertretern derselben Polarregion aufgrund der hohen Genomplastizität dieser Organismen ähnlich hohe Unterschiede aufweisen wie die Genome der hier untersuchten Octadecabacter-Vertreter der Arktis und der Antarktis.

Die in dieser Arbeit präsentierten Analysen von Xanthorhodopsin- und Cyanophycin-LigaseGenen zeigten, dass meta-omics Ansätze für detaillierte Habitatvergleiche und biogeographische Analysen unerlässlich sind. Insbesondere vergleichende MetatranskriptomAnalysen würden dazu beitragen, signifikante Unterschiede in der genetischen Ausstattung arktischer und antarktischer Bakteriengemeinschaften sichtbar zu machen. Hierfür müsste jedoch eine hohe Vergleichbarkeit der jeweiligen Datensätze bezüglich allgemeiner Umweltfaktoren (z.B. Jahreszeit, Wassertiefe und Eisbedeckung) sowie methodischer Aspekte gewährleistet werden.

2) Mögliche direkte Verbindungen zwischen endemischen Populationen beider Polarregionen sollten intensiv überprüft werden. Würden psychrophile Vertreter polarer Bakteriengemeinschaften durch kalte Tiefenströmungen unter den warmen Oberflächengewässern des Äquators hindurch übertragen, so sollten solche Vertreter in den entsprechenden TiefseeWassermassen nachweisbar sein. Dies könnte durch spezifischen PCR-Nachweis ausgewählter Taxa (beispielsweise dem Genus Octadecabacter) erfolgen. Komplementiert werden könnten solche Untersuchungen durch vergleichende Analysen polarer sowie tropischer Oberflächen- und Tiefengewässer mittels 16S Amplikonsequenzierung oder denaturierender Gradienten-Gelelektrophorese (DGGE). Die nötige Grundlage hierfür bietet die hohe Zahl an Oberflächen- und Tiefenwasserproben, welche (unter anderem im Rahmen dieser Doktorarbeit) während der Polarsternexpeditionen AntXXVIII/2,4+5 im Südpolarmeer und Atlantik genommen wurden (Bumke 2012; Kattner 2012; Lucassen 2012). 
3) Die Bedeutung von horizontalem Gentransfer (HGT) in Meereishabitaten sollte weiter untersucht werden. Durch vergleichende Metagenomanalysen von Meereis- und Meerwasserproben ließe sich feststellen, ob die Anzahl HGT- und TE-assoziierter Gene in Meereishabitaten signifikant erhöht ist.

4) Die genaue Bedeutung verschiedener Mechanismen des HGT ist in Vertretern der Roseobacter-Gruppe bislang kaum untersucht. Daher sollten sowohl Häufigkeit als auch phylogenetische Übertragungsweiten von HGT durch Konjugations-, Transformations- und Transduktionsversuche zwischen Bakterienstämmen verschiedener Roseobacter-Taxa unterschiedlicher Verwandtschaftsgrade gemessen werden. Als Marker böten sich beispielsweise Antibiotikaresistenzen an. Die hierfür benötigten gentechnischen Methoden wurden bereits durch Piekarski et al. (2009) für Vertreter der Roseobacter-Gruppe etabliert.

5) Die geplante Genomanalyse eines kürzlich gewonnenen Octadecabacter-Isolats aus der deutschen Nordsee (AG Simon, ICBM, Oldenburg; noch nicht veröffentlicht) wird für die Klärung der Verwandtschaftsverhältnisse polarer und nichtpolarer Octadecabacter-Vertreter von sehr hoher Bedeutung sein. Hierdurch wird sich unter anderem die Hypothese eines exklusiven gemeinsamen Genpools arktischer und antarktischer Octadecabacter-Vertreter (siehe 4.2.2) effektiv überprüfen lassen.

6) Das Wissen über die Funktion und ökologische Bedeutung der XanthorhodopsinUntergruppen kann durch weitere funktionelle Analysen noch erheblich vertieft werden. Beispielsweise sollte die Befähigung zur Keto-Carotenoid-Bindung in weiteren Vertretern beider Untergruppen untersucht werden. Durch Mutationsversuche ließe sich zudem die funktionelle Bedeutung einzelner Bestandteile der Keto-Carotenoid-Bindestellen gezielt überprüfen. Desweiteren sollte der Photozyklus zahlreicher Vertreter der XanthorhodopsinUntergruppen I und II bei unterschiedlichen Temperaturen, pH-Werten und Salzkonzentrationen untersucht und verglichen werden. Der Photozyklus eines Rhodopsins gibt Aufschluss über dessen Aktivität bei definierten Umweltbedingungen und wird üblicherweise mittels Flash-Photolyse gemessen (Dioumaev et al. 2002; Wang et al. 2003), einer Methode die im Zuge dieser Doktorarbeit nicht zur Verfügung stand. 


\section{Literaturverzeichnis}

Adekambi, T. \& Drancourt, M. (2004) Dissection of phylogenetic relationships among 19 rapidly growing Mycobacterium species by $16 \mathrm{~S}$ rRNA, hsp65, sodA, recA and rpoB gene sequencing. Int J Syst Evol Microbiol, 54, 2095-2105.

Alldredge, A.L. \& Silver, M.W. (1988) Characteristics, dynamics and significance of marine snow. Prog Oceanogr, 20, 41-82.

Altenhoff, A.M. \& Dessimoz, C. (2009) Phylogenetic and Functional Assessment of Orthologs Inference Projects and Methods. PLoS Comp Biol, 5, e1000262

Anton, J., Oren, A., Benlloch, S., Rodriguez-Valera, F., Amann, R. \& Rossello-Mora, R. (2002) Salinibacter ruber gen. nov., sp nov., a novel, extremely halophilic member of the Bacteria from saltern crystallizer ponds. Int J Syst Evol Microbiol, 52, 485-491.

Ariya, P.A., Dastoor, A.P., Amyot, M., Schroeder, W.H., Barrie, L., Anlauf, K., Raofie, F., Ryzkhov, A., Davignon, D., Lalonde, J. \& Steffen, A. (2004) The Arctic: a sink for mercury. Tellus B, 56, 397-403.

Armstrong, G.A. (1997) Genetics of eubacterial carotenoid biosynthesis: A colorful tale. Annu Rev Microbiol, 51, 629-659.

Balashov, S.P. (2000) Protonation reactions and their coupling in bacteriorhodopsin. Biochim Biophys Acta Bioenerg, 1460, 75-94.

Balashov, S.P., Imasheva, E.S., Boichenko, V.A., Anton, J., Wang, J.M. \& Lanyi, J.K. (2005) Xanthorhodopsin: a proton pump with a light-harvesting carotenoid antenna. Science, 309, 2061-2064.

Balashov, S.P., Imasheva, E.S., Choi, A.R., Jung, K.H., Liaaen-Jensen, S. \& Lanyi, J.K. (2010) Reconstitution of Gloeobacter rhodopsin with echinenone: Role of the 4-Keto group. Biochemistry, 49, 9792-9799.

Balashov, S.P. \& Lanyi, J.K. (2007) Xanthorhodopsin: Proton pump with a carotenoid antenna. J Cell Mol Life Sci, 64, 2323-2328.

Bano, N., Ruffin, S., Ransom, B. \& Hollibaugh, J.T. (2004) Phylogenetic composition of Arctic Ocean archaeal assemblages and comparison with antarctic assemblages. Appl Environ Microbiol, 70, 781-789.

Beja, O., Aravind, L., Koonin, E.V., Suzuki, M.T., Hadd, A., Nguyen, L.P., Jovanovich, S., Gates, C.M., Feldman, R.A., Spudich, J.L., Spudich, E.N. \& DeLong, E.F. (2000) Bacterial rhodopsin: Evidence for a new type of phototrophy in the sea. Science, 289, 1902-1906.

Berg, H. (2003) Untersuchungen zu Funktion und Struktur der Cyanophycin-Synthetase von Anabaena variabilis ATCC 29413. Dissertation, Humboldt-Universität zu Berlin.

Berg, H., Ziegler, K., Piotukh, K., Baier, K., Lockau, W. \& Volkmer-Engert, R. (2000) Biosynthesis of the cyanobacterial reserve polymer multi-L-arginyl-poly-L-aspartic acid (cyanophycin) - Mechanism of the cyanophycin synthetase reaction studied with synthetic primers. Eur J Biochem, 267, 5561-5570. 
Biers, E.J., Wang, K., Pennington, C., Belas, R., Chen, F. \& Moran, M.A. (2008) Occurrence and expression of gene transfer agent genes in marine bacterioplankton. Appl Environ Microbiol, 74, 2933-2939.

Bowman, J.P., McCammon, S.A., Brown, M.V., Nichols, D.S. \& McMeekin, T.A. (1997) Diversity and association of psychrophilic bacteria in Antarctic sea ice. Appl Environ Microbiol, 63, 3068-3078.

Bowman, J.S., Rasmussen, S., Blom, N., Deming, J.W., Rysgaard, S. \& Sicheritz-Ponten, T. (2012) Microbial community structure of Arctic multiyear sea ice and surface seawater by 454 sequencing of the 16S RNA gene. ISME J, 6, 11-20.

Boyer, S.L., Flechtner, V.R. \& Johansen, J.R. (2001) Is the 16S-23S rRNA internal transcribed spacer region a good tool for use in molecular systematics and population genetics? A case study in Cyanobacteria. Mol Biol Evol, 18, 1057-1069.

Braumann, I., van den Berg, M. \& Kempken, F. (2008) Strain-specific retrotransposonmediated recombination in commercially used Aspergillus niger strain. Mol Genet Genomics, 280, 319-325.

Brinkhoff, T., Fischer, D., Vollmers, J., Voget, S., Beardsley, C., Thole, S., Mussmann, M., Kunze, B., Wagner-Dobler, I., Daniel, R. \& Simon, M. (2012) Biogeography and phylogenetic diversity of a cluster of exclusively marine Myxobacteria. ISME J, 6, $1260-1272$.

Brinkhoff, T., Giebel, H.A. \& Simon, M. (2008) Diversity, ecology, and genomics of the Roseobacter clade: a short overview. Arch Microbiol, 189, 531-539.

Brinkmeyer, R., Knittel, K., Jurgens, J., Weyland, H., Amann, R. \& Helmke, E. (2003) Diversity and structure of bacterial communities in arctic versus antarctic pack ice. Appl Environ Microbiol, 69, 6610-6619.

Brix, H. \& Gerdes, R. (2003) North Atlantic Deep Water and Antarctic Bottom Water: Their interaction and influence on the variability of the global ocean circulation. $J$ Geophys Res-Oceans, 108, 3022.

Brock, T. \& Freeze, H. (1969) Thermus aquaticus gen. n. and sp. n., a nonsporulating extreme thermophile. J Bacteriol, 98, 289-297.

Broecker, W.S. (1991) The great ocean conveyor. Oceanography, 4, 79-89.

Brown, L. (2004) Fungal rhodopsins and opsin-related proteins: eukaryotic homologues of bacteriorhodopsin with unknown functions. Photoch Photobio Sci, 3, 555-565.

Brown, M. \& Bowman, J. (2001) A molecular phylogenetic survey of sea-ice microbial communities (SIMCO). FEMS Microbiol Ecol, 35, 267-275.

Buchan, A., Gonzalez, J.M. \& Moran, M.A. (2005) Overview of the marine Roseobacter lineage. Appl Environ Microbiol, 71, 5665-5677.

Bumke, K. (2012) The expedition of the research vessel "Polarstern" to the Antarctic in 2012 (ANT-XXVIII/5). Rep. Polar Mar. Res., 1-77.

Burch, M.D. (1988) Annual cycle of phytoplankton in Ace Lake, an ice covered, saline meromictic lake. Biology of the Vestfold Hills, Antarctica (eds J.M. Ferris, H.R. Burton, G.W. Johnstone \& I.A.E. Bayly), pp. 59-75. Springer, Netherlands.

Cascales, E. \& Christie, P.J. (2003) The versatile bacterial type IV secretion systems. Nat Rev Microbiol, 1, 137-149. 
Clark, W.A. (1976) A simplified Leifson flagella stain. J Clin Microbiol, 3, 632-634.

Collins, R.E. \& Deming, J.W. (2011a) Abundant dissolved genetic material in Arctic sea ice Part I: Extracellular DNA. Polar Biol, 34, 1819-1830.

Collins, R.E. \& Deming, J.W. (2011b) Abundant dissolved genetic material in Arctic sea ice Part II: Viral dynamics during autumn freeze-up. Polar Biol, 34, 1831-1841.

Collins, R.E., Rocap, G. \& Deming, J.W. (2010) Persistence of bacterial and archaeal communities in sea ice through an Arctic winter. Environ Microbiol, 12, 1828-1841.

Comte, K., Sabacka, M., Carre-Mlouka, A., Elster, J. \& Komarek, J. (2007) Relationships between the Arctic and the Antarctic Cyanobacteria; three Phormidium-like strains evaluated by a polyphasic approach. FEMS Microbiol Ecol, 59, 366-376.

Cunliffe, M. (2010) Correlating carbon monoxide oxidation with cox genes in the abundant Marine Roseobacter Clade. ISME J, 5, 685-691.

Czechowska, K., Sentchilo, V., Beggah, S., Rey, S., Seyfried, M. \& van der Meer, J.R. (2013) Examining chemical compound biodegradation at low concentrations through bacterial cell proliferation. Environ Sci Technol, 47, 1913-1921.

Cánovas, D., Vargas, C., Kneip, S., Morón, M.J., Ventosa, A., Bremer, E. \& Nieto, J.J. (2000) Genes for the synthesis of the osmoprotectant glycine betaine from choline in the moderately halophilic bacterium Halomonas elongata DSM 3043, USA. Microbiology+, 146 ( Pt 2), 455-463.

Darling, A.C.E., Mau, B., Blattner, F.R. \& Perna, N.T. (2004) Mauve: Multiple alignment of conserved genomic sequence with rearrangements. Genome Res, 14, 1394-1403.

Darling, A.E., Mau, B. \& Perna, N.T. (2010) progressiveMauve: Multiple genome alignment with gene gain, loss and rearrangement. PLoS One, 5, e11147.

de la Torre, J., Christianson, L., Beja, O., Suzuki, M., Karl, D., Heidelberg, J. \& DeLong, E. (2003) Proteorhodopsin genes are distributed among divergent marine bacterial taxa. Proc Natl Acad Sci U S A, 100, 12830-12835.

de Vries, J. \& Wackernagel, W. (2002) Integration of foreign DNA during natural transformation of Acinetobacter sp. by homology-facilitated illegitimate recombination. Proc Natl Acad Sci U S A, 99, 2094-2099.

Delcher, A.L., Bratke, K.A., Powers, E.C. \& Salzberg, S.L. (2007) Identifying bacterial genes and endosymbiont DNA with Glimmer. Bioinformatics, 23, 673-679.

Delille, D. (1992) Marine bacterioplankton at the Weddell Sea ice edge, distribution of psychrophilic and psychrotophic populations. Polar Biol, 12, 205-210.

DeLong, E.F. \& Beja, O. (2010) The Light-Driven Proton Pump Proteorhodopsin Enhances Bacterial Survival during Tough Times. PLoS Biol, 8, e1000359.

Dinsdale, E.A., Edwards, R.A., Hall, D., Angly, D., Breitbart, M., Brulc, J.M., Furlan, M., Desnues, C., Haynes, M., Li, L., McDaniel, L., Moran, M.A., Nelson, K.E., Nilsson, C., Olson, R., Paul, J., Brito, B.R., Ruan, Y., Swan, B.K., Stevens, R., Valentine, D.L., Thurber, R.V., Wegley, L., White, B.A. \& Rohwer, F. (2008) Functional metagenomic profiling of nine biomes. Nature, 452, 629-632.

Dioumaev, A.K., Brown, L.S., Shih, J., Spudich, E.N., Spudich, J.L. \& Lanyi, J.K. (2002) Proton transfers in the photochemical reaction cycle of proteorhodopsin. Biochemistry, 41, 5348-5358. 
Dubey, S.K. \& Holmes, D.S. (1995) Biological cyanide destruction mediated by microorganisms. World J Microbiol Biotechnol, 11, 257-265.

Ebinghaus, R., Kock, H.H., Temme, C., Einax, J.W., Löwe, A.G., Richter, A., Burrows, J.P. \& Schroeder, W.H. (2002) Antarctic springtime depletion of atmospheric mercury. Environ Sci Technol, 36, 1238-1244.

Ehrlich, S. (1989) Illegitimate recombination in bacteria. Mobile DNA (eds D. Berg \& M. Howe), pp. 799-824. Am Soc Microbiol, Washington, DC, USA.

Fang, J.S., Zhang, L. \& Bazylinski, D.A. (2010) Deep-sea piezosphere and piezophiles: geomicrobiology and biogeochemistry. Trends Microbiol, 18, 413-422.

Franzmann, P.D., Deprez, P.P., Burton, H.R. \& van den Hoff, J. (1987) Limnology of Organic Lake, Antarctica, a meromictic lake that contains high concentrations of dimethyl sulfide. Austral J Mar Fresh Res, 38, 409-417.

Fronzes, R., Christie, P.J. \& Waksman, G. (2009) The structural biology of type IV secretion systems. Nat Rev Microbiol, 7, 703-714.

Fu, Y., MacLeod, D., Rivkin, R., Chen, F., Buchan, A. \& Lang, A. (2010) High diversity of Rhodobacterales in the subarctic North Atlantic Ocean and gene transfer agent protein expression in isolated strains. Aquat Microb Ecol, 59, 283-293.

Fuhrman, J.A., Schwalbach, M.S. \& Stingl, U. (2008) Opinion - Proteorhodopsins: an array of physiological roles? Nat Rev Microbiol, 6, 488-494.

Füser, G. \& Steinbüchel, A. (2007) Analysis of genome sequences for genes of cyanophycin metabolism: Identifying putative cyanophycin metabolizing prokaryotes. Macromol Biosci, 7, 278-296.

Gevers, D., Cohan, F., Lawrence, J., Spratt, B., Coenye, T., Feil, E., Stackebrandt, E., Van de Peer, Y., Vandamme, P., Thompson, F. \& Swings, J. (2005) Re-evaluating prokaryotic species. Nat Rev Microbiol, 3, 733-739.

Ghiglione, J.-F., Galand, P.E., Pommier, T., Pedrós-Alió, C., Maas, E.W., Bakker, K., Bertilson, S., Kirchman, D.L., Lovejoy, C., Yager, P.L. \& Murray, A.E. (2012) Pole-topole biogeography of surface and deep marine bacterial communities. Proc Natl Acad Sci U S A, 109, 17633-17638.

Ghiglione, J.F. \& Murray, A.E. (2012) Pronounced summer to winter differences and higher wintertime richness in coastal Antarctic marine bacterioplankton. Environ Microbiol, 14, 617-629.

Gilbert, J.A., Thomas, S., Cooley, N.A., Kulakova, A., Field, D., Booth, T., McGrath, J.W., Quinn, J.P. \& Joint, I. (2009) Potential for phosphonoacetate utilization by marine bacteria in temperate coastal waters. Environ Microbiol, 11, 111-125.

Giovannoni, S.J. \& Stingl, U. (2005) Molecular diversity and ecology of microbial plankton. Nature, 437, 343-348.

Giovannoni, S.J., Tripp, H.J., Givan, S., Podar, M., Vergin, K.L., Baptista, D., Bibbs, L., Eads, J., Richardson, T.H., Noordewier, M., Rappe, M.S., Short, J.M., Carrington, J.C. \& Mathur, E.J. (2005) Genome streamlining in a cosmopolitan oceanic bacterium. Science, 309, $1242-1245$.

Gomez-Consarnau, L., Akram, N., Lindell, K., Pedersen, A., Neutze, R., Milton, D.L., Gonzalez, J.M. \& Pinhassi, J. (2010) Proteorhodopsin phototrophy promotes survival of marine bacteria during starvation. PLoS Biol, 8, e1000358. 
Gomez-Consarnau, L., Gonzalez, J.M., Coll-Llado, M., Gourdon, P., Pascher, T., Neutze, R., Pedros-Alio, C. \& Pinhassi, J. (2007) Light stimulates growth of proteorhodopsincontaining marine Flavobacteria. Nature, 445, 210-213.

González, J.M. \& Moran, M.A. (1997) Numerical dominance of a group of marine bacteria in the alpha-subclass of the class Proteobacteria in coastal seawater. Appl Environ Microbiol, 63, 4237-4242.

Goris, J., Konstantinidis, K.T., Klappenbach, J.A., Coenye, T., Vandamme, P. \& Tiedje, J.M. (2007) DNA-DNA hybridization values and their relationship to whole-genome sequence similarities. Int J Syst Evol Microbiol, 57, 81-91.

Gosink, J.J., Herwig, R.P. \& Staley, J.T. (1997) Octadecabacter arcticus gen. nov., sp. nov., and $O$. antarcticus, sp. nov., nonpigmented, psychrophilic gas vacuolate bacteria from polar sea ice and water. Syst Appl Microbiol, 20, 356-365.

Gosink, J.J. \& Staley, J.T. (1995) Biodiversity of Gas Vacuolate Bacteria from Antarctic Sea Ice and Water. Appl Environ Microbiol, 61, 3486-3489.

Grammann, K., Volke, A. \& Kunte, H.J. (2002) New type of osmoregulated solute transporter identified in halophilic members of the bacteria domain: TRAP transporter TeaABC mediates uptake of ectoine and hydroxyectoine in Halomonas elongata DSM 2581T. $J$ Bacteriol, 184, 3078-3085.

Gray, H. (2000) It takes two transposons to tango: transposable-element-mediated chromosomal rearrangements. Trends Genet, 16, 461-468.

Grzymski, J.J., Riesenfeld, C.S., Williams, T.J., Dussaq, A.M., Ducklow, H., Erickson, M., Cavicchioli, R. \& Murray, A.E. (2012) A metagenomic assessment of winter and summer bacterioplankton from Antarctica Peninsula coastal surface waters. ISME J, 6, 1901-1915

Hacker, J. \& Carniel, E. (2001) Ecological fitness, genomic islands and bacterial pathogenicity. A Darwinian view of the evolution of microbes. EMBO Rep, 2, 376-381.

Hanson, T.E. \& Tabita, F.R. (2001) A ribulose-1,5-bisphosphate carboxylase/oxygenase (RubisCO)-like protein from Chlorobium tepidum that is involved with sulfur metabolism and the response to oxidative stress. Proc Nat Acad Sci U S A, 98, 4397 4402 .

Haupts, U., Tittor, J. \& Oesterhelt, D. (1999) Closing in on bacteriorhodopsin: Progress in understanding the molecule. Annu Rev Biophys Biomol Struc, 28, 367-399.

Havig, J.R., Raymond, J., Meyer-Dombard, D.R., Zolotova, N. \& Shock, E.L. (2011) Merging isotopes and community genomics in a siliceous sinter-depositing hot spring. $J$ Geophys Res, 116, G01005.

Hennessey, J.P. \& Scarborough, G.A. (1989) An optimized procedure for sodium dodecylsulfate polyacrylamide-gel electrophoresis analysis of hydrophobic peptides from an integral membrane-protein. Anal Biochem, 176, 284-289.

Hewson, I., Paerl, R.W., Tripp, H.J., Zehr, J.P. \& Karl, D.M. (2009) Metagenomic potential of microbial assemblages in the surface waters of the central Pacific Ocean tracks variability in oceanic habitat. Limnol Oceanograph, 54, 1981-1994.

Hollibaugh, J.T., Lovejoy, C. \& Murray, A.E. (2007) Microbiology in Polar Oceans. Oceanography, 20, 140-145. 
Horikoshi, K. \& Tsujii, K. (1999) Extremophiles in deep-sea environments. pp. 316. Springer, Tokyo.

Hsiao, W., Wan, I., Jones, S.J. \& Brinkman, F.S.L. (2003) IslandPath: aiding detection of genomic islands in prokaryotes. Bioinformatics, 19, 418-420.

Huber, B., Escudero, R., Busse, H.J., Seibold, E., Scholz, H.C., Anda, P., Kampfer, P. \& Splettstoesser, W.D. (2010) Description of Francisella hispaniensis sp nov., isolated from human blood, reclassification of Francisella novicida (Larson et al. 1955) Olsufiev et al. 1959 as Francisella tularensis subsp. novicida comb. Nov. and emended description of the genus Francisella. Int J Syst Evol Microbiol, 60, 1887-1896.

Hugenholtz, P., Goebel, B.M. \& Pace, N.R. (1998) Impact of culture-independent studies on the emerging phylogenetic view of bacterial diversity. J Bacteriol, 180, 4765-4774.

Hulsen, T., Huynen, M.A., de Vlieg, J. \& Groenen, P.M.A. (2006) Benchmarking ortholog identification methods using functional genomics data. Genome Biol, 7, R31.

Hylander, L.D. \& Goodsite, M.E. (2006) Environmental costs of mercury pollution. Sci Total Environ, 368, 352-370.

Imasheva, E.S., Balashov, S.P., Choi, A.R., Jung, K.H. \& Lanyi, J.K. (2009) Reconstitution of Gloeobacter violaceus Rhodopsin with a Light-Harvesting Carotenoid Antenna. Biochemistry, 48, 10948-10955.

Jebbar, M., Sohn-Bosser, L., Bremer, E., Bernard, T. \& Blanco, C. (2005) Ectoine-induced proteins in Sinorhizobium meliloti include an ectoine ABC-type transporter involved in osmoprotection and ectoine catabolism. J Bacteriol, 187, 1293-1304.

Jensen, M.A., Fukushima, M. \& Davis, R.W. (2010) DMSO and betaine greatly improve amplification of GC-rich constructs in de novo synthesis. PLoS One, 5, e11024.

Jiao, N., Herndl, G.J., Hansell, D.A., Benner, R., Kattner, G., Wilhelm, S.W., Kirchman, D.L., Weinbauer, M.G., Luo, T.W., Chen, F. \& Azam, F. (2010) Microbial production of recalcitrant dissolved organic matter: long-term carbon storage in the global ocean. Nat Rev Microbiol, 8, 593-599.

Johansson, A., Celli, J., Conlan, W., Elkins, K.L., Forsman, M., Keim, P.S., Larsson, P., Manoil, C., Nano, F.E., Petersen, J.M. \& Sjostedt, A. (2010) Objections to the transfer of Francisella novicida to the subspecies rank of Francisella tularensis. Int J Syst Evol Microbiol, 60, 1717-1718.

Johnson, W.V. \& Anderson, P.M. (1987) Bicarbonate is a recycling substrate for cyanase. Fed Proc, 46, 2226.

Junge, K., Christner, B. \& Staley, J.T. (2011) Diversity of psychrophilic bacteria from sea iceand glacial ice communities. Extremophiles Handbook (ed. K. Horikoshi), pp. 794-815. Springer, Tokyo.

Junge, K., Imhoff, F., Staley, T. \& Deming, J. (2002) Phylogenetic diversity of numerically important arctic sea-ice bacteria cultured at subzero temperature. Microb Ecol, 43, 315328.

Kalhöfer, D., Thole, S., Voget, S., Lehmann, R., Liesegang, H., Wollher, A., Daniel, R., Simon, M. \& Brinkhoff, T. (2011) Comparative genome analysis and genome-guided physiological analysis of Roseobacter litoralis. BMC Genomics, 12, 324.

Kamennaya, N. \& Post, A. (2011) Characterization of Cyanate Metabolism in Marine Synechococcus and Prochlorococcus spp. Appl Environ Microb, 77, 291-301. 
Kan, J., Clingenpeel, S., Macur, R., Inskeep, W., Lovalvo, D., Varley, J., Gorby, Y., McDermott, T. \& Nealson, K. (2011) Archaea in Yellowstone Lake. ISME J, 5, 17841795.

Karsten, U., Sawall, T., Hanelt, D., Bischof, K., Figueroa, F.L., Flores-Moya, A. \& Wiencke, C. (1998) An inventory of UV-absorbing mycosporine-like amino acids in macroalgae from polar to warm-temperate regions. Bot Mar, 41, 443-453.

Kattner, G. (2012) The expedition of the research vessel "Polarstern" to the Antarctic in 2011/12 (ANT-XXVIII/2). Rep. Polar Mar. Res., 1-94.

Kawanabe, A., Furutani, Y., Jung, K.H. \& Kandori, H. (2009) Engineering an inward proton transport from a bacterial sensor rhodopsin. J Am Chem Soc, 131, 16439-16444.

Keim, P., Johansson, A. \& Wagner, D. (2007) Molecular Epidemiology, Evolution, and Ecology of Francisella. Ann N Y Acad Sci, 1105, 30-66.

Kiko, R. (2010) Acquisition of freeze protection in a sea-ice crustacean through horizontal gene transfer? Polar Biol, 33, 543-556.

Kirchman, D.E. (2008) Microbial Ecology of the Oceans, 2. edn. John Wiley \& Sons, Inc., Hoboken, NJ, USA.

Klappenbach, J.A., Dunbar, J.M. \& Schmidt, T.M. (2000) rRNA operon copy number reflects ecological strategies of bacteria. Appl Env Microbiol, 66, 1328-1333.

Klassen, J.L. (2010) Phylogenetic and evolutionary patterns in microbial carotenoid biosynthesis are revealed by comparative genomics. PLoS One, 5, e11257.

Kurtz, S., Phillippy, A., Delcher, A.L., Smoot, M., Shumway, M., Antonescu, C. \& Salzberg, S.L. (2004) Versatile and open software for comparing large genomes. Genome Biol, 5, R12.

Kuzniar, A., van Ham, R.C., Pongor, S. \& Leunissen, J.A. (2008) The quest for orthologs: finding the corresponding gene across genomes. Trends Genet, 24, 539-551.

Kyndt, J.A., Hurley, J.K., Devreese, B., Meyer, T.E., Cusanovich, M.A., Tollin, G. \& Van Beeumen, J.J. (2004) Rhodobacter capsulatus photoactive yellow protein: genetic context, spectral and kinetics characterization, and mutagenesis. Biochemistry, 43, 1809-1820.

Laemmli, U.K. (1970) Cleavage of structural proteins during assembly of the head of bacteriophage-T4. Nature, 227, 680-685.

Lang, A.S. \& Beatty, J.T. (2000) Genetic analysis of a bacterial genetic exchange element: the gene transfer agent of Rhodobacter capsulatus. Proc Natl Acad Sci U S A, 97, 859-864.

Lang, A.S., Zhaxybayeva, O. \& Beatty, J.T. (2012) Gene transfer agents: phage-like elements of genetic exchange. Nat Rev Microbiol, 10, 472-482.

Langille, M.G.I. \& Brinkman, F.S.L. (2009) IslandViewer: an integrated interface for computational identification and visualization of genomic islands. Bioinformatics, 25, 664-665.

Langille, M.G.I., Hsiao, W.W.L. \& Brinkman, F.S.L. (2008) Evaluation of genomic island predictors using a comparative genomics approach. BMC Bioinformatics, 9, 329.

Lanyi, J.K. \& Balashov, S.P. (2008) Xanthorhodopsin: A bacteriorhodopsin-like proton pump with a carotenoid antenna. BBA-Bioenergetics, 1777, 684-688. 
Larkin, M.A., Blackshields, G., Brown, N.P., Chenna, R., McGettigan, P.A., McWilliam, H., Valentin, F., Wallace, I.M., Wilm, A., Lopez, R., Thompson, J.D., Gibson, T.J. \& Higgins, D.G. (2007) Clustal W and clustal X version 2.0. Bioinformatics, 23, 29472948.

Lauro, F.M. \& Bartlett, D.H. (2008) Prokaryotic lifestyles in deep sea habitats. Extremophiles, $12,15-25$.

Lauro, F.M., DeMaere, M.Z., Yau, S., Brown, M.V., Ng, C., Wilkins, D., Raftery, M.J., Gibson, J.A.E., Andrews-Pfannkoch, C., Lewis, M., Hoffman, J.M., Thomas, T. \& Cavicchioli, R. (2011) An integrative study of a meromictic lake ecosystem in Antarctica. ISME J, 5, 879-895.

Lawrence, J.G. \& Roth, J.R. (1996) Selfish operons: Horizontal transfer may drive the evolution of gene clusters. Genetics, 143, 1843-1860.

Leifson, E. (1951) Staining, shape and arrangement of bacterial flagella. J Bacteriol, 62, 377 389.

Lucassen, M. (2012) The expedition of the research vessel "Polarstern" to the Antarctic in 2012 (ANT-XXVIII/4). Rep. Polar Mar. Res., 1-89.

Ludwig, W., Strunk, O., Westram, R., Richter, L., Meier, H., Yadhukumar, Buchner, A., Lai, T., Steppi, S., Jobb, G., Förster, W., Brettske, I., Gerber, S., Ginhart, A.W., Gross, O., Grumann, S., Hermann, S., Jost, R., König, A., Liss, T., Lüssmann, R., May, M., Nonhoff, B., Reichel, R., Strehlow, R., Stamatakis, A., Stuckmann, N., Vilbig, A., Lenke, M., Ludwig, T., Bode, A. \& Schleifer, K.H. (2004) ARB: a software environment for sequence data. Nucleic Acids Res, 32, 1363-1371.

Lutnaes, B.F., Oren, A. \& Liaaen-Jensen, S. (2002) New C-40-carotenoid acyl glycoside as principal carotenoid in Salinibacter ruber, an extremely halophilic eubacterium. $J$ Nat Prod, 65, 1340-1343.

Madigan, M.T., Jung, D.O., Karr, E.A., Sattley, W.M., Achenbach, L.A. \& Van Der Meer, M.T.J. (2005) Diversity of Anoxygenic Phototrophs in Contrasting Extreme Environments. Diversity of anoxygenic phototrophs in contrasting extreme environments (eds W.P. Inskeep \& T.R. McDermott), pp. 203-220. Montana State University Publications, USA.

Mahillon, J., Léonard, C. \& Chandler, M. (1999) IS elements as constituents of bacterial genomes. Res Microbiol, 150, 675-687.

Margulies, M., Egholm, M., Altman, W.E., Attiya, S., Bader, J.S., Bemben, L.A., Berka, J., Braverman, M.S., Chen, Y.J., Chen, Z.T., Dewell, S.B., Du, L., Fierro, J.M., Gomes, X.V., Godwin, B.C., He, W., Helgesen, S., Ho, C.H., Irzyk, G.P., Jando, S.C., Alenquer, M.L.I., Jarvie, T.P., Jirage, K.B., Kim, J.B., Knight, J.R., Lanza, J.R., Leamon, J.H., Lefkowitz, S.M., Lei, M., Li, J., Lohman, K.L., Lu, H., Makhijani, V.B., McDade, K.E., McKenna, M.P., Myers, E.W., Nickerson, E., Nobile, J.R., Plant, R., Puc, B.P., Ronan, M.T., Roth, G.T., Sarkis, G.J., Simons, J.F., Simpson, J.W., Srinivasan, M., Tartaro, K.R., Tomasz, A., Vogt, K.A., Volkmer, G.A., Wang, S.H., Wang, Y., Weiner, M.P., Yu, P.G., Begley, R.F. \& Rothberg, J.M. (2005) Genome sequencing in microfabricated high-density picolitre reactors. Nature, 437, 376-380.

Markowitz, V.M., Chen, I.M., Palaniappan, K., Chu, K., Szeto, E., Grechkin, Y., Ratner, A., Jacob, B., Huang, J., Williams, P., Huntemann, M., Anderson, I., Mavromatis, K., 
Ivanova, N.N. \& Kyrpides, N.C. (2012) IMG: the Integrated Microbial Genomes database and comparative analysis system. Nucleic Acids Res, 40, D115-122.

Martens, M., Dawyndt, P., Coopman, R., Gillis, M., De Vos, P. \& Willems, A. (2008) Advantages of multilocus sequence analysis for taxonomic studies: a case study using 10 housekeeping genes in the genus Ensifer (including former Sinorhizobium). Int J Syst Evol Microbiol, 58, 200-214.

Martens, T., Heidorn, T., Pukall, R., Simon, M., Tindall, B.J. \& Brinkhoff, T. (2006) Reclassification of Roseobacter gallaeciensis Ruiz-Ponte et al. 1998 as Phaeobacter gallaeciensis gen. nov., comb. nov., description of Phaeobacter inhibens sp nov., reclassification of Ruegeria algicola (Lafay et al. 1995) Uchino et al. 1999 as Marinovum algicola gen. nov., comb. nov., and emended descriptions of the genera Roseobacter, Ruegeria and Leisingera. Int J Syst Evol Microbiol, 56, 1293-1304.

Martinez, A., Tyson, G.W. \& DeLong, E.F. (2009) Widespread known and novel phosphonate utilization pathways in marine bacteria revealed by functional screening and metagenomic analyses. Environ Microbiol, 12, 222-238.

McCarren, J. \& DeLong, E.F. (2007) Proteorhodopsin photosystem gene clusters exhibit coevolutionary trends and shared ancestry among diverse marine microbial phyla. Environ Microbiol, 9, 846-858.

McDaniel, L., Young, E., Delaney, J., Ruhnau, F., Ritchie, K. \& Paul, J. (2010) High Frequency of Horizontal Gene Transfer in the Oceans. Science, 330, 50-50.

McKenzie, R.L., Aucamp, P.J., Bais, A.F., Bjorn, L.O. \& Ilyas, M. (2007) Changes in biologically-active ultraviolet radiation reaching the Earth's surface. Photochem Photobiol Sci, 6, 218-231.

Medigue, C., Krin, E., Pascal, G., Barbe, V., Bernsel, A., Bertin, P.N., Cheung, F., Cruveiller, S., D'Amico, S., Duilio, A., Fang, G., Feller, G., Ho, C., Mangenot, S., Marino, G., Nilsson, J., Parrilli, E., Rocha, E.P.C., Rouy, Z., Sekowska, A., Tutino, M.L., Vallenet, D., von Heijne, G. \& Danchin, A. (2005) Coping with cold: The genome of the versatile marine Antarctica bacterium Pseudoalteromonas haloplanktis TAC125. Genome Res, 15, 1325-1335.

Medini, D., Donati, C., Tettelin, H., Masignani, V. \& Rappuoli, R. (2005) The microbial pangenome. Curr Opin Genet Dev, 15, 589-594.

Methé, B.A., Nelson, K.E., Deming, J.W., Momen, B., Melamud, E., Zhang, X., Moult, J., Madupu, R., Nelson, W.C., Dodson, R.J., Brinkac, L.M., Daugherty, S.C., Durkin, A.S., DeBoy, R.T., Kolonay, J.F., Sullivan, S.A., Zhou, L., Davidsen, T.M., Wu, M., Huston, A.L., Lewis, M., Weaver, B., Weidman, J.F., Khouri, H., Utterback, T.R., Feldblyum, T.V. \& Fraser, C.M. (2005) The psychrophilic lifestyle as revealed by the genome sequence of Colwellia psychrerythraea $34 \mathrm{H}$ through genomic and proteomic analyses. Proc Natl Acad Sci U S A, 102, 10913-10918.

Mieczkowski, P., Lemoine, F. \& Petes, T. (2006) Recombination between retrotransposons as a source of chromosome rearrangements in the yeast Saccharomyces cerevisiae. DNA Rep, 5, 1010-1020.

Mindlin, S., Minakhin, L., Petrova, M., Kholodii, G., Minakhina, S., Gorlenko, Z. \& Nikiforov, V. (2005) Present-day mercury resistance transposons are common in bacteria preserved in permafrost grounds since the Upper Pleistocene. Res Microbiol, 156, 994-1004. 
Miroux, B. \& Walker, J.E. (1996) Over-production of proteins in Escherichia coli: mutant hosts that allow synthesis of some membrane proteins and globular proteins at high levels. J Mol Biol, 260, 289-298.

Montresor, M., Lovejoy, C., Procaccini, G. \& Roy, S. (2003) Bipolar distribution of the cystforming dinoflagellate Polarella glacialis. Polar Biol, 26, 186-194.

Moran, M.A., Belas, R., Schell, M.A., Gonzdlez, J.M., Sun, F., Sun, S., Binder, B.J., Edmonds, J., Ye, W., Orcutt, B., Howard, E.C., Meile, C., Palefsky, W., Goesmann, A., Ren, Q., Paulsen, I., Ulrich, L.E., Thompson, L.S., Saunders, E. \& Buchanlo, A. (2007) Ecological genomics of marine Roseobacters. Appl Environ Microbiol, 73, 4559-4569.

Moran, M.A., Buchan, A., Gonzalez, J.M., Heidelberg, J.F., Whitman, W.B., Kiene, R.P., Henriksen, J.R., King, G.M., Belas, R., Fuqua, C., Brinkac, L., Lewis, M., Johri, S., Weaver, B., Pai, G., Eisen, J.A., E., R. \& al., e. (2004) Genome sequence of Silicibacter pomeroyi reveals adaptations to the marine environment. Nature, 432, 910-913.

Morozov, E.G., Demidov, A.N., Tarakanov, R.Y. \& Zenk, W. (2010) Deep Water Masses of the South and North Atlantic. Abyssal Channels in the Atlantic Ocean (ed. G. Weatherly), pp. 25-50. Springer, Netherlands.

Morris, R.M., Rappé, M.S., Connon, S.A., Vergin, K.L., Siebold, W.A., Carlson, C.A. \& Giovannoni, S.J. (2002) SAR11 clade dominates ocean surface bacterioplankton communities. Nature, 420, 806-810.

Muramatsu, Y., Uchino, Y., Kasai, H., Suzuki, K.-I. \& Nakagawa, Y. (2007) Ruegeria mobilis sp. nov., a member of the Alphaproteobacteria isolated in Japan and Palau. Int J Syst Evol Microbiol, 57, 1304-1309.

Murray, A. \& Grzymski, J. (2007) Diversity and genomics of Antarctic marine microorganisms. Philos TR Soc B, 362, 2259-2271.

Møller, A., Barkay, T., Al-Soud, W., Sørensen, S., Skov, H. \& Kroer, N. (2012) Diversity and characterization of mercury-resistant bacteria in snow, freshwater and sea-ice brine from the High Arctic. FEMS Microbiol Ecol, 75, 390-401.

Nakamura, Y., Kaneko, T., Sato, S., Mimuro, M., Miyashita, H., Tsuchiya, T., Sasamoto, S., Watanabe, A., Kawashima, K., Kishida, Y., Kiyokawa, C., Kohara, M., Matsumoto, M., Matsuno, A., Nakazaki, N., Shimpo, S., Takeuchi, C., Yamada, M. \& Tabata, S. (2003) Complete genome structure of Gloeobacter violaceus PCC 7421, a cyanobacterium that lacks thylakoids. DNA Res, 10, 137-145.

Needleman, S.B. \& Wunsch, C.D. (1970) A General Method Applicable to Search for Similarities in Amino Acid Sequence of 2 Proteins. J Mol Biol, 48, 443-453.

Newton, R.J., Griffin, L.E., Bowles, K.M., Meile, C., Gifford, S., Givens, C.E., Howard, E.C., King, E., Oakley, C.A., Reisch, C.R., Rinta-Kanto, J.M., Sharma, S., Sun, S.L., Varaljay, V., Vila-Costa, M., Westrich, J.R. \& Moran, M.A. (2010) Genome characteristics of a generalist marine bacterial lineage. ISME J, 4, 784-798.

Nichols, D. (2007) Cultivation gives context to the microbial ecologist. FEMS Microbiol Ecol, 60, 351-357.

Nies, D.H. (1999) Microbial heavy-metal resistance. Appl Microbiol Biotechnol, 51, 730-750.

Ortega-Retuerta, E., Jeffrey, W.H. \& Joux, F. (2012) Evidence of heterotrophic prokaryotic activity limitation by nitrogen in the Western Arctic Ocean during summer. Polar Biol, 35, 785-794. 
Osborn, A., Bruce, K., Strike, P. \& Ritchie, D. (1997) Distribution, diversity and evolution of the bacterial mercury resistance (mer) operon. FEMS Microbiol Rev, 19, 239-262.

Ottesen, E.A., Marin, R., Preston, C.M., Young, C.R., Ryan, J.P., Scholin, C.A. \& DeLong, E.F. (2011) Metatranscriptomic analysis of autonomously collected and preserved marine bacterioplankton. ISME J, 5, 1881-1895.

Overbeek, R., Larsen, N., Walunas, T., D'Souza, M., Pusch, G., Selkov, E., Liolios, K., Joukov, V., Kaznadzey, D., Anderson, I., Bhattacharyya, A., Burd, H., Gardner, W., Hanke, P., Kapatral, V., Mikhailova, N., Vasieva, O., Osterman, A., Vonstein, V., Fonstein, M., Ivanova, N. \& Kyrpides, N. (2003) The ERGO genome analysis and discovery system. Nucleic Acids Res, 31, 164-171.

Palys, T., Berger, E., Mitrica, I., Nakamura, L.K. \& Cohan, F.M. (2000) Protein-coding genes as molecular markers for ecologically distinct populations: the case of two Bacillus species. Int J Syst Evol Microbiol, 50, 1021-1028.

Palys, T., Nakamura, L.K. \& Cohan, F.M. (1997) Discovery and Classification of Ecological Diversity in the Bacterial World: The Role of DNA Sequence Data. Int J Syst Bacteriol, 47, 1145-1156.

Pearce, D.A., Cockell, C.S., Lindstrom, E.S. \& Tranvik, L.J. (2007) First evidence for a bipolar distribution of dominant freshwater lake bacterioplankton. Antarctic Sci, 19, 245-252.

Pesciaroli, C., Cupini, F., Selbmann, L., Barghini, P. \& Fenice, M. (2012) Temperature preferences of bacteria isolated from seawater collected in Kandalaksha Bay, White Sea, Russia. Polar Biol, 35, 435-445.

Petrosino, J., Xiang, Q., Karpathy, S., Jiang, H., Yerrapragada, S., Liu, Y., Gioia, J., Hemphill, L., Gonzalez, A., Raghavan, T., Uzman, A., Fox, G., Highlander, S., Reichard, M., Morton, R., Clinkenbeard, K. \& Weinstock, G. (2006) Chromosome Rearrangement and Diversification of Francisella tularensis Revealed by the Type B (OSU18) Genome Sequence. J Bacteriol, 188, 6977-6985.

Pfeifer, F. (2012) Distribution, formation and regulation of gas vesicles. Nat Rev Microbiol, 10, 705-715.

Piekarski, T., Buchholz, I., Drepper, T., Schobert, M., Wagner-Doebler, I., Tielen, P. \& Jahn, D. (2009) Genetic tools for the investigation of Roseobacter clade bacteria. BMC Microbiol, 9, 265.

Pocard, J.-A., Vincent, N., Boncompagni, E., Smith, L., Poggi, M.-C. \& Le Rudulier, D. (1997) Molecular characterization of the bet genes encoding glycine betaine synthesis in Sinorhizobium meliloti 102F34. Microbiology+, 143, 1369-1379.

Poulain, A., Ní Chadhain, S., Ariya, P., Amyot, M., Garcia, E., Campbell, P., Zylstra, G. \& Barkay, T. (2007) Potential for mercury reduction by microbes in the high arctic. Appl Environ Microbiol, 73, 2230-2238.

Prudhomme, M., Libante, V. \& Claverys, J.-P. (2002) Homologous recombination at the border: Insertion-deletions and the trapping of foreign DNA in Streptococcus pneumoniae. Proc Natl Acad Sci U S A, 99, 2100-2105.

Pruesse, E., Peplies, J. \& Glöckner, F.O. (2012) SINA: Accurate high-throughput multiple sequence alignment of ribosomal RNA genes. Bioinformatics, 28, 1823-1829. 
Qian, D., Jiang, L., Lu, L., Wei, C. \& Li, Y. (2011) Biochemical and Structural Properties of Cyanases from Arabidopsis thaliana and Oryza sativa. PLoS One, 6, e18300.

Rajendhran, J. \& Gunasekaran, P. (2011) Microbial phylogeny and diversity: Small subunit ribosomal RNA sequence analysis and beyond. Microbiol Res, 166, 99-110.

Rankin, L., Gibson, J., Franzmann, P. \& Burton, H. (1996) The chemical stratification and microbial communities of Ace Lake, Antarctica: A review of the characteristics of a marine-derived meromictic lake. Polarforschung, 66, 33-52.

Rappé, M.S., Connon, S.A., Vergin, K.L. \& Giovannoni, S.J. (2002) Cultivation of the ubiquitous SAR11 marine bacterioplankton clade. Nature, 418, 630-633.

Raymond, J., Fritsen, C. \& Shen, K. (2007) An ice-binding protein from an Antarctic sea ice bacterium. FEMS Microbiol Ecol, 61, 214-221.

Reichenbach, H. (1999) The ecology of the Myxobacteria. Environ Microbiol, 1, 15-21.

Rich, V.I., Pham, V.D., Eppley, J., Shi, Y. \& DeLong, E.F. (2011) Time-series analyses of Monterey Bay coastal microbial picoplankton using a 'genome proxy' microarray. Environ Microbiol, 13, 116-134.

Richter, M. \& Rosselló-Móra, R. (2009) Shifting the genomic gold standard for the prokaryotic species definition. Proc Natl Acad Sci U S A, 106, 19126-19131.

Rippka, R., Waterbury, J. \& Cohen-Bazire, G. (1974) A Cyanobacterium Which Lacks Thylakoids. Arch Microbiol, 100, 419-436.

Romero, F., Fernández-Chimeno, R., de la Fuente, J. \& Barredo, J. (2012) Selection and taxonomic identification of carotenoid-producing marine actinomycetes. Methods $\mathrm{Mol}$ Biol, 892, 13-20.

Rosselló-Mora, R. \& Amann, R. (2000) The species concept for prokaryotes. FEMS Microbiol Rev, 25, 39-67.

Rusch, D.B., Halpern, A.L., Sutton, G., Heidelberg, K.B., Williamson, S., Yooseph, S., Wu, D.Y., Eisen, J.A., Hoffman, J.M., Remington, K., Beeson, K., Tran, B., Smith, H., Baden-Tillson, H., Stewart, C., Thorpe, J., Freeman, J., Andrews-Pfannkoch, C., Venter, J.E., Li, K., Kravitz, S., Heidelberg, J.F., Utterback, T., Rogers, Y.H., Falcon, L.I., Souza, V., Bonilla-Rosso, G., Eguiarte, L.E., Karl, D.M., Sathyendranath, S., Platt, T., Bermingham, E., Gallardo, V., Tamayo-Castillo, G., Ferrari, M.R., Strausberg, R.L., Nealson, K., Friedman, R., Frazier, M. \& Venter, J.C. (2007) The Sorcerer II Global Ocean Sampling expedition: Northwest Atlantic through Eastern Tropical Pacific. PLoS Biol, 5, 398-431.

Rutherford, K., Parkhill, J., Crook, J., Horsnell, T., Rice, P., Rajandream, M.A. \& Barrell, B. (2000) Artemis: sequence visualization and annotation. Bioinformatics, 16, 944-945.

Sabehi, G., Loy, A., Jung, K.H., Partha, R., Spudich, J.L., Isaacson, T., Hirschberg, J., Wagner, M. \& Beja, O. (2005) New insights into metabolic properties of marine bacteria encoding proteorhodopsins. PLoS Biol, 3, e273.

Sambrook, J., Fritsch, E.F. \& Maniatis, T. (1989) Molecular cloning: a laboratory manual. Cold Spring Habor Laboratory Press, New York, USA.

Sambrook, J. \& Russel, D.W. (2001) Molecular cloning: a laboratory manual, 3. edn. Cold Spring Harbor Laboratory Press, New York, USA. 
Sangar, V., Blankenberg, D., Altman, N. \& Lesk, A. (2007) Quantitative sequence-function relationships in proteins based on gene ontology. BMC Bioinformatics, 8, 294.

Sanger, F., Nicklen, S. \& Coulson, A.R. (1977) DNA sequencing with chain-terminating inhibitors. Proc Nat Acad Sci U S A, 74, 5463-5467.

Sasaki, J. \& Spudich, J.L. (1998) The transducer protein HtrII modulates the lifetimes of sensory rhodopsin II photointermediates. Biophys $J$, 75, 2435-2440.

Scanlan, D., Ostrowski, M., Mazard, S., Dufresne, A., Garczarek, L., Hess, W., Post, A., Hagemann, M., Paulsen, I. \& Partensky, F. (2009) Ecological Genomics of Marine Picocyanobacteria. Microbiol Mol Biol R, 73, 249.

Schatz, M.C., Delcher, A.L. \& Salzberg, S.L. (2010) Assembly of large genomes using second-generation sequencing. Genome Res, 20, 1165-1173.

Schmidt, T.M. (2006) The maturing of microbial ecology. Int Microbiol, 9, 217-223.

Schneiker, S., Perlova, O., Kaiser, O., Gerth, K., Alici, A., Altmeyer, M.O., Bartels, D., Bekel, T., Beyer, S., Bode, E., Bode, H.B., Bolten, C.J., Choudhuri, J.V., Doss, S., Elnakady, Y.A., Frank, B., Gaigalat, L., Goesmann, A., Groeger, C., Gross, F., Jelsbak, L., Jelsbak, L., Kalinowski, J., Kegler, C., Knauber, T., Konietzny, S., Kopp, M., Krause, L., Krug, D., Linke, B., Mahmud, T., Martinez-Arias, R., McHardy, A.C., Merai, M., Meyer, F., Mormann, S., Munoz-Dorado, J., Perez, J., Pradella, S., Rachid, S., Raddatz, G., Rosenau, F., Rückert, C., Sasse, F., Scharfe, M., Schuster, S.C., Suen, G., TreunerLange, A., Velicer, G.J., Vorhölter, F.-J., Weissman, K.J., Welch, R.D., Wenzel, S.C., Whitworth, D.E., Wilhelm, S., Wittmann, C., Blöcker, H., Pühler, A. \& Müller, R. (2007) Complete genome sequence of the myxobacterium Sorangium cellulosum. Nature Biotechnol, 25, 1281-1289.

Selje, N., Simon, M. \& Brinkhoff, T. (2004) A newly discovered Roseobacter cluster in temperate and polar oceans. Nature, 427, 445-447.

Sharma, A.K., Sommerfeld, K., Bullerjahn, G.S., Matteson, A.R., Wilhelm, S.W., Jezbera, J., Brandt, U., Doolittle, W.F. \& Hahn, M.W. (2009) Actinorhodopsin genes discovered in diverse freshwater habitats and among cultivated freshwater Actinobacteria. ISME J, 3, 726-737.

Sharma, A.K., Spudich, J.L. \& Doolittle, W.F. (2006) Microbial rhodopsins: functional versatility and genetic mobility. Trends Microbiol, 14, 463-469.

Shiba, T. (1991) Roseobacter litoralis gen. nov., sp. nov., and Roseobacter denitrificans sp. nov., aerobic pink-pigmented bacteria which contain bacteriochlorophyll-a. Syst Appl Microbiol, 14, 140-145.

Siguier, P., Perochon, J., Lestrade, L., Mahillon, J. \& Chandler, M. (2006) ISfinder: the reference centre for bacterial insertion sequences. Nucleic Acids Res, 34, D32-D36.

Simon, C., Wiezer, A., Strittmatter, A.W. \& Daniel, R. (2009) Phylogenetic Diversity and Metabolic Potential Revealed in a Glacier Ice Metagenome. Appl Environ Microbiol, 75, 7519-7526.

Slamovits, C., Okamoto, N., Burri, L., James, E. \& Keeling, P. (2011) A bacterial proteorhodopsin proton pump in marine eukaryotes. Nature Commun, 2, 183.

Solioz, M. \& Marrs, B. (1977) The gene transfer agent of Rhodopseudomonas capsulata. Purification and characterization of its nucleic acid. Arch Biochem Biophys, 181, 300307. 
Soria-Carrasco, V., Valens-Vadell, M., Pena, A., Anton, J., Amann, R., Castresana, J. \& Rossello-Mora, R. (2007) Phylogenetic position of Salinibacter ruber based on concatenated protein alignments. Syst Appl Microbiol, 30, 171-179.

Spudich, J., Yang, C., Jung, K. \& Spudich, E. (2000) Retinylidene proteins: Structures and functions from archaea to humans. Annu Rev Cell Dev Biol, 16, 365-392.

Spudich, J.L. \& Jung, K.-H. (2005) Microbial Rhodopsins: Phylogenetic and Functional Diversity. Handbook of Photosensory Receptors (ed. W.R. Briggs \& J.L. Spudich). Wiley-VCH Verlag GmbH \& Co. KGaA, Weinheim, Germany.

Staden, R. (1996) The Staden sequence analysis package. Mol Biotechnol, 5, 233-241.

Staley, J.T. \& Gosink, J.J. (1999) Poles apart: Biodiversity and biogeography of sea ice bacteria. Annu Rev Microbiol, 53, 189-215.

Stark, G.R. (1965) Reactions of cyanate with functional groups of proteins .III. reactions with amino and carboxyl groups. Biochemistry, 4, 1030-1036.

Stevens, H., Brinkhoff, T. \& Simon, M. (2005) Composition and seasonal dynamics of freeliving, aggregate- and sediment surface-associated bacterial communities in the German Wadden Sea. Aquat Microb Ecol, 38, 15-30.

Stevenson, B.S. \& Schmidt, T.M. (2004) Life history implications of rRNA gene copy number in Escherichia coli. Appl Env Microbiol, 70, 6670-6677.

Swingley, W.D., Sadekar, S., Mastrian, S.D., Matthies, H.J., Hao, J., Ramos, H., Acharya, C.R., Conrad, A.L., Taylor, H.L., Dejesa, L.C., Shah, M.K., O'huallachain, M.E., Lince, M.T., Blankenship, R.E., Beatty, J.T. \& Touchman, J.W. (2007) The complete genome sequence of Roseobacter denitrificans reveals a mixotrophic rather than photosynthetic metabolism. J Bacteriol, 189, 683-690.

Tabita, F.R., Hanson, T.E., Li, H.Y., Satagopan, S., Singh, J. \& Chan, S. (2007) Function, structure, and evolution of the RubisCO-like proteins and their RubisCO homologs. Microbiol Mol Biol Rev, 71, 576-599.

Takahashi, T., Olafsson, J., Goddard, J.G., Chipman, D.W. \& Sutherland, S.C. (2010) Seasonal variation of $\mathrm{CO} 2$ and nutrients in the high-latitude surface oceans: A comparative study. Global Biochem Cy, 7, 843-878.

Tatusov, R.L., Fedorova, N.D., Jackson, J.D., Jacobs, A.R., Kiryutin, B., Koonin, E.V., Krylov, D.M., Mazumder, R., Mekhedov, S.L., Nikolskaya, A.N., Rao, B.S., Smirnov, S., Sverdlov, A.V., Vasudevan, S., Wolf, Y.I., Yin, J.J. \& Natale, D.A. (2003) The COG database: an updated version includes eukaryotes. BMC Bioinformatics, 4, 41.

Tech, M. \& Merkl, R. (2003) YACOP: Enhanced gene prediction obtained by a combination of existing methods. In Silico Biol, 3, 441-451.

Tettelin, H., Riley, D., Cattuto, C. \& Medini, D. (2008) Comparative genomics: the bacterial pan-genome. Curr Opin Microbiol, 11, 472-477.

Thole, S., Kalhöfer, D., Voget, S., Berger, M., Engelhardt, T., Liesegang, H., Wollherr, A., Kjelleberg, S., Daniel, R., Simon, M., Thomas, T. \& Brinkhoff, T. (2012) Phaeobacter gallaeciensis genomes from globally opposite locations reveal high similarity of adaptation to surface life. ISME J, 6, 2229-2244.

Thomas, D.N. \& Dieckmann, G.S. (2002) Antarctic Sea Ice--a Habitat for Extremophiles. Science, 295, 641-644. 
Thomas, T., Rusch, D., DeMaere, M.Z., Yung, P.Y., Lewis, M., Halpern, A., Heidelberg, K.B., Egan, S., Steinberg, P.D. \& Kjelleberg, S. (2010) Functional genomic signatures of sponge bacteria reveal unique and shared features of symbiosis. ISME J, 4, 1557-1567.

Thompson, F.L., Gevers, D., Thompson, C.C., Dawyndt, P., Naser, S., Hoste, B., Munn, C.B. $\&$ Swings, J. (2005) Phylogeny and Molecular Identification of Vibrios on the Basis of Multilocus Sequence Analysis. Appl Environ Microbiol, 71, 5107-5115.

Urbance, J.W., Bratina, B.J., Stoddard, S.F. \& Schmidt, T.M. (2001) Taxonomic characterization of Ketogulonigenium vulgare gen. nov., sp. nov. and Ketogulonigenium robustum sp. nov., which oxidize L-sorbose to 2-keto-L-gulonic acid. Int J Sys Evol Microbiol, 51, 1059-70.

van der Meer, M.T.J., Klatt, C.G., Wood, J., Bryant, D.A., Bateson, M.M., Lammerts, L., Schouten, S., Damsté, J.S.S., Madigan, M.T. \& Ward, D.M. (2010) Cultivation and genomic, nutritional, and lipid biomarker characterization of Roseiflexus strains closely related to predominant in situ populations inhabiting Yellowstone hot spring microbial mats. J Bacteriol, 195, 3033-3042.

Varin, T., Lovejoy, C., Jungblut, A.D., Vincent, W.F. \& Corbeil, J. (2010) Metagenomic profiling of Arctic microbial mat communities as nutrient scavenging and recycling systems. Limnol Oceanogr, 55, 1901-1911.

Voget, S., Wemheuer, B., Brinkhoff, T., Vollmers, J., Dietrich, S., Giebel, H.-A., Beardsley, C., Bakenhus, I., Billerbeck, S., Daniel, R. \& Simon, M. (2013) Genome-based analysis and active role of a photoheterotrophic and $\mathrm{CO}$ oxidizing Roseobacter RCA population in the ocean. ISME J, (Submitted).

Vollmers, J. (2007) Strukturanalyse mariner Myxobakterienpopulationen. Diplomarbeit, Carlvon-Ossietzky Universität Oldenburg.

Vollmers, J., Voget, V., Dietrich, S., Gollnow, K., Smits, M., Meyer, K., Brinkhoff, T., Simon, M. \& Daniel, R. (2013) Poles apart: Arctic and Antarctic Octadecabacter strains share high genome plasticity and a new type of xanthorhodopsin. PLoS One, 8, e63422.

Waack, S., Keller, O., Asper, R., Brodag, T., Damm, C., Fricke, W.F., Surovcik, K., Meinicke, P. \& Merkl, R. (2006) Score-based prediction of genomic islands in prokaryotic genomes using hidden Markov models. BMC Bioinformatics, 7, 142.

Wagner, S., Klepsch, M.M., Schlegel, S., Appel, A., Draheim, R., Tarry, M., Högbom, M., van Wijk, K.J., Slotboom, D.J., Persson, J.O. \& de Gier, J.W. (2008) Tuning Escherichia coli for membrane protein overexpression. Proc Natl Acad Sci U S A, 105, 1437114376.

Wagner-Döbler, I. \& Biebl, H. (2006) Environmental biology of the marine Roseobacter lineage. Annu Rev Microbiol, 60, 255-280.

Wallden, K., Rivera-Calzada, A. \& Waksman, G. (2010) Type IV secretion systems: versatility and diversity in function. Cell Microbiol, 12, 1203-1212.

Walsby, A.E. (1994) Gas vesicles. Microbiol Rev, 58, 94-144.

Walter, J.M., Greenfield, D., Bustamante, C. \& Liphardt, J. (2007) Light-powering Escherichia coli with proteorhodopsin. Proc Nat Acad Sci U S A, 104, 2408-2412.

Wang, W.W., Sineshchekov, O.A., Spudich, E.N. \& Spudich, J.L. (2003) Spectroscopic and photochemical characterization of a deep ocean proteorhodopsin. J Biol Chem, 278, 33985-33991. 
Wayne, L.G., Brenner, D.J., Colwell, R.R., Grimont, P.A.D., Kandler, O., Krichevsky, M.I., Moore, L.H., Moore, W.E.C., Murray, R.G.E., Stackebrandt, E., Starr, M.P. \& Truper, H.G. (1987) Report of the ad hoc committee on reconciliation of approaches to bacterial systematics. Int J Syst Bacteriol, 37, 463-464.

Wollherr, A. (2010) Komparative Genomanalyse zur Stammoptimierung produktionsnaher Bacillus-Stämme. Dissertation, Georg-August-Universität Göttingen.

Woyke, T., Xie, G., Copeland, A., Gonzalez, J.M., Han, C., Kiss, H., Saw, J.H., Senin, P., Yang, C., Chatterji, S., Cheng, J.F., Eisen, J.A., Sieracki, M.E. \& Stepanauskas, R. (2009) Assembling the Marine Metagenome, One Cell at a Time. PLoS One, 4, e5299.

Yau, S., Lauro, F.M., DeMaere, M.Z., Brown, M.V., Thomas, T., Raftery, M.J., AndrewsPfannkoch, C., Lewis, M., Hoffman, J.M., Gibson, J.A. \& Cavicchioli, R. (2011) Virophage control of antarctic algal host-virus dynamics. Proc Natl Acad Sci U S A, 108, 6163-6168.

Yi, H., Lim, Y.W. \& Chun, J. (2007) Taxonomic evaluation of the genera Ruegeria and Silicibacter: a proposal to transfer the genus Silicibacter Petursdottir and Kristjansson 1999 to the genus Ruegeria Uchino et al. 1999. Int J Syst Evol Microbiol, 57, 815-819.

Yokoyama, A., Shizuri, Y., Hoshino, T. \& Sandmann, G. (1996) Thermocryptoxanthins: novel intermediates in the carotenoid biosynthetic pathway of Thermus thermophilus. Arch Microbiol, 165, 342-345.

Zdobnov, E.M. \& Apweiler, R. (2001) InterProScan--an integration platform for the signaturerecognition methods in InterPro. Bioinformatics, 17, 847-848.

Zeng, Y., Zou, Y., Grebmeier, J., He, J. \& Zheng, T. (2012) Culture-independent and dependent methods to investigate the diversity of planktonic bacteria in the northern Bering Sea. Polar Biol, 35, 117-129.

Zeng, Y.X., Zheng, T., Yu, Y., Chen, B. \& He, J.F. (2010) Relationships between Arctic and Antarctic Shewanella strains evaluated by a polyphasic taxonomic approach. Polar Biol, 33, 531-541.

Zhang, J. \& Peterson, T. (1999) Genome rearrangements by nonlinear transposons in maize. Genetics, 153, 1403-1410.

Zhang, J. \& Peterson, T. (2004) Transposition of reversed Ac element ends generates chromosome rearrangements in maize. Genetics, 167, 1929-1937.

Ziegler, K., Diener, A., Herpin, C., Richter, R., Deutzmann, R. \& Lockau, W. (1998) Molecular characterization of cyanophycin synthetase, the enzyme catalyzing the biosynthesis of the cyanobacterial reserve material multi-L-arginyl-poly-L-aspartate (cyanophycin). Eur J Biochem, 254, 154-159. 


\section{Anhang}

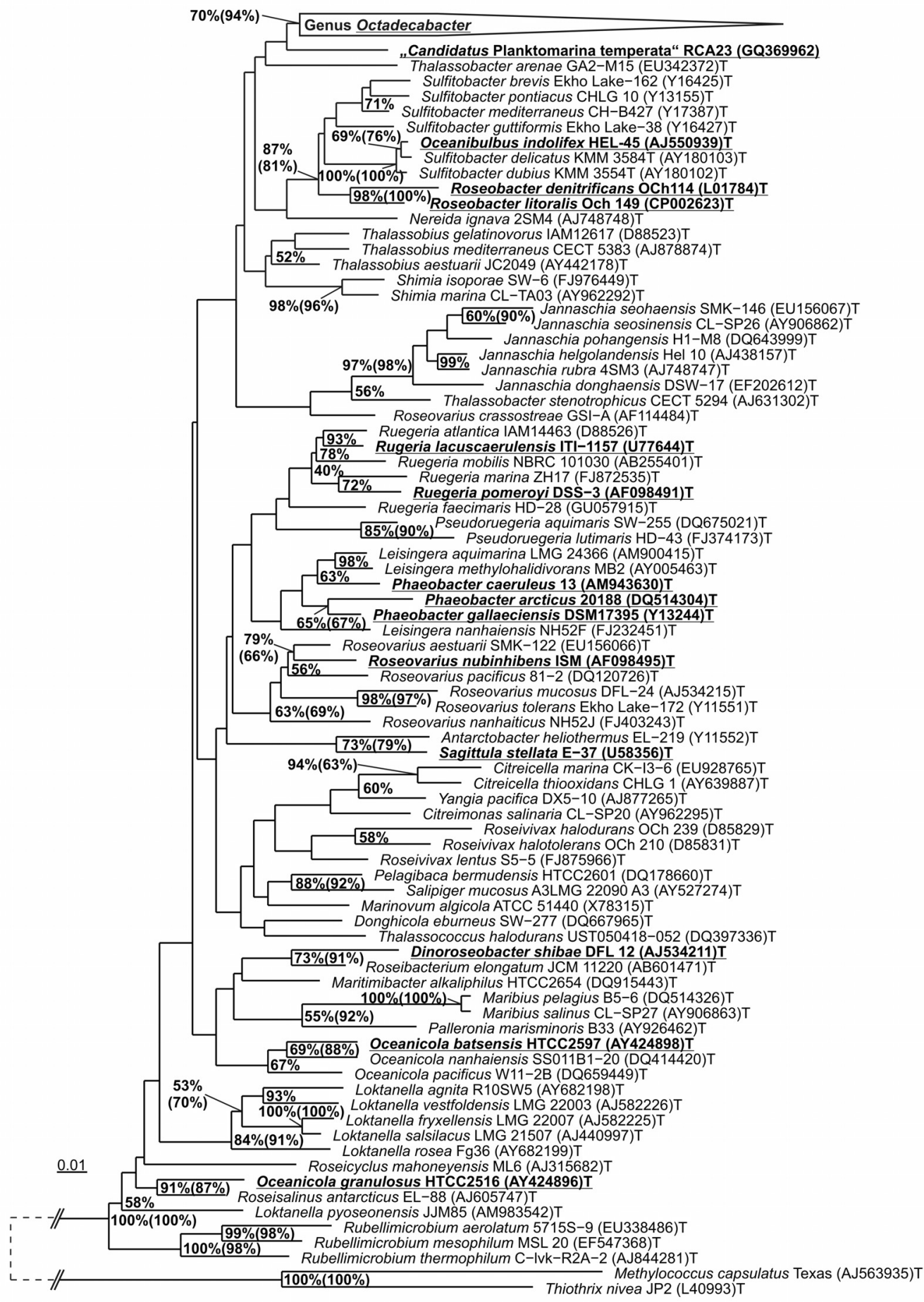

Abb. A1 Neighbor-Joining Baum der Roseobacter-Gruppe, basierend auf 16S rRNA Gensequenzen

Die entsprechenden NCBI accession-Nummern sind jeweils hinter der Organismenbezeichung in Klammern angegeben. Typstämme beschriebener Arten sind mit einem „T“ markiert. Neighbor-Joining bootstrap-Werte über $50 \%$ sind an den entsprechenden Verzweigungen angegeben. Verzweigungen, welche auch in MaximumLikelihood Stammbäumen mit bootstrap-Werten $>50 \%$ reproduziert werden konnten, sind zusätzlich mit den entsprechenden Maximum-Likelihood bootstrap-Werten in Klammern beschriftet. 16S rNRA Gensequenzen der Gammaproteobacteria Methylococcus capsulatus Texas und Thiothrix nivea JP2 dienten als outgroup. Beschriftungen von Organismen, deren Genomsequenzen im Rahmen dieser Arbeit für vergleichende Analysen herangezogen wurden, sind hervorgehoben. 
A

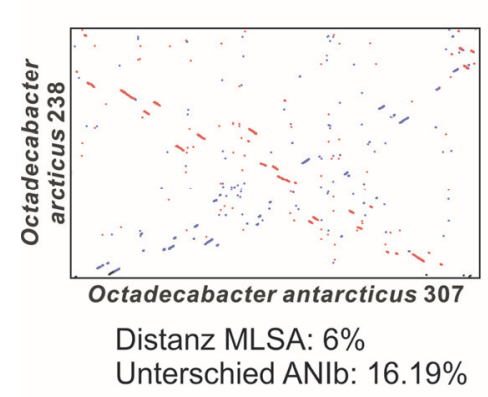

D

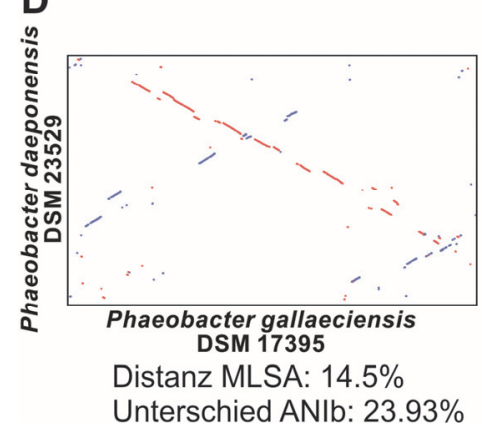

B

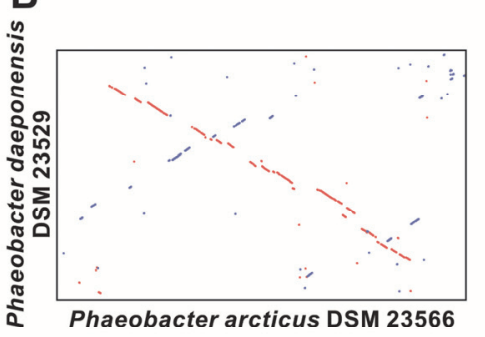

Distanz MLSA: $15.4 \%$

Unterschied ANIb: $24.07 \%$

E

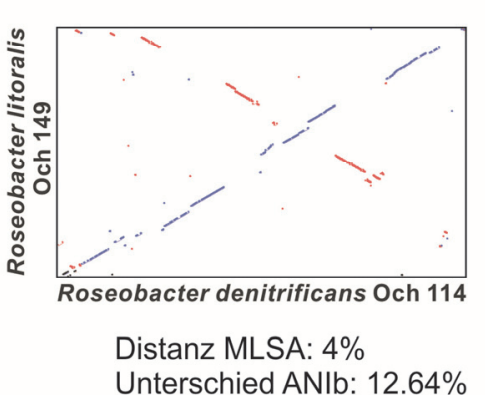

C

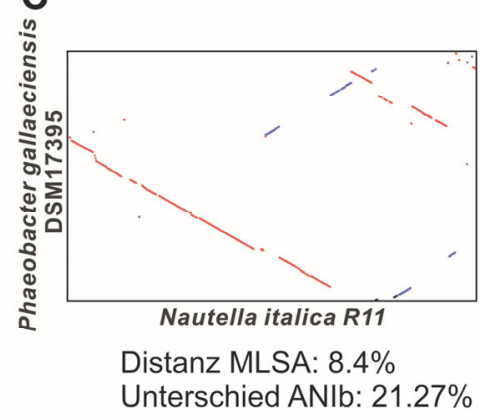

$\mathbf{F}$

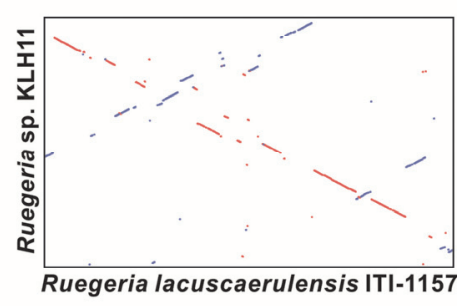

Distanz MLSA: $11 \%$

Unterschied ANIb: $21.83 \%$

Abb. A2 Syntenie-Plots der Genome ausgewählter Roseobacter Vertreter

Die Syntenie-Plots basieren auf paarweisen, mittels der MUMmer software (Kurtz et al. 2004) erstellten, Genom-alignments. Lineare Markierungen weisen auf Sequenzhomologien in zusammenhängenden Genomabschnitten hin. Homologe Genomabschnitte welche in den Vergleichsgenomen identische Orientierungen aufweisen, sind in Rot dargestellt, Inversionen sind in Blau dargestellt. Zum besseren Vergleich sind die entsprechenden Distanz-werte auf Multilokus Sequenzanalyse (MLSA)-Ebene und auf BLAST-basierter durchschnittlicher Nukleotididentitäts (ANIb)-Ebene (siehe 3.1.3) für jedes Genom-Paar angegeben. Trotz ihrer Ähnlichkeiten auf MLSA- und ANIb-Ebene weisen die Octadecabacter-Genome kaum Syntenien auf (A). Andere Vergleichsorganismen weisen, trotz ähnlicher oder höherer Distanzen auf MLSA- und ANIb-Ebene weitaus höhere Syntenien auf (B-F). Dies ist auch bei Organismen der Fall, welche von global entgegengesetzten Standorten isoliert wurden $(\mathrm{C}, \mathrm{D})$. 


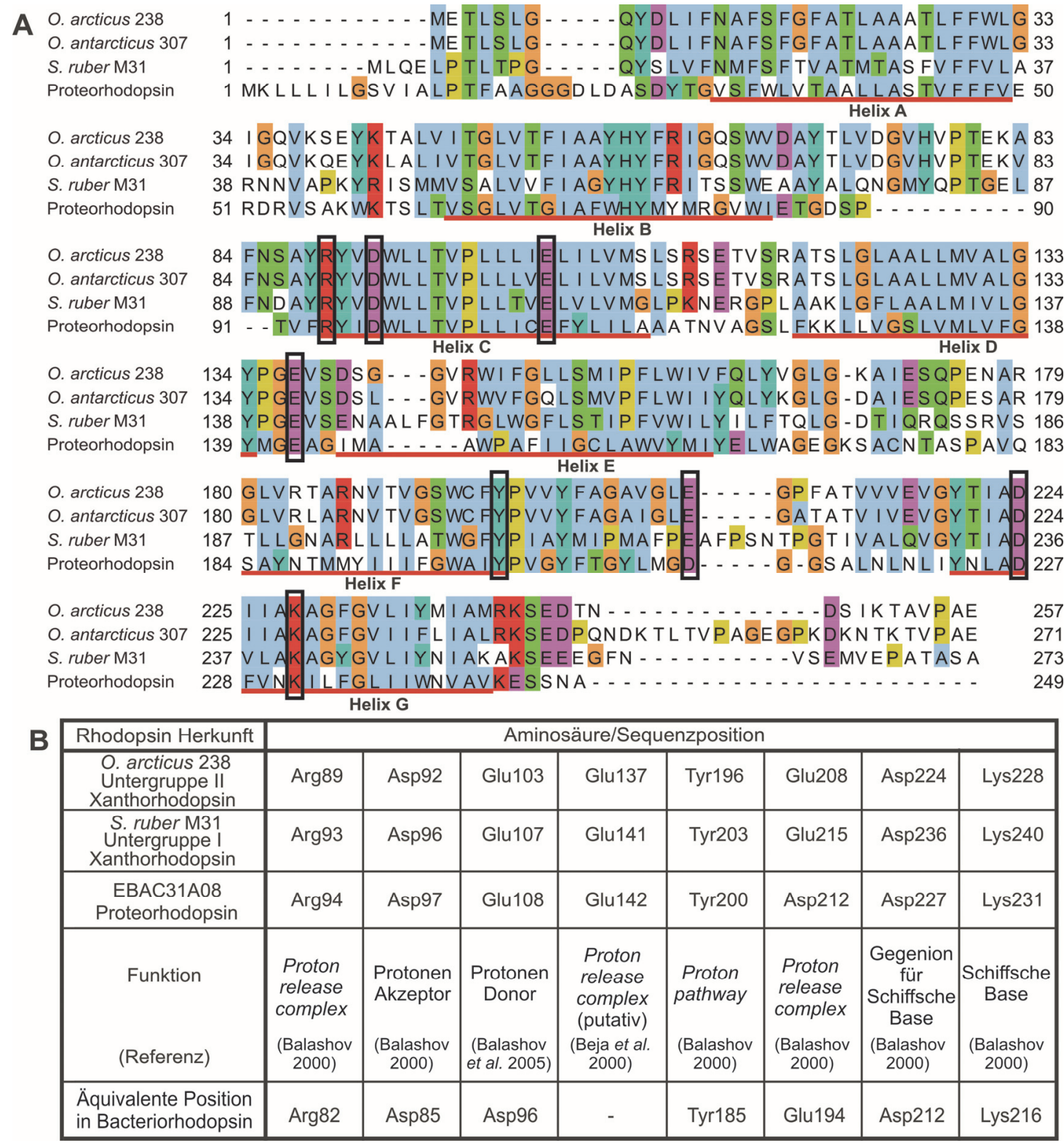

\section{Abb. A3 Rhodopsin-Aminosäuresequenzpositionen welche mit Protonenpumpenaktivität in Verbindung gebracht werden}

(A) Alignment des Untergruppe I-Xanthorhodopsins von S. ruber M31, der Untergruppe II-Xanthorhodopsine der Octadecabacter-Stämme und des Proteorhodopsins des Metagenom-Klons EBAC31A08. Die alignmentPositionen der Transmembran-Helices von Proteorhodopsin sind durch rote Linien markiert und beschriftet. Konservierte Aminosäuresequenzpositionen welche mit Protonenpumpen-Funktion in Verbindung gesetzt werden, sind durch schwarze Umrandung gekennzeichnet. (B) Aminosäuresequenzpositionen die in Proteo- und Xanthorhodopsinen mit Potonenpumpen-Funktion in Verbindung gesetzt werden. Die jeweilige Funktion der einzelnen Aminosäuren im Rahmen der Protonentranslokation ist gemeinsam mit der entsprechenden Referenz für jede dieser Sequenzpositionen angegeben. Äquivalente Sequenzpositionen in Bacteriorhodopsin sind in der untersten Zeile angegeben. 

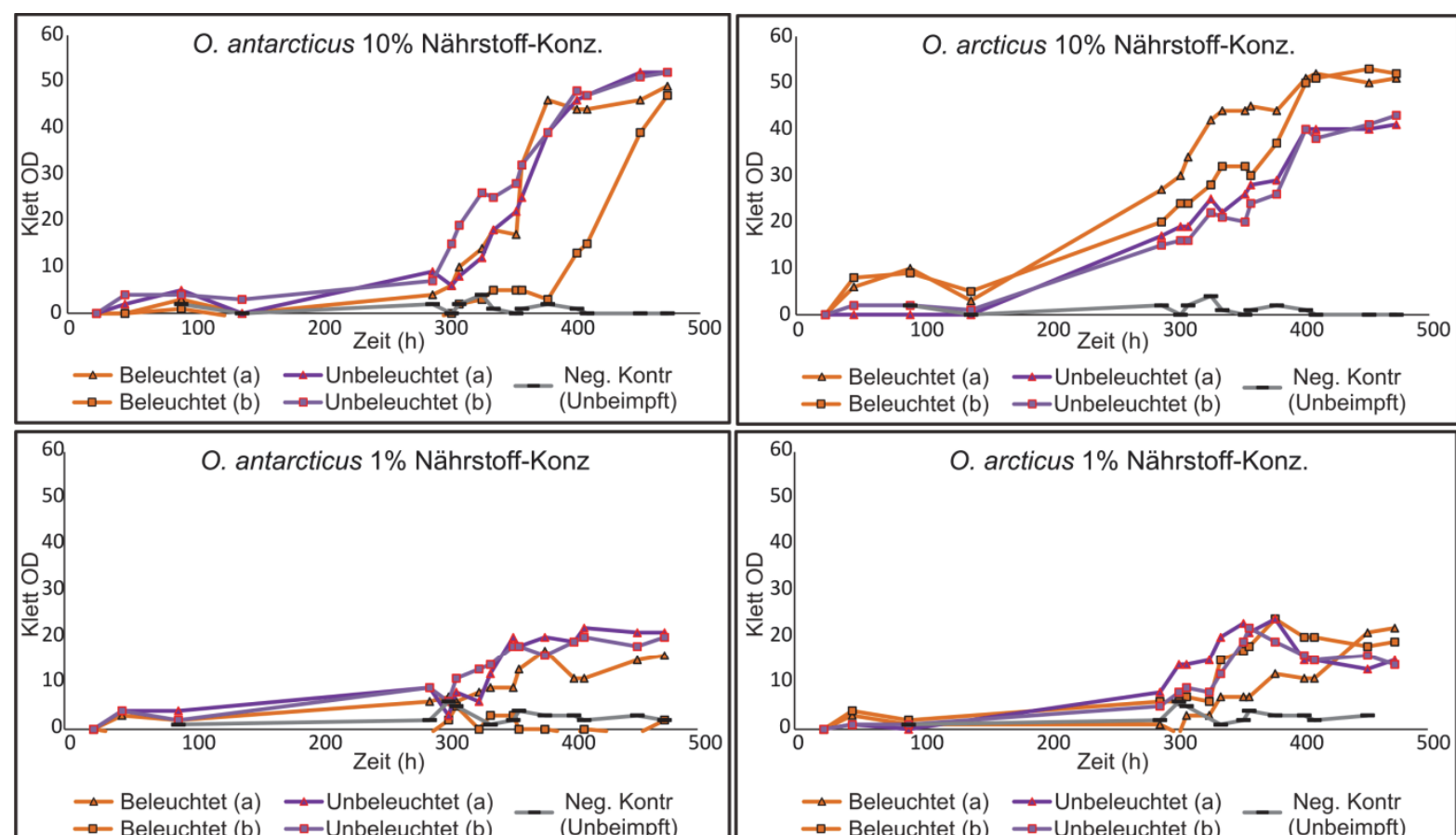
$\begin{aligned} & \rightarrow \text { Beleuchtet (a) } \rightarrow \text { Unbeleuchtet (a) } \\ & \rightarrow-\text { Beleuchtet (b) } \rightarrow-\text { Unbeleuchtet (b) }\end{aligned}-\begin{aligned} & \text { Neg. Kontr } \\ & \text { (Unbeimpft) }\end{aligned}$

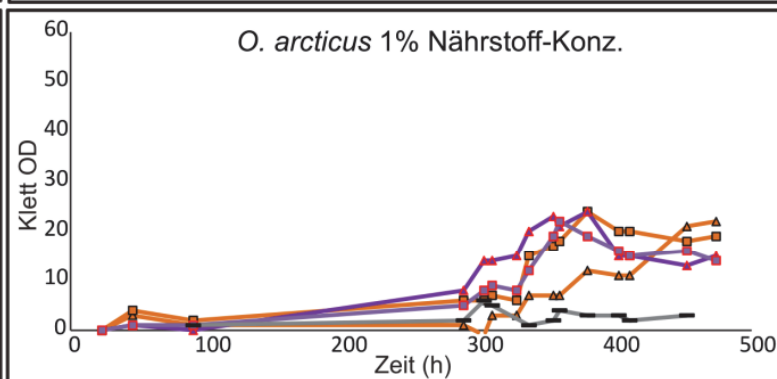

$\triangle$ Beleuchtet (a) $\rightarrow$ Unbeleuchtet (a) _ Neg. Kontr $\rightarrow-$ Beleuchtet (b) $\rightarrow-$ Unbeleuchtet (b) $\rightarrow$ (Unbeimpft)
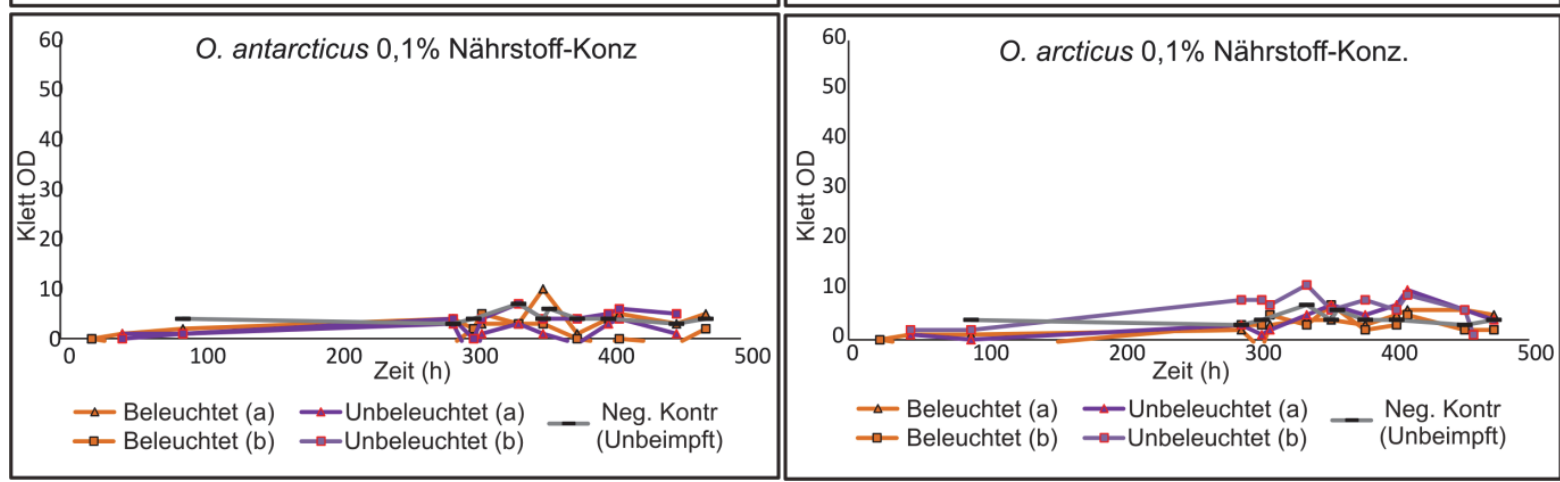

Abb. A4 Wachstumsversuche bei verschiedenen Nährstoffkonzentrationen und Beleuchtungszuständen Als Medium diente modifiziertes gepuffertes MB2216-Medium ( $\mathrm{pH} 7,5$ ) mit reduzierten Anteilen der Nährstoffe Hefeextrakt und Pepton. Es wurden jeweils nur 10\%, 1\% bzw 0,1\% der normalerweise für MB2216-Medium verwendeten Mengen an Hefeextrakt und Pepton zugegeben (siehe 2.2.1). Kulturen wurden mit bzw. ohne Beleuchtung angezogen. Es wurden jeweils zwei Parallelen durchgeführt (a und b). Wachstum wurde durch Trübungsmessung mittels eines Klett-Summerson Photometers verfolgt. Für jede Kultur ist die optische Dichte (OD in Klett-Einheiten) gegen die Zeit (in Stunden) aufgetragen. 


\begin{tabular}{|c|c|c|c|c|c|c|c|c|c|c|c|c|c|c|c|c|c|}
\hline Locus tag & $\sum_{\sum}^{\mathbb{N}}$ & 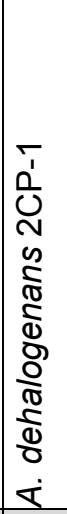 & 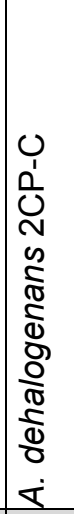 & 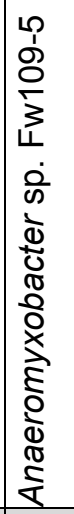 & 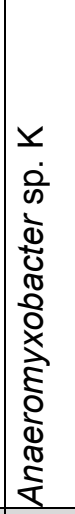 & 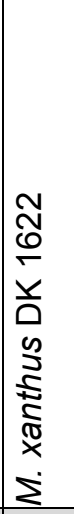 & 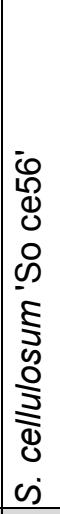 & 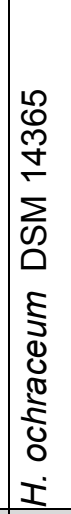 & Locus tag & 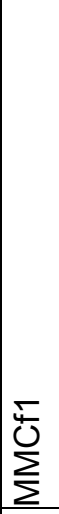 & 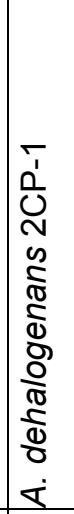 & 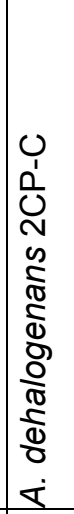 & 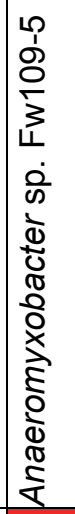 & 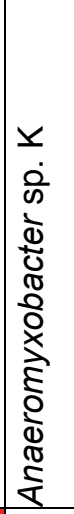 & 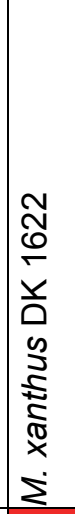 & 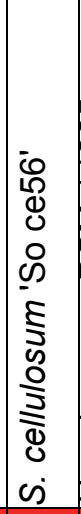 & 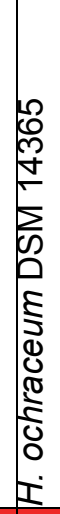 \\
\hline- & & & & & & & & & MMCf2_10 & & & & & & & & \\
\hline- & & & & & & & & & MMCf2_20 & & & & & & & & \\
\hline- & & & & & & & & & MMCf2_30 & & & & & & & & \\
\hline- & & & & & & & & & MMCf2_40 & & & & & & & & \\
\hline- & & & & & & & & & MMCf2_50 & & & & & & & & \\
\hline- & & & & & & & & & MMCf2_60 & & & & & & & & \\
\hline- & & & & & & & & & MMCf2_70 & & & & & & & & \\
\hline- & & & & & & & & & MMCf2_80 & & & & & & & & \\
\hline- & & & & & & & & & MMCf2_90 & & & & & & & & \\
\hline- & & & & & & & & & MMCf2_100 & & & & & & & & \\
\hline MMCf1_20 & & & & & & & & & MMCf2_120 & & & & & & & & \\
\hline MMCf1_30 & & & & & & & & & MMCf2_130 & & & & & & & & \\
\hline MMCf1_40 & & & & & & & & & MMCf2_140 & & & & & & & & \\
\hline MMCf1_50 & & & & & & & & & MMCf2_150 & & & & & & & & \\
\hline MMCf1_60 & & & & & & & & & MMCf2_160 & & & & & & & & \\
\hline MMCf1_70 & & & & & & & & & MMCf2_170 & & & & & & & & \\
\hline MMCf1_80 & & & & & & & & & MMCf2_180 & & & & & & & & \\
\hline MMCf1_90 & & & & & & & & & MMCf2_190 & & & & & & & & \\
\hline MMCf1_100 & & & & & & & & & MMCf2_200 & & & & & & & & \\
\hline MMCf1_110 & & & & & & & & & MMCf2_210 & & & & & & & & \\
\hline MMCf1_120 & & & & & & & & & MMCf2_220 & & & & & & & & \\
\hline MMCf1_130 & & & & & & & & & MMCf2_230 & & & & & & & & \\
\hline MMCf1_140 & & & & & & & & & MMCf2_240 & & & & & & & & \\
\hline MMCf1_150 & & & & & & & & & MMCf2_250 & & & & & & & & \\
\hline MMCf1_160 & & & & & & & & & MMCf2_260 & & & & & & & & \\
\hline MMCf1 170 & & & & & & & & & MMCf2 270 & & & & & & & & \\
\hline MMCf1_180 & & & & & & & & & MMCf2_280 & & & & & & & & \\
\hline MMCf1_190 & & & & & & & & & MMCf2_290 & & & & & & & & \\
\hline MMCf1_200 & & & & & & & & & MMCf2_300 & & & & & & & & \\
\hline MMCf1_210 & & & & & & & & & MMCf2_310 & & & & & & & & \\
\hline MMCf1_220 & & & & & & & & & - & & & & & & & & \\
\hline MMCf1_230 & & & & & & & & & - & & & & & & & & \\
\hline MMCf1_240 & & & & & & & & & - & & & & & & & & \\
\hline
\end{tabular}

Abb. A5 Orthologe zwischen den MMC-Fosmiden und den Genomen bekannter Myxobakterien

Orthologe wurden mithilfe bidirektionaler BLAST-Analysen bestimmt (siehe 2.10.3) und sind durch rote Färbung gekennzeichnet. 
Tab. A1 Unterschiedliche Ergebnisse für die Grösse des Coregenoms und die Anzahl an einzigartigen Genen (singletons) bei bidirektionalen BLAST-Analysen ausgehend von unterschiedlichen ReferenzGenomen

\begin{tabular}{|c|c|c|c|c|c|c|c|c|c|}
\hline \multirow[b]{2}{*}{ Organismus } & \multicolumn{2}{|c|}{ Coregenom } & \multicolumn{2}{|c|}{ Singeltons } & \multirow[b]{2}{*}{ Organismus } & \multicolumn{2}{|c|}{ Coregenom } & \multicolumn{2}{|c|}{ Singeltons } \\
\hline & $\begin{array}{l}\text { Anzahl } \\
\text { Gene }\end{array}$ & $\begin{array}{c}\text { Genom- } \\
\text { Anteil }\end{array}$ & $\begin{array}{l}\text { Anzahl } \\
\text { Gene }\end{array}$ & $\begin{array}{c}\text { Genom- } \\
\text { Anteil }\end{array}$ & & $\begin{array}{l}\text { Anzahl } \\
\text { Gene }\end{array}$ & $\begin{array}{c}\text { Genom- } \\
\text { Anteil }\end{array}$ & $\begin{array}{l}\text { Anzahl } \\
\text { Gene }\end{array}$ & $\begin{array}{l}\text { Genom } \\
\text {-Anteil }\end{array}$ \\
\hline Citreicella sp. 357 & 744 & $16.4 \%$ & 750 & $16.6 \%$ & $\begin{array}{l}\text { Rhodobacterales sp. } \\
\text { HTCC2083 }\end{array}$ & 749 & $17.9 \%$ & 819 & $19.6 \%$ \\
\hline Citreicella sp. SE45 & 735 & $13.5 \%$ & 906 & $16.7 \%$ & $\begin{array}{l}\text { Rhodobacterales sp. } \\
\text { HTCC2150 }\end{array}$ & 759 & $20.7 \%$ & 589 & $16.1 \%$ \\
\hline $\begin{array}{l}\text { Dinoroseobacter } \\
\text { shibae DFL-12 }\end{array}$ & 745 & $17.8 \%$ & 528 & $12.6 \%$ & $\begin{array}{l}\text { Rhodobacterales sp. } \\
\text { HTCC2255 }\end{array}$ & 757 & $16.8 \%$ & 184 & $4.1 \%$ \\
\hline $\begin{array}{l}\text { Jannaschia sp. } \\
\text { CCS1 }\end{array}$ & 756 & $17.7 \%$ & 549 & $12.8 \%$ & $\begin{array}{l}\text { Rhodobacterales sp. } \\
\text { MED193 }\end{array}$ & 744 & $16.4 \%$ & 459 & $10.1 \%$ \\
\hline $\begin{array}{l}\text { Ketogulonicigenium } \\
\text { vulgare WSH-001 }\end{array}$ & 750 & $24.6 \%$ & 705 & $23.1 \%$ & $\begin{array}{l}\text { Rhodobacterales sp. } \\
\text { R2A57 }\end{array}$ & 758 & $17.3 \%$ & 950 & $21.7 \%$ \\
\hline $\begin{array}{l}\text { Loktanella sp. } \\
\text { CCS2 }\end{array}$ & 757 & $20.7 \%$ & 457 & $12.5 \%$ & $\begin{array}{l}\text { Rhodobacterales sp. } \\
\text { SK209-2-6 } \\
\text { Roseobacter }\end{array}$ & 747 & $16.5 \%$ & 573 & $12.6 \%$ \\
\hline Loktanella sp. SE62 & 746 & $16.2 \%$ & 923 & $20.1 \%$ & $\begin{array}{l}\text { denitrificans OCh } \\
114\end{array}$ & 750 & $18.2 \%$ & 382 & $9.3 \%$ \\
\hline $\begin{array}{l}\text { Loktanella } \\
\text { vestfoldensis } \\
\text { SKA53 }\end{array}$ & 761 & $24.8 \%$ & 269 & $8.8 \%$ & $\begin{array}{l}\text { Roseobacter litoralis } \\
\text { Och } 149\end{array}$ & 748 & $16.5 \%$ & 451 & $9.9 \%$ \\
\hline $\begin{array}{l}\text { Maritimibacter } \\
\text { alkaliphilus } \\
\text { HTCC2654 }\end{array}$ & 749 & $15.9 \%$ & 920 & $19.5 \%$ & $\begin{array}{l}\text { Roseobacter sp. } \\
\text { AzwK-3b }\end{array}$ & 760 & $18.3 \%$ & 698 & $16.8 \%$ \\
\hline Nautella italica R11 & 757 & $20.7 \%$ & 298 & $8.2 \%$ & $\begin{array}{l}\text { Roseovarius } \\
\text { nubinhibens ISM }\end{array}$ & 758 & $21.4 \%$ & 285 & $8.0 \%$ \\
\hline $\begin{array}{l}\text { Oceanibulbus } \\
\text { indolifex HEL-45 }\end{array}$ & 745 & $17.9 \%$ & 544 & $13.1 \%$ & Roseovarius sp. 217 & 742 & $15.5 \%$ & 567 & $11.9 \%$ \\
\hline $\begin{array}{l}\text { Oceanicola } \\
\text { batsensis } \\
\text { HTCC2597 }\end{array}$ & 754 & $17.9 \%$ & 484 & $11.5 \%$ & $\begin{array}{l}\text { Roseovarius sp. } \\
\text { TM1035 }\end{array}$ & 747 & $18.2 \%$ & 353 & $8.6 \%$ \\
\hline $\begin{array}{l}\text { Oceanicola } \\
\text { granulosus } \\
\text { HTCC2516 }\end{array}$ & 759 & $20.0 \%$ & 415 & $10.9 \%$ & $\begin{array}{l}\text { Ruegeria } \\
\text { lacuscaerulensis ITI- } \\
1157\end{array}$ & 757 & $21.0 \%$ & 361 & $10.0 \%$ \\
\hline $\begin{array}{l}\text { Octadecabacter } \\
\text { antarcticus } 307\end{array}$ & 753 & $16.8 \%$ & $892^{\mathrm{A}}$ & $19,9 \%^{\mathrm{A}}$ & $\begin{array}{l}\text { Ruegeria pomeroyi } \\
\text { DSS-3 }\end{array}$ & 739 & $17.4 \%$ & 264 & $6.2 \%$ \\
\hline $\begin{array}{l}\text { Octadecabacter } \\
\text { arcticus } 238\end{array}$ & 749 & $16.0 \%$ & $1091^{\mathrm{A}}$ & $23,9 \%{ }^{\mathrm{A}}$ & Ruegeria sp. KLH11 & 751 & $17.6 \%$ & 765 & $17.9 \%$ \\
\hline $\begin{array}{l}\text { Pelagibaca } \\
\text { bermudensis }\end{array}$ & 737 & $13.5 \%$ & 909 & $16.7 \%$ & $\begin{array}{l}\text { Ruegeria sp. } \\
\text { TM1040 }\end{array}$ & & & 250 & 6 \\
\hline $\begin{array}{l}\text { HTCC2601 } \\
\text { Phaeobacter } \\
\text { arcticus DSM }\end{array}$ & 744 & $15.7 \%$ & 418 & $8.8 \%$ & $\begin{array}{l}\text { Ruegeria sp. } \\
\text { TrichCH4B }\end{array}$ & 753 & $19.5 \%$ & 250 & $.5 \%$ \\
\hline $\begin{array}{l}\text { Phaeobacter } \\
\text { caeruleus } 13\end{array}$ & 736 & $14.3 \%$ & 730 & $14.2 \%$ & $\begin{array}{l}\text { Ruegeria conchae. } \\
\text { TW15 }\end{array}$ & 749 & $17.1 \%$ & 439 & $10.0 \%$ \\
\hline $\begin{array}{l}\text { Phaeobacter } \\
\text { daeponensis DSM } \\
23529\end{array}$ & 742 & $17.3 \%$ & 131 & $3.1 \%$ & $\begin{array}{l}\text { Sagittula stellata E- } \\
37\end{array}$ & 743 & $14.7 \%$ & 728 & $14.4 \%$ \\
\hline $\begin{array}{l}\text { Phaeobacter } \\
\text { gallaeciensis } 2.10\end{array}$ & 753 & $19.4 \%$ & 90 & $2.3 \%$ & $\begin{array}{l}\text { Sulfitobacter sp. EE- } \\
36\end{array}$ & 755 & $21.7 \%$ & 172 & $5.0 \%$ \\
\hline $\begin{array}{l}\text { Phaeobacter } \\
\text { gallaeciensis } \\
\text { DSM17395 }\end{array}$ & 752 & $19.4 \%$ & 142 & $3.7 \%$ & $\begin{array}{l}\text { Sulfitobacter sp. } \\
\text { GAl101 }\end{array}$ & 747 & $17.8 \%$ & 485 & $11.5 \%$ \\
\hline $\begin{array}{l}\text { Phaeobacter } \\
\text { inhibens T5 }\end{array}$ & 754 & $19.4 \%$ & 128 & $3.3 \%$ & $\begin{array}{l}\text { Sulfitobacter sp. } \\
\text { NAS-14.1 }\end{array}$ & 746 & $18.8 \%$ & 323 & $8.2 \%$ \\
\hline $\begin{array}{l}\text { Phaeobacter sp. } \\
\text { Y4I }\end{array}$ & 744 & $18.0 \%$ & 317 & $7.7 \%$ & $\begin{array}{l}\text { Thalassiobium sp. } \\
\text { R2A62 }\end{array}$ & 759 & $20.5 \%$ & 671 & $18.2 \%$ \\
\hline $\begin{array}{l}\text { "Ca. Planktomarina } \\
\text { temperata" RCA23 }\end{array}$ & 747 & $24.5 \%$ & 293 & $9.6 \%$ & $\begin{array}{l}\text { Wenxinia marina } \\
\text { DSM } 24838\end{array}$ & 755 & $18.7 \%$ & 499 & $12.3 \%$ \\
\hline
\end{tabular}

${ }^{A}$ Ohne Abzug TE-assoziierter Gene 


\section{Inhaltsverzeichnis des digitalen Anhangs}

\begin{tabular}{|c|c|c|}
\hline Tabelle & Beschreibung & Dateiname \\
\hline DA01 & Abgeschlossene und laufende Roseobacter Genomprojekte & Tab_DA01.xls \\
\hline DA02 & Binäre Matrix für gene content-Analysen (Text-Format mit Tabstops) & Tab_DA02.tab \\
\hline DA03-DA53 & Ergebnisse der Orthologensuche für die einzelnen Vergleichsstämme: & \\
\hline DA03 & Octadecabacter antarcticus 307 & Tab_DA03.xls \\
\hline DA04 & Octadecabacter arcticus 238 & Tab_DA04.xls \\
\hline DA05 & Nautella italica $\mathrm{R} 11$ & Tab_DA05.xls \\
\hline DA06 & Phaeobacter arcticus DSM23566 & Tab_DA06.xls \\
\hline DA07 & Phaeobacter caeruleus 13 & Tab_DA07.xls \\
\hline DA08 & Phaeobacter daeponensis DSM23529 & Tab_DA08.xls \\
\hline DA09 & Phaeobacter gallaeciensis 2.10 & Tab_DA09.xls \\
\hline DA10 & Phaeobacter gallaeciensis DSM17395 & Tab_DA10.xls \\
\hline DA11 & Phaeobacter inhibens T5 & Tab_DA11.xls \\
\hline DA12 & Phaeobacter sp. Y4I & Tab_DA12.xls \\
\hline DA13 & Rhodobacteraceae sp. MED193 & Tab_DA13.xls \\
\hline DA14 & Rhodobacteraceae sp. SK209-2-6 & Tab_DA14.xls \\
\hline DA15 & Ruegeria conchae TW15 & Tab_DA15.xls \\
\hline DA16 & Ruegeria pomeroyi DSS-3 & Tab_DA16.xls \\
\hline DA17 & Ruegeria sp. KLH11 & Tab_DA17.xls \\
\hline DA18 & Ruegeria sp. TM1040 & Tab_DA18.xls \\
\hline DA19 & Ruegeria sp. TrichCH4B & Tab_DA19.xls \\
\hline DA20 & Rugeria lacuscaerulensis ITI-1157 & Tab_DA20.xls \\
\hline DA21 & Oceanobulbus indolifex HEL45 & Tab_DA21.xls \\
\hline DA22 & Roseobacter denitrificans OCh114 & Tab_DA22.xls \\
\hline DA23 & Roseobacter litoralis Och149 & Tab_DA23.xls \\
\hline DA24 & Sulfitobacter sp. EE36 & Tab_DA24.xls \\
\hline DA25 & Sulfitobacter sp. GAI101 & Tab_DA25.xls \\
\hline DA26 & Sulfitobacter sp. NAS141 & Tab_DA26.xls \\
\hline DA27 & Citreicella aestuarii 357 & Tab_DA27.xls \\
\hline DA28 & Citreicella sp. SE45 & Tab_DA28.xls \\
\hline DA29 & Oceanicola batsensis HTCC 2597 & Tab_DA29.xls \\
\hline DA30 & Pelagibaca bermudensis HTCC2601 & Tab_DA30.xls \\
\hline DA31 & Rhodobacteraceae sp. AzwK-3b & Tab_DA31.xls \\
\hline DA32 & Roseovarius nubinhibens ISM & Tab_DA32.xls \\
\hline DA33 & Roseovarius sp. SP217 & Tab_DA33.xls \\
\hline DA34 & Roseovarius sp. TM1035 & Tab_DA34.xls \\
\hline DA35 & Sagittula stellata E-37 & Tab_DA35.xls \\
\hline DA36 & Ketogulonicigenium vulgare WSH-001 & Tab_DA36.xls \\
\hline DA37 & Ketogulonicigenium vulgare Y25 & Tab_DA37.xls \\
\hline DA38 & Loktanella sp. CCS2 & Tab_DA38.xls \\
\hline DA39 & Loktanella sp. SE62 & Tab_DA39.xls \\
\hline DA40 & Loktanella vestfoldensis SKA53 & Tab_DA40.xls \\
\hline DA41 & Oceanicola granulosus HTCC2516 & Tab_DA41.xls \\
\hline
\end{tabular}


DA42 Thalassiobium sp. R2A62

DA43 Wenxinia marina DSM24838

DA44 Dinoroseobacter shibae DFL-12

DA45 Jannaschia sp. CCS1

DA46 "Ca. Planktomarina temperata" RCA23

DA47 Maritimibacter alkaliphilus HTCC2654

DA48 Rhodobacteraceae sp. HTCC2083

DA49 Rhodobacteraceae sp. HTCC2150

DA50 Rhodobacteraceae sp. HTCC2255

DA51 Rhodobacteraceae sp. R2A57

DA52 Escherichia coli K-12 MG1655

DA53 Parvarcula bermudensis HTCC2053

DA54 BLAST-basierte durchschnittliche Nukleotididentitäts-Werte (ANIb) zwischen den Vergleichsstämmen

DA55 Korrelationskoeffizienten der Tetranukleotid-Zusammensetzung in den Vergleichsstämmen

Übersicht ausgewählter Merkmale in Regionen erhöhter

DA56 Genomplastizität (RGPs) in den Genomen von Octadecabacter arcticus (Oar-RGP1-17, pOAR118, pOAR160) und Octadecabacter antarcticus (Oan-RGP1-16, pOAN63)

DA57 Cyanophycin-Ligasen und Cyanophycin-Ligase-ähnliche Proteine deren Sequenzen für phylogenetische Analysen genutzt wurden

DA58 Ergebnisse der vorläufigen Schwermetall-Versuche

DA59 Liste von Rhodopsinsequenzen welche für phylogenetische Analysen und Screenings von Metagenomen herangezogen wurden

DA60
Tab_DA42.xls

Tab_DA43.xls

Tab DA44.xls

Tab DA45.xls

Tab DA46.xls

Tab_DA47.xls

Tab_DA48.xls

Tab_DA49.xls

Tab_DA50.xls

Tab_DA51.xls

Tab_DA52.xls

Tab DA53.xls

Tab DA54.xls

Tab_DA55.xls

Tab_DA56.xls

Tab_DA57.xls

Tab_DA58.xls

Tab_DA59.xls

Tab_DA60.xls

\section{Literaturverzeichnis Anhang}

Balashov, S.P. (2000) Protonation reactions and their coupling in bacteriorhodopsin. Biochim Biophys Acta Bioenerg, 1460, 75-94.

Balashov, S.P., Imasheva, E.S., Boichenko, V.A., Anton, J., Wang, J.M. \& Lanyi, J.K. (2005) Xanthorhodopsin: a proton pump with a light-harvesting carotenoid antenna. Science, 309, 2061-2064.

Beja, O., Aravind, L., Koonin, E.V., Suzuki, M.T., Hadd, A., Nguyen, L.P., Jovanovich, S., Gates, C.M., Feldman, R.A., Spudich, J.L., Spudich, E.N. \& DeLong, E.F. (2000) Bacterial rhodopsin: Evidence for a new type of phototrophy in the sea. Science, 289, 1902-1906.

Kurtz, S., Phillippy, A., Delcher, A.L., Smoot, M., Shumway, M., Antonescu, C. \& Salzberg, S.L. (2004) Versatile and open software for comparing large genomes. Genome Biol, 5, R12. 


\section{Abbildungsverzeichnis}

Abb. 1 Beispiele mariner Wassermassen und Meereströmungen..................................... 9

Abb. 2 Herkunft exemplarischer Vertreter der Roseobacter-Gruppe ................................. 13

Abb. 3 Mikrobielle Rhodopsine. Schematischer Aufbau ................................................ 15

Abb. 4 Graphische Übersicht der Octadecabacter Genome. ............................................. 47

Abb. 5 Genomeigenschaften von Roseobacter-Vertretern mit unterschiedlicher Lebensweise

Abb. 6 Neighbor-Joining Baum basierend auf der Gen-Ausstattung (gene content) von Roseobacter-Vertretern mit Darstellung der entsprechenden COG-Kategorien ..... 51

Abb. 7 Anteile an Genen verschiedener COG-Kategorien in Roseobacter-Vertretern unterschiedlicher Lebensweise

Abb. 8 MLSA-basierte Phylogenie der Roseobacter-Gruppe ............................................ 55

Abb. 9 Phylogenetische Stammbäume basierend auf rRNA-Gensequenzen 57

Abb. 10 Verwandtschaftsverhältnisse zwischen Roseobacter-Vertretern basierend auf Gesamtgenomvergleichen.

Abb. 11 Phylogenetische Beziehungen zwischen Octadecabacter-Vertretern unterschiedlicher geographischer Standorte

Abb. 12 Detailierte zirkuläre Darstellung der Octadecabacter Genome 64

Abb. 13 Regionale Anhäufung einiger Gruppen von transposablen Elementen (TEs) in den Genomen von $O$. arcticus 238 und $O$. antarcticus 307.

Abb. 14 Genomalignments der Octadecabacter-Stämme sowie verschiedener Vergleichsorganismen.....

Abb. 15 Cyanophycin-Gencluster mit Typ VI Cyanophycin-Ligase ................................. 70

Abb. 16 Diversität bakterieller Cyanophycin-Ligasen ................................................... 71

Abb. 17 Biogeographie von Gruppe-VI Cyanopycin-Ligasen in marinen und Eisassoziierten Standorten

Abb. 18 Gencluster der assimilatorischen Nitrat-Redukion in R. litoralis und O. antarcticus.

Abb. 19 Wachstum von O. antarcticus mit verschiedenen Stickstoffquellen .... 76

Abb. 20 Wachstum von Octadecabacter-Kulturen mit Ectoin als hauptsächlicher

Kohlenstoffquelle. 77

Abb. 21 Gencluster RuBisCO-ähnlicher Gene in Roseobacter-Vertretern 
Abb. 22 Gencluster der Typ IV Sekretionssysteme in O. arcticus 238 und ausgewählten Vergleichsorganismen

Abb. 23 Phylogenie von Typ IV-Sekretionssystemen in Vertretern der Roseobacter-

Gruppe

Abb. 24 Gene Transfer Agent (GTA)-Gencluster und Umgebung in verschiedenen

Roseobacter-Vertretern.

Abb. 25 Neighbor-Joining-Baum von GTA-Genprodukten in Vertretern der Roseobacter-Gruppe 82

Abb. 26 Flagellen-Gencluster in O. arcticus 238 und O. antarcticus 307.

Abb. 27 Phylogenie der Flagellen-Gencluster in Vertretern der Roseobacter-Gruppe

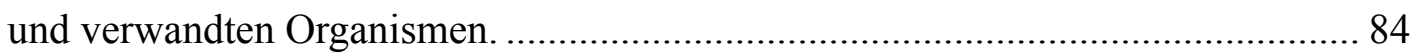

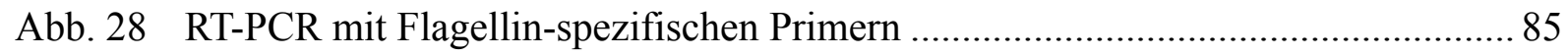

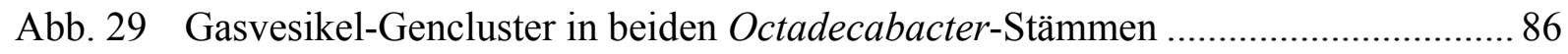

Abb. 30 Schwermetall-Resistenz-Gencluster in den Octadecabacter-Stämmen 87

Abb. 31 Rhamnose-Import- und Verwertungs-Gencluster in O. arcticus 238 und O. antarcticus 307

Abb. 32 Rhamnose-Verwertung in den Octadecabacter-Stämmen.................................... 89

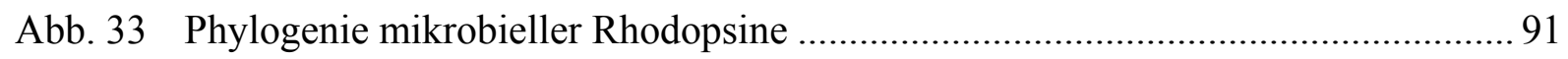

Abb. 34 Habitat-Bevorzugung und detaillierte Phylogenie der Xanthorhodopsin Untergruppen 93

Abb. 35 Anteil von Rhodopsin-Gensequenzen in Sanger-Sequenzierungs-basierten Metagenomen 94

Abb. 36 Anteil von Rhodopsin-Gensequenzen in 454-Sequenzierungs-basierten Metagenomen 96

Abb. 37 Vergleich der Genumgebungen von Xanthorhodopsinen der Untergruppen I und II 98

Abb. 38 Potentielle Keto-Carotenoid-Bindestellen in verschiedenen Xanthorhodopsinen... 99

Abb. 39 Western-Blots und Spektralanalysen heterolog exprimierter Rhodopsine 101

Abb. 40 Protonenpumpenaktivitäten heterolog exprimierter Rhodopsine

Abb. 41 Nachweis der Expression von Xanthorhodopsinen in nativen OctadecabacterKulturen

Abb. 42 Versuche zur Keto-Carotenoid Bindefähigkeit von Untergruppe I- und Untergruppe II-Xanthorhodopsinen..... 103 
Abb. 43 Vergleich allgemeiner Genomeigenschaften zwischen MLSA-basierten Roseobacter Gruppen 106

Abb. 44 Zusammenhang zwischen MLSA-basierter Phylogenie, gene content Analysen und Lebensweise verschiedener Roseobacter-Vertreter

Abb. 45 Verteilung charakteristischer Eigenschaften innerhalb der Roseobacter-Gruppe 115

Abb. 46 Vergleich der Lebensbedingungen von Organismen mit Xanthorhodopsinen der Untergruppe I oder II

Abb. 47 Zusammenfassung der relativen Rhodopsin-Anteile in verschiedenen Habitaten 131

Abb. A1 Neighbor-Joining Baum der Roseobacter-Gruppe, basierend auf 16S rRNA Gensequenzen......

Abb. A2 Syntenie-Plots der Genome ausgewählter Roseobacter Vertreter 158

Abb. A3 Rhodopsin-Aminosäuresequenzpositionen welche mit Protonenpumpenaktivität in Verbindung gebracht werden 159

Abb. A4 Wachstumsversuche bei verschiedenen Nährstoffkonzentrationen und Beleuchtungszuständen. 160

Abb. A5 Orthologe zwischen den MMC-Fosmiden und den Genomen bekannter Myxobakterien 161 


\section{Tabellenverzeichnis}

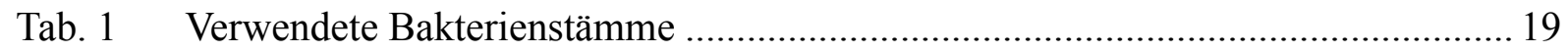

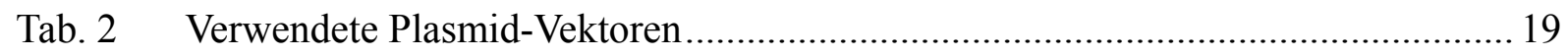

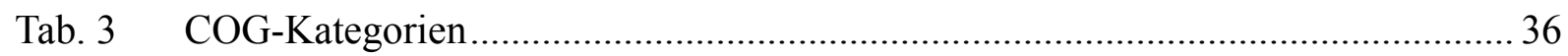

Tab. 4 Liste der nach spezifischen Genen durchsuchten Metagenom-Projekte ................ 41

Tab. 5 Primer zur Amplifikation von Opsingenen........................................................... 42

Tab. 6 In dieser Arbeit erzeugte rekombinante E. coli-Stämme zur heterologen

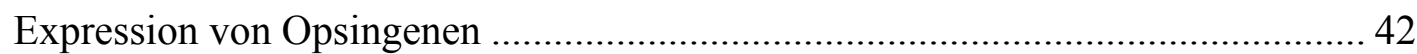

Tab. 7 Genomeigenschaften der Untersuchten Roseobacter-Vertreter ............................ 48

Tab. 8 Anteile von Octadecabacter-Vertretern in polaren Habitaten ................................. 60

Tab. 9 Klassifikation der Transposablen Elemente von O. arcticus und O. antarcticus

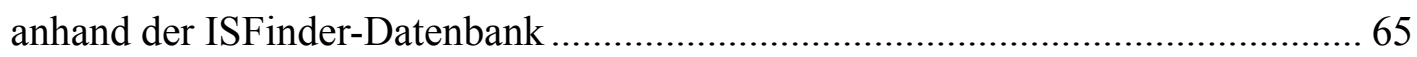

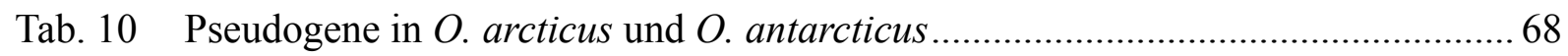

Tab. 11 Liste der Gruppe-VI Cyanophycin Ligasen und der zugehörigen Organismen. ..... 72

Tab. 12 Ergebnisse verschiedener Motilitäts-Tests mit $O$. arcticus 238 und O. antarcticus 307

Tab. A1 Unterschiede in der Größe des Coregenoms bei bidirektionalen BLASTAnalysen ausgehend von unterschiedlichen Referenz-Genomen 162 


\section{Danksagung}

Mein besonderer Dank gilt meinem Doktorvater Prof. Dr. Rolf Daniel für die Ermöglichung dieser Arbeit, für die Unterstützung die er mir zuteil werden ließ, für seine konstruktiven Anregungen und nicht zuletzt auch für seine Geduld. Desweiteren möchte ich meinem Korreferenten Prof. em. Dr. Gerhard Gottschalk für sein Engagement, und auch dafür dass er uns Doktoranden auf seine freundliche Art und mit seinen interessanten Anekdoten an seinem Erfahrungsschatz teilhaben ließ, herzlich danken. Den weiteren Mitgliedern der Prüfungskommission, Prof. Dr. Pöggeler, Jun-Prof. Dr. Heimel, PD Dr. Hoppert und PD Dr. Kramer, möchte ich für die Bereitschaft diese Aufgabe zu übernehmen, ebenfalls herzlich danken.

Ein spezieller Dank geht an Dr. Sonja Voget, die mir mit ihrem unermüdlichen Engagement stets konstruktiv zur Seite stand, und bei der ich mir immer einen guten Rat abholen konnte. Bei der Korrektur dieser Arbeit und meines Papers war sie ebenfalls eine unentbehrliche Hilfe. Nicht zuletzt versteht sie es durch ihre fröhliche und hilfreiche Art, wenn nötig, auch sehr beruhigend zu wirken.

Unserem engen Kooperationspartner, der AG Simon des ICBM in Oldenburg, möchte ich für die gute Zusammenarbeit danken. Besonders hervorzuheben sind hierbei Prof. Dr. Meinhard Simon, Dr. Thorsten Brinkhoff, Dr. Mascha Wurst, Dr. Helge-Ansgar Giebel und Sara Billerbeck.

Der Crew sowie dem wissenschaftlichen Team der Polarstern-Expeditionen ANTXXVII-2 und ANTXXVII-4 möchte ich danken für die unvergesslichen und einzigartigen Erfahrungen, die ich im Rahmen dieser spannenden Ausfahrten machen durfte. Auch meinem Doktorvater und nicht zuletzt unseren Kooperationspartnern im Rahmen des SFB TTR51 möchte ich an dieser Stelle nochmal besonders dafür danken, dass mir die Teilnahme an diesen Expeditionen ermöglicht wurde.

Den TAs unserer Arbeitsgruppe, insbesondere Kathleen Gollnow, Frauke-Dorothee Meyer und Mechthild Bömeke, möchte ich für ihre große Hilfe und ihren kompetenten Rat danken. In diesem Zusammenhang möchte ich auch dem gesamten Team der AG Daniel und des G2Ls für die gute Zusammenarbeit danken.

Ein besonders inniger Dank geht an meine tapferen Mitstreiter und Doktorandenkollegen die mit mir viel Freud und Leid und einiges an Erfahrung geteilt haben. Im Speziellen möchte ich hierbei Sandra Wiegand, Katrin Hartwich, Andreas Leimbach, Marvin Djukic und Shiva 
nennen, mit denen ich mir so manche späte Abende und Wochenenden um die Ohren gehauen habe.

Bei meinen Eltern Claus und Sally, meiner Schwester Annie und meiner Nichte Carla möchte ich mich aus tiefstem Herzen dafür bedanken, dass ich mich immer darauf verlassen kann, dass sie für mich da sind. Auch dafür, dass sie es mir nicht übelnehmen, dass ich sie im Zuge meiner Arbeit oft schändlich vernachlässigt habe, bin ich ihnen unendlich dankbar. 


\section{Publikationsliste}

Brinkhoff, T., Fischer, D., Vollmers, J., Voget, S., Beardsley, C., Thole, S., Mussmann, M., Kunze, B., Wagner-Dobler, I., Daniel, R. \& Simon, M. (2012) Biogeography and phylogenetic diversity of a cluster of exclusively marine Myxobacteria. ISME J, 6, $1260-1272$.

Voget, S., Wemheuer, B., Brinkhoff, T., Vollmers, J., Dietrich, S., Giebel, H.-A., Beardsley, C., Bakenhus, I., Billerbeck, S., Daniel, R. \& Simon, M. (2013) Genome-based analysis and active role of a photoheterotrophic and $\mathrm{CO}$ oxidizing Roseobacter RCA population in the ocean. ISME J (Submitted).

Vollmers, J., Voget, V., Dietrich, S., Gollnow, K., Smits, M., Meyer, K., Brinkhoff, T., Simon, M. \& Daniel, R. (2013) Poles apart: Arctic and Antarctic Octadecabacter strains share high genome plasticity and a new type of xanthorhodopsin. PLoS One, 8, e63422. 


\title{
Promovierenden-Erklärung der Georg-August-Universität Göttingen
}

\author{
Name: $\quad$ Vollmers, John Felix \\ Anschrift: Hannoversche Str. 103, 37077 Göttingen
}

Ich beabsichtige, eine Dissertation zum Thema „Molekularbiologische Charakterisierung und vergleichende Genomik von ausgewählten Vertretern mariner Roseobacter-Stämme“ an der Georg-August-Universität Göttingen anzufertigen. Dabei werde ich von Herrn Prof. Dr. Rolf Daniel betreut.

Ich gebe folgende Erklärung ab:

1. Die Gelegenheit zum vorliegenden Promotionsvorhaben ist mir nicht kommerziell vermittelt worden. Insbesondere habe ich keine Organisation eingeschaltet, die gegen Entgelt Betreuerinnen und Betreuer für die Anfertigung von Dissertationen sucht oder die mir obliegenden Pflichten hinsichtlich der Prüfungsleistungen für mich ganz oder teilweise erledigt.

2. Hilfe Dritter wurde bis jetzt und wird auch künftig nur in wissenschaftlich vertretbarem und prüfungsrechtlich zulässigem Ausmaß in Anspruch genommen. Insbesondere werden alle Teile der Dissertation selbst angefertigt; unzulässige fremde Hilfe habe ich dazu weder unentgeltlich noch entgeltlich entgegengenommen und werde dies auch zukünftig so halten.

3. Die Richtlinien zur Sicherung der guten wissenschaftlichen Praxis an der Universität Göttingen werden von mir beachtet.

4. Eine entsprechende Promotion wurde an keiner anderen Hochschule im In- oder Ausland beantragt; die eingereichte Dissertation oder Teile von ihr wurden nicht für ein anderes Promotionsvorhaben verwendet.

Mir ist bekannt, dass unrichtige Angaben die Zulassung zur Promotion ausschließen bzw. später zum Verfahrensabbruch oder zur Rücknahme des erlangten Grades führen.

Göttingen, den 27.06.2013 


\section{Lebenslauf}

Dipl.-Biol. John Felix Vollmers

Geboren am 30. April 1979 in Bad Soden

Seit $02 / 2008$

\section{Promotionsstudium}

Abteilung für Genomische und Angewandte Mikrobiologie und Laboratorium für Genomanalyse, Institut für Mikrobiologie und Genetik, Georg-August-Universität Göttingen

Seit $01 / 2013$

Wissenschaftlicher Mitarbeiter

Abt. Evolutionary Functional Genomics (Jun.-Prof. Dr. Claudia Acquisti), Institut für Evolution und Biodiversität, Westfälische Willhelms-Universität Münster

12/2006 - 08/2007 Diplomarbeit „Strukturanalyse mariner Myxobakterienpopulationen“ AG Biologie geologischer Prozesse (Prof. Dr. Meinhard Simon), Institut für Chemie und Biologie des Meeres, Carl von Ossietzky Universität Oldenburg

10/2001 - 08/2007 Studium der Biologie (Diplom)

Carl von Ossietzky Universität Oldenburg

Hauptfächer: Mikrobiologie, Genetik und Biochemie

$06 / 2000-05 / 2001$

Zivildienst

Horst-Schmitt-Kliniken, Wiesbaden

06/1999

\section{Abitur}

Pestalozzi-Gymnasium, Idstein (Taunus) 